NMEI 10

\title{
REGIONAL OPERATIONS RESEARCH PROGRAM FOR DEVELOPMENT OF GEOTHERMAL ENERGY IN THE SOUTHWEST UNITED STATES
}

\author{
Final Technical Report \\ June 1977 to August 1978
}

\section{January 1979}

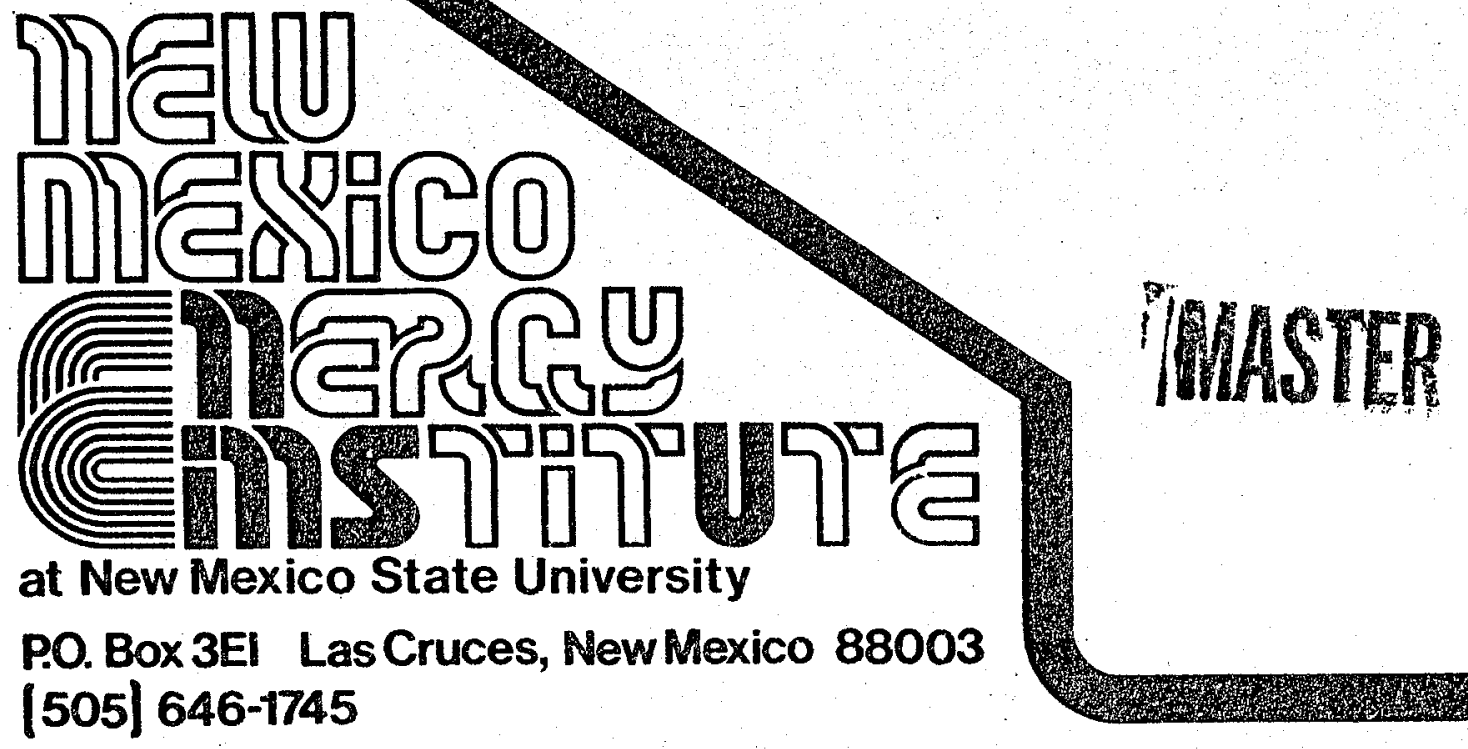




\section{DISCLAIMER}

This report was prepared as an account of work sponsored by an agency of the United States Government. Neither the United States Government nor any agency Thereof, nor any of their employees, makes any warranty, express or implied, or assumes any legal liability or responsibility for the accuracy, completeness, or usefulness of any information, apparatus, product, or process disclosed, or represents that its use would not infringe privately owned rights. Reference herein to any specific commercial product, process, or service by trade name, trademark, manufacturer, or otherwise does not necessarily constitute or imply its endorsement, recommendation, or favoring by the United States Government or any agency thereof. The views and opinions of authors expressed herein do not necessarily state or reflect those of the United States Government or any agency thereof. 


\section{DISCLAIMER}

Portions of this document may be illegible in electronic image products. Images are produced from the best available original document. 


\begin{abstract}
REGIONAL OPERATIONS RESEARCH PROGRAM FOR DEVELOPMENT OF GEOTHERMAL ENERGY

IN THE SOUTHWEST UNITED STATES
\end{abstract}

Final Technical Report June 1977 to August 1978

Principal Investigators Joseph M. Marlin, Project Director Richard Christ Paul McDevitt Kenneth Nowotny Patrick O'Dea

C. R. Ráo

Chandler Swanberg

New Mexico Energy Institute New Mexico State University Las Cruces, New Mexico

January 1979

This profect was conducted under the auspices of the NEW MEXICO ENERGY INSTITUTE at NeW Mexico State University. The research project was supported by the New Mexico Energy and Minerals Department as Project No. 76-262, the Four Corners Regional Commission as Contract No. 672-066-075, and the United States Department of Energy as Contract No. EG-77-S043992. 
This research was conducted with the support of the New Mexico Energy and Minerals Department (EMD) and the New Mexico Energy Institute at New Mexico State University, Las Cruces, New Mexico, (NMEI at NMSU) under Contract No. 76-262. However, any opinions, findings, conclusions, or recommendations expressed within this report are those of the author(s) and do not necessarily reflect the views of the EMD or of the NMEI at NMSU.

NMEI 10 


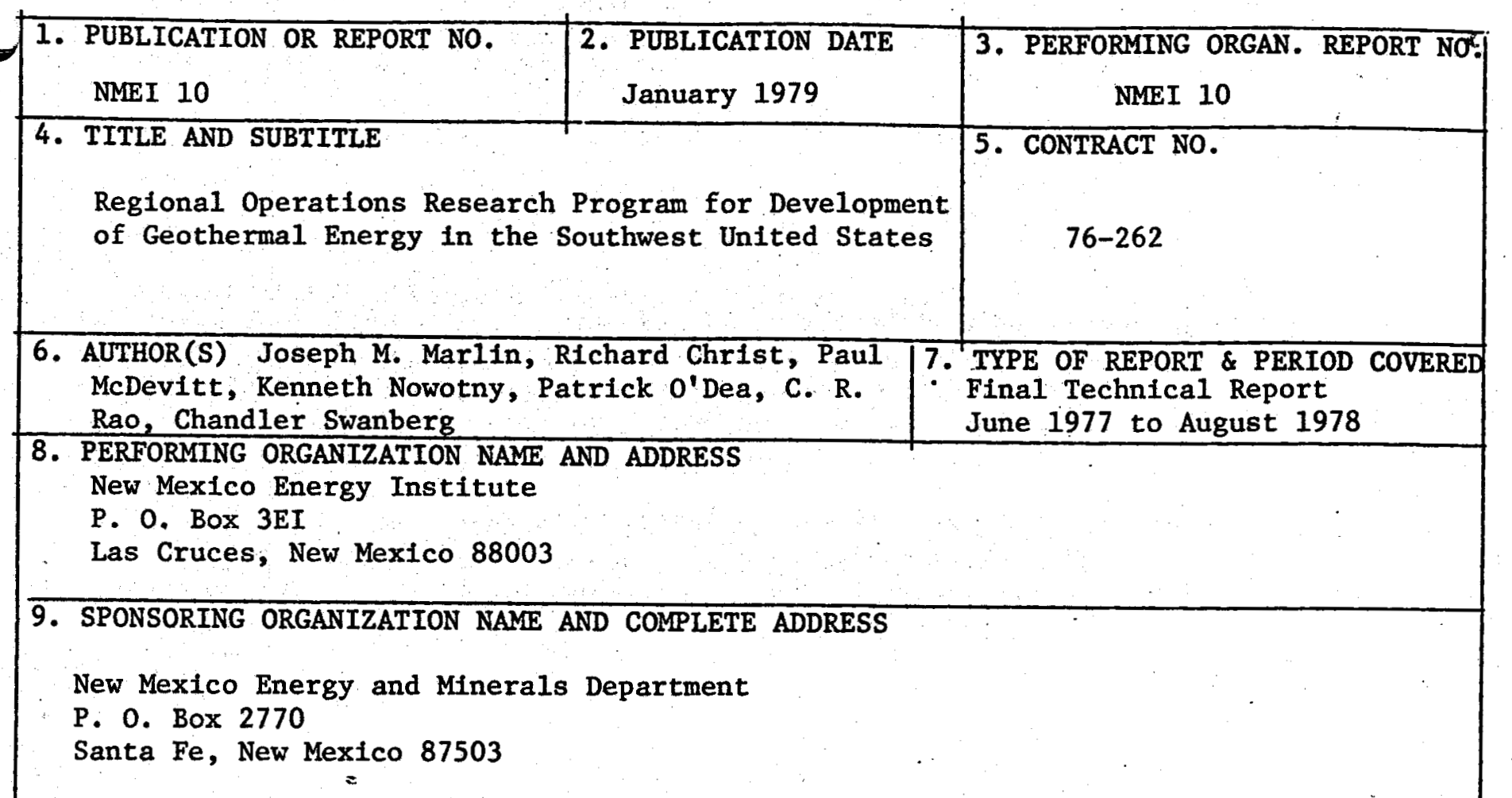

10. ABSTRACT

This report describes the work accomplished from June 1977 to August 1978 of the Regional Operational Research Program for the Development of Geothermal Energy in the Southwest United States. The scope of work is as described in New Mexico State University technical proposal entitled, "Regiona1 Operations Research for the Development of Geothermal Energy, Southwest United States," dated March 11, 1977.

This report describes the efforts by the Core and State Teams in data acquisition, electric and non-electric economic studies, development of computer support functions and operations, and preparation of geothermal development scenarios.

\section{KEY WORDS}

Commercialization

Data base

Economic analysis

Geothermal energy

Legal and institutional factors
Operations research

Policy initiative

Power production

Rate of return

Regional program progress monitor

Scenarios

12. AVAILABILITY

National Technical Information Service, U. S. Dept. of Commerce 5258 Port Royal Road, Springfield, Virginia 22161 
$L$

L

4

6

,

G

l.

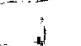

6

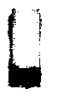


TABLE OF CONTENTS

Page

ABSTRACT

LIST OF TABLES

LIST OF FIGURES

ACKNOWLEDGEMENTS

SUMMARY

I. INTRODUCTION

II. PROJECT DISCUSSION: FORECASTING AND OPERATIONS

2.1 Resource Knowledge and Scenario Assumption

2.2 Legal and Institutional Factors

2.3 Electric1ty Production From Geothermal Energy

2.4 Non-Electric Utilization of Geothermal Energy

2.5 Data Base and Region Program Progress Monitor

III. LEGAL AND INSTITUTIONAL FACTORS IN THE DEVELOPMENT OF GEOTHERMAL RESOURCES

3.1 Federal Geothermal Program

3.2 Federal Laws and Regulation Relevant to Geothermal Energy

3.3 Activities During Development of a Federal Geothermal Resource

3.4 Federal Response to Legal and Institutional Barriers to Geothermal Development

3.5 Previous State and Regional Studies of Institutional Factors

3.6 Summary of Previous Reglonal and State Polfcy Studies

IV. GEOTHERMAL DEVELOPMENT AND THE PRODUCTION OF ELECTRICITY

4.1 Research Philosophy

4.2 Sensitivity of Profits to Policy Parameters

4.3 Aggregated Power on Line Estimates

4.4 Policy Analysis and Recommendations

4.5 Review and Summary of Pollcy Analysis

4.6 The Market for Electricity

4.7 Electric Energy Consumption
71

75

86

90

\section{v}

vii

viii

$\mathrm{x}$

1

5

7

9

10

11

12

13

15

16

19

27

35

42

69

91

91 
TABLE OF CONTENTS (Continued)

V. GEOTHERMAL DEVELOPMENT FOR SPACE HEATING

Page

5.1 Geothermal Space Heating in the United States:

101

The Historical Record

5.2 A Technical Screening of the Regional Low

103

5.3 Simulation Results

5.4 Scenario Forecasts

VI. DATA BASE AND REGIONAL PROGRAM PROGRESS MONITOR

6.1 Market Area Determination

6.2 Data Base Design

6.3 The Data Base Management System

142

6.4 Leasing and Drilling Information

143

6.5 Data Base Functions

REFERENCES

201

DISTRIBUTION

204

APPENDICES

1. SUMMARY OF GEOTHERMAL ALGORITHM - ELECTRIC USES

1-1

(GIRORA-ELECTRIC)

2. A DISTRICT SPACE HEATING MODEL - GIRORA: NONELECTRIC 2-1

3. THE GEOTHERMAL RPPM DATABASE 3-1

4. SUMMARY OF FEDERAL, STATE, AND PRIVATE ACTIONS 4-1 RECOMMENDED TO ACCELERATE GEOTHERMAL ENERGY DEVELOPMENT IN THE SOUTHWEST REGION

5. SUMMARY OF STATE TEAM SCENARIOS

6. ARIZONA STATE TEAM REPORT . 6-1

7. COLORADO STATE TEAM REPORT 7-1

8. NEVADA STATE TEAM REPORT 8-1

9. NEW MEXICO STATE TEAM REPORT 9-1

10. UTAH STATE TEAM REPORT 10-1 
2.1 Hydrothermal Resources Present in the Five State Region 8

3.1 Stages of Geothermal Development on Federal Land and 20 Agency Responsibility

3.2 Land Ownership in Southwest Region 46

3.3 Mineral Acreage Reserved to the State and to the United 46 States in Million Acres

3.4 Acreage of State and Federal Geothermal Leases 48

3.5 Status of Lease Sales on Federal KGRA's $\quad 49$

3.6 Age of Noncompetitive Lease Application Still Pending 51 for Federal Land

3.7 Leasing of State Land 53

3.8 State Geothermal Lease Provisions 54

3.9. Exploratory and Development Activities in the Southwest 56 Region

3.10 State Agencies Which Participate in Geothermal Development 58 in Arizona

3.11 State Agencies Which Participate in Geothernal Development 59 in Colorado

3.12 State Atencies Which Participate in Geothermal Development 60 in Nevada

3.13 State Agencies Which Participate in Geothermal Development 61 in New Mexico

3.14 State Agencies Which Participate in Geothermal Development 62 in Utah

3.15 Preliminary Assessment of Agencies and Permits Involved 64 in Geothermal Development in Utah

4.1 Base Case Values Geothermal Energy Producer 72

4.2 Elasticity (E) of $R$ with Respect to Selected Variables 74 at $225^{\circ} \mathrm{C}\left(437^{\circ} \mathrm{F}\right)$

4.3 Values of Choice Variables and Parameters: Optimistic and 76 Pessimistic Market Scenarios

4.4 Electric Power Estimated In Megawatts for Arizona 77

4.5 Electric Power Estimated in Megawatts for Colorado 78

4.6 Electric Power Estimated in Megawatts for Nevada 79

4.7 Electric Power Estimated in Megawatts for New Mexico 83

4.8 Electric Power Estimated in Megawatts for Utah 83

4.9 Electric Power Estimated in Megawatts for the Five States 84

4.10 Results of the Forecasting Mode1 93 
4.11 Sensitivity Analysis Parameters for Projections of Page Electricity Consumption

5.1 Distribution of Low Temperature Geothermal Resources by State 104

5.2 Preliminary Values for Technological Screening Criteria 107

5.3 Distribution by State of Low Temperature Geothermal Resources 109 Which Pass Initial Technological Screening

5.4 The Baseline Case Values

5.5 Optimistic and Pessimistic Scenarios

5.6 Distribution by State of Low Temperature Geothermal Resources Which Pass Technological and Economic Screening

5.7 Sumary Table of Technological and Economic Feasibility of Low Temperature Geothermal Resources in the Southwest 
3.1 Typical Exploration and Development Sequence 21

3.2 Interagency Geothermal Coordinating Council 29

3.3 Geothermal Regulatory Activities: Pre-Lease Activities 31

3.4 Geothermal Regulatory Processes: Post-Lease Acrivities 32

3.5 Colorado. Time-Phased Activities 66

4.1 Time-Phased Scenarios Under Conditions of Minimum Competition 85

4.2 Time-Phased Scenarios Under Some Competition for Development 87 Resources

4.3 Time-Phased Scenarios With Policy Incentives $\quad 89$

4.4 Projections of Demand for Electricity in the Five State Region 96

4.5 Projections of Required Plant Capacity in the Five State Region 97

5.1 Low Temperature Sites in Southwestern Region 105

5.2 Technologically Feasible Low Temperature Sites in Southwestern 111 Region

5.3 Estimated Energy Potential of Low Temperature Geothermal 112 Energy before and after Technological and Economic Screening

5.4 Sensitivity of $R$ to Changes in Temperature $\quad 116$

5.5 Sensitivity of $R$ to Changes in Distance (in miles) 117

5.6 Sensitivity of $R$ to Changes in Population $\quad 119$

5.7 Sensitivity of $R$ to Changes in Royalty Rates $\quad 120$

5.8 Sensitivity of $R$ to Changes in Bond Rate $\quad 121$

5.9 Sensitivity of $R$ to Changes in Energy Prices 123

5.10 Sensitivity of $R$ to Changes in Depletion Allowance $\quad 124$

5.11 Sensitivity of $R$ to Changes in Investment Credits $\quad 125$

5.12 Sensitivity of $R$ to Changes in Load Factor $\quad 127$

5.13 Estimated R for Optimistic and Pessimistic Scenarios 129

5.14 Estimated Energy Potential of Low Temperature Geothermal $\quad 134$ Energy before and after Technological and Economic Screening

5.15 Economically Feasible Low Temperature Sites in the Southwestern 135 Region

6.1 Resource Area Data Sheet 138

6.2 Drilling Data Sheet 140 


\section{ACKNOWLEDGEMENTS}

The work reported here is the result of efforts of a core team at New Mexico State University and State teams from Arizona, Colorado, Nevada, New Mexico, and Utah.

The N. M. S. U. Core Team is composed of:

Mr. Joseph M. Marlin, Project Director; Professors Richard Christ, Paul McDevitt, and Kenneth Nowotny of the Center for Business Services; Mr. Patrick O'Dea of the Physical Science Laboratory; Professor C. R. Rao of Industrial Engineering; and Professor Chandler Swanberg of Earth Sclences and Physics.

The State Teams are:

Arizona: James F. Warnock and Dr. Frank Mancini of the Arizona Solar Energy Research Commission; Professors Donald White and David Wolfe of University of Arizona; Richard Hahman of Arizona Bureau of Geology and Mineral Technology.

Colorado: Richard Pearl and Ms. Barbara Coe of Colorado Geological Survey.

Nevada: Noel Clark of the Nevada Department of Energy; Martin Booth, Ms. Barbara Helseth and Ms. Doris Weber.

New Mexico: Thomas Ortiz, Dennis Fedor, and Wesley Horner of New Mexico Energy Resources Board.

Utah: Stan Green and Ward Wagstaff of Utah Division of Water Rights.

Research Assistants are:

Ms. Mary Beth Ball, Wllllam Ha11, Steve Martinez, Dave Mendive, John Nance, Ms. Sandra Rybarczyk, Awadhesh Singh, George Stephens, Roy Heath, and Kathy Kern. 


\section{ACKNOWLEDGEMENTS (Continued)}

Regional Advisory Group Members are:

Mr. Kefth Dotson, Project Monftor, Four Corners Regional Commission

Mr. Doug Sacarto, National Conference of State Legislatures

Mr. George Vranesh, Rocky Mountain Mineral Law Foundation

Mr. Robert S. Sanchez, Jr., Speclal Assistant to the Secretary, U. S. Department of the Interior

Mr. Willlam M. Dolan, Manager, Geothermal Exploration, Amax Exploration, Inc.

Dr. Charles Wm. Berge, Manager, Geothermal Exploration, Phillips Petroleum Company

Mr. Joel Robinson, Vice President and Manager, Geothermal Division, Union Oil Company of California

Mr. James Kingsolver, Manager, Geothermal Operations, Smith Tool Company

Mr. John Arlidge, Assistant to the Vice President, Nevada Power Company

Mr. John Woods, Vice President, Bank of Montreal-California

Dr. David Atkinson, Low Temperature Geothermal Consultant

Dr. Richard T. Meyer, President, Western Energy Planners, Ltd.

Four Corners Regional Commission State Alternates are:

Mr. J. Morris Richards, Arizona; Mr. Roy Romer, Colorado;

Mr. Carol Hawks, Nevada; Mr. Leo Murphy, New Mexico; Mr.

Mickey Gallivan, Utah.

Conclusions, opintions and other evaluative portions of this document solely reflect the views of the authors. Their inclusion herein does not indicate either their acceptance or rejection by the New Mexico Energy Institute at New Mexico State Unfversity, project subcontractors or any other cooperating or funding agencies. 
This report describes the work accomplished in the first fourteen months of the Regional Operations Research Program for Development of Geothermal Energy in the Southwest United States.

The work is being performed by a core team at New Mexico State University/New Mexico Energy Institute, with subcontracts to state teams from Arizona, Colorado, Nevada, New Mexico, and Utah.

The objectives of the program are:

(1) To develop realistic but aggressive scenarios with certainty factors for the development of each identified geothermal resource area in Arizona, Colorado, Nevada, New Mexico, and Utah.

(2) To delineate the public actions, together with their schedules required, for the scenarios to materialize.

(3) To develop a computer-base data storage and retrieval system of a regional program progress monitor of the level of a preliminary working model which is capable of displaying program approach, but not. loaded with all available data.

The mafor accomplishments of this project during this contract year have been:

- Establishment of core team, state teams, and regional and state advisory groups.

- Identification of locations and geophysical conditions of potential geothermal sites.

- Modeling of geothermal energy development activities including technological, economic, and institutional factors.

- Review and analysis of legal and institutional factors in geothermal energy development.

- Design and creation of computer data base system and software to support economic analyses, scenario design, and progress monitoring.

- Development of local, state, and reglonal power-on-1ine time phased scenarios for geothermal energy in the Southwest.

At the outset, it is useful to review and compare what was known about potential geothermal sites at the beginning of the contract year as compared with the assessments at the close of the contract year. The following table displays by state the large growth in the number of potential geothermal sites in the region. As indicated, the number of potential electric sites increased from twenty-nine to eighty, and the number of potential nonelectric 
sites increased from fifty-three to five hundred. As is indicated, the potential number of sites increased more than seven-fold due to the active state team and Core Team review of available 11terature and parallel low temperature assessment programs that were ongoing during the contract year.

TABLE I

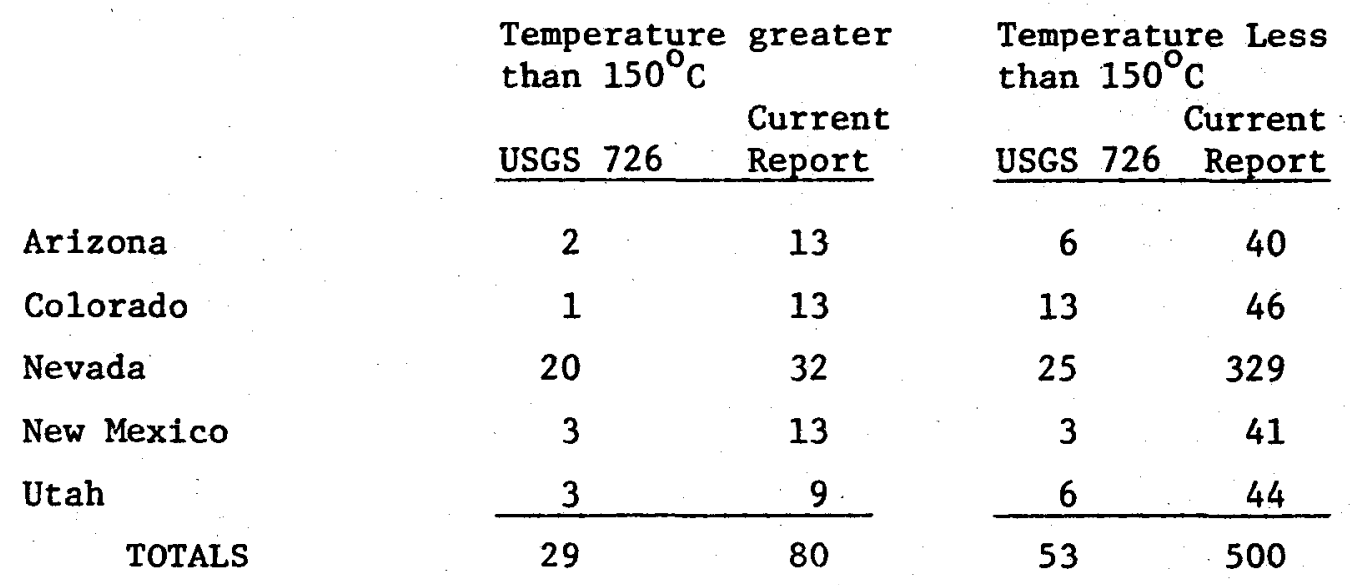

Geothermal resources with temperatures in excess of $150^{\circ} \mathrm{C}$ are considered candidates for generating electricity. Since the production technology is established, the future potential of geothermally produced electricity hinges upon its market competitiveness with alternative fuel sources. Accordingly, a simulation model was developed in order to estimate an internal rate of return on investment in geothermal energy development. The internal rate of return on investment is a general indicator of profitability which provides a measure of the financial attractiveness of geothermal energy.

The examination of the electricity producing potential of geothermal energy consists of an analysis of each of the known high temperature geothermal resources in the Southwest. Primary data were gathered by personnel within each of the states, and on this basis the internal rate of return on producer's equity is calculated for each source site. Several sets of plausible circumstances were proposed, and a unique rate of return was calculated for each. Based upon the estimated profitability of each geothermal resource, an ordinal ranking of resource sites was prepared. Those sites with the highest rate of expected return on investment are expected to come "on line" first, while the least profitable are expected to come "on line" last if at all. In this manner, a time-phased growth path of high temperature geothermal resources was created.

The analysis indicates (1) that the principal impediments to growth in the use of geothermal energy for producing electricity are geophysical or engineering in nature (e.g., subsurface cemperatures and flowrates), or at least, are not subjected to policy manipulation; (2) that, of the available policy options, the investment tax credit rate and the bond rates are the most potent alternatives for stimulating development. Traditional 
policy tools, such as depletion allowances or royalty rates, seem to be of much less value.

With current levels of economic policy variables, a minimum of 4,000 and a maximum of 20,000 MW of electricity could be brought on line by year 2020. Adequate incentives in the form of bond rate subsidies and investment tax credits could raise the lower estimate to $8,000 \mathrm{MW}$ by 2020 , while the maximum estimate cannot be affected by financial incentives.

In addition to the high temperature geothermal resources, the Southwest has also been generous1y endowed with low temperature $\left(T \leq 150^{\circ} \mathrm{C}\right)$ resources as we11. These resources can be employed for space heating and cooling, water heating, and cooling, and numerous agricultural, aquacultural, and industrial applications. To date, only district space heating applications have been considered.

Because of the large number of low temperature resources, the market potential of geothermal space heating applications was examined in 2 stages. First, the total population if resource sites was considered for its technological acceptability. These resources that are usable given current production techniques were separated from those which are not usable, and the latter were eliminated from further consideration.

In the second stage, the economic potential of the remaining resources was indicated on the basis of an estimated internal rate of return on investment. Those resources which are not expected to generate a minimum acceptable return were then eliminated from further consideration. The remaining resources constitute the estimated regional supply aggregate of low temperature geothermal resources.

The "In ground" potential of low temperature geothermal resources in the Southwest is estimated to be $39,000 \mathrm{MBtuh}$. Most of these resources are remote from population centers, and because of the inherent cost factors in transmitting geothermal fluid over large distance, these sites do not prove to be economically feasible. In fact, of the approximately 39,000 MBtuh of geo-heat potential available in these sites, based on estimated internal rate of return, only 27 of the sites or approximately 1800 MBtuh offer realistic potential for district space heating purposes under currently forecast conditions. However, this low figure represents a conservative leve1. As site exploration and development continue, and as population growth rates and trends are incorporated in the model, it can be expected that an increase in geothermal usage will result.

Based on the state teams power-on-line time phased scenarios, a regional power-on-1ine scenario was aggregated. Appendices 5 through 10 contain details of the state teams scenarios as well as the regional aggregation.

Concerning the progress toward attaining DOE goals for geothermal development, the following table compares DOE goals for the ten state Rocky Mountain Range and Basin with the estimated geothermal potential sites in the Southwest Region. For the Southwest Region, the optimistic electrical development assumes implicitly that technology will be developed to make feasible the generation of electricity from sites with temperatures in the 
range of $150^{\circ}$ to $300^{\circ} \mathrm{C}$. The pessimistic scenario assumes that only sites with a temperature greater than $190^{\circ} \mathrm{C}$ will be developed. As indicated previously, the nonelectric potential that is displayed in this table is for district space heating only. It is estimated that a significant increase in industrial process heat applications, agriculture, aquaculture, and other uses of low and moderate geothermal potential will be developed during the next 40 years. However, at this time, techniques have not yet been refined to develop and analyze this latter potential. As is indicated by the table, the Southwest Region alone under the optimistic scenarios can be expected to attain approximately $60 \%$ of the ten state region electric capacity in the optimistic case. District space heating, although apparently attractive, is constrained by the limited population of the Southwest Region. As the model is refined to incorporate population growth rate trends and other factors, the nonelectric potential can be expected to increase.

\section{TABLE II}

DOE GOALS FOR RMB\&R REGION FOR 2020

VS

CALCULATIONS FOR SOUTHWEST REGION

\section{Rocky Mountain Range Basin DGE Goals 1}

Electric Capacity $\quad 35,000$ (MWe)

MEGW Equiv. (Direct Thermal)

Electrical Quads/yr

Direct Thermal Quad/yr Total

Barrels of $0 i 1$ (Equivalent)

Cost Avoidance Oil Import

$$
60,000
$$

$$
2.91
$$

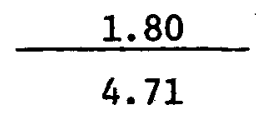

$793 \times 10^{6} / \mathrm{yr}$

\$11 Billion
Southwest Region ${ }^{2}$

Optimistic

20,000

Pessimistic

3,000

$600^{3}$

1.66

0.32

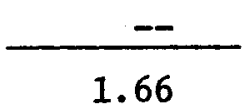

$\frac{0.02}{0.34}$

$300 \times 10^{6} / \mathrm{yr}$ $60 \times 10^{6} / y x$

$\$ 4.2$ Billion

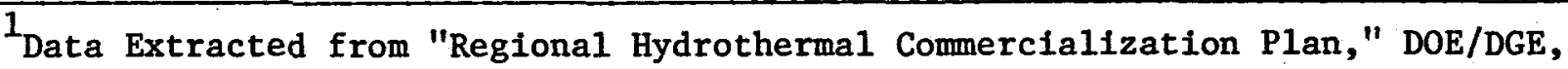
July 14, 1978

2 Data for five Southwestern State based on calculations using GIRORA Models.

${ }^{3}$ This is economically feasible, district space heating only, assuming no population growth, for low temperature sites only.
} 
CHAPTER I

INTRODUCTION

During the past several years, the United States has been relying increasingly on imported ofl to meet its energy needs. This trend will continue unless greater use is made of all avallable domestic energy resources. To achieve this objective the Department of Energy (DOE), through its Division of Geothermal Energy, has established as one of 1ts goals: to stimulate commercial development of geothermal energy as a rellable, operationally safe, and an environmentally acceptable energy resource (1) . To provide early momentum to this effort, DOE has initlated several research, development and demonstration type projects and administrative and policy initiatives to stimulate rapid exploration of "1iquid dominated hydrothermal" resources. This class of geothermal resources, In comparison with the various other types of geothermal resources (e.g., vapor dominated, geopressured, hot dry rock, etc), is considered most 1ikely to make a significant contribution to the nation's energy supplies in the near future.

According to the estimates presented In USGS $726^{(2)}$, geothermal energy has the potential of contributing thousands of quads to the nation's energy resources. However, there are significant environmental, technological and socio-economic problems which considerably impede the rapid development of the geothermal resources. These problems must be 1dentified and mitigated to realize the geothermal potential that exists. Many of these problems are beyond the capability of U. S. Industry to solve, and will require the assistance of action by the public sector. At the national level, this has been recognized by the congress and the administration, who in 1970 passed the Geothermal Steam Act (PL 91-581) to open up federally owned lands for leasing for geothermal development and in 1974 passed the Geothermal Research, Development and Demonstration Act (PL 93-410) to stimulate the environmentally acceptable development of geothermal energy.

As geothermal energy is a regional resource by its nature, its development will require approaches which recognize its regional character. At the same time, there will be many problems common to all regions. In recognition of this factor, DOE (ERDA) has established a regional planning activity, to identify 
the specific problems associated with geothermal development in each region of the country, and has established a national planning activity to coordinate the activities of the regional planners and recommend actions and policy initiatives for DOE (ERDA) activities on the basis of maximum national benefit.

One of the regions so established by DOE (ERDA) is the Southwest Region, which consists of the states, Arizona, Colorado, Nevada, New Mexico, and Utah. This region contains a relatively large number of high temperature hydrothermal convective resources. To exploit the possibllitles, DOE (ERDA) has contracted with the New Mexico Energy Institute at New Mexico State University for assistance in the development of a plan for stimulating the development of Southwest Region's geothermal resources. In addition, the New Mexico Energy and Minerals Department and the Four Corners Regional Commission have jointly financed the efforts by the New Mexico Energy Institute.

The USGS, in its circular 726, estimates that the recoverable energy content of identified hot water resources show $150^{\circ} \mathrm{C}$ in the Southwest Region could produce 1312 megawatt - centuries of electrical power, equivalent to an installed capacity of 4374 megawatts for 30 years using current conversion technology. In addition, $3.57 \times 10^{17}$ calories (equivalent to $1560 \mathrm{MW}$ for 30 years) is available as usable heat for direct thermal applications, such as space heating, agriculture, aquaculture and process heating.

The USGS further estimates that as much as five times this amount of enérgy may be recoverable from as yet unidentified hydro-thermal resources, and perhaps even more from hot dry rock. If it is assumed that the utilization of geothermal energy can be made economically competitive with other energy resources and that it is in the public interest to utilize the available domestic resource to help meet the growing energy demands in the region/nation and reduce dependence on imported energy sources, then the questions to be addressed are:

1) How rapidly can geothermal energy resources be developed in an environmentally acceptable manner; given the present level of knowledge of the resource, present technology, development status, present environmental knowledge and concerns, and present socioeconomic conditions;

2) What action alternatives are available to the public sector to stimulate the rapid development of geothermal resources; and

3) What set of these alternatives will most effectively supply the needed stimulation whlle protecting all legitimate interests of the public. 
An attempt is made to answer these questions during the first year effort of the operations research study for the Southwest Region. This report covers the findings of the study on the state by state and aggregated region basis. 


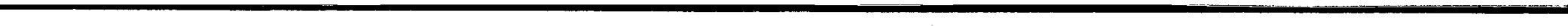


CHAPTER II

PROJECT DISCUSSION: FORECASTING AND OPERATIONS

The project undertaken by the New Mexico Energy Institute at New Mexico State University is a multi-faceted, multi-discipline regional operations research in the development of geothermal energy resources for the Division of Geothermal Energy (DGE) of the Department of Energy, the Four Corners Regional Commission and the New Mexico Energy and Minerals Department.

In the five states of the study area, it has been broadly estimated that there are geothermal energy resources in excess of 1,800,000 megawattyears. Over 800,000 acres of land 1 le in known geothermal resource areas (KGRA's) in the states, and over 25,000,000 acres have been established as prospectively valuable. However, there are a large number of barriers to the exploitation of the energy resources. Avallable technology does not exist to develop all of these resources. Public utilities are uncertain about the quality and quanity of this resource. This uncertainty, together with the national economic situation, means that available capital for the development of the resource is 1 imited. Institutional barriers, in the form of federal, state and local government laws and regulations, such as environmental controls, tax laws, and land use policies, may inhibit the aggressive exploration and exploitation of the resource. A major task of the contract is to Identify these factors and to quantify the relative importance of these factors in terms of their effect on the rate of deployment of this energy resource in the Southwest Region.

The broad method chosen to identify the above barriers and to achieve the DGE's mission, namely, to accelerate the actual commercial utilization of geothermal energy, is the development of a series of scenarios, the outputs of which are a prediction of the amount of commercial power (electric and non-electric) brought on line versus time. Hence a scenario will constitute the mission for the DGE mission-oriented approach to geothermal energy resource development. Since most forms of geothermal energy represent local resources 
and since many of the problems associated with commercial geothermal development are local or regional in nature, the local and regional problems are addressed in developing the scenarios. In considering the local problems within each of the five states, the key energy officials in the states were consulted. Each state team leader was responsible for data collection and gathering information from local governments and industries.

The preliminary development scenarios, based on inputs from the regional and local interest groups together with supplemental data concerning the extent and quality of the geothermal resources will show the locally preferred time phasing of power on line. State teams were tasked to supply this kind of information.

The economics of harnessing the geothermal resource (either for electricity production or for direct application) play a major role in the future development of geothermal energy resources. In this free market society, geothermal energy must compete with other sources of energy. The economic analysis must show a distinct advantage for geothermal energy if utilities are to be induced to make extensive financial commitments to the development of this relatively new technology. Associated with the scenario for geothermal energy development are projections of costs of power from alternate resources. Analyses of these projections are very useful in the planning process. For instance, the projections may show that geothermal energy in a particular region will not be economically viable for some years in the future. In order to accelerate geothermal energy development in that case, the gap between the geothermal costs and the lowest cost alternatives must be closed. Economic analyses are required to determine the impacts of several possible alternative actions on the cost of goethermal power such as, technology improvements, tax incentives, government subsidies, and loan guarantees.

One obvious way to decrease the cost of geothermal power is to improve the efficiency of the energy conversion process through research and technology development programs. This is a very desirable approach in that it contributes towards energy resource conservation by providing more energy per unit of resource. However, there are limits to increases in efficiency which can be achieved through research and development. Thermal cycle efficiency is limited to carnot cycle efficiency for a given reservoir, and heat sink temperatures and mechanical efficiency must be less than unity. Further, as the quality of resources decreases (which is an uncertain element) the cost of power tends to increase due to the intrinsic decrease in cycle efficiency associated with 
lower temperatures and the need for more expensive equipment (such as heat exchangers and pumps). The increase in the cost of geothermal power tends to delay the commercial use of lower quality resources until technology improves or other policy initiatives which are economically supportive are adopted. If the analyses show that the amount of technology improvement cannot close the gap between the costs of geothermal and alternate energy sources, then it is desirable to consider policy initiatives which temporarily close the gap. Modifications to tax regulations, government guaranteed loans, or even government subsidies are possible techniques for artifically altering the economics of geothermal energy development.

\subsection{Resource Knowledge and Scenario Assumptions}

The Southwest Region is rich in geothermal resources. They include the familiar hydrothermal systems typified by those under development at Valles Caldera, New Mexico, and Roosevelt Hot Springs, Utah. In addition, they have hot igneous (hot dry rock) and conduction dominated systems which may ultimately prove to be much more extensive and valuable than the hydrothermal systems. A summary of the number of hydrothermal systems present in the five state region is given in Table 2.1. These estimates are obtained from United States Geological Survey (USGS), local researchers at New Mexico State University, and the appropriate state teams. The high temperature hydrothermal systems (i.e., temperatures over $150^{\circ} \mathrm{C}$ ) are especially important because of their potential for near term commercial development for electric power generation. In addition, they can support industrial processes which demand high temperatures, such as paper pulp digestion, timber drying and aluminum extraction. Medium temperature geothermal systems (temperatures between 65 and $150^{\circ} \mathrm{C}$ ) can be used for direct applications such as domestic space heating, greenhouse heating and other industrial uses which do not demand very high temperatures. Finally, low temperature systems, commonly known as warm springs can be utilized for mushroom growing, balneological baths, and other agriculture and aquaculture applications. The subject of the report basically constitutes the scenarios for electric power generation utillzing high temperature resources and district space heating using the medium temperature resources.

There are large uncertainties in the resource estimates. The assessment of geothermal potential presented in this report is based on limited data available. As USGS has indicated, no single estimate of geothermal energy from 
Table 2.1

Hydrothermal Resources Present in the Five State Region

\begin{tabular}{|l|c|c|c|c|}
\hline \multirow{2}{*}{ State } & \multicolumn{4}{|c|}{ Number of Hydrothermal Resources } \\
\cline { 2 - 5 } & $\begin{array}{c}\text { Temperature } \\
\text { Over } 150^{\circ} \mathrm{C}\end{array}$ & $\begin{array}{c}\text { Temperature } \\
\text { Between } \\
65^{\circ} \& 150^{\circ} \mathrm{C}\end{array}$ & $\begin{array}{l}\text { Temperature } \\
\text { Less Than } \\
65^{\circ} \mathrm{C}\end{array}$ & Total \\
\hline Arizona & 13 & 15 & 25 & 53 \\
Colorado & 14 & 24 & 21 & 59 \\
Nevada & 32 & 52 & 276 & 360 \\
New Mexico & 13 & 20 & 26 & 59 \\
Utah & 8 & 13 & 32 & 53 \\
\hline TOTAL & 80 & 124 & 380 & 584 \\
\hline
\end{tabular}


a particular area included in the assessment should be relled upon as an established fact. For some areas, the information was relatively good, but for other areas it was very poor at the time the estimates were made.

It is expected that further research and exploration will show a significant number of additional geothermal fields in the region besides those 1isted in Table 2.1. Further exploration could also considerably modify the estimates for the sites identified. Further discoveries, according to USGS, could be possibly five times the volume and heat content of the high temperature systems $\left(>150^{\circ} \mathrm{C}\right)$ already identified. The discoveries could result from:

1) New knowledge of the extent of an already identified system that appreciably increases its estimated volume.

2) The temperature of an Identified system being higher than first estimated (possibly enough to raise some of the medium temperature resources into the higher temperature category).

3) The discovery of previously unknown systems.

In addition to the geological and geophysical data, more analyses need to be done to develop the scenarios. Most important of these are the identification of the Institutional factors present and the economical analysis for the feasibility of electricity production and domestic space heating. They are considered in detail in this report.

\subsection{Legal and Institutional Factors}

One of the major impediments for the rapid development of geothermal energy is the existence of nontechnical barriers. The nontechnical factors which inhibit the activities of geothermal industry are legal and institutional factors. Many geothermal developers believe that institutional factors are the major cause of the large time delays and high costs associated with the development of geothermal energy. The time involved in getting permits for leasing, drilling, environmental assessments and other legal factors all contribute to time delays. The impact of permitting delays can be very serious, which may affect the economic exploration of the resource. In the Southwest Region, the permitting process and time delays involved vary from state to state. The details of the permitting process and their impact is described in Chapter III. 


\subsection{Electricity Production from Geothermal Energy}

Experimental production of electricity from geothermal energy began in Lardarello fields in $1904^{(3)}$. By 1931, sufficlent quantities of electricity were being generated to begin selling electricity to the Italian Railway System. After being destroyed in World War II, the generating facilities were rebuilt and expanded. The Lardarello fields currently generate enough electricity to supply a city of 600,000 at U. S. consumption rates. Commercial generation of electricity from geothermal energy in the U. S. began in 1960 at The Geysers, California. By 1973, the U. S. was the largest producer of electricity from geothermal steam $^{(3)}$. Currently $1000 \mathrm{MW}$ of electricity are generated from geothermal steam worldwide, half of which is produced at The Geysers.

Although worldwide production of electricity from geothermal resources continues to increase yearly, it is doubtful that the overall contribution of this production will be large in the near future. Assuming the production in the world continues to increase at the present rate, $3000 \mathrm{MW}$ will be produced by 1980 . This projected production still would constitute less than one percent of the current energy demands.

There are several inherent technological problems in producing electricity from geothermal energy. One major problem is locating a geothermal source with the necessary heat content to produce electricity. Generating electricity from geothermal water at temperatures $150^{\circ} \mathrm{C}$ or less is generally not economical due to the low efficiencies (less than 7 percent) and large flow rates required $(4)$. However, $1 t$ is quite likely that the competitive economics of electrical generation using lower temperature geothermal resources will improve as the technology in the field advances and conventional energy costs continue to rise.

Another problem associated with using geothermal energy is that geothermal water tends to have a higher mineral content than ground water. This high mineral content produces scaling problems in equipment and inhibits production capabilities. Calcium carbonate deposits also cause scaling problems in wet steam utilization. These problems can be eliminated by using binary cycle for energy conversion in contrast to the more traditional flash cycle. In a binary cycle, heat from the geothermal fluid is transferred to a secondary fluid, usually having a low boiling point (e.g., iso-butane) through heat exchangers. The advantages are two-fold: one, the corrosion and scaling problems are reduced and the other, the amount of usable heat 
(enthalpy) is greater in the binary fluid. Even the moderately high temperature resources (temperatures between $150^{\circ}$ and $200^{\circ} \mathrm{C}$ ) can be more effictently exploited with the binary cycle technology. Of course, the cost of heat exchangers and the other necessary equipment adds to the capital cost of the power plant.

The details of the economic analysis and sensitivity analysis and their impact on scenario generation for geothermal electricity production are discussed in Chapter IV of this report.

\subsection{Non-Electric Utilization of Geothermal Energy}

The production of a significant amount of electricity from geothermal energy is years in the future. In comparison, the utilization of geothermal energy for non-electrical purposes holds great possibilities in the near future. The advantages of non-electric utilization of geothermal energy $\operatorname{are}^{(5)}$ :

1) Approximately one-third of the fossil fuel consumption is used for residential purposes, the majority of which could potentially be supplied from low temperature geothermal sources.

2) Low temperature resources are more numerous and genera1ly less polluting than high temperature sources, which are required for electrical production.

3) The efficiency of non-electrical utilization is greater than for electrical production.

4) Technology is sufficiently advanced to allow immediate development where the resources exist.

Space heating accounts for 18 percent of U.S. yearly energy consumption(4). Since known geothermal sites are seldom close to large population center, geothermal energy cannot be presently used to supply the bulk of space heating demands. However, as exploration techniques improve and as new geothermal sites are discovered, an increase in the application of geothermal energy to space heating can be expected. In addition to the space heating applications there are several industrial uses of low temperature geothermal energy. The use of this energy for industrial applications basically depends on the heat requirements of the particular industry, quality of the geothermal resource and the proximity of the industry to the resource.

In this report, the economics of space heating is considered. Applications to industrial processes need extensive data and individual economic analyses, and are not considered in this report. The economic model developed 
for space heating, sensitivity analysis and scenario generation is discussed in Chapter $V$.

2.5 Data Base and Region Program Progress Monitor

In order to perform the studies described in the previous sections, extensive amounts of data are required. The data can be broadly classified into six categories, namely,

1) Data relating to the geothermal energy resource,

2) Data relating to the utilization of the resource,

3) Data relating to legal and institutional factors,

4) Data relating to economics of resource exploitation,

5) Data relating to technology development, and

6) Data relating to regional industry status.

Data are collected as much as possible in all the above areas and are stored in the data base. Part of this data is automated, and is entitled Regional Program Progress Monitor (RPPM). The complete description of the RPPM is given in Chapter VI. 


\section{LEGAL AND INSTITUTIONAL FACTORS IN \\ THE DEVELOPMENT OF GEOTHERMAL RESOURCES}

While the potential for geothermal resources is great, only a very small fraction of this potential has been realized. Virtually everyone agrees that numerous technical and nontechnical factors are impeding the rapid development and utilization of the resource. While not ignoring the technical barriers, this chapter will stress the nontechnical factors which Impact upon efforts to accelerate the development of geothermal resources. The nontechnical factors of concern will be restricted to the legal and institutional factors which may inhibit the activities of the geothermal industry.

It has been estimated that over $\$ 75$ billion of capital financing will be needed over the next 20 years if the potential for geothermal resources is to be achieved. (6) There is, however, a great hesitancy on the part of industry to commit this degree of financing to the task. The belief is almost universal that the cause of this hesitance is two-fold: (a) restrictive laws, court decisions, and regulations and (b) actions (and inactions) of a large number of Individuals who singly and jolntly make decistons that are unresponsive to the needs of the industry. In short many, if not most, developers believe or talk as if they believe that institutional factors are the major cause of the long delays and high costs associated with the development of this natural resource.

That belief has been challenged by others who contend that the principal impediments to the rapid development of geothermal resources spring not from institutional factors but rather are due to uncertainties associated with the resource itself, the technology necessary to develop the resource, and overall economic risk. (7) Even those promoting this latter point of view recognize, however, that legal and institutional factors can accentuate the uncertainty and risk associated with geothermal potential.

If the number of studies and reports concerned with legal and institutional factors is accepted as a measure of the Intensity of the belief that these factors are important, the belief is indeed intense. In July 1976, there were 118 references to articles concerned with legal and institutional issues in a bibliography which cited over 5400 research articles in the area of geothermal resources. (8) By January 1978, the Department of Energy published a bibliography containing 485 references to 1 egal and institutional research in the area. 
Hence, in 18 months there was a 300 percent increase in the number of articles concerned with legal and institutional impediments to geothermal development.

The overall goal of the legal and institutitutional aspect of the Southwestern Regional Operations Research Program has been to identify the individuals and agencies whose single and mutually interactive participation affect the rate of geothermal resource development. These participants in the development process may be categorized into four major classes as a function of the locus, if not the magnitude of their potential effect: (a) federal agencles and regulations; (b) state agencles and regulations; (c) the policies and decisions of resource developers and utility operators; and (d) the attitudes and actions of local officials and residents.

During the past year the Southwest Regional Program has concentrated on identifying the state agencies and the state laws and regulations that affect geothermal development within the Southwest Region. The issues involved at the federal level and between the federal and state levels of operation were also reviewed. Using the bibliography referred to above, previous studies concerned with the role of policy variables in other states were also analyzed.

The institutional studies conducted by the Southwestern Reglonal Program had three specific goals. First, it is recognized that institutional factors are a major element in regional aggregated scenarios which depict the time-phased activities required to develop geothermal energy. Hence, these studies were necessary to the creation of those scenarios. Second, it was reasoned that through an analysis of the development scenarios it would be possible to identify factors which act as constraints and other factors which serve as opportunities to the development of geothermal resources. Third, based upon the knowledge acquired from an examination of development scenarios policy initiatives would be recommended which would overcome or mitigate the constraints and exploit the opportunities to geothermal development.

A fourth goal of the program was to assist in the development of a knowledgeable and properly motivated infrastructure that could and would promote the development of geothermal resources within each state in the region. It has been noted that whether the climate for the use of geothermal energy sources will be positive or negative is often directly related not only to state policies but also to the attitudes of elected state officials. (10) Hence, by the very act of conducting these investigations it was hoped that there would be an increase in public perception of the issues at hand and that 
these perceptions would lead to a higher degree of political interest and an increase in necessary political leadership.

None of the goals listed are unique to the program centered at New Mexico State University. Significant efforts directed at the same goals have occurred at the national level through the efforts of such groups as the National Conference of State Legislatures, (6) at regional level by such groups as the Pacific Northwest Regional Commission, $(7,11,12)$ and at the state level by such groups as the Batelle Human Affairs Research Centers. (13) In fact the institutional constraints and opportunities Identified by the Southwest Operations Research Program are distinctive primarily to the extent that they are often unique to the five states which comprise the regional area. While there is no intention to deemphasize the significance nor the generality of the results to be reported, the most noteworthy accomplishment of these efforts may have been the establishment of knowledgeable proponents of geothermal energy in the executive branch of each state and to have facilitated an interaction among local, state, and regiona1 agencies.

The following discussion of legal and institutional factors affecting geothermal development is organized into three parts: (a) a review of federal laws, regulations and procedures; (b) a review of state and regional studies; and (c) a description of legal and institutional factors in the Southwest Region.

\subsection{Federa1 Geothermal Program}

An examination of the federal geothermal program is necessary to obtain an understanding of institutional factors which affect the development of geothermal resources in the Southwest. There are at least four reasons why the federal program has a large Impact on reglonal programs: (a) most identified and expected resources are on federal land; (b) the national energy policies serve as a model for and actually stimulate the formation of state policies; (c) the principal source of economic incentive for geothermal development will be through tax relief, grants, and loans which originate in federal legislation, and (d) the federal government is the originator and the enforcer of most environmental protection and conservation regulations.

This part of Chapter III is divided into three sections. Section 3.2 summarizes federal laws and regulations which affect geothermal development. Section 3.3 describes the activities and responsibilities of different participants at each stage of geothermal development and utilization. Section 3.4 
discusses the overall organization and purpose of the federal geothermal program and discusses several activities designed to mitigate legal and institutional barriers to geothermal development.

\subsection{Federal Laws and Regulations Relevant to Geothermal Energy}

Essentially all major phases of geothermal energy development are subject to federal laws and regulations. The three laws which enable and control the development of geothermal resources on federal lands and which attempt to encourage development on any land are briefly summarized below.

\section{Geothermal Steam Act of 1970}

The Geothermal Steam Act of 1970 is one of the most significant laws affecting the pace and direction of geothermal energy development. It controls leasing of federal lands and all phases of post-lease operations on those lands. Prelease and leasing requirements are regulated by the Department of Interior, Bureau of Land Management through Title 43, Chapter II of the Code of Federal Regulations ( 43 CFR, Group 3200). Post-lease operations are administered by the Department of Interior, U. S. Geological Survey through Title 30, Chapter II of the Code of Federal Regulations (30 CFR, Parts 270-271). On other than federal lands, state and local regulations have generally been patterned after those of the Geothermal Steam Act. On federal lands the implementation of federal regulations is guided by Geothermal Resource Operational Orders issued by U. S. Geological Survey. Geothermal Resources Operational Orders have been issued and are titled: Exploratory Operations, Drilling Completion, and Spacing of Geothermal Wells; Pluggings and Abandonment of Wells; General Environmental Protection Requirements; Pipelines and Surface Production Facilities; and Production and Royalty Measurements, Equipment, and Testing Procedures.

Federal Nonnuclear Energy Research and Development Act of 1974

This is the Act which mandated the activities of the Energy Research and Development Administration. One of those activities is the active encouragement of geothermal energy technology development through comercial demonstration. The Act also provides for the acceleration of the commercial demonstration of environmental control systems for energy technologies.

Geothermal Energy Research, and Development, and Demonstration Act of 1974

This act authorizes and defines more specifically the responsibilities of the federal government in developing and demonstrating the commercial viability 
of geothermal energy conversion. The objectives of the Act are to be accomplished in concert with private developers through grants, contracts, and 1oan guarantees.

In addition to enabling and implementing legislation, all geothermal development activity is subject to many environmental protection and conservation laws. The more prominent of these laws are briefly discussed below.

\section{National Environmental Policy Act of 1969}

This Act has had profound effects in calling public attention to the environmental consequences of major new projects. The Geothermal Steam Act was the first federal action to which it applied. The Act requires an environmental impact statement for all major federal actions affecting the quality of the human environment. The Act produced a ripple effect in that most states have similar laws for state actions. In most cases of major development, an environmental impact statement can be anticipated at some stage prior to commercial energy production, whether it is on federal, state, or private land. The impact statement must describe adverse impacts including those caused by any kind of pollution, on society and its environment. It also must discuss alternatives to the proposed development and their consequences and must describe irretrievable resource comitments.

Clean Air Act as Amended (1970)

The Clean Air Act also has several sections which may significantly affect geothermal energy development. For example, one section allows and provides for the establishment of intrastate and interstate Air Quality Control Regions In which the states must provide implementation plans for assuring air quality. Under another section the Administrator of the Environmental Protection Agency may publish air quality criteria. Based upon the criteria, he then publishes national primary (to protect public health) and secondary (to protect public welfare) ambient air quality standards for pollutants determined to have adverse effects.

\section{Federal Water Pollution Control Act Amendments of 1972}

Several sections of this Act apply to geothermal development. Probably the most significant sections are in Title III - Standards and Enforcement. One of these sections calls for the application of "best practicable control technology currently available" by July 1, 1977, for point sources other than publicly owned treatment works. This section further calls for the application 
of "best available technology economically achievable" by July 1, 1983. This section further requires the elimination of all pollutants where technologically and economically achievable. Another section in Title II calls for the definition by the Environmental Protection Agency of such technologies, and effluent limits attainable thereby, through the issuance of "Effluent Guidelines" regulations. For the geothermal energy industry, those regulations have not yet been developed and are not currently scheduled. However, such regulations may be expected when the industry is firmly established and technologies have been demonstrated.

Noise Control Act of 1972

This Act contains broad noise control provisions for regulating and labeling products, many of which are used at geothermal facilities. In addition, the Environmental Protection Agency has been given coordination authority of all programs of other federal agencies relating to noise research and noise control. It has also been given authority to insure that all federal facilities comply with appropriate federal, state, and local noise regulations. Many states and local communities regulate noise, and the U. S. Geological Survey has noise regulations for developers on leased federal lands.

Safe Drinking Water Act (1974)

This Act is administered by the Environmental Protection Agency and allows and provides for state implementation of its provisions. Part $\mathrm{C}$ of the Act, "Protection of Underground Sources of Drinking Water," is of greatest significance to geothermal energy development in that it requires the promulgation of regulations to control underground injection. Reinjection is an integral part of most existing and proposed geothermal development.

Resource Conservation and Recovery Act of 1976

The provisions of this Act, administered by the Environmental Protection Agency, are principally concerned with solid wastes. Subpart C - Hazardous Waste Management, important to geothermal energy development, involves regulatory control of storage, treatment, and disposal of potentially hazardous wastes in landfills and surface impoundments. The potentially hazardous wastes may be liquid, solid, or a combination. Wastes considered potentially hazardous are those which may cause or contribute to adverse effects on human health or the environment when not properly controlled, Regulations to be developed under 
the Act are likely to have significant ramifications for the geothermal industry in those cases where spent brine surface impoundments are used and where waste sludges are created, such as in the treatment of waters and noncondensible gases.

Toxic Substances Control Act (1976)

This Act is aimed principally at manufacturers and distributors of toxic chemicals in order to control indiscriminate proliferation of such materials in the environment. The provisions of the Act can conceivably apply to minerals which might be commerclally produced from geothermal development.

Land Policy and Management Act of 1976; National Forest Management Act of 1976, Fish and Wildlife Coordination Act; Endangered Species Act; Wilderness Act; and Marine Protection, Research and Sanctuaries Act

These federal laws allow for prohibition of or advisory action against certain activities in the interest of preserving land values, wildlife habitats, and esthetic values. They also may allow for or require mitigating measures where harm may occur.

\subsection{Activities During Development of a Federal Geothermal Resource}

The process of acquiring the right to explore, develop, and produce geothermal resources on federal land is described in detall in a preliminary report by Roschen and Cook. (14) The six phases of development for any given area are described as prelease exploration, competitive or noncompetitive leasIng, postlease exploration, development, production, and closeout or abandonment. A brief description of each phase as extracted from the Roschen and Cook report is given below. The responsibility of land management agencies (Bureau of Land Management, BLM; U. S. Forest Service, FS; and U. S. Fish and Wildlife Service, FWS) and the U. S. Geological Survey (GS) at each stage of development is summarized in Table 3.1. Figure 3.1 shows a typical exploration and development sequence, including points at which a company might discontinue or abandon its efforts.

\section{Pre-lease Exploration}

Prelease exploration is divided into "Casual Use" and "Exploration Operations."

(1) Casual Use. "Casual Use" as defined In 43 CFR 3209 means "activities that involve practices which do not ordinarily lead to any appreciable disturbance or damage to lands, resources, and improvements." The activities do not 
Tatila 3.1

Stages of Geothermal Development on Federal Land and Agency Responsibility.

Land Management Planning

Pre-lease Exploration Permit

Pre-lease Environmental Analysis

Non-Competitive Leasing Schedule

Non-Competitive Lease Application Review

Competitive Lease Sale Schedule

Competitive Lease Sale

Development of Lease Stipulations

Issuance of Lease

Post-lease Environmental Analysis

Post-lease Review of Plans of Operation

Post-lease Permitting

\section{BLM/FS}

BLM/FS (Primary) GS and FWS (Consulting)

BLM and/or FS (Primary) GS and FWS (Consulting)

BLM/FS (Primary)

GS/FWS (Consulting)

BLM (Primary)

FS/GS/FWS (Consulting)

BLM/FS/GS/ Industry

BLM (Primary)

FS/GS/FWS/DOE (Consulting)

BLM/FS/GS/DOE

BLM/DOE

GS (Primary)

BLM/FS/FWS (Consulting)

GS (Primary)

BLM/FS/FWS (Consulting)

GS (Primary)

BLM/FS/FWS (Consulting) 
PRE-LEASE EXPLORATION - Casual USe (no permit required)

Literature Search Aerial Plate Study Geologic Mapping

Geochenical Sampling Aeromagnetic Survey

Operator may conduct any combination of these exploratory techniques

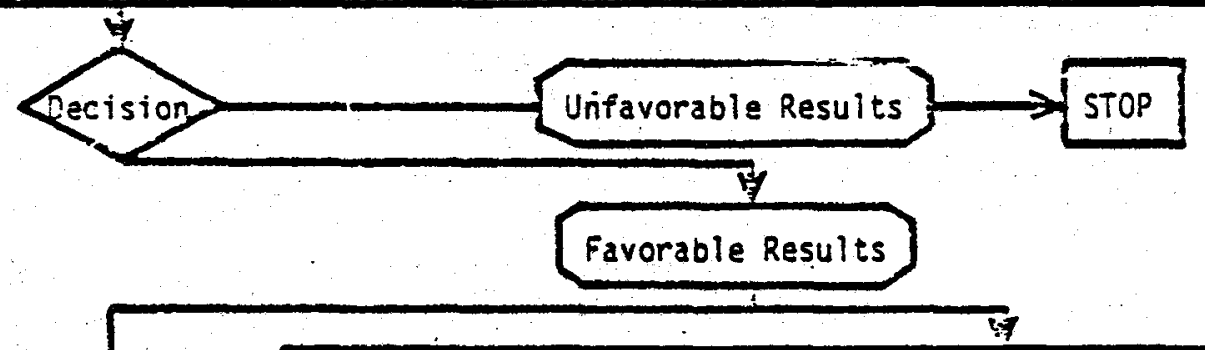

PRE-LEASE EXPLORATION - Intensive Exploration

(Requires Notice of Intent to Conduct Geothermal Operations)

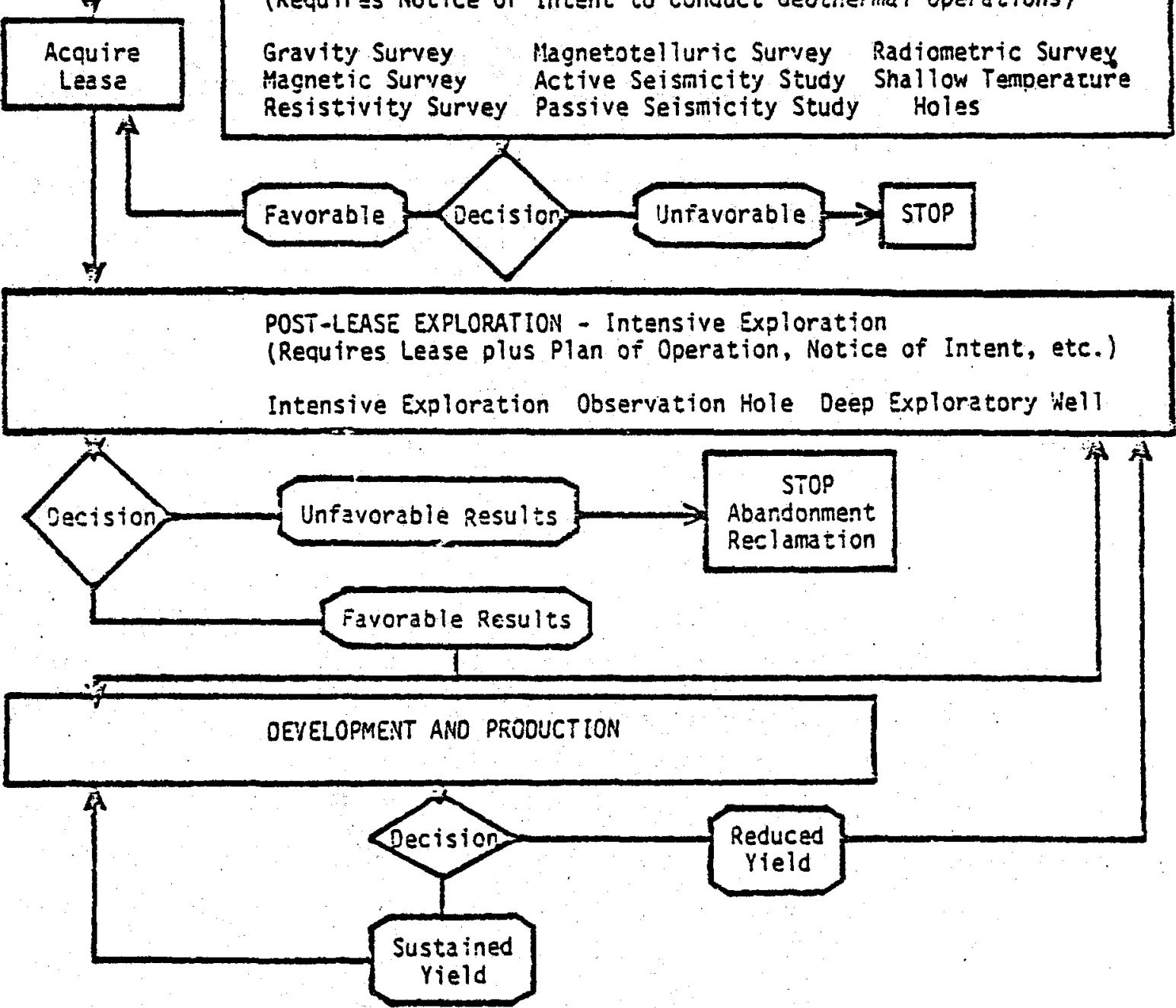

Figure 3.1 Typical Explotation and Sevelopment Sequence

Adapted from Raschen and Cook, 1976 
involve use of heavy equipment or explosives, and do not involve vehicular movement except over established roads and trails. Casual use does not require a permit or environmental assessment. Casual use generally includes the following: 1iterature review, geological reconnaissance, geochemical survey, and airborne surveys.

(2) Exploration Operations. Exploration operations have been defined in 43 CFR 3209 as "any activity which requires physical presence upon public land and which may result in damage to public lands, or resources." These operations may include, but are not limited to: geophysical operations; drilling of shallow temperature gradient holes (holes of no more than $152 \mathrm{~m}$ or 500 feet in depth); construction of roads and trails; and cross-country transit by vehicles over public lands.

Groups who wish to conduct exploration operations on BLM or FS land must file a "Notice of Intent to Conduct Geothermal Resource Exploration Operations" for each operation they propose. This "Notice" must be accompanied by a $\$ 5,000$ surety bond or rider to a state-wide or nation-wide bond. The bond ensures compliance with all federal regulations and stipulations governing exploration operations.

Within 30 days after receiving the "Notice of Intent" and the attached bond or rider, the BLM and/or FS prepares an Environmental Assessment Record (EAR) evaluating the impacts of the proposed project. Fish and Wild Life Service and GS provide some input to this document in the form of special stipulations designed to reduce or eliminate anticipated adverse impacts. When this has been done, the BLM's Authorized officer or the Forest Supervisor will attach all spectal stipulations necessary to protect the environment to the "Notice of Intent," and will approve the proposed project in writing.

After the exploration project has been concluded, a "Notice of Completion of Geothermal Exploration Operations" must be filed. The Bureau of Land Management will inspect the former project location within 90 days, and will notify the group responsible for the project whether they have complied satisfactorily with all the regulations and stipulations.

\section{Leasing}

The process of leasing federal geothermal resources is separated into competitive and non-competitive leasing.

(1) Competitive leasing. Competitive leases are usually issued to the highest qualified bidder on designated tracts of land within a known Geothermal 
Resource Area (KGRA). These tracts of land are selected by surface and subsurface geological features, drill log data, chemical analysis of water, or by competitive interest in areas.

When a sale is to be conducted, notice is published weekly in a paper of general circulation for four consecutive weeks. The notice specifies time, place, bidding requirements, land descriptions, royalty, rental terms, and any special stipulations. An application, with one-half of the bonus bid, is filed. On the date, at the time and place of the competitive bid, all bids are opened and displayed. The lessor has 30 days to accept or reject the bids, When a bidder is successful, he is required to sign three coples of the lease contract, to pay the first year's rental, to pay the balance of the bonus bid, to file the required bond or bonds, and to submit a proposed "Plan of Exploration." If these requirements are accomplished in the specified time frame, a geothermal lease contract is issued. Fallure to comply within the time allowed will result in rejection of the bid and any money submitted with the bid will be forfeited. If a bidder is unsuccessful, the money tendered with the bonus bid is returned to the applicant with the information about the lease sale.

(2) Non-competitive leasing. Non-competitive leases are issued on any available federa1 lands outside of a KGRA. Geothermal resources supposedly have a lower potential in these areas. Certain lands are, or may be, withheld from leasing. A non-competitive lease is acquired in a manner simflar to competitive leasing. An application, bond, or bonds, an application fee, and a proposed "Plan of Exploration" are sent to the proper BLM office. No bonus bids are required on non-competitive geothermal leases. When the application is approved, three copies of the lease contract are sent to the applicant. The applicant must sign the lease contracts and return them along with the first year's rent.

(3) Lease terms. The "Plan of Exploration" is required by federal regulations. This plan should describe briefly the activities that will be conducted on the lands described in the application.

The "Geothermal Resource Lease Contract" allows the federal government to lease geothermal resources and at the same time provides protection for other natural resources. Provisions within the contract require protection of the environment, antiquities, historic values, etc., in compliance with federal regulations. In addition, special stipulations needed to protect unique values of a particular area may be incorporated into the lease contract and compliance becomes mandatory. 


\section{Post-lease Exploration}

After a lease is issued, federal regulations require that a "Plan of Operation" be filed and approved by the land management agency and GS before any activity other than "casual use" may commence. The "plan," accompanied by maps, will describe all exploration activities that will be conducted on the leased lands. The U. S. Geological Survey, the lead agency, studies the "Plan" and sends coples to the surface managing agency and other interested agencies for comments.

The GS must prepare an Environmental Analysis (EA) covering the specific site of the "Plan of Operation." A discussion of the proposed exploration, such as gravity, resistivity, and temperature gradient surveys, may be included in the "Plan." Generally, the proposal is to drill one or more geothermal resource exploratory wells. An on-site inspection with representatives of the lessee, GS, and the land management agency is then conducted to assess the potential impacts of the proposed operation. The "Plan" and a draft EA are presented to the Geothermal Environmental Advisory Panel (GEAP), who then advises the GS's Area Geothermal Supervisor on the environmental aspects of the "Plan of Operation." The GEAP also recommends mitigating measures to protect the environment. The EA is completed after input is obtained from the GEAP. After considering the effects upon the environment and developing the special conditions or stipulations deemed necessary to protect the environment, the Area Geothermal Supervisor and the appropriate land management agency jointly approve the "Plan of Operation."

Upon approval of the lessee's application(s) for "Permit to Dri11," a permit is issued. The lessee then may commence only those operations authorized under the approved "Plan of Operations." The lessee's authorized operations are continuously monitored and inspected by the Area Geothermal Supervisor to ensure that the lessee complies with the applicable regulations and stipulations. Any additional exploratory operations proposed by the lessee require an additional "Plan of Operation." resulting in a procedure essentially the same as the preceding steps.

Pre-lease exploration methods have been defined previously; however, post-lease exploration uses many of these methods on a more intensive basis. For example, exploratory drilling methods, geological information holes and deep exploration wells requiring depths of more than $152 \mathrm{~m}$ (500 ft) may be used. These wells require large drilling rigs, a cleared and leveled drilling pad of 
one to two acres, and construction of a service road to provide access for men and equipment. If an exploratory well discovers a geothermal reservoir, a series of tests are made to determine whether there is potential for an economically productive well.

\section{Development}

Once a successful exploratory well is drilled, plans are made to develop the geothermal resource. A new plan, called a "Plan of Development," must be filed. No development operations will commence until the "Plan" is approved by GS and the appropriate land managing agency. Another EA covering the activities within the "P1an of Development" is prepared by GS. The GEAP again recommends mitigating measures for protection of the environment, which may result in additional stipulations imposed upon the lessee. The lessee then may commence only those development operations authorized by the "Plan of Development."

Again, all activities must be in compliance with the regulations and stipulations. The development of the geothermal resource requires the drilling of a number of development wells. Development wells are drilled and completed in basically the same manner as the exploratory wells, and require the same considerations.

\section{Production}

After a sufficient number of development wells are drilled, plans are made for the most economical and feasible use of the geothermal resource. The "Plan of Development" may be revised and submitted to the GS for approval, and no action will proceed until the revised "Plan" is approved.

A number of procedures must be followed before production begins within a geothermal field. Prior to placing the subject wells on prolonged production, the lessee must collect data concerning existing air and water quality, noise, seismic and land subsidence activities, and the ecosystem of the leased lands for at least one year prior to the submission of a "Plan of Production." Additionally, the lessee must submit an annual report of compliance with environmental protection requirements, giving a full account of the actions taken. The use of the leased lands or other federal lands for geothermal production will be authorized only under a separate permit issued by the appropriate agency.

An EAR is a prerequisite to the issuance of a permit for the use of the leased lands or other federal lands for a power generation plant, pipeline, transmission line, or other facility. Granting of a permit is not a license 
to construct the facilities. The construction, operation, and maintenance of a power generation plant can only be accomplished by obtaining a "Certificate of Public Convenience and Necessity." This certificate is granted by the Public Utilities Commission of the state having jurisdiction and regulatory authority over the company making application. Pipelines; power plants, and transmission lines may be constructed if the resource is such that electricity can be produced. A power plant and associated wells, similar to those at The Geysers, would occupy about 640 acres or one section of land within a township.

If the production of electricity is not feasible because of the reservoir conditions, the geothermal resource may be used for other purposes, such as greenhouses, hothouses, space heating - air conditioning, food processing, etc. These industrial uses may occur also in conjunction with electrical generating plants.

\section{Close out}

A sizable geothermal field would be abandoned gradually; in a small field, an abrupt cessation may be likely. If the exhausted production wells are strategically located, fluids reinjected into the reservoir through the exhausted wells may lengthen the life of the remaining field. If the wells are shut in, tests may reveal that the bottom hole temperatures and fluids have recharged after a lapse of time. Plugging and abandonment of geothermal wells must be done in accordance with Geothermal Resource Operation Order No. 3. In short, close-out or abandonment of all or a portion of a geothermal field requires abandonment of the subsurface, removal of the surface installations, and rehabilation of the surface.

\section{Summary of Participants and Activities}

As just discussed and as shown in Figure 3.1, the process of discovering, developing, and utilizing geothermal resources is quite complex. There are many separate classes of activities, carried out by individuals and agencies with different objectives and responsibilities, and the activities of these individuals occur in a context of potentially conflicting and restrictive rules and regulations.

The objectives of the investors and of industry representatives are to minimize the time and money involved in developing and utilizing geothermal resources, and to maximize their profits. As previously indicated, these individuals may decide to continue or to abandon their efforts at any point in 
the process for any number of reasons. A particular resource area may prove to be of unacceptable volume or quality, or the technology required to exploit a resource may not be avaliable or, if available, of uncertain reliability. The time and financlal cost involved in preparing a site for drilling, actually drilling the well, developing a production field, and producing and distributing the resultant energy may or may not be acceptable in terms of investment potential. However, in addition to these minimum costs for conducting their business, other factors also must be considered. These are the costs resulting from institutional issues. Time is required for activities like preparing plans of operation, processing permits, and gathering environmental data. Additional cost factors include the expense of environmental reports, bonds, and fees required by government permits, and mitigating technology required for obtaining permits.

The objectives of government agencies are generally not opposed to geothermal development, indeed they may be supportive of such development. However, by law and regulation, government agencies have the responsibility to assure that any activities associated with geothermal development are compatible with air and water standards, wildlife, and existing patterns of land uses. They must also hold public hearings before granting permits. Generally, they have a responsibllity for controlling the pace of development, and they have a desire to achieve a politically acceptable resolution between pro-and anti-growth forces.

Public interest groups and private citizens may differ among themselves in terms of their attitudes toward geothermal development. In general, however, while they tend to have very little knowledge concerning the details of such developments, they are concerned with minimizing adverse environmental and socio-economic impact. $(15,16)$

clearly, cooperative activity is required to achieve any degree of geothermal development. Each participant has a set of operating procedures based upon or imposed by a rational set of objectives. Since, however, there is actual or potential conflict, political cooperation is required. (12)

\subsection{Federal Response to Legal and Institutional Barriers to Geothermal Development The Federal Program}

The overall purpose of the federal geothermal program is to stimulate commercial development by private industry and local public power authorities. 
The program goal is to increase commercial utilization of geothermal energy from the present rate of 0.04 Quads per year to about 6.0 quads per year 2000 and to over 16.0 Quads by the year 2020. (17)

The federal program, which includes the programs of a number of federal agencies, is coordinated by the Interagency Geothermal Coordination Council (Figure 3.2). The council is quite young; it was established and had its first

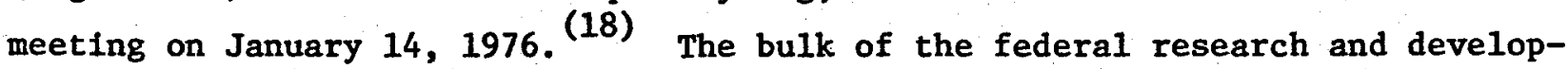
ment is now carried out by DOE and its Division of Geothermal Energy (DGE), and by the agencies of the Department of Interior (DOI), especially the U. S. Geological Survey. Environmental research, monitoring, and policy development recelve the attention of the Environmental Protection Agency (EPA) and DOI's FWS, and the Water Resource Council as well as DOE. Institutional and policy research are being advanced by DOE and the Treasury Department. The Geothermal Loan Guaranty Program has been instituted by DOE.

In support of the commercialization component of the program, the federal government is working closely with state and local governments, industry, municipal authorities, and environmental and other public interest groups in identifying appropriate federal initiatives that would most effectively encourage investment in geothermal energy and promote public acceptance of its development. An Advisory Committee on Geothermal Energy has been established to facilitate exchange of information and advice with the non-federal sector.

Institutional Barriers Panel

As shown in Figure 3.2, three panels were established under the Council's Charter: Resources Panel, Research and Technology Panel, and Institutional Barriers Panel. Each panel was given the responsibility for gathering relevant information and for developing recommendations for council's consideration. of greatest concern to this chapter was the Institutional Barriers Panel (IBP). This panel was given the following responsibility:

It is responsible for assessing legal, environmental, regulatory, and other aspects of federal, state, and local government policy as they relate to geothermal energy and for developing recommendations for changes and improvements in related laws, policies and procedures, and for examination of other institutional aspects of geothermal energy, including nongovernmental aspects. (18) 


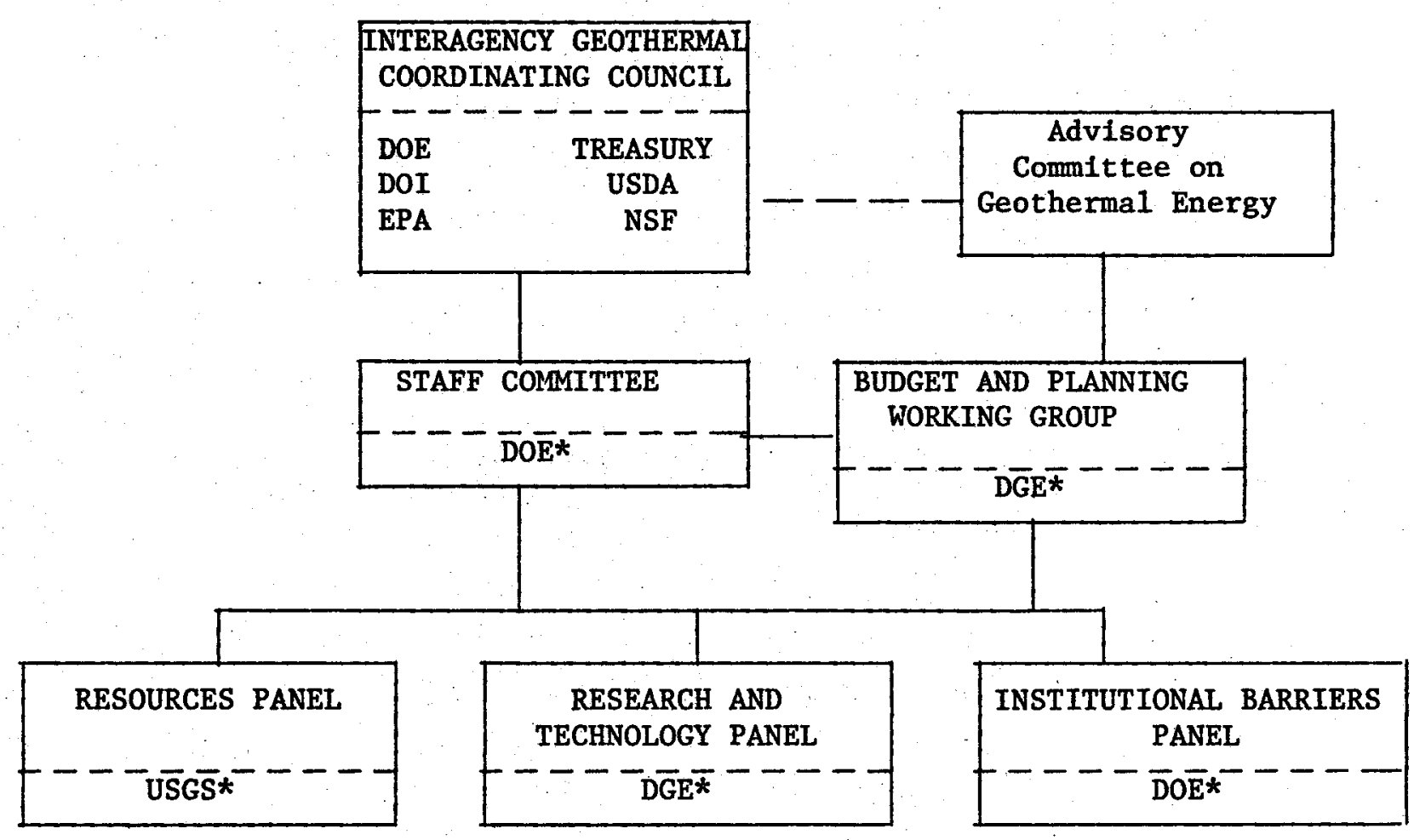

*Chairmanship Function

Figure 3.2 Interagency Geothermal Coordinating Council Adapted from 20, p. 128 
A number of problems which affected geothermal development were identified by IBP. These problems included the following: federal taxation, federal-state utility rate structuring, and federal-state environmental protection and standard. A rather large number of problems were derived from the Geothermal Steam Act of 1970; these included issues assoclated with overlapping lease applications, cash bonus competitive leasing, acreage limitations, work requirements, and casual use exploration. Numerous recommendations were made by IBP to the Council. The necessary actions to implement the approved recommendations are underway in the various responsible agencies. $(18,19,20)$

In particular, the following actions were taken. Several amendments were proposed to the Geothermal. Steam Act of 1970 and some of these were incorporated into the energy program the President proposed to Congress. Amendments also were proposed to the regulations designed to implement the Steam Act. In addition, amendments were proposed to the Internal Revenue Code of 1954 and to the Geothermal Research Development and Demonstration Act of 1974.

In short, the action of the IBP through the Council has led to a number of activities which should change certain federal policies that were perceived to be impeding the development of geothermal resources. The panel has also reported that a high degree of interest in their activities was evident in their discussion with industry and in inquiries from members of Congress and others.

\section{Cooperative Arrangements in the Department of Interior}

In addition to the problems mentioned above, the IBP identified problems associated with delays in obtaining leases, environmental reviews, and various types of permits. At least in part through the activities of the Council, a Memorandum of Understanding for the Geothermal Program was approved by the directors of BLM, GS, and FWS. (21) This memorandum is an agreement among these DOI agencies to cooperate on a set of procedures for federal land management practices. Figure 3.3 and 3.4 illustrate the various participants and the administrative procedures for geothermal regulatory processes during pre-1ease and post-lease activities, respectively.

As may be seen in Figures 3,3 and 3.4, three different offices of BLM, five offices of GS, three offices of FWS, the GEAP, and DOE, all have responsibilities in regulating and controlling geothermal development on lands under DOE control. Some of the activities shown in these two figures were also discussed in reference to Table 3.1, but here the routine steps in the process 

such as the requirement of notification, comment, approva1, signature, and transmittal among over a dozen agencies are described in considerable detail. The memorandum of understanding among the agencies of DOI and DOE serves as a vehicle for coordination of these activities. The net effect is to expedite pre-lease and post-lease activities and reduce many of the uncertainties associated with federal land management.

Interagency Geothermal Streamlining Task Force

While the Memorandum of Understanding was a major step toward Improving the management of federal land, it only applied to the management of land under the control of DOI. In the Southwest Region, very large tracts of land with geothermal potential are on Department of Agriculture (DOA) lands administered by the U. S. Forest Service (FS). An Interagency Geothermal Streamlining Task Force was formed to assist in coordinating the activities of DOE, DOI, and DOA as they related to geothermal development.

Specifically, the Task Force is developing recommendations to IGCC for appropriate action to Implement the President's commitment to Congress that:

"The Department of the Interior and Agriculture will streamline

leasing and environmental review procedures to remove unnecessary

barriers to development of geothermal resources." (22)

This objective was included in the President's comprehensive energy program submitted to Congress in April 1977. The commitment was prompted by the fact that although the Geothermal Steam Act was passed nearly seven and onehalf years ago, there is still no commercial production of this resource on federal lands.

The Interagency Geothermal Streamlining Task Force has undertaken a study which includes a) a comprehensive analysis of the elements of the present program designed to identify the sources of delay and quantify delays which are actually occuring; and $b$ ) the determination of the potential effects upon program performance of a series of options for program modification. The effectiveness of alternative options will be assessed in terms of their relative ability to support the Department of Energy's projected geothermal power-online schedule while adequately protecting the public interest and the environment.

The study w111 also incorporate input provided by the public, industry, environmental groups, and state agency officials through a series of workshops held in the western states in June. The schedule for these meetings was widely publicized in order to obtain the broadest participation possible. 
The Task Force developed a series of options for modifying the geothermal leasing and permitting program (described below) and comments on them were requested from the above groups. In addition, suggestions for additional alternatives were solicited.

Below are listed the three options that were proposed by the Task Force and the program modifications under consideration for each option. Various advantages and disadvantages were discussed for each alternative in the announcement distributed by the Task Force. (22)

Option 1. Improve the present system through changes in regulation and administrative procedures.

A. Use regional or areawide environmental analyses in pre-lease review and conduct site specific studies only during the post-lease permitting process.

B. Set time limits or timeframes (through administrative directive and/or regulations) for issuance of leases permits.

C. Improve coordination in all phases of pre and postlease activities.

D. Improve uniformity and consistency of policies and procedures with respect to lease stipulation among the involved agencies.

E. Institute formal nomination procedures for KGRA's and non-competitive areas.

F. Allow no-surface-occupancy leases in wilderness study areas and other special areas where requested.

G. Modify KGRA regulations.

H. Allow issuance of non-competitive leases unless the area is in a KGRA at the time of application.

I. Provide budgets in proportion to workloads, organizational needs, and priorities.

Option II. Base leasing decisions on areawide environmental assessment in combination with land management plan.

Option III. Provide for separate environmental analysis of exploration and development phases, with initial review of exploratory impacts only and comprehensive review after a discovery is made.

The next part of this chapter reviews some of the studies which led to these recommendations. 


\subsection{Previous State and Regional Studies of Institutional Factors}

The aim of this section is to review the assumptions, procedures, and results of some recent research conducted at the regional and state level on the legal and institutional barriers to geothermal development. Two excellent papers, one by Sacarto ${ }^{(6)}$ and the other by Schuller et al, (13) adequately illustrate two approaches used In this type of research. These two papers show that very similar lists of needs and similar sets of recommendations are generated regardless of how the issue of state-level and institutional constraints to geothermal development are studied. The two general types of approach to the study of legal and institutional factors affecting geothermal development may be classified as (a) those which promote or encourage changes in the legal and institutional infrastructure which controls the geothermal process as a means of reducing the uncertainties, the delays, and the cost experienced by the legal and institutional framework so that participants can more efficiently learn the process and the steps required to adapt to $1 t$; and (b) those which promote stable policies. These two approaches and the recommendations they generate are discussed below.

Studies Promoting Policy Changes

In State Policies for Geothermal Development, Sacarto reviews for the National Conference of State Legislatures (NCSL) the various technical, economic, and institutional aspects of geothermal development as they exist and as they affect geothermal development in the thirteen western states and the gulf states of Texas and Louisiana. (6) Sacarto acepts the most optimistic projections for geothermal potential as a working hypothesis. These projections are that the potential for geothermal resources is huge. For electrical generation this energy projection is in the order of $100,000 \mathrm{MW}$ over the next 20-30 years (onefifth the current $U$. S. electrical capacity). The nonelectric applications are presumed to have equally great though unspecified potential. It is further assumed that these contributions can occur at prices competitive with energy currently generated from other sources and with relatively little environmental impact. (16)

Given those assumptions, Sacarto seeks to explain why the energy industry has not invested large sums of money into the development of geothermal resources. Sacarto recognizes that utilities tend to be wary of new, unfamiliar resources, especially those for which there is a requirement for site specific power plant 
construction and for which there is still an uncertain technology for electric power generation. These uncertainties on the part of a generally, conservative industry hinder the rapid development of the resource. Sacarto, however, places a major share of the inhibitory forces in state and federal policies. His comments on obstacles to geothermal development at the very beginning of his report set the stage for what follows in his report: . . "State and federal policies that hobble geothermal development . . cripple the geothermal industry .. . falled to encourage large scale development . . accentuate the uncertainty and risk already inherent to geothermal exploration and development." $(6)$

After examining, in turn, features of the resource, factors which characterize and affect the exploration and development of a geothermal resource area, and the means by which various types of taxes are applied to geothermal development, Sacarto reviews how the states have characterized the resource and how they regulate the leasing of state lands and the development of the resource within the states. Based upon this review of the industry and the state and federal policies which affect the industry, Sacarto identifies six conditions needed by the industry if it is to pursue large scale development; utility confidence in the resource, equitable tax treatment, prompt exploration of extensive land areas, long and secure tenure for productive properties, prompt facility siting and development, and competitive access to various consumers.

Sacarto recommends a set of nine policies which could be enacted by state governments to achieve these conditions. These policies and their objectives are as follows:

1. Policies designed to direct public attention to geothermal resources as an alternative form of energy and power. Both policy makers and the general public need to be exposed to more information concerning the immediate and longterm values available from geoth ermal resources.

2. Policies designed to create and nurture an interstate geothermal development compact. Such a compact would facliftate communications between the states and other participants in the geothermal process and thereby lead to improvements in geothermal legislation and regulations.

3. Policies designed to clarify the statutory definition of geothermal resources. Such clarification is necessary to remove 
uncertainties associated with such issues as resource ownership, taxing policies, and regulatory processes. A distinction between geothermal resources and established water resources is especially important in the water scarce Southwest Region.

4. Policies designed to reduce the need for unreasonably high levels of water appropriation. Statutory assurance is needed by industry that water rights are necessary for only the water that is consumed by the geothermal process, not for the total volume which may be processed.

5. Policies designed to establish more uniform and more realistic provisions for assessing the value of undeveloped geothermal properties for the purpose of taxation. These policies would recognize that no income value can be attributed to prospective geothermal production before commercial quantities of the resource are actually produced and sold.

6. Policies designed to provide state tax benefits and encourage federal tax benefits to the geothermal industry. Income tax deductions for intangible drilling costs and percentage depletion allowance will enable the Industry to attract the necessary investment capital.

7. Policies designed to establish more secure leasing provisions for state-owned land and encourage the establishment of federal lease provisions more suited to geothermal development, These provistons would include a reevaluation of terms, renewal arrangements, acreage limitations and lease adjustment clauses.

8. Policies designed to improve the market position of electric power produced from geothermal energy. These policies would encourage utilities to invest in geothermal projects through such means as financial incentives, demonstration projects, and siting priorities.

9. Policies designed to encourage nonelectric application of geothermal resources. The direct application of geothermal resources may, in the long run, be the most efficient and effective use of the resource.

The impact and thoroughness of the NCSL publication can be measured by the extent to which it is referenced by other investigators and by the estent to 
which the recommendations made by Sacarto are also made by other independent investigators. For example, a speclal report by the staff of the Western Governors Regional Energy Policy office in May, 1976, made recommendations for encouraging geothermal development which are essentially indistinguishable from those made by the NCSL report. (13)

A series of studies commissioned by the Northwest Energy Policy Project (NEPP) came up with conclusions which with one important exception, are in basic agreement with those of Sacarto, $(7,11,12)$ In one of these studies, Johnson, et $a 1,(7)$ agreed with Sacarto that the main hinderances to geothermal development in the Northwest are the economic risks faced by potential developers. They argue, however, that there is little the states can do to significantly mitigate those hindrances other than "to be aware of the potential and of the limitations of geothermal energy." (7) They emphasize that potential lands for development are federally controlled, the principal tax obligation is federal, and (by implication) the funds needed for effective stimulation of exploration and development must come from the federal treasury.

As part of another study in the same NEPP series of reports Hiatt focused on institutional constraints and opportunities for "unconventional energy sources" including a geothermal energy development. (10) Hiatt reviewed a wide range of state and local governmental actions which could be categorized as negative and positive incentives. He further gives examples of official action which would or could affect the development of geothermal energy sources. These actions, with regard to unconventional energy production, were grouped into four categories: no action, direct economic incentives, indirect efforts at promotion, and direct action toward production. When specifically addressing the public policy options application to geoth ermal energy Hiatt intensively drew upon Sacarto's work. In fact Hiatt's presentation of policy options and his recommendations were extracted fron the State Policies Report published by NCSL.

Before leaving this subsection concerned with the status of and changes required in state policies, reference should be made to NCSL's Geothermal Policy Project. This new project was launched on January 16, 1978. "The objective of the project is to stimulate and assist the review of state policies that affect the development of geothermal resources. Successful completion of the project is to facilitate state statutory and regulatory environments that are consistent with efficient development of geothermal resources." (24) Hence, the project is an obvious extension of the previous work performed by Sacarto 
for NCSL. The project has selected six states in which to concentrate its efforts during 1978. Two of these six states (New Mexico and Utah) are currently in the Southwest Region. This effort, funded by DOE, w111 complement the efforts being made by the Southwest Regional Program as reflected by the present chapter. Studies Promoting Stable Policies

Schuller et al., concentrated on identifying and analyzing the nontechnical problems which hamper the production of electricity from geothermal resources in California. (13) The assumptions they made in performing that analysis and the possible solutions they proposed are equally appropriate for none electric applications and to regions outside of the state of California.

Schuller et al., like Sacarto and others, notes the discrepancy between the potential and the actual plans for the utflization of geothermal energy. They also accept the conclusion that nontechnical problems such as leasing, financing, and permitting appear to be a major reason for significant and costly delays in geothermal development. However, rather than focusing on the laws and regulations which might create or contribute to these nontechnical problems, Schuller et al., focuses on the behavior of the significant participants who must operate within the constraints imposed by the nontechnical problems.

In particular, Schuller et al, argue that "smoothing or making minor modifications to the existing regulatory process is likely to do more to speed the development of the geothermal industry than attempting wholesale changes to the process." (13) This argument is based on the concept of institutional learning which holds that in any process certain minimums of time, money, and trouble are required to learn the substance and procedures of the process, When the process is unstable and when the participants cannot devote continuous and undivided attention to the process, the learning will be even less efficient.

Even though there are large areas of uncertainty concerning the impacts of procedural and polfcy actions, there are a few Individuals and organizations who have learned a great deal about the geothermal development process; they have learned what is necessary to operate effectively. Others are in various stages of aquiring the necessary knowledge. If the process remains stable, a type of institutional learning will continue. All the participants will continue to acquire useful knowledge which they can in turn share with others in the process. Hence, even if a policy or regulatory system is not as good in some sense as it might be, the participants can perform well within that system. Any new system of policies and regulations would require that all 
participants begin the learning process all over again; the time, cost, and trouble of learning ihe new system may outweigh the gains the new system were to produce.

Schuller et al., examined the nontechnical problems within each of five technical stages in the development of geothermal resources (1easing, exploration, marketing the resource to a utflity, constructing the power plant, and transmitting the electric power to consumers: as well as nontechnical problems associated with financing, environmental impact reporting, and the activity of several sgencies unique to California. In each area, these investigators examined proposals made by various participants in the process (federal and state agencles, representatives of industry and public interest groups, and others).

A11 proposals were evaluated in terms of whether they would help participants adapt to, or promote relatively minor modifications in the existing system. Six classes of proposals were acceptable under that criterion.

(1) Those that emphasized the value of gathering and disseminating information about the substance and procedure to those that need it (e.g., baseline environmental data, resource exploitation technology, mitigation technology, and discussion of procedural rules),

(2) Those that are aimed at refining and codifying substantive and procedural rules that may be a source of delay of difficulty because of their ambiguity (e.g., either more formal statements to increase the stability of a rule or more flexible rules which are sensitive to site specific peculiarities).

(3) Those that emphasize the use of technological or procedural innovations to mitigate problems of legal, institutional, or political nature (e.g., methods such as slant drilling and well head mufflers that can be used to satisfy environmental requirements).

(4) Those that emphasize the value of advance planning to reduce administrative costs, delays, and troubles, (e.g., careful preparation for negotiations between parties).

(5) Those that involve the selective resolution of political and legal problems (e.g., generating public support for the industry). 
(6) Those that suggest the direction that should be taken by future research and development (e.g., proposals that encourage DOE and others to provide demonstration grants rather than basic research grants).

These six classes constitute only relatively minor changes that were designed to minimize the need for new institutional learning or to maximize the efficiency of any institutional learning which must occur. With the same criteria in mind, Schuller, et al, also gave support to two kinds of major change. In the latter two instances the criterion was that the change would require the acquisition of only minor amounts of new knowledge. These acceptable proposals for major change are as follows:

(1) Any major change that would increase the relative attractiveness of the geothermal industry in the investment area (e.g., tax credits for geothermal investments).

(2) Any major change that would reduce the number of participants through organizational integration (e.g., reservoir untization, or vertically integrated companies).

The eight types of proposals listed above all meet the criterion that changes in policy should help participants adopt to, or promote relatively minor modifications in the existing system. Schuller et a1., imposed the further restriction that acceptable proposals must in some way reduce the time, money, and trouble associated with (a) the process of bringing the proposal Itself into law or into practice and (b) the effect of the proposal once it is put into practice. Clearly, there are proposals such as one which might seek to exempt the geothermal industry from environmental impact legislation, which would accelerate the development and utilization of geothermal resources if they became law, but which probably could not become law or perhaps could but only with large expenditures of time and money and large amounts of trouble.

The criteria developed by Schuller et al., for evaluating proposed changes in the geothermal process seem to recognize the needs of industry and also take into account the probable reactions of special interest groups and the realities of the American political scene. Schuller et al., used these same criteria to Identify proposals that should be avoided. These included:

1. Proposals that add more steps in the regulatory process - for example, proposals for environmental appeals boards. 
2. Proposals afmed at remoying geothermal development from local control or the environmental review process.

3. Proposals involving major overhauls of the existing lease system.

4. Proposals involving significant changes in normal patterns of property taxation.

5. Proposals using federal or state "expediters" to resolve conflicts or to provide information.

\subsection{Summary of Previous Regional and State Policy Studies}

The difference between those studies which promote changes in state policies and those which encourage caution in accepting proposals for changes in state policy may be more in style than in substance. The major recommendations each derives from their efforts are not significantly different.

Sacarto provides an excellent starting point for one just beginning an analysis of the institutional factors which may affect the development of geothermal resources. His report indicates what to look for, where to 1ook, and what you might find as a result of your efforts, While his proposed policies for state government are clearly designed to most directly benefit the geothermal industry, they are not oblivious to the needs of the governmental and public sectors nor do they ignore the problems associated with adjusting to major revisions in policy and regulation. However, Sacarto's references to the needs of the government and public domains are primarily concerned with the more obvious consequences of geothermal development. For example, the statement that "irresponsible geothermal operations can pose clear dangers to public health and local environments." (6) Furthermore, the concerns expressed over the effects of major changes in policy are directed at the cost to industry for converting to the new approaches and the seriousness to industry of unforseen complications which the new procedures may introduce. With respect to major changes in leasing methods, Sacarto notes that "the procedures may fail in practice to protect the explorer."(6)

Schuller et al., provide a careful analysis of over 98 separate proposals for changes in the legal, institutional, and political context of geothermal development. In the process of doing so they provide future researchers with two important guides for success. First, Schuller et a1., explicitly underscore the importance of behavior issues which must be taken into account when a decision is to be made concerning the policles and procedures. It 
is a generally accepted truth that individuals and groups w111 react differently in familiar (though perhaps undersirable) situations than they will in situations which are unfamiliar and hence within which outcome are more uncertain, It is also true that individuals and organizations representing different legitimate interests will perceive the consequences of a given change in policy in quite different ways. Second, Schuller et al, have developed a systematic procedure for examining proposals for change and a set of well defined criteria for choosing among those proposals which should benefit future researchers in the area of policy regulations.

One proposal is common to both the Sacarto and the Schuller et al, studies. That is the proposal to encourage cooperative activities among the various industrial and governmental participants. This may be an especially important Issue for participants operating at the state level. If Johnson et al, are correct in their observation that there is little state and local level policy action can accomplish by themselves, (7) their only recourse may be for state and local agencies to combine their efforts at promoting geothermal development and at promoting changes in federal policies for land management, regulation, and taxing. Industrial and federal policy making entities sometimes might view local participation as constraints on their ability to proceed responsibly. However, local participation should be viewed as an opportunity for securing local and public input, understanding, and even support. (11)

Institutional Factors Operating in the Southwest Region

The following discussion of state-level legal and institutional factors in the development of geothermal energy is organized into four sections: objectives, procedures, results concerning the current stätus of geothermal development, and results in terms of the identification of major participants within each state.

Objectives

The objectives of this section of the report are two-fold. The first objective is to identify for each of the southwest states the current status of geothermal development with the aim of isolating the contribution of legal and institutional factors. The goal is to identify how various state-level statutes or regulations and state level taxing or environmental protection procedures may have affected the rate of leasing, exploring, developing, and utilizing geothermal resources within each state. 
The second objective is to identify the principal participants in the geothermal development process within each state. According to this approach, the factors of interest occur as a result of actions of and the interactions among participants in the development process. These actions and interactions are initiated and constrained by various statutes, regulations and policies, but they also may change as a result of institutional learning.

The major theme of the second objective is that the behavior of an individual participant (and the collective behavior of a group of individuals in the same institutional agency) is affected by the experiences that individual (or group) has had. Consequently, the perceptions attitudes, and behavior of participants in the geothermal development process can be predicted on the basis of concepts derived from the behavior sciences.

To underscore the importance of the behavioral aspects of the entire process, it must be emphasized that any given regulation or the consequences of any given action may be perceived quite differently by participants who have different responsibilities. For example, one developer has complained that it may take as long as six months to obtain a permit to drill a geothermal well. On the other hand, a state-level regulator was attempting to be quite positive when he pointed out that a permit to drill a geothermal well can be obtained in as little as twelve to eighteen months. The developer and the regulator should not be expected to automatically perceive the permitting process in the same way. The resulting conflict in goals and operating procedures may be resolved without any special mitigating action by anyone. Resolution of the conflicts may occur through a mutual learning process that will occur as the participants continue to interact with one another. At times, resolution of conflicts can be hastened by a change in technology or in the legal and regulatory content.

Three types of data were needed to achieve an understanding of the role of institutional factors in geothermal development in the Southwest. First, information concerning the status of geothermal development was needed for each state. In particular, it was necessary to determine how much activity was occuring at each stage in the development process. Second, information was needed concerning the current status of laws, regulations, and policies within each state. Third, information was needed about the various participants in the geothermal development process.

Information concerning the status of geothermal leasing, exploration and development was obtained from a number of independent sources. Information of 
this type was provided in the resource data sheets the state teams provided for each resource area. Current information on the status of geothermal resource development was also avallable from BLM lease status reports and from the land departments within each state. Information concerning the legal and regulatory provisions, and the identify and characteristics of participants was obtained from reports prepared by data collectors working for the respective state teams.

Results - Current Status of Geothermal Activity

\section{Leasing of Resource Areas}

The issue of whether or not a geothermal resource is developed depends initially upon a developer's ability to acquire stable access to the geothermal reservoir. The relative accessibility of the reservoir depends upon ownership of resource, and that in turn often depends upon how the resource is legally defined.

In this regard, the states may have little control over who, if anyone, has access to the resource. The states generally own relatively small amounts of land surface. Table 3.2 shows the extent of federal, state, and private land ownership among the five southwestern states. No state owns more than about fourteen percent of its surface area and most own less than ten percent. Federal ownership accounts for from one-third to over four-fifths of the land. Private ownership of land is also quite high, ranging from just over thirteen percent to nearly sixty percent.

If the geothermal resource is defined as a type of water or mineral resource, it may be legally separated from the land surface. In this manner, ground water is considered a property of the subsurface estate and is controlled by the state as a public resource. Azirona is the only exception to this rule in the five southwestern states. In Arizona, ground water is generally attached to the surface, and hence its ownership may be determined through court orders.

Minerals are generally attached to subsurface estates, and ownership of these minerals also may be separated from ownership of the land surface. State and federal land management practice has often reserved mineral rights to the government while selling off the surface rights. Consequently, since surface and subsurfa e estates may be independently owned and controlled, the attachment of the geothermal resource to either estate or to nefther estate will determine who has legal custody of the resource. Table 3.3 shows the amount 
Table 3.2

Land Ownership in Southwest Region*

In Million Acres

\begin{tabular}{|c|c|c|c|c|c|c|c|}
\hline \multirow[t]{2}{*}{ State } & \multirow[t]{2}{*}{$\begin{array}{l}\text { Total } \\
\text { Acreage }\end{array}$} & \multicolumn{2}{|c|}{ F ederal } & \multicolumn{2}{|c|}{ State } & \multicolumn{2}{|c|}{ Private } \\
\hline & & Acres (M) & $\%$ & Acres (M) & $\%$ & $\operatorname{Acres}(\mathrm{M})$ & $\%$ \\
\hline Arizona & 72.688 & 32.433 & 44.6 & 9.222 & 12.7 & 31.033 & 42.7 \\
\hline Colorado & 66.486 & 24.152 & 36.3 & 3.233 & 4.9 & 39.101 & 58.8 \\
\hline Nevada & 70.264 & 60.7 .25 & 86.4 & 0.086 & 0.1 & 9.453 & 13.5 \\
\hline New Mexico & 77.766 & 26.388 & 33.9 & 11.032 & 14.2 & 40.436 & 51.9 \\
\hline U tah & 52.697 & 35.060 & 66.5 & 4.923 & 9.3 & 12.714 & 24.2 \\
\hline
\end{tabular}

* rom Sacarto State Policles for Geothermal Development, November, 1976 (Ref. No. 6)

Table 3.3

Mineral Acreage Reserved to the State and to the United States* In Million Acres

\begin{tabular}{|l|c|c|}
\hline \multirow{2}{*}{ State } & \multicolumn{2}{|c|}{ Mineral Subsurace Estate } \\
\cline { 2 - 3 } & Reserved by State & Reserved by U.S. \\
Arizona & $1.000,000$ & $5.662,640$ \\
Colorado & $1.000,000$ & $12.929,974$ \\
Nevada & - & $0.738,593$ \\
New Mexico & $2.000,000$ & $24.275,069$ \\
Utah & $0.919,000$ & $3.765,561$ \\
\hline
\end{tabular}

*Adapted from Sacarto, State Policies for Geothermal Development, November, 1976. The acreage given for state mineral lands are only rough approximations. The acreage given for federal reserves are accurate as shown through 1948; approximately $15 \%$ more land was patented with mineral reserves through 1974 . 
of land acreage in each state reserved to the state and federal governments because of these mineral reservations.

The net effect of mineral and ground water reservations is to create considerable uncertainty about who controls access to the geothermal reservoir. The 1ssue would of course be settled if there were a common definition of what is and is not a geothermal resource. However, as pointed out by Sacarto, there are important differences in how the five southwest states define the resource. (16) New Mexico and Utah explicitly distinguish between the thermal and mineral components of the geothermal resource and the waters which transmit those components. Arizona and Colorado make clear distinction between water, mineral, and geothermal resources. Following the definition used by the federal government, these latter two states include all products (including water) of the geothermal process in their definttion of a geothermal process. To complicate the issue further, while Arizona includes any mineral or minerals, exclusive of fossil fuels and helium, in their definition of geothermal resources, Colorado explicitly states that geothermal resources are not mineral. Finally, to complete a summary of the five states, Nevada defines geothermal resources as simply. heat and is adopting special regulations to govern their development in the state.

As a result of the widely varying and still unstable definition of geothermal resources across the five states, there is uncertainty concerning which level of government owns the resource and which agencies within the state government have regulatory control over leasing, exploration, and development of the resource.

While these uncertaintles remain, leasing has nevertheless occurred. Table 3.4 shows the amount of federal and state lands that have been leased for geothermal exploration and development in the Southwest Region. The numbers in parentheses refer to the number of separate leases in each category. As may be seen, leasing activity varies considerably across the Southwest Region. The status of leasing is moderately high in both Colorado and New Mexico. The total acres leased in Colorado include 40,000 acres which have been dropped after the completion of exploratory drilling.

Taken together, the acreages of state and federal land leased for geothermal activity may appear quite high, suggesting that there are no barriers to geothermal development at the leasing stage. That may be a misleading conclusion. Table 3.5 shows a more detailed breakdown on the status of lease 
Table 3.4

Acreage of State and Federal Geothermal Leases*

\begin{tabular}{|l|c|c|c|}
\hline \multirow{2}{*}{ State } & \multicolumn{2}{|c|}{ Federal Leases } & State Leases \\
\cline { 2 - 4 } Arizona & KGRA & Non-KGRA & - \\
Colorado & $5,036(3)$ & $6,508(?)$ & $83,192(27)$ \\
Nevada & $152,662(79)$ & $729,309(?)$ & - \\
New Mexico & $70,911(40)$ & $88,490(45)$ & $63,374(147)$ \\
Utah & $86,447(50)$ & $340,011(199)$ & $210,570(221)$ \\
\hline \multirow{2}{*}{ Totals } & $315,056(172)$ & $1,192,806(269)$ & $357,136(395)$ \\
\hline
\end{tabular}

*From State Team Final Reports, August, 1978 
Table $\quad 3.5$

Status of Lease Sales on Federal KGRA's*

\begin{tabular}{|c|c|c|c|c|c|c|c|c|}
\hline \multirow[t]{2}{*}{ State } & \multicolumn{2}{|c|}{$\begin{array}{l}\text { Theoretically Avall } \\
\text { able for Leasing }\end{array}$} & \multicolumn{2}{|c|}{ Acres Offered } & \multicolumn{2}{|c|}{ Acres Bid on } & \multicolumn{2}{|c|}{ Acres Accepted } \\
\hline & BEM & FS & BLM & FS & $\overline{B L M}$ & $\overline{\text { FS }}$ & BLM & FS \\
\hline$A Z$ & 3,240 & 0 & 780 & 0 & 0 & 0 & 0 & 0 \\
\hline Co & 11,271 & 1,513 & 11,271 & 0 & 5,036 & 0 & 5,036 & 0 \\
\hline NV & 326,802 & 4,160 & 201,988 & 2,560 & 148,163 & 0 & 145,682 & 0 \\
\hline NM & 190,320 & $1,224,004$ & 101,693 & 29,375 & 62,482 & 18,050 & 62,482 & 18,050 \\
\hline UT & 83,215 & 15,572 & 78,966 & 10,852 & 77,277 & 10,852 & 77,277 & 10,852 \\
\hline Total & 614,848 & $1,245,249$ & 394,698 & 42,787 & 292,958 & 28,902 & 290,477 & 28,902 \\
\hline
\end{tabular}

*From Streamlining Task Force, April, 1978 
sales of Federal KGRA lands in the Southwest. This table shows KGRA acreage theoretically available, the acreage actually offered for bids, and those for which bids were recelved and accepted. This breakdown is shown separately for BLM and FS lands. (22) of the KGRA land under their management and theoretically available for leasing, BLM has offered 64 percent for bids but FS has offered only 3 percent. Clearly, there must either be a large difference in the types of lands these two federal agencies manage or a difference in how they process these lands for the impact of geothermal development activities. Once the KGRA lands are offered they may not have received any bids. The success ratio here does not differ substantially between BLM and FS (73 percent of the acres offered subsequently received bids). The relative success of competitive KGRA land offerings is much higher in the Southwest than it has been across the $U$. $S$. For the U. S. as a whole, bids were received for only 45 percent of the KGRA acreage offered. In the Southwest (and the nation as a whole) the land managers generally accepted a bid for a KGRA offer when one was received.

The relative success of non-KGRA leasing parallels that just discussed for KGRAs. As of December 31, 1975, 301 non-competitive lease applications were filled with FS of which 14 (5\%) were issued and 121 (40\%) were either rejected or subsequently withdrawn. For the same period. 2613 non-competitive lease applications were filed with BLM of which $709(27 \%)$ were issued and 1508 (57\% were rejected. Hence, BLM rejects about fifty percent more non-competitive lease applications than FS, but it also issues 600 percent more non-competitive leases. The difference in success between BLM and FS non-competitive lease application is about the same for the country as a whole as it is for the Southwest. Over both land management agencies, however, percent of non-competitive lease applications 1ssued is much higher in the Southwest than for the country as a whole ( $26 \%$ vs. $16 \%$ ). Hence, there is a large discrepancy in actual noncompetitive leasing activity between BLM and FS, and this difference is probably a reflection of policy or manpower allocations emanating from the federal level of government. However, there is a higher level of Federal non-competitive leasing activity in the Southwest than in the country as a whole. This latter finding may reflect differences in the relative sensitivity of the land, the adequacy of the resource, or competence of the potential lessees.

Table 3.6 illustrates another phenomenon associated with the leasing of federal non-KGRA lands. As shown, there were 928 non-competitive lease applications for federal land as of April 1978. The majority of these pending 
Table 3.6 Age of Noncompetitive Lease Application Still Pending for Federal Land* (as of Apri1, 1978)

\begin{tabular}{|c|c|c|c|c|c|c|c|c|c|c|}
\hline \multirow{2}{*}{ State } & \multicolumn{2}{|c|}{ Less than 12 mos. } & \multicolumn{2}{|c|}{$12-23 \mathrm{mo}$. } & \multicolumn{2}{|c|}{$24-35 \mathrm{mo}$. } & \multicolumn{2}{|c|}{ More than 35 mo. } & \multicolumn{2}{|c|}{ Total } \\
\hline & BLM & F S & BLM & F S & BLM & F S & BLM & F S & BLM & F S \\
\hline Arizona & 5 & 27 & 11 & 0 & 2 & 26 & 7 & 1 & 25 & 54 \\
\hline Colorado & 0 & 0 & 0 & 0 & 0 & 0. & 9 & 27 & 9 & 27 \\
\hline Nevada & 53 & 1 & 7 & 0 & 17 & 1 & 197 & 8 & 274 & 10 \\
\hline New Mexico & 34 & 11 & 24 & 0 & 8 & 3 & 144 & 28 & 210 & 42 \\
\hline Utah & 38 & 2 & 34 & 15 & 9 & 3 & 135 & 41 & 216 & 61 \\
\hline TOTALS & 130 & 41 & 76 & 15 & 36 & 33 & 492 & 105 & 734 & 194 \\
\hline
\end{tabular}

* From Streamlining Taș F orce, April 1978 
applications has been pending for three or more years. The indicated long delay In issuing a decision for these non-competitive lease applications is slightly. higher for BLM than for FS (6.7\% vs. $54 \%$ for 3 or more years). However, as described earlier, about 55 percent non-competitive lease applications to FS are still pending compared to only 29 percent for BLM.

Unfortunately, the status of leasing activity for state lands is not as well documented as is the status of leasing activity for federal lands. The sparsity of information on the leasing status of state-owned geothermal resources is due in part to the small amount of land owned by the states in the Sou thwest (on the average about $8 \%$ ). The absence of leasing data for state land is also due to moratoriums on the leasing of state-owned lands in Nevada and Arizona, and the absence of any state geothermal leasing activity in New Mexico since 1974. The absence of activity in this regard is due in part to legal challenges to non-competitive sale of state land (In Arizona), and in part to the need for regulatory policy (In Nevada).

Table 3.7 summarizes the status of procedures governing the leasing of state-owned land for geothermal exploration development. As may be seen the criteria for distinguishing between state KGRAs and state non-KGRAs differs among the southwestern states. Table 3.8 summarizes the terms of leases issued for state geothermal lands, and for comparison, for federal geothermal lands. As may be seen, there are considerable differences in leasing provisions among the southwestern states and between the states and federal government. Five year primary lease terms are specified in the lease provisions of Arizona and New Mexico while Utah and the federal government allow for a 10 year primary lease term. Furthermore, the frequency with which lease terms may be negotiated is either unspecified (as in Arizona and Nevada), or is required every three, five, or ten years (for Utah, Colorado, and New Mexico, respectively). It is of course, very difficult to get an investor to commit : large amounts of capital to develop geothermal resources when there is no guarantee that the developer will continue to have secure access to those resources after the initial primary lease term expires. This is especially true since once a resource is made productive, it may take 20-40 years to amortize the large investments that were required. The current status of leasing and lease adjustment provisions raise too much uncertainty for many prospective investors. 
Table 3.7 .

Leasing of State Land*

\begin{tabular}{|c|c|c|c|c|}
\hline \multirow{2}{*}{ State } & \multicolumn{2}{|l|}{ Non-KGRA } & \multicolumn{2}{|l|}{ KGRA } \\
\hline & Newly Offered & $\begin{array}{l}\text { If Applications } \\
\text { Overlap }\end{array}$ & Bidding Factor & $\begin{array}{l}\text { Designative } \\
\text { Criteria }\end{array}$ \\
\hline$A Z$ & By Application & $\begin{array}{l}\text { Cash Bonus Bid- } \\
\text { ding or Qualifi- } \\
\text { cation }\end{array}$ & Cash Bonus & $\begin{array}{l}\text { Geology and/or } \\
\text { Competitive } \\
\text { Interest }\end{array}$ \\
\hline co & $S_{p}$ & ecified by state I & and Commissioner & \\
\hline NV & Mo & ratorlum since 197 & & 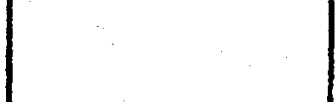 \\
\hline $\mathrm{NM}$ & $\begin{array}{l}\text { Competitive } \\
\text { (3-day fil- } \\
\text { ing) }\end{array}$ & By Application & Cash Bonus & $\begin{array}{l}\text { Determined by } \\
\text { Commissioner of } \\
\text { Lands }\end{array}$ \\
\hline UT & $\begin{array}{l}\text { Cash Bonus } \\
\text { (15-day fil- } \\
\text { Ing) }\end{array}$ & By Application & No such $D E$ & signation \\
\hline
\end{tabular}

*From Sacarto State Policies for Geothermal Development, November, 1976 
Table 3.8

State Geothermal Lease Provisions*

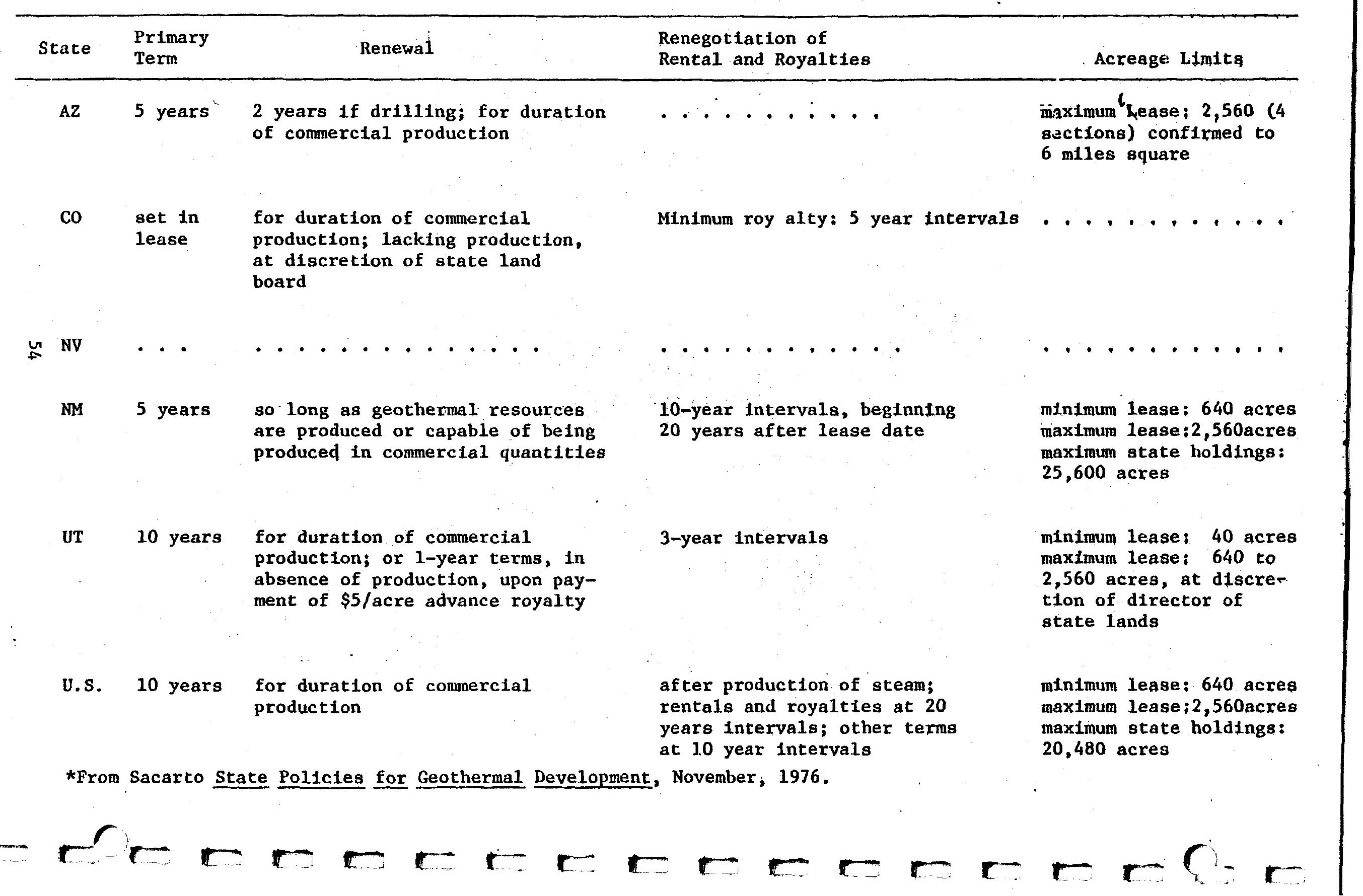


The restrictions on the acreage that a developer may have in a given lease tract and limits on the total acreage a developer may hold in a given state generally follow federal acreage limitations. These state-1evel limitations are subject to the same criticisms as are levied against those federal acreage limitations. In short, the size of the limits is too small to provide security for any possible discoveries that are made and too small to permit the developer to most efficiently distribute his risks over a wide enough area to optimize his chances of success.

\section{Exploration and Development of Resource Areas}

Table 3.9 shows the status of exploration and development in each state. The number of exploratory thermal gradient wells which have been drilled is shown in the upper portion of the table, broken down when possible into shallow and deep wells. The status of applications for drilling permits is shown in the center portion of the table. The lower portion of the table shows the status of active field development within each state.

As may be seen in Table 3.9 the level of exploratory drilling within each of the five states parallels the level of leasing activities shown in Table 3.4. While little exploratory drilling has occurred in Arizona and Colorado, there have been large numbers of exploratory holes drilled in each of the other three states. Deep test wells have been drilled in only the four states in which there has been leasing activity. Relatively large amounts of drilling activity are 1ikely to occur in the near future in the two most active states. Nevada has over 150 Notices of Intent on file, 25 of which are for deep exploratory wells. Developers in Utah have received permits to drill 51 deep wells and only 14 have been drilled.

Development of geothermal resources has progressed considerably on at least four sites: at least two in Nevada, Roosevelt Hot Springs in Utah, and Valles Caldera in New Mexico. In each of those areas, it is projected that there will be 50-55 MW demonstration plants with power on line before the mid 1980 's.

It is of course very difficult to know how much progress there might be in the exploration and development of geothermal resources if there were no legal or institutional barriers. On the other hand, the data used in constructing Table 3.9 show that development is occurring and will continue to occur at an even faster rate in the near future. Overall, there is reason for optimism. Not only have plans for future field activity been formulated by 
Table 3.9

Exploratory and Development Activities in the Southwest Region*

\begin{tabular}{|c|c|c|c|c|c|}
\hline Drilling & AZ & CO & NV & NM & UT \\
\cline { 2 - 6 } Exploratory wells & 8 & 6 & $1000+$ & 156 & $225+$ \\
Shallow (<500 ft) & $(15)$ & $(5)$ & $(11)$ & $(-)$ & $(-)$ \\
Deep ( $>500 \mathrm{ft})$ & $(3)$ & $(1)$ & $(51)$ & $(-)$ & $(-)$ \\
Deep-Test wells & - & 1 & 64 & 1.7 & 19 \\
Drilling Permits Approved & - & -- & 166 & 20 & 51 \\
Applications on file & $50+$ & 6 & 150 & - & - \\
Development & - & -- & $\begin{array}{l}\text { Desert } \\
\text { Peak }\end{array}$ & $\begin{array}{l}\text { Valles } \\
\text { Caldera }\end{array}$ & $\begin{array}{l}\text { Roose- } \\
\text { velt }\end{array}$ \\
\hline
\end{tabular}

*From State Team Final Reports 
developers, there are also several indications of meaningful changes in the structure and response times of agencies responsible for regulation. The activity of the IBP, the memorandum of understanding for cooperative procedures initiated and approved by agencies within DOI, and the activities of the streamlining task force all hold forth the promise of more enlightened behavior if not actual changes in the operating procedures of federal land management agencies.

In addition, the Environmental Protection Agency has produced a set of recommended interim guidelines for environmental standards which hopefully will be uniformly acceptable to all regulatory agencies, and hence, reduce the uncertainty which presumably served to constrain geothermal development. This type of action among the land management and regulatory agencies is extremely meaningful and represents the types of interagency cooperation that should increase as the nature of the problems and benefits associated with geothermal resources becomes better understood.

There is evidence for the existence of the type of institutional learning which is predicted to occur more frequently as all participants acquire more experience in the geothermal development business. For example, in Colorado lease time has decreased from 35 months for some applications filed in January 1974, to only 10 months for some applications filed in March 1975.

Many of the improvements in the status of institutional factors have occurred in the federal arena. It is expected that similar improvements will occur if meaningful integration of objectives and procedures occur among state agencies and between agencies at the state and federal levels.

\section{Results - Identification of Major Participants}

In addition to Identifying the status of leasing, drilling, and development activities within each state, an attempt was made to identify which state agencies were participants in one or more stages of the geothermal development process. Tables 3.10 through 3.14 summarlze the results obtained from the efforts.

These tables show the names of state agencies which become participants and the stage in the development process in which this involvement occurs. Whenever possible, the magnitude and nature of the participants' involvment is also specified in the table. An asterisk is used to indicate that a participant is the lead state agency at a given stage in the development process. The letter $\underline{P}$ Indicates that the agency must issue a formal permit before development may occur. The letter $\underline{\mathrm{C}}$ indicates that the agency must consent or must give its approval before development of a geothermal resource may continue. 
Tab1e 3.10

STATE AGENCIES WHICH PARTICIPATE IN GEOTHERMAL DEVELOPMENT IN ARIZONA

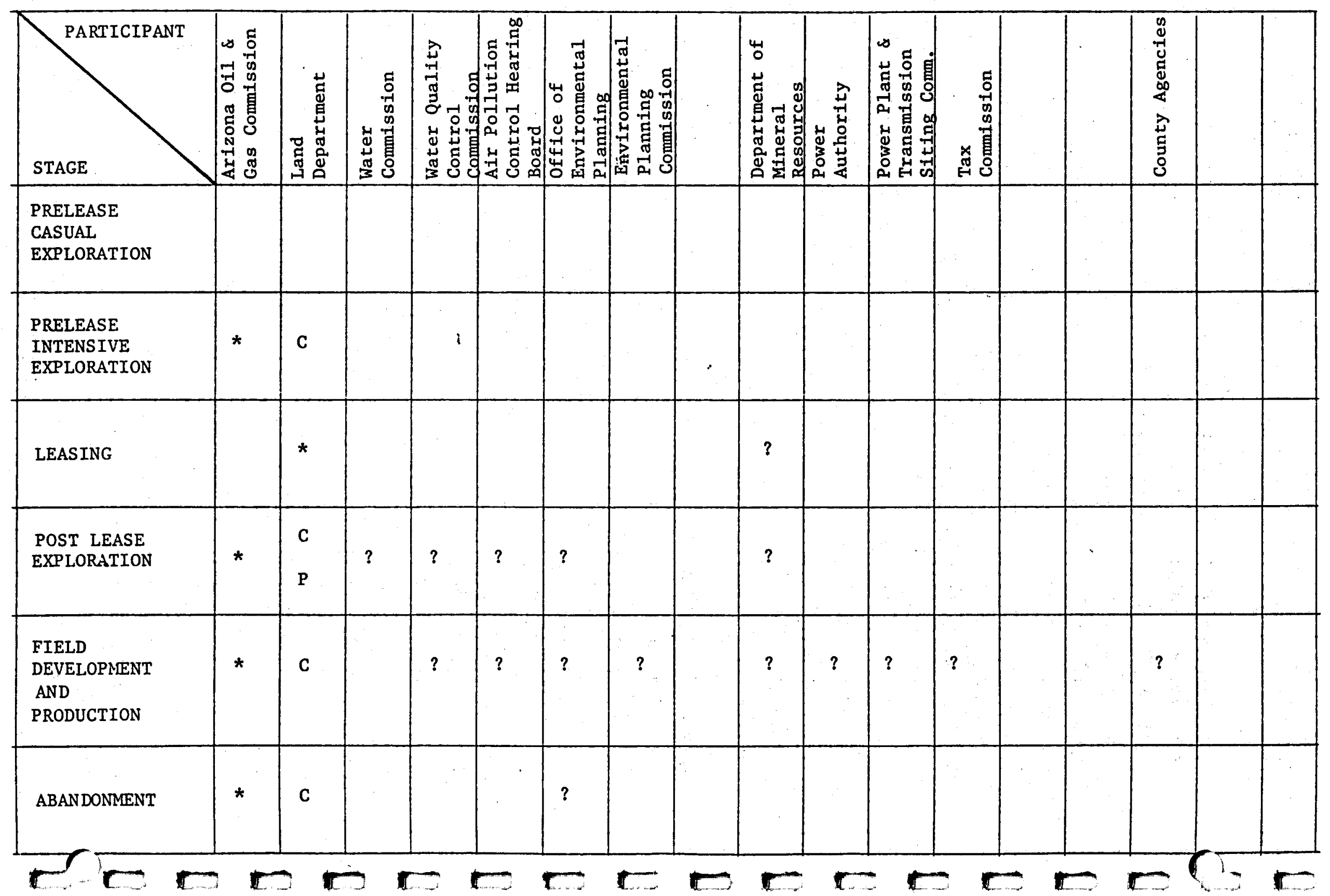




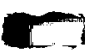 \\ $r c$ $I$

Table 3.11

STATE AGENCIES WHICH PARTICIPATE IN GEOTHERMAL DEVELOPMENT IN COLORADO

PRELEASE

INTENSIVE

EXPLORATION

PRELEASE

CASUAL

EXPLORATION

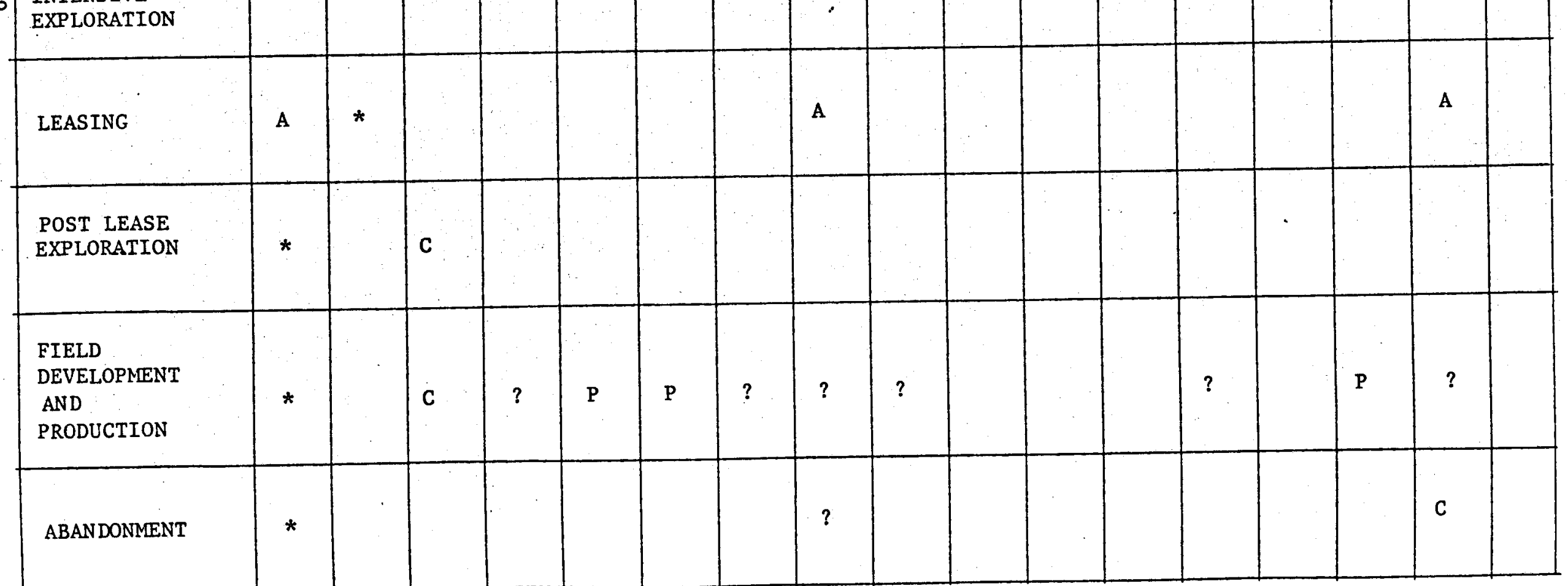

CRS 31-32-201 \& 31-12-101 laws establish conditions for municipal govnts. 
Table 3.12

STATE AGENCIES WHICH PARTICIPATE IN GEOTHERMAL DEVELOPMENT IN NEVADA

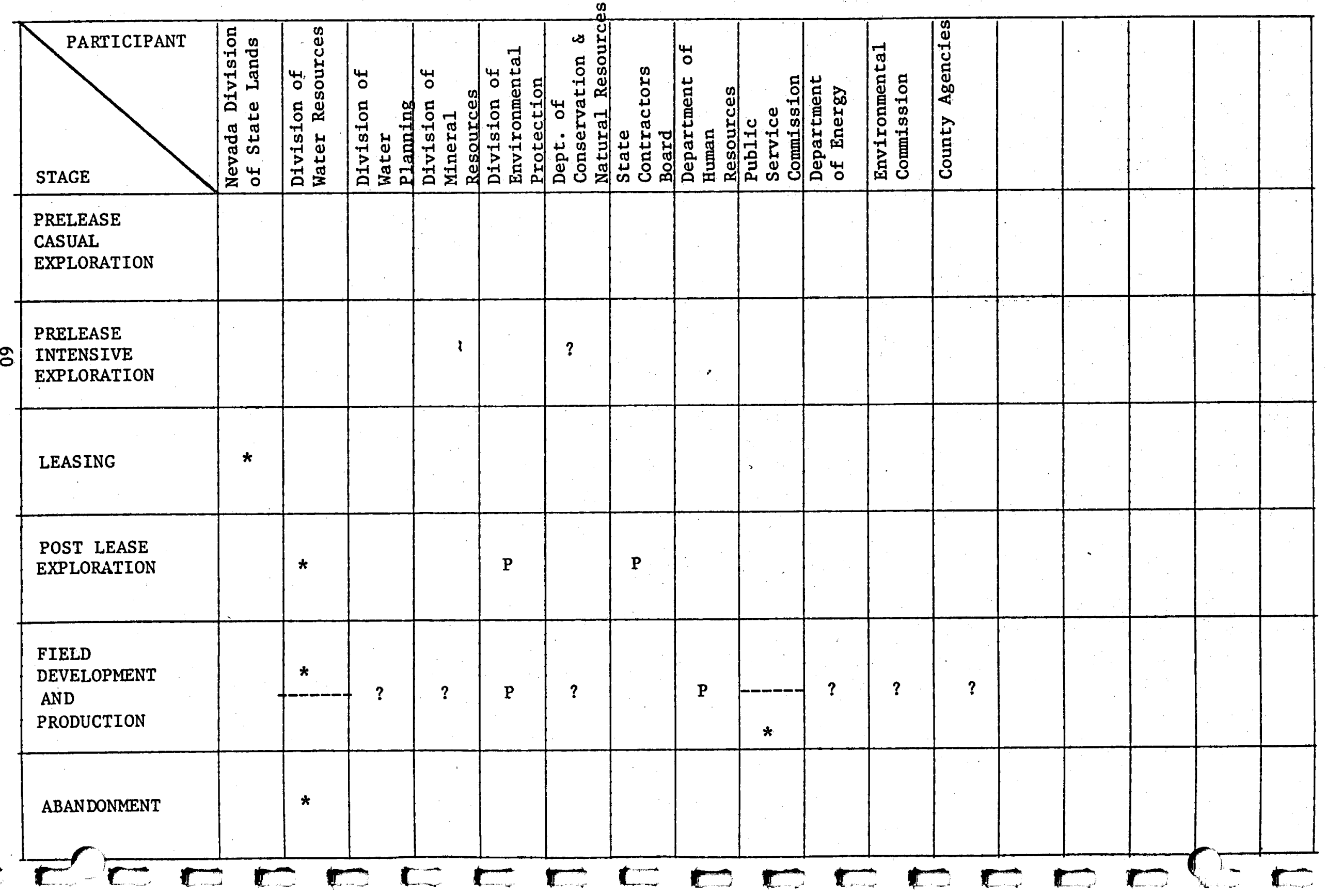




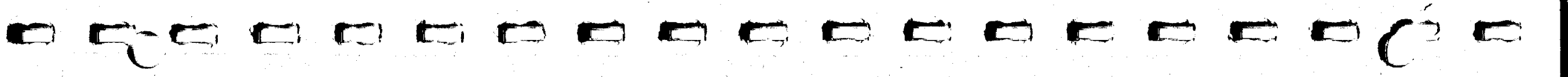

Table 3.13

STATE AGENCIES WHICH PARTICIPATE IN GEOTHERMAL DEVELOPMENT IN NEW MEXICO

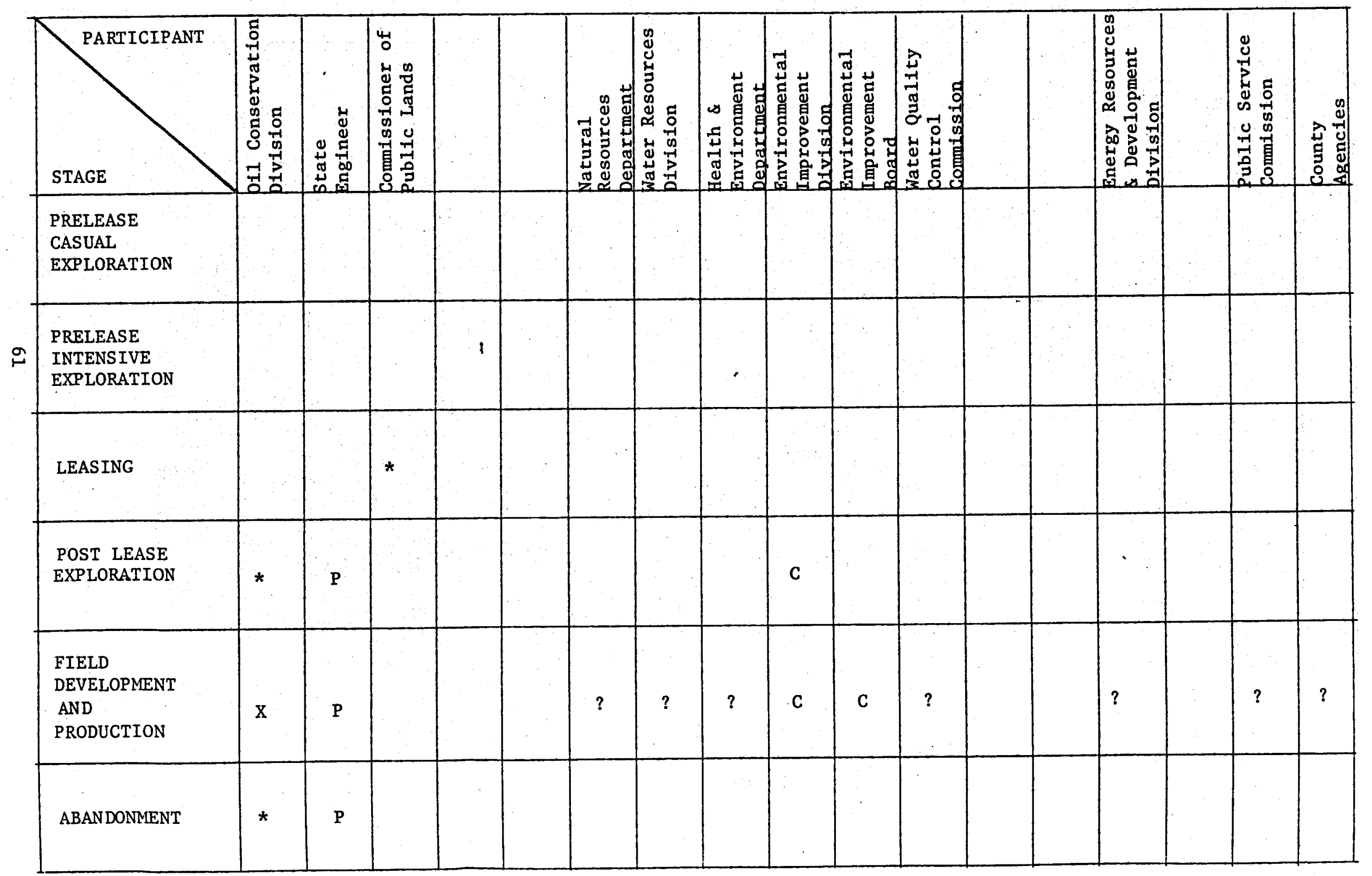


TABLE 3.14

STATE AGENCIES WHICH PARTICIPATE IN GEOTHERMAL DEVELOPMENT IN UTAH

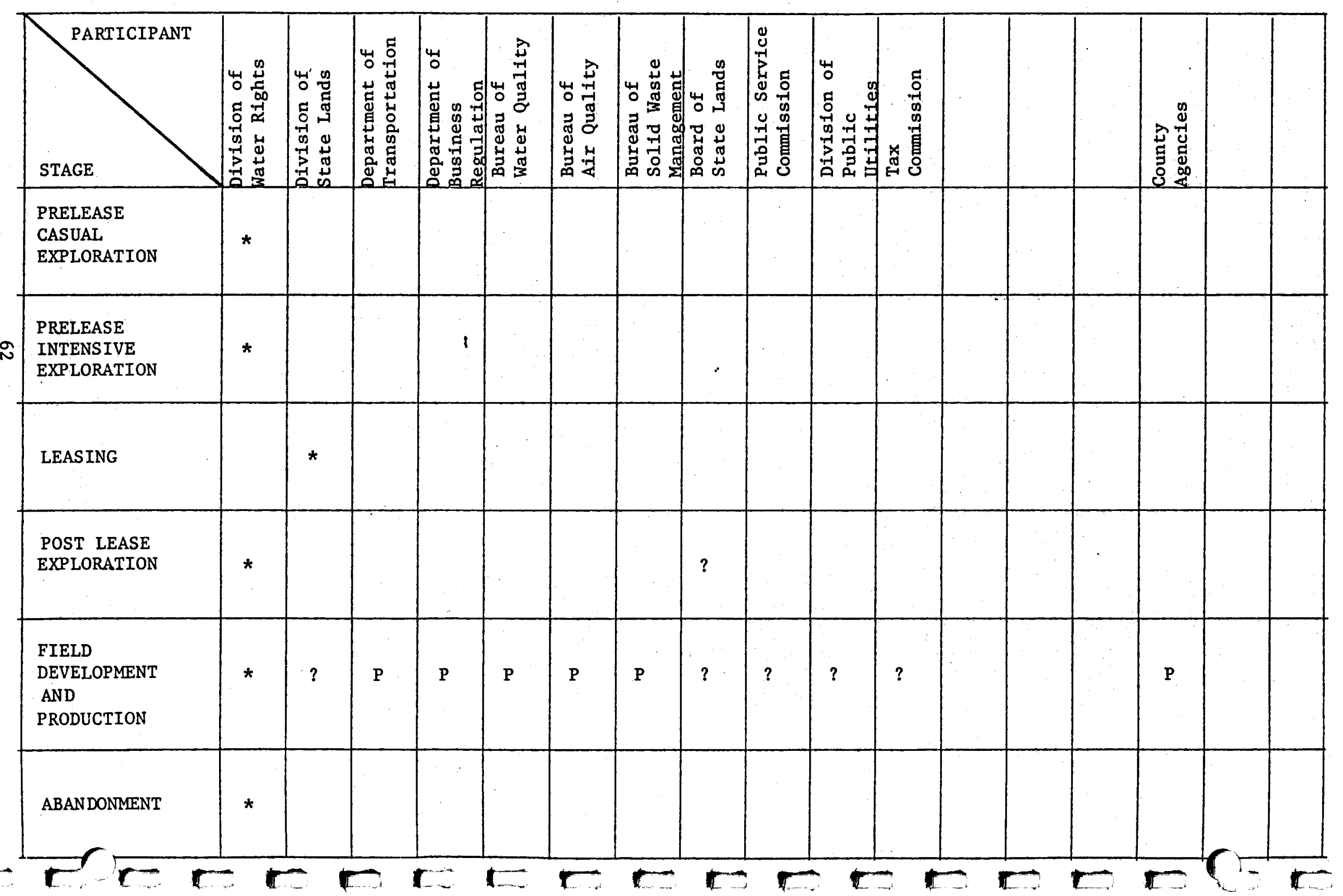


The letter A indicates that a state or local agency is requested to provide comment or advice concerning how the lead agency might proceed. A question mark indicates that an agency is probably involved in a given stage of the development process but that the exact magnitude or nature of that involvment is unknown.

Available state documents were analyzed to obtain this latter information. In addition, the quarterly reports of each state team were analyzed to identify any references to state agency involvment in the process. The charts and tables which describe the organization of state governments were analyzed to provide information as to which state agencies were or could be involved as participants in the development of geothermal resources in the state.

Even when a large number of participants is involved, there is reason to question the legal status and the precise nature of the role those participants have in the geothermal development process. Except for the State of California, there have been no fully developed geothermal reservoirs in the United States, hence agencies which are participants at advance stages in the geothermal development process have had no first-hand experience with the activity they are to monitor or regulate. Also, as a result of the relative newness of the development process, it is not clear to what extent or in what manner two or more state agencies will interact while they carry out their respective responsibilities.

Table 3.15 summarizes information concerning the role of various state and local agencies in the geothermal development process in Utah. The table shows the types of permits that must be issued by each of severa1 lead agencies in the State of Utah. Also, shown in the table is the stage of development at which these agencies become participants and the approximate amount of time needed by these agencies to issue a permit.

Figure 3.5 shows time-phased activitles of institutional entities which participate in the leasing of state lands for geothermal development in the state of Colorado. Several things should be noted with respect to the information in Figure 3.5: (a) The leasing of state land is under the control of the Board of Land Commissioners whose responsibility is to maximize the income from state lands. (b) Colorado rules and regulations require the Land Commissioners to send copies of the developer's application to at least the three other agencies specified for their review and comment. (c) The leasing of state-owned land may occur through either competitive or non-competitive bidding processes but due to limited interest in geothermal leasing only non-competitive leases have 
Table 3.15

Preliminary Assessment of Agencies and Permits Involved in Geothermal Development in Utah $x$

\section{Permit}

\section{zoning}

Business License

Health Code Enforcement

Building Inspection

Lease state Lands

Division of state. Lands $(4,5)$

8

Special Use Permit

Encroachment Permits

Department of Transportation (6)
Division of water Rights $(7,8)$

\section{Required Prior To:}

Depends on county zoning ordinances

Sale of electricity

Use of buildings

Estimated Time

Exploration.or use of lands

Surface disturbance (Construction of plant)

Use of state highway lands for utility

lines

Use of highway for Oversized Vehicles Permit

Permits for Thermal Gradient Wells
Permit for Exploratory "Test" Wells
Drilling of thermal gradient wells

Drilling of exploratory wells
For Issuance

Variable

Varies

Not known--possfbly about 2 months

few days

Notes

Already accomplished in some counties

May be competitive bidding in some cases but that does not significantiy increase issue time

Has not yet been applied for in Utah

Would be necessary for use of or crossing of State Highway Rights of Vay with utility lines such as power lines. vater mains, sewage jipes etc.

About a day

Few days to few weeks

Letter of approval

Few days to few weeks

Letter of approval 


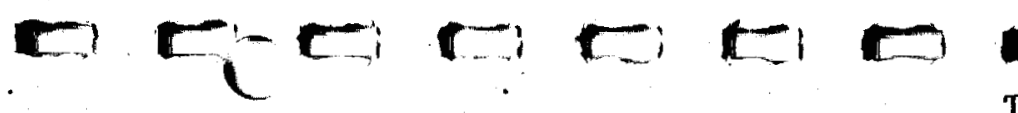

Table 3.15 (Continued)

Permit

Notification of Reservoir Test

Appropriation of water

production and Injection Wells

\section{Environmental Health} - Services

\section{: Bureau of Water Quality (3)}

in

Construction Plan Review and Permit

Public Water Supply Approval
Draft and Certification of Discharge Permit (Sanitary)

Liguid Waste Disposal System Approval

Bureau of Air Quality (9)

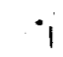

Bureau of solid Waste Management (3)

Department of Business Regulation (10)

$$
\begin{aligned}
& \text { Certificate of Conven- } \\
& \text { ience and Necessity } \\
& \text { or Approval of Contract } \\
& \text { Between Utillty and } \\
& \text { Electricity. Praducer }
\end{aligned}
$$

\section{Regulred Prior To:}

Reservolr tests

Use of water

6 monthe ox Iongex

$\bullet$

$\therefore$ For Issuance
Construction About 2 months

Use of bullding

Use of building

Use of building

Construction

Use of plant

Sale of Electrlcty

1 to 2 months
Estimated Tlme

1 to 2 months

1 to 2 monthg

About 3 months

About 3 months

3 to 4 months
Notes

May depend on how fast the developer wants approval

Covered by Approprlation of water if included in the Plan of Operations

Pre-planning worke

In confunction with EPA which issues the permit

In confunction with EPA

plant discharges

Certificate of convenience and necessity if utllity owns plant; if utility buys power, approval of contract is regulred

*From the Utah Final Report (29, pp. 62-63) 
Relevant to Geothermal Development

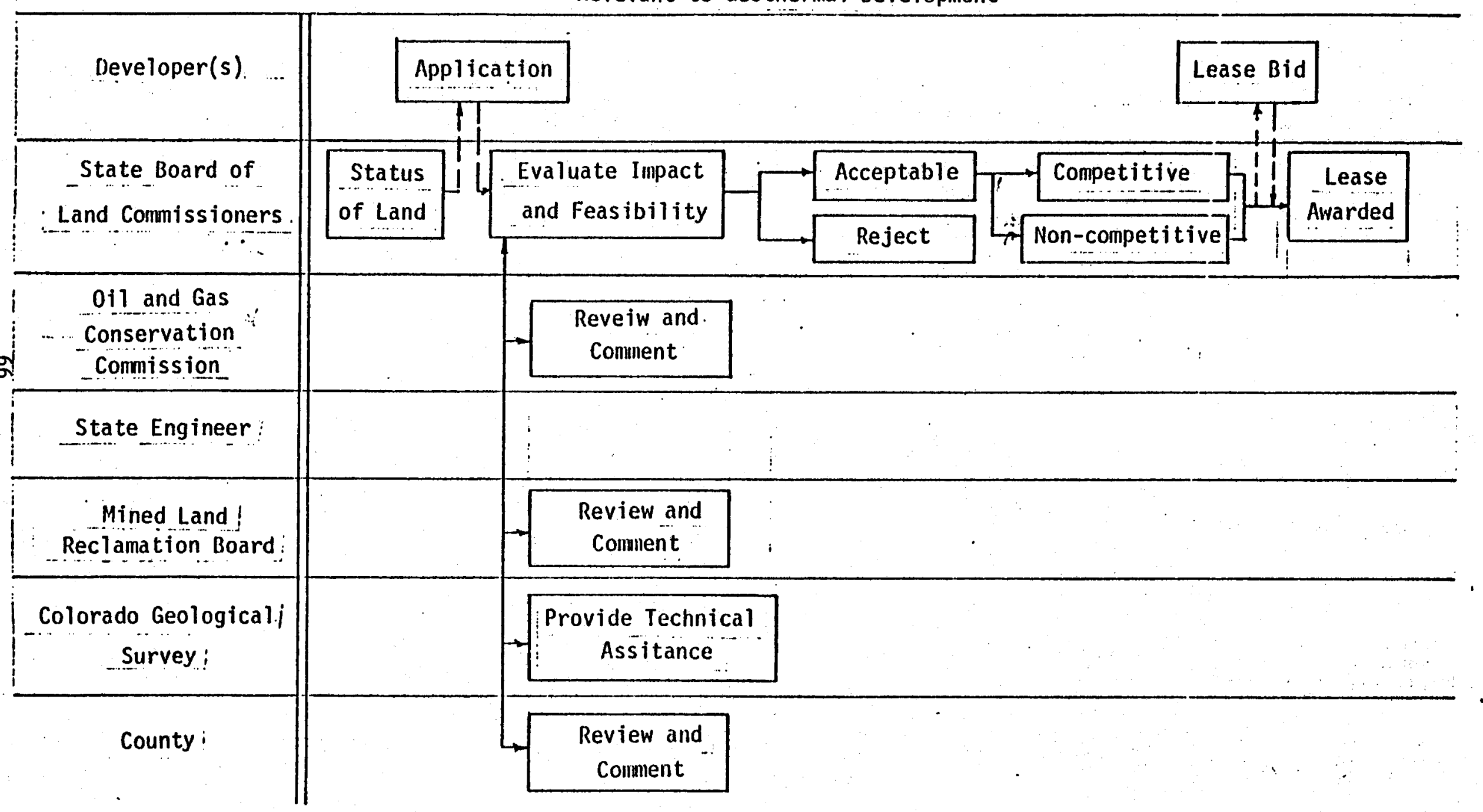

Figure 3. 5 Colorado. Time-Phased Activities

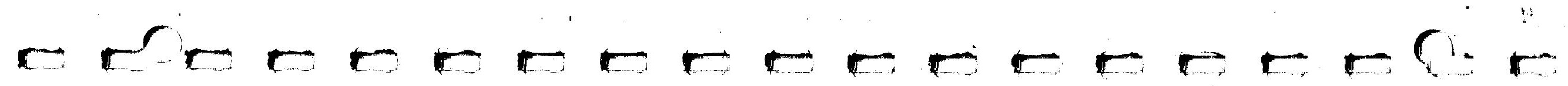


been issued. (d) The state team estimates that the entire process of leasing state lands could be completed in seven to eight months.

Except for Colorado, a single office appears to have sole responsibility for leasing state-owned lands. None of the states have any formal regulations for prelease casual exploratory activity. With the possible exception of colorado, there are no legal and binding provisions at the state level for an environmental assessment before state land is leased for geothermal development. Drilling permits are handled by oil and gas commissions in three states, (Arizona, Colorado, and New Mexico), and in Arizona that commission has sole responsibility for all water and environmental issues that might arise with respect to field exploration and development. Drilling permits are regulated by state engineers assigned to Department of Water Resources or Water Rights in two states (Nevada and New Mexico), and in both cases the state engineer has the lead responsibility for all aspects and impacts of fleld exploration and development operations.

In summary, there is considerable variability in the status of legal and institutional factors across the five states which comprise the Southwest Region. It appears that each state has developed slightly different procedures for interacting with federal agencies. An informed sampling of opinions conducted by Dr. Richard T. Meyer confirms the extent to which these findings are almost universally accepted by government and industry representatives. (Dr. Meyer's work is in Appendix D.) The bottom line is that leasing and permitting processes are cumbersome and time consuming. Therefore, the successful development of geothermal resources may depend upon the creation of a national policy which will alleviate some of these fragmented policies and procedures. 

CHAPTER IV

GEOTHERMAL DEVELOPMENT AND THE PRODUCTION OF ELECTRICITY

This section covers the logic underlying the research performed, the tools used, and the results of the research concerning the potential contribution of geothermal development to electricity production in the Southwest Region (Arizona, Colorado, Nevada, New Mexico and Utah). First, the underlying philosophy of the research program is described. Next, the sensitivity of profits to changes in physical and policy variables circumscribing the development of geothermal electric power is discussed. Then, site-by-site profitability as determined by GIRORA-Electric and aggregation of resulting power estimates is described and power-on-1ine projections are discussed. In addition, the sensitivity of power-on-line estimates to policy initiatives is discussed. Finally, preliminary estimates of electric power supply and demand conditions are presented. The impact of the development of geothermal electric plants is discussed under three possible sets of alternative assumptions. The complete description of the GIRORA-Electric model and the associated computer program (written in FORTRAN IV) is given in Appendix 1. We turn first to a discussion of the philosophy underlying the research accomplished concerning the development of geothermal electric power.

\subsection{Research Philosophy}

Underlying all considerations of this research was the assumption that electric plants driven by geothermal energy, and the fields which deliver that energy, will be developed by the private or non-federal government sectors. For the most part, this means private developers in conjunction with regulated electric utilities (although exceptions may and will likely exist). A concomitant assumption is that a geothermal resource will be developed only if it is economic to do so (that is, economic feastbility is a necessary but not sufficient condition). Because private developers and electric utilities are the actors, it is necessary to consider economic feasibility (profitability) from their point of view. 
The second principal assumption is that geothermal energy is only one of a variety of energy sources at the disposal of an electric utility (or anyone, for that matter, in need of electric power). A concomitant of this second assumption is that geothermal energy must compete in the marketplace for energy. Because geothermal energy is a marginal energy source (marginal in the sense that it is a relatively small source), and in this region enters the scene chronologically late, it must compete at prices established by other fuels (coal, nuclear, oll, gas, and hydroelectric).

The result of the first two principal assumptions is that if geothermal energy is not profitable for both the geothermal developer and the electric utility, at a price which enables the electric power thus generated to be competitive with that generated by other fuels, the resource will not be developed. This is the bottom line. Given other institutional, attitudinal, and economic factors, a particular resource may not be developed, even if it is economically competitive.

Moreover, even though a particular resource is economically competitive and faces no non-economic barriers, being a marginal fuel, it may not be developed for lack of effective demand. This could occur under two conditions: (1) increases in the price of electricity result in sufficient consumer substitutions to reduce quanity of electricity demanded below some critical level, or (2) general economic growth is insufficient to require the capacity that would be added by a geothermal development. The first condition may have some general applicability, while the second might occur only in remote, sparsely populated areas (due to the portability of electricity).

At each juncture, government policy makers may have an option to affect the environment in which private developers make decisions or perceive opportunities. It was the aim of the research effort described below (1) to ascertain what elements under the influence of DOE-DGE could efficiently alter the profitability of geothermal resources as perceived by investors, (2) to identify the magnitude of impact policy action might reasonably be expected to have, and (3) to estimate in a preliminary way the level of market potential for electricity generated by geothermal energy.

Because geothermal energy is not free, it is an economic resource which should be developed efficiently with due concern for its place in a total energy perspective. Private entrepreneurs cannot discount the value of national balance of payments deficits or other social concerns, when considering 
the desirability of an investment. It must be DOE-DGE's role to consider this broader perspective and insure the avallability of sufficient incentives (or the absence of disincentives) so that private entrepreneurs will perceive geothermal energy as an attractive opportunity.

The criterion for evaluation chosen for this research is the rate of return on equity investment. There are a variety of criteria which could be used, each having its own special strengths and weaknesses. The one chosen for this research seems most appropriate because of the overall capital insensitivity of the process. It should be added that in the process of ranking geothermal sites, or judging the relative effectiveness of policy actions, any criterion of profitability or economic feasibility would yield approximately

$\rightarrow$ the same answer as another, so long as the methodology is consistent.

As will be noted in the next section, the simulation model used to evaluate geothermal electric projects uses the rate of return as the basis for comparison rather than the price of electricity. This is due to our assumption that geothermal energy must compete at the margin with established fuels. The price of electricity is then an independent rather than dependent variable. Moreover, using a rate of return on equity as the dependent variable focuses our attention on the profit motive of the developer. The developer can invest in geothermal energy or any other income-yielding prospect. If the rate of return on geothermal energy is not high enough (at a price where it can effectively compete), the developer will place investments elsewhere.

\subsection{Sensitivity of Profits to Pollcy Parameters}

Having developed and calibrated GIRORA-Electric (calibrated with other models of the genre), the next step up was to determine the sensitivity of the output, rate of return (R), to changes in policy parameters. This was done by first establishing an estimate of $R$, given a "baseline" set of policy, geophysical, and market parameters. The "baseline" parameters are not held to be "typical" or "characteristic". Resource areas in Southwest Region could be characterized as being of a wide varlety of temperatures, salinity, distance to demand areas, etc. On the other hand, all will be confronted, given the nature of electricity markets, with simflar market parameters, and, of course, federal policy parameters. Table 4.1 lists the more important parameters for the "baseline" case. 
Table 4.1

Base Case Values

Geothermal Energy Producer

\begin{tabular}{|lll|}
\hline \multicolumn{1}{c|}{ Variable } & Value \\
\hline BR: & Bond Rate & 0.085 \\
CRRT: & Investment Tax Credit Rate & 0.12 \\
FR: & Flow Rate & $585,794 \mathrm{lb} / \mathrm{hr}$ \\
TEMP: & Initial Downhole Temperature & $190^{\circ} \mathrm{C}$ \\
EPK: & Equity Proportion of Capital & 0.30 \\
DPK: & Debt Proportion of Capital & 0.70 \\
A: & Royalty Rate & 0.10 \\
Z: & Depletion Allowance Rate & 0.0 \\
EXP: & Exploration Period & 0 years \\
DVP: & Development Period & 8 years \\
TXRT: & Income Tax Rate & 0.50 \\
\hline IRR: & Internal Rate of Return & 0.15 \\
\hline
\end{tabular}

Electric Utility

\begin{tabular}{|lll|}
\hline & \multicolumn{1}{c|}{ Variable } & Value \\
\hline CAP: & Capacity & 50,000 Kilowatts (Net) \\
LF: & Plant Factor & 0.80 \\
UF: & Plant Use of Power (Proportion) & 0.18 \\
PB $:$ & Base Price of Electricity (Busbar) & 0.021 (\$/kwh; current \$) \\
$\dot{P}:$ & Escalation Rate of Base Price & 0.05 \\
EK: & Equity Proportion of Capital & 0.50 \\
DK: & Debt Proportion of Capital & 0.50 \\
UR: & Regulated Return to Equity & 0.12 \\
BR: & Bond Rate & 0.085 \\
TXRT: & Income Tax Rate \\
\hline
\end{tabular}


The next step was to vary relevant parameters, one at a time, to determine the sensitivity of $R$ to changes in each parameters. The measure used here for such sensitivity is elasticity (E). Elasticity is a concept in economics which means the percent change in one variable given a one percent change in another. The formula used to calculate elasticity is given below, where $R$ is the rate of return and IV is the independent variable. The subscripts 1 and 2 refer to the values of each variable at subsequent positions.

$$
E=-\frac{R_{2}-R_{1}}{\left(R_{2}+R_{1}\right) / 2} \div \frac{I V_{1}-I V_{1}}{\left(I V_{2}+I V_{1}\right) / 2}
$$

The average value is used as a base for both variables so that $E$ takes on the same value whether one is moving from a higher to lower or lower to higher set of variable values. The values of $E$ for selected variables are given in Table 4.2 .

Briefly, the elasticity of $R$ with respect to plant capacity in megawatts (CAP) is -0.268 . This means that for every 1 percent increase in plant capacity, we might expect about a 0.27 percent decrease in the rate of return. The calculated $\mathrm{E}$ for the depletion allowance rate is 0.051 . This means that for every 1 percent increase in the depletion rate, there would be a 0.05 percent increase in the rate of return.

The larger the value of $\mathrm{E}$, the greater the impact of changes in a variable on R. Of the various policy variables analyzed in Table 4.2., E ranges from 2.433 for the investment tax credit rate (when resource temperature is $190^{\circ} \mathrm{C}$ ) to 0.051 for the depletion allowance rate. Others are: Bond rate, -1.714 (at temperature $190^{\circ} \mathrm{C}$ ) or -0.156 (at temperature $225^{\circ} \mathrm{C}$ ); Royalty Rate, -0.0208 . Market variables which might be affected by polfcy action are: Capacity Cost for Binary Plants, -2.625; Exploration Period, -0.044; Development Period, -0.468 and Base Price of Electricity, 0.632 .

Those variables which have the highest $E$ are those which impact capital costs in low temperatures (binary) systems. This is due to the greater capital insensitivity of these systems relative to flash systems.

After observing the variability of $R$ with changes in individual independent varlables, we must also consider the range of $\mathrm{R}$ as several variables are changed simultaneously. This gives a range for expected values of $R$ under a variety of circumstances. 
Table 4.2 Elasticity (E) of $R$ with

Respect to Selected Variables at $225^{\circ} \mathrm{C}\left(437^{\circ} \mathrm{F}\right)$

\begin{tabular}{|lc|}
\hline \multicolumn{1}{|c|}{ Variable } & $\mathrm{E}$ \\
\hline Power Plant Capacity & -0.268 \\
Depletion Allowance & 0.051 \\
Investment Tax Credit at $225^{\circ} \mathrm{C}$ & 0.851 \\
Investment Tax Credit at $190^{\circ} \mathrm{C}$ & 2.433 \\
Royalty Rate & -0.208 \\
Base Price of Electricity $\$ / \mathrm{kwh}$ & 0.632 \\
Load Factor & 1.838 \\
Producer Debt $/$ Equity Rat1o & 0.134 \\
Flow Rate & 1.156 \\
Exploration Period, years & -0.044 \\
Development Period, Years & -0.468 \\
Bond Rate at $225^{\circ} \mathrm{C}$ & -0.156 \\
Bond Rate at $190^{\circ} \mathrm{C}$ & -1.714 \\
Temperature & 2.703 \\
\hline
\end{tabular}


Considering such a range is a more reasonable approach to forecasting than simple point estimates. This is because the future cannot be predicted with any precision and thus those factors which might impact geothermal development cannot be predicted with any great precision. Looking at a range, however, permits us to realistically analyze the likely effects of policy initiatives.

Table 4.3 11sts the parameter values for what is here discussed as "pessimistic" and "optimistic" market scenarios and a "baseline" $R$ for each potential electric site (estimate for base temperature over $150^{\circ} \mathrm{C}$ ) in the Southwest Region. In Tables 4.4 through 4.8, megawatt estimates are given for each site under the conditions specified by sets of parameter values. A required return to equity of 15 percent is assumed. Those sites which do not receive a required return under a given set of parameter values are rated at zero megawatts. The estimates are given at three levels: pessimistic, baseline, and optimistic.

If a positive megawatt value is shown, it is the maximum thirty-year usable energy estimate of the resource given estimated temperature and volume. (In many cases the volume is a default value from USGS Circular $726^{(2)}$, thus making the "optimistic" estimate possibly conservative). The optimistic case is the maximum probable energy that could be obtained under any circumstances. Table 4.9 summarizes the megawatt estimate for the Southwest Region from Tables 4.4 through 4.8 .

\subsection{Aggregated Power on Line Estimates}

Under conditions of minimum competition for development inputs (drilling rigs, labor, casing, pipe, etc.), and given the projected scenarios for development of individual sites, a time-phasing of power on line can be constructed for the region. This is illustrated in Figure 4.1. Figure 4.1 contains three basic projections for this time-phasing, one "optimistic", one "baseline", and one "pessimistic". Each is the region-wide aggregation of megawatt estimates for the five states for each year according to site-by-site projections. The range between the two extreme projections represents the most highly probable range for the development of geotheraml electricity production, given minimum competition for development inputs.

For a planning outlook, however, this perspective must be modified. The range illustrated in Figure 4.1 could be realized only if sufficient resources are devoted to the production of drilling rigs and the training of geothermal drilling teams. An obvious policy recommendation is that DOE-DGE should assure an environment in which such resources may be readily avallable. 
Table 4.3 Values of Choice Variables and Parameters: Optimistic and Pessimistic Market Scenarios

\begin{tabular}{|c|c|c|}
\hline . & "Pessimistic" & "Optimistic" \\
\hline Load Factor & $60 \%$ & $75 \%$ \\
\hline Base Price of Electricity & $21 \mathrm{mils} / \mathrm{kwh}$ & $30 \mathrm{mils} / \mathrm{kwh}$ \\
\hline Escalation factor for Price of Electricity & $5 \%$ & $6.5 \%$ \\
\hline Debt/Equity ratio of Utility & 1 & 1 \\
\hline Debt/Equity ratio of Producer & 1.5 & 1.86 \\
\hline Utility's Return (regulated) & $15 \%$ & $12 \%$ \\
\hline Tax Rate & $48 \%$ & $48 \%$ \\
\hline Bond Rate & $8.5 \%$ & $7.5 \%$ \\
\hline Investment Tax Credit & $12 \%$ & $12 \%$ \\
\hline Flow Rate & $250,000 \mathrm{lb} / \mathrm{hr}$ & $400,0001 \mathrm{~b} / \mathrm{hr}$ \\
\hline Royalty Rate & $10 \%$ & $5 \%$ \\
\hline Depletion & $0 \%$ & $22 \%$ \\
\hline Exploration Time & 5 years & 5 years \\
\hline Development Time & 8 years & 5 years \\
\hline
\end{tabular}


Table 4.4 Electric Power Estimated

in Megawatts for Arizona

\begin{tabular}{|c|c|c|c|c|}
\hline \multirow[t]{2}{*}{ Site } & \multirow[t]{2}{*}{ Temp ${ }^{\circ} \mathrm{C}$} & \multicolumn{3}{|c|}{ Estimated Power in Megawatts } \\
\hline & & Pessimistic & Baseline & Optimistic \\
\hline Power Ranch & 184 & 0 & $\therefore 0$ & 50 \\
\hline C1ifton H.S. & 160 & 0 & 0 & 50 \\
\hline Verde H.S. & 150 & 0 & 0 & 50 \\
\hline Statewide (Kingman) & $50-200$ & 0 & 0 & 0 \\
\hline White Mountains (Flag- & 210 & 0 & 100 & 1000 \\
\hline Yuma & $150-180$ & 0 & 50 & 50 \\
\hline Hyder Valley & 200 & 0 & 50 & 500 \\
\hline Wilcox* & 205 & 0 & 0 & 100 \\
\hline Springerville* & 210 & 0 & 100 & 500 \\
\hline Tucson* & $60-120$ & 0 & 0 & 50 \\
\hline Safford & 210 & 0 & 100 & 100 \\
\hline Total & & 0 & 400 & 2450 \\
\hline
\end{tabular}

* Indicates that the resource is hot dry rock. 
Table 4.5 Electric Power Estimated in Megawatts for Colorado

\begin{tabular}{|l|c|c|c|c|}
\hline Site & Temp ${ }^{\circ} \mathrm{C}$ & \multicolumn{3}{|c|}{ Estimated Power in Megawatts } \\
\cline { 4 - 5 } $\begin{array}{l}\text { Mt. Princeton/Cotton- } \\
\text { wood Creek }\end{array}$ & $170-200$ & 0 & 100 & 100 \\
Poncha Springs & $175-200$ & 0 & 0 & 200 \\
Cebolla Hot Springs & 145 & 0 & 0 & 200 \\
\hline Total & & 0 & 100 & 500 \\
\hline
\end{tabular}


Table 4.6 Electric Power Estimated In Megawatts for Nevada

\begin{tabular}{|c|c|c|c|c|}
\hline \multirow{2}{*}{ Site } & \multirow{2}{*}{ Temp ${ }^{\circ} \mathrm{C}$} & \multicolumn{3}{|c|}{ Estimated Power in Megawatts } \\
\hline & & Pessimistic & Baseline & Optimistic \\
\hline The Needles Rocks & 200 & 0 & 245 & 245 \\
\hline Surprise Valley & 185 & 0 & 0 & 45 \\
\hline South Smoke Creek Desert & 200 & 0 & 65 & 65 \\
\hline Anaho Island & 185 & 0 & 0 & 45 \\
\hline Dyke Hot Spring & 200 & 0 & 245 & 245 \\
\hline Baltazor Hot Spring & 185 & 0 & 0 & 45 \\
\hline Bi11 Creek Reservoir & 200 & 0 & 65 & 65 \\
\hline Bog Hot Springs & 170 & 0 & 0 & 40 \\
\hline Howard Hot Springs & 200 & 0 & 65 & 65 \\
\hline Pinto Hot Springs & 185 & 0 & 0 & 45 \\
\hline Cordero Mercury Mine & 185 & 0 & 0 & 45 \\
\hline Hot Sulpbur Spring & 185 & 0 & 0 & 180 \\
\hline The Hot Springs & 170 & 0 & 0 & 40 \\
\hline Humboldt Wells & 200 & 0 & 245 & 245 \\
\hline Mineral Hot Springs & 185 & 0 & 0 & 90 \\
\hline San Emidio Desert & 200 & 0 & 245 & 245 \\
\hline Gerlach, N.E. & 200 & - & - & - \\
\hline $\begin{array}{l}\text { Double Hot Spring/Black Ro } \\
\text { Hot Spring }\end{array}$ & 200 & 0 & 735 & 735 \\
\hline Gerlach & 200 & 0 & 370 & 370 \\
\hline Colona & 185 & 0 & 0 & 45 \\
\hline F1y Ranch & 185 & 0 & 0 & 45 \\
\hline Fly Ranch, N.E. & 185 & 0 & 0 & 45 \\
\hline Trego & 185 & 0 & 0 & 45 \\
\hline MacFairlane's & 185 & 0 & 0 & 45 \\
\hline Sulphur & 185 & 0 & 0 & 45 \\
\hline Rye Patch & 185 & 0 & 0 & 540 \\
\hline Colado & 185 & 0 & 0 & 180 \\
\hline South Eugene Mountains & 185 & 0 & 0 & 180 \\
\hline Golconda & 185 & 0 & 0 & - \\
\hline Hot Springs (Tipton)Ranch & 200 & 0 & 245 & 245 \\
\hline
\end{tabular}


Table 4.6 (Continued)

\begin{tabular}{|c|c|c|c|c|}
\hline \multirow[t]{2}{*}{ Site } & \multirow[t]{2}{*}{ Temp ${ }^{\circ} \mathrm{C}$} & \multicolumn{3}{|c|}{ Estimated Power In Megawatts } \\
\hline & & Pessimistic & Baseline & Optimistic \\
\hline Hot Pot & 185 & 0 & 0 & 45 \\
\hline Sand Dunes & 185 & 0 & 0 & - \\
\hline Winnemucca Mountain & 90 & 0 & 0 & - \\
\hline Leach Hot Springs & 200 & 0 & 735 & 735 \\
\hline Kyle Hot Springs & 200 & 0 & 245 & 245 \\
\hline Battle Mountain & 185 & 0 & 0 & - \\
\hline Smith Creek Valley & 200 & 0 & 245 & 245 \\
\hline Beowawe Geysers & 245 & 1220 & 1220 & 1220 \\
\hline Horseshoe Ranch Spring & 185 & 0 & 0 & 45 \\
\hline Hot Springs Point & 185 & 0 & 0 & 180 \\
\hline Duff Creek & 185 & 0 & 0 & 45 \\
\hline Darrough's Hot Spring & 185 & 0 & 0 & 45 \\
\hline E1ko Hot Springs & 185 & 0 & 0 & - \\
\hline Walh Hot Springs & 185 & 0 & 0 & 45 \\
\hline Bruffey's Hot Springs & 185 & 0 & 0 & 45 \\
\hline Kolbe Hot Springs & 185 & 0 & 0 & 45 \\
\hline Spenser Hot Springs & 185 & 0 & 0 & 45 \\
\hline Carlin & 185 & 0 & 0 & - \\
\hline Sulphur Hot Springs & 200 & 0 & 490 & 490 \\
\hline Monte Neva Hot Springs & 185 & 0 & 0 & 180 \\
\hline Ruby Lake & 200 & 0 & 245 & 245 \\
\hline Cherry Creek Hot Spring & 170 & 0 & 0 & 40 \\
\hline Steamboat Spring/Huffaker & 215 & 0 & 400 & 400 \\
\hline Steamboat Spring/Huffaker & 60 & 0 & 0 & - \\
\hline Moana Spring/Lawton & 60 & 0 & 0 & - \\
\hline Comstock Mining District & 155 & 0 & 0 & 38 \\
\hline Washoe Valley & 60 & 0 & 0 & - \\
\hline Desert Peak & 215 & 0 & 665 & 665 \\
\hline Brady's Hot Springs & 215 & 0 & 265 & 265 \\
\hline Huxley & 200 & 0 . & 65 & 65 \\
\hline Eagle Salt Works & 215 & 0 & - & - \\
\hline
\end{tabular}


Table 4.6 (Continued)

\begin{tabular}{|c|c|c|c|c|}
\hline \multirow{2}{*}{ Site } & \multirow{2}{*}{ Temp ${ }^{\circ} \mathrm{C}$} & \multicolumn{3}{|c|}{ Estimated Power in Megawatts } \\
\hline & & Pessimistic & Baseline & Optimistic \\
\hline Hot Springs Mountains & 215 & 0 & 265 & 265 \\
\hline Hazen & 200 & 0 & 65 & 65 \\
\hline Brady's Hot Springs & 215 & 0 & - & - \\
\hline $\begin{array}{l}\text { Carson Sink/Alkali Flat } \\
\text { West Side }\end{array}$ & 200 & 0 & 65 & 65 \\
\hline $\begin{array}{l}\text { Carson Sink/Alkali Flat } \\
\text { East Side }\end{array}$ & 200 & 0 & 65 & 65 \\
\hline Lone Rock & 185 & 0 & 0 & 45 \\
\hline Soda Lake/Upsal Hogback & 215 & 0 & 400 & 400 \\
\hline Soda Lake/Upsal Hogback & 215 & 0 & - & - \\
\hline Stillwater & 215 & 0 & 530 & 530 \\
\hline Carson Lake & 185 & 0 & 0 & 65 \\
\hline Lee Hot Springs & 185 & 0 & 0 & 63 \\
\hline Eight Mile Flat & 185 & 0 & 0 & 63 \\
\hline Stil1water & 215 & 0 & - & - \\
\hline Dixie Hot Springs & 200 & 0 & 245 & 245 \\
\hline Sou Hot Springs & 185 & 0 & 0 & 135 \\
\hline McCoy Springs & 185 & 0. & 0 & 135 \\
\hline Hyder Hot Spring & 200 & 0 & 145 & 145 \\
\hline Senator & 185 & 0 & 0 & - \\
\hline $\begin{array}{l}\text { Dixie Comstock Mine/ } \\
\text { Homboldt Marsh }\end{array}$ & 185 & 0 & 0 & 135 \\
\hline IXI & 170 & 0 & 0 & - \\
\hline Buffalo Hot Springs & 185 & 0 & 0 & 135 \\
\hline Jersey Valley & 200 & 0 & 145 & 145 \\
\hline Wabuska Hot Springs & 170 & 0 & 0 & 40 \\
\hline Wabuska Hot Springs & 170 & 0 & 0 & - \\
\hline Wilson Hot Springs & 170 & 0 & 0 & 40 \\
\hline Hind's Hot Springs & 155 & 0 & 0 & - \\
\hline Dead Horse Wells/Wedell Sp $\$$ & s 170 & 0 & 0 & 165 \\
\hline West Gabbs Valley & 170 & 0 & 0 & 165 \\
\hline Sodaville Springs & 140 & 0 & 0 & - \\
\hline Fish Lake Valley & 260 & 390 & 390 & 390 \\
\hline
\end{tabular}


Table 4.6 (Continued)

\begin{tabular}{|l|c|c|c|c|}
\hline \multirow{2}{*}{ Site } & \multirow{2}{*}{ Temp ${ }^{\circ} \mathrm{C}$} & \multicolumn{3}{|c|}{ Estimated Power in Megawatts } \\
\cline { 2 - 5 } & & Pessimistic & Baseline & Optimistic \\
\hline Silver Peak Hot Springs & 200 & 0 & 63 & 63 \\
Silver Peak Hot Springs & 200 & 0 & - & - \\
Southern Clayton Valley & 170 & 0 & 0 & 40 \\
Warm Springs & 170 & 0 & 0 & 45 \\
Railroad Valley/Pancake & 170 & 0 & 0 & 45 \\
Range & 170 & 0 & 0 & 45 \\
Hot Creek Canyon & 155 & 0 & 0 & 38 \\
Hot Creek Valley & 185 & 0 & 0 & 180 \\
Lunar Crater & 65 & 0 & 0 & - \\
Caliente Hot Springs & 65 & 0 & 0 & - \\
Sarcobadus Flat/Beatty & & 1610 & 9478 & 13600 \\
\hline ToTALS & & & & \\
\hline
\end{tabular}


Table 4.7 Electric Power Estimated

In Megawatts for New Mexico

\begin{tabular}{|l|r|r|r|r|}
\hline Site & Temp ${ }^{\circ} \mathrm{C}$ & \multicolumn{3}{|c|}{ Estimated Power in Megawatts } \\
\cline { 3 - 5 } & & Pessimistic & Baseline & Optimistid \\
\hline Lightening Dock & 170 & 10 & 20 & 100 \\
Kilbourne Hole & 155 & 10 & 20 & 50 \\
Radium Springs & 130 & 0 & 0 & 50 \\
Valles Caldera & 260 & 1900 & 2000 & 2000 \\
Lower Frisco H.S. & 150 & 0 & 0 & 50 \\
\hline TOTALS & & 1920 & 2040 & 2250 \\
\hline
\end{tabular}

Table 4.8 Electric Power Estimated in Megawatts for Utah

\begin{tabular}{|l|r|r|r|r|}
\hline Site & Temp ${ }^{\circ} \mathrm{C}$ & \multicolumn{3}{|c|}{ Estimated Power in Megawatts } \\
\cline { 2 - 5 } & & Pessimistic & Baseline & Optimistic \\
\hline \multirow{2}{*}{ Rooseve1t } & 230 & 300 & 500 & 500 \\
Cove Fort & 200 & 0 & 200 & 200 \\
Thermo & 185 & 0 & 100 & 100 \\
West Cove Ft. & 200 & 0 & 200 & 200 \\
North Cove Ft. & 200 & 0 & 200 & 200 \\
\hline TOTALS & & 300 & 1200 & 1200 \\
\hline
\end{tabular}


Table 4.9 Electric Power Estimated

In Megawatts for the Five States

\begin{tabular}{|l|c|c|c|}
\hline \multirow{2}{*}{ State } & \multicolumn{3}{|c|}{ Estimated Power In Megawatts } \\
\cline { 2 - 4 } & Pessimistic & Baseline & Optimistic \\
\hline Arizona & 0 & 400 & 2450 \\
Colorado & 0 & 100 & 500 \\
Nevada & 1610 & 9478 & 13600 \\
New Mexico & 1920 & 2040 & 2250 \\
Utah & 300 & 1200 & 1200 \\
\hline Total for the Region & 3830 & 13218 & 20000 \\
\hline
\end{tabular}




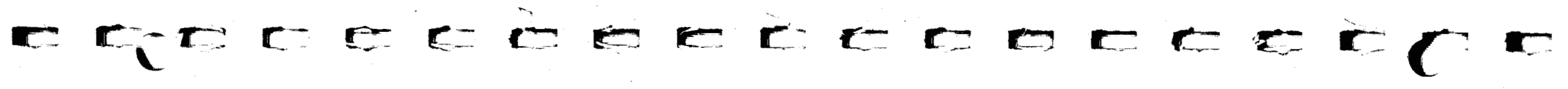

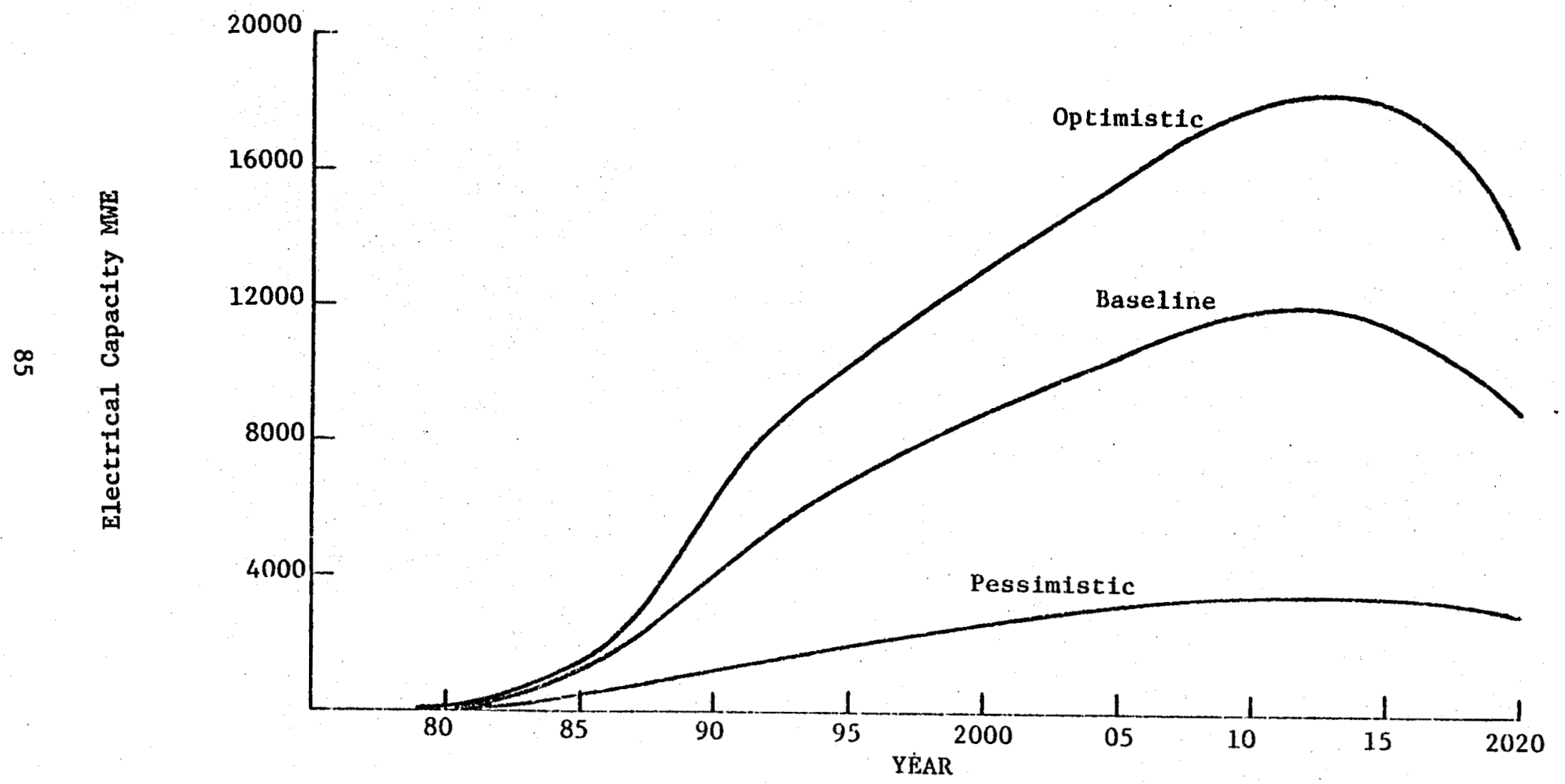

Figure 4.1 Tine-Phased Scenarios Under Condltions of Minimun Competition 
However, in the presence of development resource competition one could expect a time-phasing more along the lines of that presented in Figure 4.2. Assuming that the provision of development resources grows at a more or less constant rate, the slope of the initial growth phase must be less steep while the period of maximum output is more extended. Since it is likely that some competition for development resources will exist, we will assume for the sake of policy analysis that the power on line time-phasing suggested in Figure 4.2 is the relevant case. It must be kept in mind, however, that this timephasing is subject to policy initiatives.

\subsection{Policy Analysis and Recommendations}

The final step is to consider the sensitivity of the time-phased aggregations to changes in policy parameters. In order to accomplish this, however, the logic of these aggregations must be revlewed. The aggregations are the sum of the parts which are site-specific estimations of power and the timephasing of those sites.

The three cases illustrated for the time-phased aggregations are the result of an essentially "go" or "no-go" decision for each site. The "optimistic" boundary is the result of a "go" decision for all sites within the region, as a brief review of Tables 4.4 through 4.8 will show. Thus, the upper bound of our, range of likely power-on-1ine estimates can increase or change only subject to the following conditions: (1) the volume or temperature estimates are altered, or (2) as noted earlier, the supply of development resources is increased or decreased. Thus, the effect of DOE-DGE policy can only be to raise the middle estimate and lower boundry of the range or to alter the rate of development by ensuring a timely supply of development resources.

The policy parameters indicated previously, then, can only affect the position of two of the three estimates, the "baseline" and the "pessimistic" projections for power on line, in Figure 4.2. The following policy analysis is, therefore, directed at the sensitivity of these lower two estimates to changes in policy parameters.

It must be recalled that the lower estimates are the result of the confluence of a variety of negative influences on the rate of return ( $R$ ). Moreover, as a result of this confluence, the "pessimistic" case results in zero or lower 


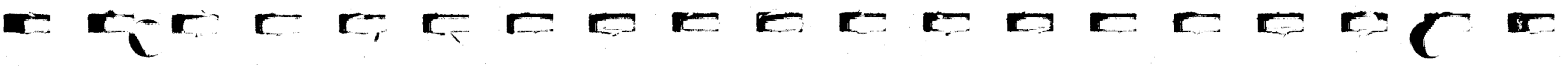

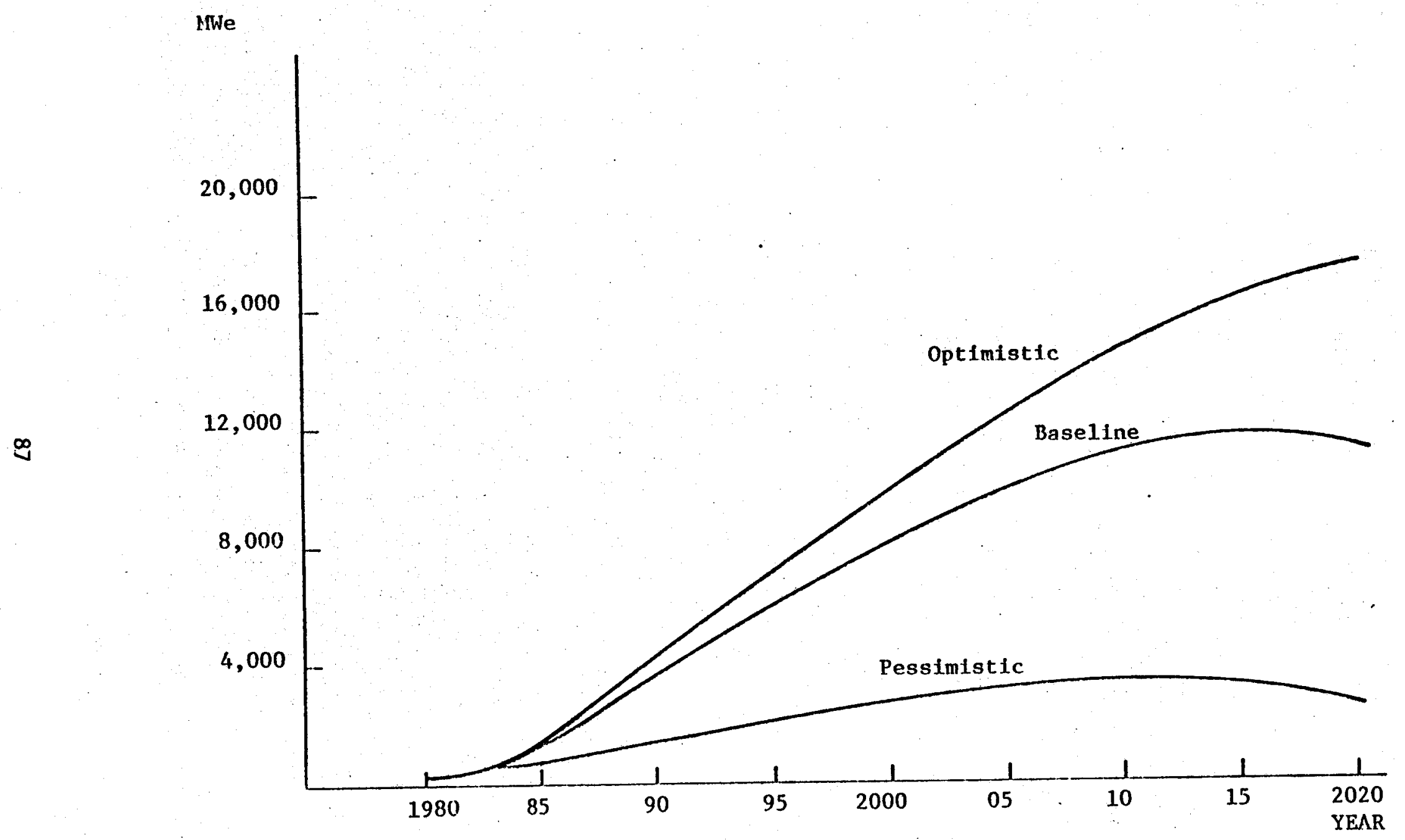

Figure 4.2 Time-Phased Scenarios Under Some Competition for Development Resources 
estimates for $\mathrm{R}$ for all sites having down-hole temperature of $200^{\circ} \mathrm{C}$ or lower. If the "go" or "no-go" decision point for a site is at an approximate $R$ of, say 15 percent per annum, substantial increases in $R$ are necessary for sites below $230^{\circ} \mathrm{C}$ in the pessimistic scenario. Given the very low $E$ of $R$ with respect to either the depletion allowance or the royalty rate, it should not be surprising that substantial changes in either of these policy variables will not noticeably affect the lower bound or the "baseline" case of our estimated range. Eliminating the royalty rate or establishing a 22 percent depletion allowance will accomplish two things: (1) increase the probability that the actual power output will fall within the range given, and (2) increase the profitability of these sites which will be developed in any event. This second result is not meant to indicate criticism. Increasing the cash flow of geothermal enterprises could inspire developers to take on riskier geothermal projects. The impact of this activity cannot, however, be measured at this time.

A further word about result (1) above is necessary. An estimated range of high and low prospects for geothermal development in the Southwest Region has been illustrated. We are saying that it can be expected that, with no assistance beyond what currently exists, the development path for geothermal energy will fall within the indicated range. It cannot be said with any certainty what the likelihood is that this will occur. The likelihood may be a 60 percent probability or a 90 percent probability. We are only saying the probability is somewhat greater than 50 percent that the actual development path will fall within that range. We cannot be more certain than that until more precise estimates of reservoir volume and the distribution of flow rates is obtained. With this information, it would then be meaningful to assign probability weights to other parameters, and through Monte Carlo simulation techniques estimate a probability value for the range and also probability values for paths within that range. In the absence of such information we can specify the magnitude of movement, but not the magnitude of the change in probabilities.

In contrast with the two policy parameters mentioned above, an increase in the investment tax credit of 4 percentage points (say,. from 12 percent to 16 percent) or a decrease in the bond rate by 2 percentage points (from 8.5 percent to 6.5 percent) would add perhaps 7,000 megawatts of power onto the total found under the "baseline" case in Table 4.5, and perhaps 4800 megawatts to the "pessimistic" case. The lower two estimates would experience a shift as illustrated in Figure 4.3. 


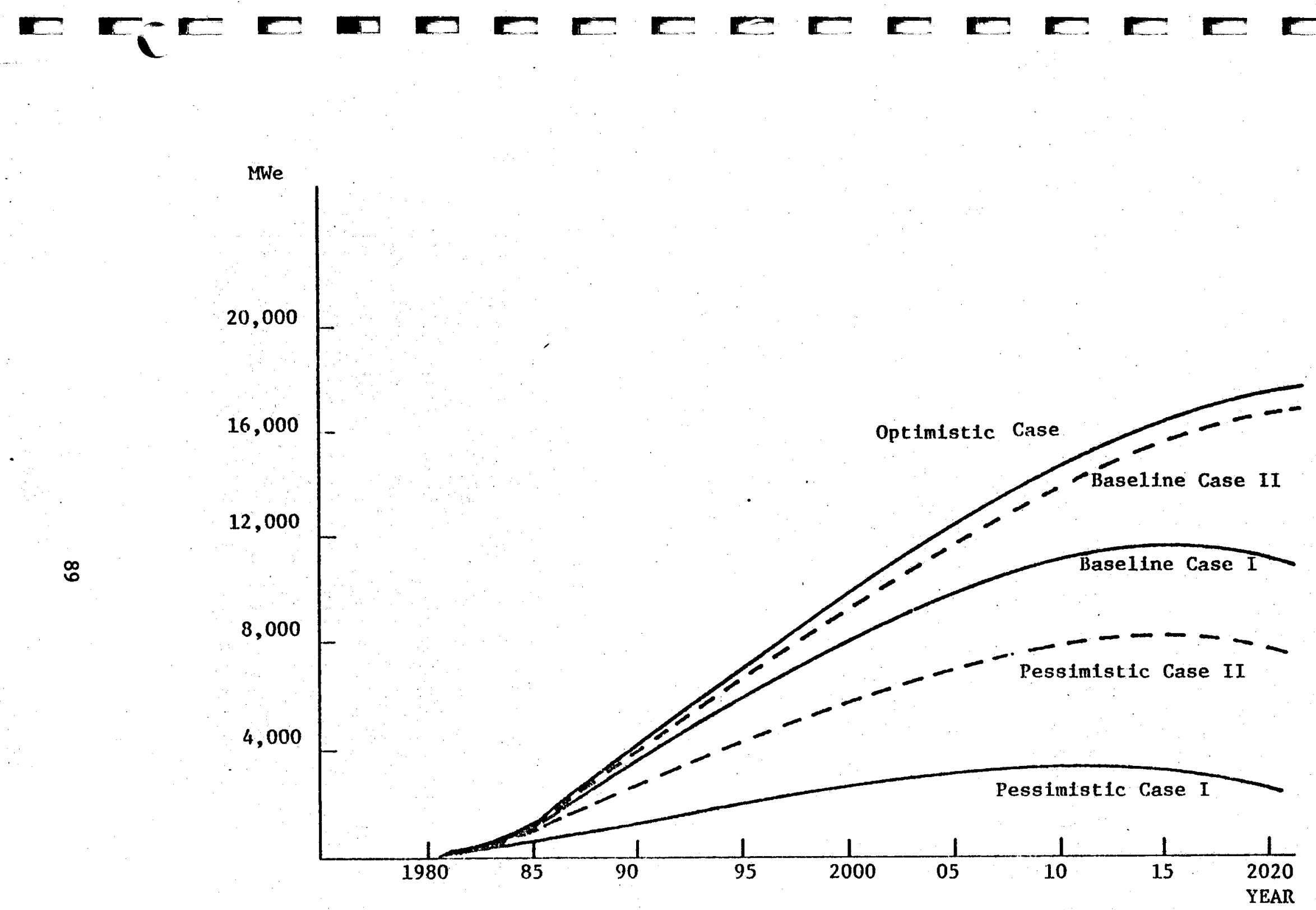

Figure 4.3 Time-Phased Scenarios With Policy Incentives 
The occasion for this result is that under the original "pessimistic" case, no site with a temperature below $230^{\circ} \mathrm{C}$ was "on 1 ine" due to the insufficient profit level, nor were sites below $190^{\circ} \mathrm{C}$ in the "baseline" case. Most of such sites would use a binary cycle plant which is more capital-intensive than flash cycle plants. It is the former plants which would receive the relatively greater incentives from changes in the investment tax credit rate and the bond rate.

A combination of both an increase in the investment tax credit rate by 4 percentage points and a decline in the bond rate by 2 percentage points would perhaps add another 2000 megawatts to the "pessimistic" case and bring the "baseline" case approximately to the maximum. In short, it could be said with a great deal of certainty that altering those two policy parameters in the amounts indicated would result in the possiblity of between 11,000 and 20,000 megawatts of geothermally generated electricity being on-line by about the year 2020 within the region. There is almost no doubt that by the year 1990 almost 6,000 megawatts of electricity could be on-1ine. In the absence of these two policy initiatives, the probability that only $3000 \mathrm{MW}$ would be on-line would be equal to that of 5000 MW being on-line. It should be added here, at least parenthetically, that any policy action which reduces the cost of capital to both the geothermal producers and the electric utilities in an amount equivalent to the policy actions indicated would have a similar result.

\subsection{Review and Summary of Policy Analysis}

Under "optimistic" conditions for development, almost all resource areas within the Southwest Region will probably develop. Under "pessimistic" conditions, in the absence of financial incentives on the part of government agencies, only those sites with temperatures greater than $230^{\circ} \mathrm{C}$ are 1 ikely to develop. To insure the speedy development of geothermal resources, DOE-DGE should concentrate its efforts on those activities which will enhance the viability of low temperature electric sites. Any activity which will lower the cost of capital by an amount equivalent to an increase in the investment tax credit rate by four percentage points and to decrease in the bond rate by two percentage points would result in an additional 5000 to 7000 megawatts of electricity generated from lower temperature sites in the Southwest Region by the year 2015. This would be a significant addition to the Southwest's electrical-generating capacity. 


\subsection{The Market for Electricity}

As noted under the "Research Philosophy" section above, even if all other conditions are favorable for the development of a geothermally-powered electric plant, the demand for the additional capacity may not exist. Because geothermal energy is a "marginal" power source, in the absence of sufficient demand utilities will probably not substitute geothermal plants, e.g., for coal-fired plants.

In order to estimate the potential utility of geothermally powered electric plants, it was necessary to accomplish two tasks. First, it was essential to estimate the relationship between the quantity of electricity demanded and other casual factors, and project those casual factors to the year 2020 to estimate electricity need through the time period. Second, it was necessary to ascertain the planned generating capacity within the region to determine whether or not a defictency might develop. We turn first to a discussion of electric energy consumption and its projection.

\subsection{Electric Energy Consumption}

Economic theory tells us that the quantity purchased of any commodity is a positive function of income, the number of consumers, and the prices of substitutes, and a negative function of price. In addition, the consumption of any commodity should also be a positive function of the consumption of complementary products. In order to economically estimate the relationship between the quantity of electricity and other assumed casual factors, it is necessary to specify a mathematical relationship between variables. This was done following Mount, Chapman, and Tyrrel1 ${ }^{(30)}$.

We begin by specifying that electricity consumption is a function of its own price, the price of natural gas (a substitute), per capita income, population, and the stock of electricity using consumer durables. We furthermore specify a model that constrains electricity consumption to a constant elasticity of growth with respect to its casual variables. This may appear restrictive, but (1) observation of long run trends suggests such an assumption, (2) the resulting model yields a good fit with historical data, and (3) it is the common practice ${ }^{(31)}$. 


$$
\begin{aligned}
& \mathrm{QE}_{t}=\text { ae }{ }^{\lambda t} \mathrm{PE}{ }^{B_{1}} \mathrm{PNG}_{t}{ }^{B_{2}} \mathrm{PCI}_{t}{ }^{\beta_{3}} \mathrm{POP}_{t}{ }^{\beta_{4}} \\
& \mathrm{QE}_{t}=\text { Quantity of Electricity consumed in year } t \\
& \mathrm{PE}_{t}=\text { Average Price of Electricity in year } t \\
& \mathrm{PNG}_{t}=\text { Price of Natural Gas in year } t \\
& \mathrm{PCI}_{t}=\text { Per Capita Income in year } t \text {, constant dollars } \\
& \mathrm{POP}_{t}=\text { Population in year } t \\
& a, \lambda, B_{1}, B_{2}, B_{3} \text {, and } \beta_{4} \text { are constants to be estimated } \\
& e=\text { Natural logarithm constant }
\end{aligned}
$$

For the purposes of estimation, equation (4.1) is transformed to the linear equation (4.2). The short-run elasticity of $Q E$ with respect to each variable $i$ is $\left(\beta_{i} / 1-N\right) \times 10^{2}$. Equation (4.2) was estimated using pooled cross-section and time series data. Estimation of $\beta_{i}$ using strictly timeseries data can result in multi-collinearity due to the strong trend element

$$
\text { In } \mathrm{QE}_{t}=\text { In } \mathrm{a}+\lambda \mathrm{t}+\beta_{1} \text { ln } \mathrm{PE}_{\mathrm{t}}+\beta_{2} \text { ln } \mathrm{PNG}+\beta_{3} \text { ln } \mathrm{PCI}+\beta_{t} \mathrm{POP}_{t}
$$

in all independent variables. Estimation using strictly cross section data yields no reason for confidence in projection through time ${ }^{(32)}$. The variable $\lambda$ is introduced to account for the adjustment of consumers to consumption levels through time and insures homoedasticity of estimated parameters.

Table 4.10 presents the results of the regression analysis and a test calibration of the estimated model.

Using this estimation of the relationship between the quantity of elasticity consumed and the casual variables, the next step was to project the quantity of electricity demand through the year 2020. This, of course, involves first, the projection of casual variable values through 2020 , thus engaging the researcher in a guessing game concerning the future. For example, although it is doubtful that the population of the United States will grow much more rapidly than one percent per annum at any time in the future, migration may result in population increases within the area of 1.2 to 1.5 percent. Real per capita income may grow at a rate between 2.5 and 3.5 percent. The range of likelthood around these potential growth rates is fairly small and so $1.35 \%$ annual population growth was assumed and a $3 \%$ annual growth was assumed for real income. 
Table 4.10 Results of the Forecasting Model

4

$\mathrm{QE}=(1.39) \mathrm{PE}^{-.134} \mathrm{PNG}^{-.095} \mathrm{PCI}^{.234} \mathrm{POP}^{1.978} \mathrm{e}^{.009 t}$

Percentage of Variance Explained $=100 \%$

\begin{tabular}{|c|c|c|c|}
\hline Year & Actual (GWH) & $\begin{array}{l}\text { Calibration } \\
\text { Predicted (GWH) }\end{array}$ & $\%$ error \\
\hline 1961 & 21.900 & 21.824 & $-0.35 \%$ \\
\hline 1962 & 23.500 & 23.646 & $0.62 \%$ \\
\hline 1963 & 25.700 & 27.713 & $0.05 \%$ \\
\hline 1964 & 27.481 & 27.210 & $-0.99 \%$ \\
\hline 1965 & 28.760 & 28.835 & $0.26 \%$ \\
\hline 1966 & 29.800 & 29.910 & $0.37 \%$ \\
\hline 1967 & 31.519 & 31.605 & $0.27 \%$ \\
\hline 1968 & 33.730 & 33.879 & $0.44 \%$ \\
\hline 1969 & 37.879 & 37.709 & $-0.45 \%$ \\
\hline 1970 & 41.079 & 40.944 & $-0.33 \%$ \\
\hline 1971 & 44.679 & 44.665 & $-0.03 \%$ \\
\hline 1972 & 49.740 & 49.491 & $-0.50 \%$ \\
\hline 1973 & 54.538 & 54.822 & $0.52 \%$ \\
\hline 1974 & 57.203 & 57.524 & $0.56 \%$ \\
\hline 1975 & 59.211 & 58.939 & $-0.46 \%$ \\
\hline
\end{tabular}


The range of uncertainty for projections in the growth of electricity consumption is due then to uncertainty concerning the price of electricity and the price of natural gas. In 1976, National Economic Research Associate (NERA) in a study for the Arizona Nuclear Power Project used company data to arrive at higher and lower estimates for real price escalations in electricity and natural gas ${ }^{(33)}$. NERA estimated a range in real price escalation for electricity of about $1 \%-3.5 \%$ per annum and in natural gas of about $1.8 \%-5 \%$ per annum. These are consistent with other estimates ${ }^{(34)}$. We have, therefore, produced four projections for electricity consumption using (1) a high growth rate in price for electricity and also a high rate for natural gas, (2) high for electricity, low for gas, (3) low for electricity, high for gas, and (4) low for gas and electricity. These are designated in Table 4.11 as I, II, III, and IV, as well as illustrated in Figure 4.4.

These projections have been translated into megawatts of required capacity and illustrated in Figure 4.5 according to the following formula. The number for GWH has been translated into MW by multiplying GWH by $10^{6} 8760$. This average MW figure has been multipled by 1.5 in order to account for peak loading. Another 0.15 has been added for reserve capacity.

Electric utilities have been polled within the region and capacity increments already in the planning or building state ascertained. There are currently some 20,708 MW on line and by 1986, an additional 16,083 MW are planned. Assuming that approximately ten percent of the increment is for replacement and that, on average, power plants consume 18 percent of power produced, and an additional ten percent is lost in transmission, planned effective capacity for 1986 is $25,965 \mathrm{MW}$, where it is currently 15,282 MW. If it is further assumed that the current proportion of export to sales remains constant at about 26 percent, the effective planned domestic (within the subject five states) capacity in 1986 is about 19,214 MW. Given reasonable growth projections as illustrated in Figure 4.5, this capacity should carry the region up to about 1990-1995. Depending upon replacement needs, additional capacity may be required prior to 1990 . By the year 2020, this region may require an additional 30,000 MW (net) of electric capacity for domestic consumption alone, and perhaps another 10,000 to 15,000 MW (net) for export. Power plants driven by geothermal steam could provide 15-30 percent of the region's total electric capacity if it can become an economically viable alternative. 
Table 4.11 Sensitivity Analysis Parameters

For Projections of Electricity Consumption

\begin{tabular}{|c|c|c|c|c|c|}
\hline CASE & & I & II & III & IV \\
\hline & PCI & $3.0 \%$ & $3.0 \%$ & $3.0 \%$ & $3.0 \%$ \\
\hline & POP & $1.35 \%$ & $1.35 \%$ & $1.35 \%$ & $1.35 \%$ \\
\hline . & $\mathbf{P E}$ & $3.5 \%$ & $3.5 \%$ & $1.0 \%$ & $1.0 \%$ \\
\hline & PNG & $5.0 \%$ & $1.8 \%$ & $5.0 \%$ & $1.8 \%$ \\
\hline
\end{tabular}




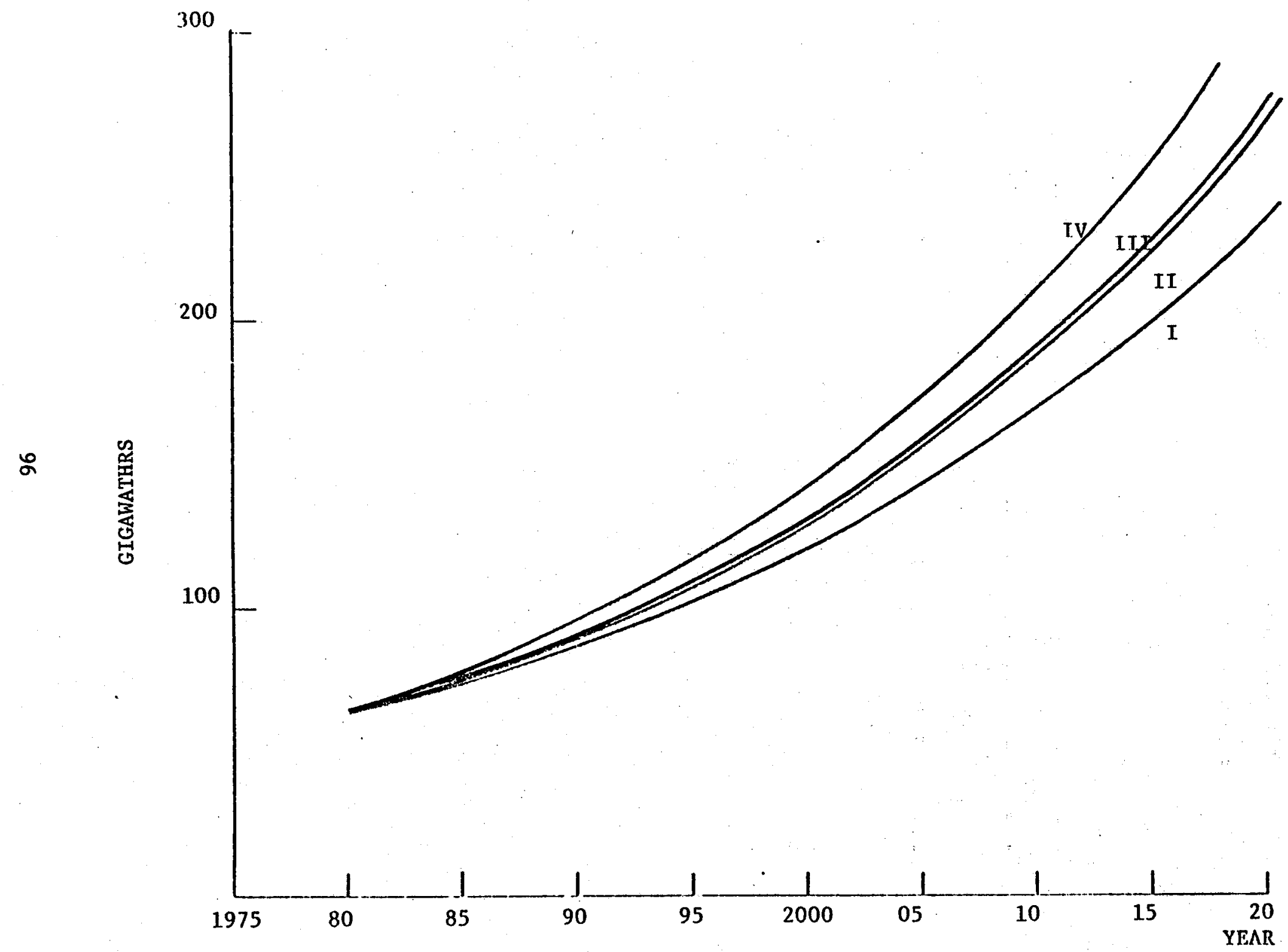

Figure 4.4 Profections of Demand for Electrictty in the Five State Region 


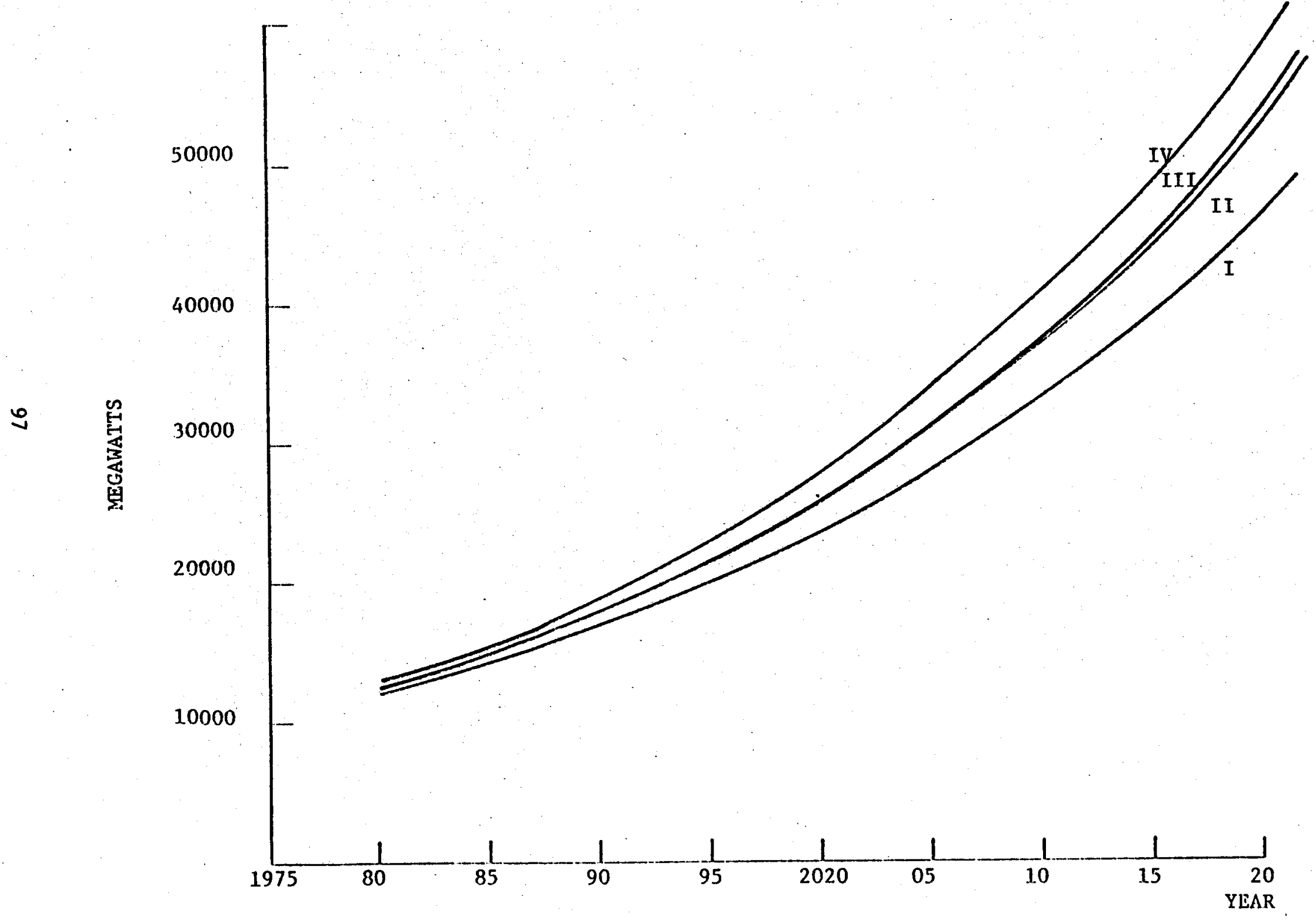

Figure 4.5 Projections of Required Plant Capacity in the Five State Region 


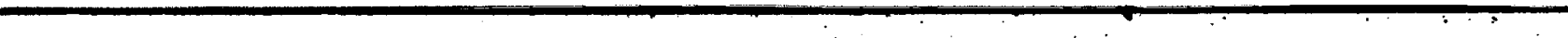




\section{CHAPTER V}

GEOTHERMAL DEVELOPMENT FOR SPACE HEATING

Much of the anlaysis of geothermal energy potential in the United States in recent years has shifted from the study of electricity generation to nonelectrical applications. These latter uses are often referred to as direct applications, ${ }^{(35)}$ in contrast to electricity generation which is an indirect application. There are a number of factors which have generated widespread concern for direct applications.

First, recent documentation of geothermal resources in the United States has revealed a large disparity in the endowment of low temperature versus high temperature resource sites. For example, 504 low temperature $\left(\mathrm{T} \leq 150^{\circ}\right)$ and 80 high temperature $\left(\mathrm{T}>150^{\circ}\right)$ sites have now been identified in the region. The sheer abundance of low temperature geothermal resources seems therefore, to warrant further investigation.

Early estimates of the energy potential offered by low temperature anomalies were promising. The most widely cited of these estimates was Reistad's. (37) Reistad calculated that if all geothermal resources up to $200^{\circ}$, $150^{\circ}$, and $100^{\circ} \mathrm{C}$ could be used for space heating, 40, 30, and 20 percent, respectively, of total United States energy needs could be met. Although these projections are impressive, some stringent assumptions were employed in the calculations. In particular, many low temperature sites included in these projections could not be harnessed because of the imperfect mapping of market supp $1 \mathrm{y}$ and demand sites.

A second reason for the recent upsurge of interest in direct geothermal applications is that such a large proportion of the nation's energy demands are for relatively low temperature space heating needs. Reistad estimated that $10,857 \times 10^{12}$ BTU or 18 percent of the 1968 United States fuel consumption was for space heating alone (37). If geothermal energy proves practical, this demand may be easily be met. Further energy needs, such as water heating and cooling, air conditioning, and refrigeration might also be met from low temperature geothermal resources.

Kunze and Richardson combined Reistad's geothermal supply estimates with some energy demand projections combined at the Stanford Research Institute ${ }^{(38)}$. The objective of this exercise was to determine the proportion of 1985 space heating needs that could be met with geothermal energy. Ignoring some admittedly 
pertinent economic considerations, they estimated that roughly 35 percent of the projected space heating needs could be geothermally supplied. (38) Again, however, the locational problem of matching supply and demand sites was ignored.

A final explanation for heightened interest in low temperature geothermal resources is that present and future low temperature energy needs are not efficiently served by existing technology using traditional fossil fuels. For these reasons at least, developmental prospects of low temperature geothermal energy in the Southwest Region will be examined in this chapter.

While the overall research approach for high temperature and low temperature resources is similar, there are, nevertheless, several distinguishing features of each analysis. One such factor which differentiates the analysis of direct from indirect applications is the mere number of candidate sites. As indicated above, the number of low temperature resources exceeds the number of high temperature resources by a margin of roughly 6 to 1 . Thus, in the preliminary analytical stages, at least, the breadth of analysis is much greater In considering direct applications.

Another distinguishing feature of low temperature geothermal resources is the nature of the low temperature applications. These anomalies are not considered adequate for electricity generation. However, the range of alternative uses include space heating and cooling, water heating and cooling, and a broad range of potential industrial process applications. Of these, only space heating will be considered in this analysis. Accordingly, the energy consuming sector in the low temperature analysis will be a district heating unit rather than an electric utility company, as in the high temperature analysis. The analytical methodology will differ accordingly.

Finally, the evaluation of low temperature geothermal resource development is characterized by the limited portability of geothermal fluid. Warm air which has been heated with low temperature geothermal fluid cannot be transported interregionally as can electricity produced from high temperature geothermal resources. Thus, differences in the technological characteristics of the ultimate products produced by geothermal resources also influence the analytical framework to be employed.

Given the factors cited above, the examination of the regional potential of low temperature geothermal energy will be organized as follows:

1. A brief review of the limited amount of experience with geothermal space heating in the United States will be presented. Factors which 
have been found crucial to the developmental prospects of low temperature space heating will be identified.

2. A complete assessment of the regional resource endowment will be compiled. The resource base will be subdivided into two groups, depending upon whether resources are usable or unusable given current recovery and production technologies.

3. An economic simulation mode1, GIRORA NON-ELECTRIC, will be employed to evaluate the financial feasibility of exfsting resources.

4. The significance of numerous pollcy variables and geophysical resources will be assessed.

5. Regional supply aggregates of 1ow temperature geothermal energy will be forecasted for several sets of circumstances.

\subsection{Geothermal Space Heating in the United States: The Historical Record}

The historical record of experience with geothermal space heating in the United States is a limited one. Klamath Fa1ls, Oregon, is the sole location in which space heating is presently employed on a broad scale. In order to place the following research in perspective, a brief review of the Klamath Falls experience with geothermal energy will be presented. Since detailed economic and engineering data are available elsewhere, the following discussion will be limited to a general description of the Klamath Falls experience and a summary of some pertinent findings which may prove helpful in the pages to come.

Klamath Falls is located in a KGRA in southern Oregon. Residents in this area have relied upon geothermal energy for space heating and other needs for over 70 years. However, a number of factors have spurred additional local demand since the mid 1960s.

First, the use of geothermal hot water for heating the buildings on the campus of the Oregon Institute of Technology began in 1964. This provided a sort of large scale demonstration project, the results of which have been encouraging. The savings in annual operating costs are estimated to be a full $\$ 225,000$ compared to the cost of conventional heating (39). Such evidence of feasibility has no doubt contributed to decisions to heat schools, hospitals, and other large residential and commercial buildings in Klamath Falls.

A second factor which spurred interest in geothermal space heating was the establishment of the Geo-Heat Utilization Center at Oregon Institute of Technology. (40) Funding for this undertaking was originally provided by the Pacific Northwest 
Regional Commission of Vancouver, Washington, in 1975. With additional support from the state of Oregon, the Center actively disseminates information and prepares research proposals pertaining to geothermal energy. Perhaps its most ambitious undertaking is the current effort to ogranize and to plan for the implementation of a large scale district heating unit in Klamath Falls.

A third factor which has stimulated interest in geothermal energy in Klamath Falls has grown steadily in recent years. There are now approximately 400 shallow-depth wells being used to heat roughly 500 structures; these range from 27 to 550 meters in depth. Space heating is used to warm private residences, schools, and a broad array of businesses. Water temperature varies between $40^{\circ}$ and $110^{\circ} \mathrm{C}$, with temperatures over $80^{\circ}$ desirable. The principle heat extractive system is the closed loop downhole heat exchanger. (41)

Some of the more recent experiences at the Oregon Institute of Technology in Klamath Falls has been fully documented, and it offers evidence of the local potential for further space heating. Several hot water wells have been dug from 400 to 600 meters deep in an area immediately adjacent to the campus. These are used to heat eight buildings of approximately 530,000 square feet. The sum of the annual operating cost plus depreciation is $\$ 25,000$ or $\$ 0.005 / \mathrm{sq}$. feet. This compares favorably with the estimated annual cost of $\$ 250,000$ ( $\$ 0.05 / \mathrm{sq}$. ft.) for conventional fuels. (39)

The 1ong experience at Klamath Falls have proven sufficient to identify a number of consideratons which are germane to developmental prospects of geothermal space heating. The first is the nature of economic costs and benefits. In the case of costs, large capital investment expenses are incurred "up front", i.e., before the system becomes operable. These costs include expenditures for drilling and casing, equipment, and building retrofitting where necessary. The costs are usually written off over 30 years, but the intial expense is sufficiently large to present a potential barrier to smaller users.

In the case of the economic benefits, the results of experience are more encouraging. As mentioned above, the annual operating costs are estimated to be a fraction of that for more conventionally fueled heating systems. In addition, the risk of supply disruption or internationally imposed price increases is eliminated. Thus, a long run incentive from a risk aversion perspective is also present.

A second consideration in evaluating the space heating potential of geothermal energy is the size of the user market. Given current production techniques, 
the technical efficiency of a space heating system is greater and the economic cost is lower as the market size,(i.e., population) grows. The pivotal factor in this relationship is the potential for raising the load factor of the geothermal physical plant. Insofar as a larger market permits the fuller utilization of system capacity, the incentive for harnessing geothermal energy for district heating will be stronger. In the analysis to follow, therefore, only the development of geothermal energy for district heating will be considered.

A final consideration is the nature of the resource itself. Two properties in particular are important: the temperature and the location of the resource vis a vis the market. Given the existing state of production technology, the hotter the resource and the closer the resource to the point of consumption, the more financially attractive geothermal investment becomes. Conversely, the cooler the resource and the farther it is from the point of consumption, the less profitable geothermal investment is.

All the consideratons discussed above are recognized in the following analysis. The nature of the revenues and cost flows are included in the specifications of the model. The user population, resource, temperature, and the distance to the market are explicitly considered below in evaluating prospective resources. The complete description of the GIRORA-Nonelectric and the associated computer progrm written in FORTRAN IV is given in Appendix 2.

\subsection{A Technical Screening of the Reglonal Low Temperature Resource Endowment.}

A complete compilation of known low temperature anomalies identifled by the Core Team and state personnel is presented in the data base section of the report. For each of these sites, the location (state and county), the latitude and longitude, a set of estimated temperatures, and the estimated reservoir volume are presented.

The distribution by state of low temperature geothermal resource sites is summarized in Table 5.1. In addition, the estimated energy potential in MBtuh is calculated for each state. The distribution of neither is balanced. For example, 328 of the 504 (65 percent) known anomalies are found in Nevada. Each of these resource sites is designated with a dot (.) in Figure 5.1. Viewed from another perspective, if the energy supply potential of these resources is calculated in MBtuh, a full 78 percent of the total is located in Nevada. Thus, just as in the case of the high temperature resources, Nevada is also rich in low temperature geothermal resources as well. 
TABLE 5.1

Discribution of tow Temperature Geothermal

Resources by State

\begin{tabular}{|l|c|c|}
\hline State & $\begin{array}{c}\text { Number of } \\
\text { Resource Sites }\end{array}$ & $\begin{array}{c}\text { Estimated SuppIy } \\
\text { Potential in iBtuh }\end{array}$ \\
\hline Arizona & 40 & 1892 \\
Colorado & 45 & 1460 \\
Nevada & 328 & 30423 \\
New Kexico & 46 & 2969 \\
Utah & 45 & 2201 \\
\hline Total & 504 & 38945 \\
\hline
\end{tabular}




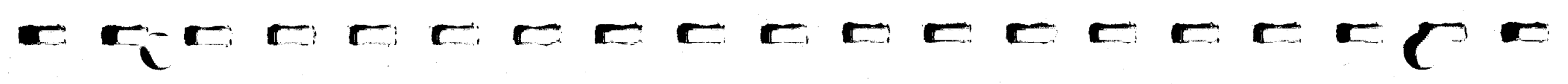

옵

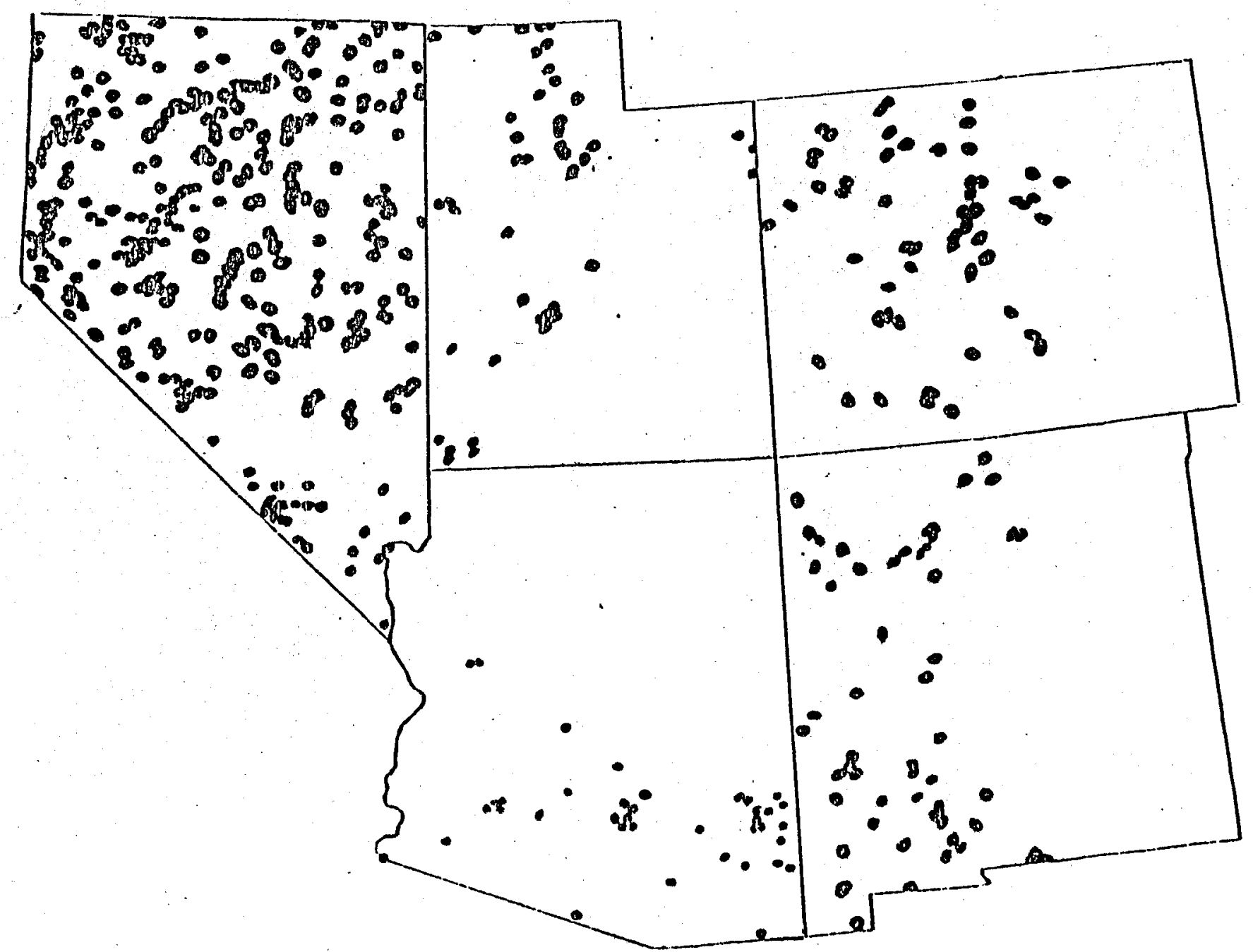

Figure 5.1 Low Temperature Sites in Southwestern Region 
The large number of resource sites and the estimated Megawatt years of energy designated in Table 5.1 present a misleading impression of the true geothermal energy potential in the Southwest region. Given the nature of resources and the state of production technology, many of these resources offer no current energy potential. The first task which must be undertaken, therefore, is to eliminate from further consideration any resource which, for one reason or another, is not a feasible supply site.

Accordingly, the initial inventory of low temperature resource sites was subjected to a technological screening. The objective of this exercise was to divide the population of sites into two samples. The first sample consists of sites which are currently usable given the existing state of production technology in the industry. Those sites which fall in the second subgroup are resources which, for one reason or another, are not considered usuable given the present state of "know how." As production techniques advance, however, these latter resources may in time become of substantive importance.

Three criteria were employed to partition the total resource base. The first is the temperature of the resource. A minimum resource temperature is required for effective space heating just as a minimum temperature is required for electricity generation from hotter resources. Earlier space heating experience in Klamath Falls, Oregon, and Boise, Idaho, were consulted in designating a minimum temperature.

The second criterion is the distance between the geothermal resource and the nearest user market. This consideration is intended to exclude from further study all resources which are not sufficiently proximate to a market to be realistically employed.

The final criterion employed for partitioning low temperature resources is the size of the potential market. A minimum feasible market size, which is measured in terms of population, is defined. If there is or is not a market of sufficient size, within the designated distance, a resource will or will not be considered usable.

The preliminary values for the technological screening criteria are presented in Table 5.2.

The technological screening described above was designed to group geothermal sites on the basis of objective (rather than subjective) benchmarks. Insofar as these criteria (temperature, distance, and demand) accurately differentiate between the currently feasible and infeasible, then some rough measure of the 
TABLE 5.2

\section{Preliminary Values for Technological}

Screening Criteria

\begin{tabular}{|l|l|}
\hline Distance & $\leq 50$ Miles \\
Market Population & $\geq 1000$ persons \\
Resource Temperature (T) & $65^{\circ} \leq \mathrm{T} \leq 150^{\circ} \mathrm{C}$ \\
\hline
\end{tabular}
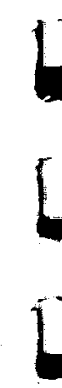

1
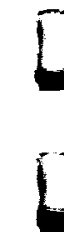
technological supply potential of low temperature resources is known. This estimate is certainly more realistic than earlier estimates (e.g., by Reistad), in that the locational configureation of supply and demand sites is explicitly recognized.

The technological screening also allows for the evaluation of the impacts of future technological innovations. The initial partitioning process can easily be reitereated for various temperatures, distances, and demand measures. Each successive iteration will thus provide a new estimate of the regional technological supply potential given a different state of production "know how."

The results of the preliminary technological screening are informative. The original cost of candidate sites has been reduced to 82 . The complete list of the remaining sites is presented in Table 5.3; the sites are distributed by state, and the estimated supply potential is also calculated. Figure 5.2 then presented a visual summary of the location of each of these resources.

Both Table 5.3 and Figure 5.2 convey a noteworthy impression: of the original 504 sites, on1y 16 percent are feasible given current production expertise. Thus, a rough but realistic evaluation of the regional geothermal supply potential considerably depresses earlier estimates. A set of histograms presented in Figure 5.3 effectively portrays the reduction in the aggregate supply potential attributable to the technological screening.

Each of the remaining sites will next be considered to evaluate its economic potential for space heating. A number of economic considerations which have not yet been introduced will contribute to this judgement. In effect this exercise will constitute a second screening on the basis of economic rather than technological criteria.

The primary output of the GIRORA-Nonelectric model then is the calculated internal rate of return, $R$. This estimate of profitability is analytically useful for a number of reasons. First, of course, the estimated value of $R$ provides a general measure of market profitability. As technologically feasible geothermal resources are more or less profitable, private firms are more or less likely to develop them. Second, if an internal rate of return can be calculated for each geothermal site, then an ordinal ranking of resource areas may be compiled on the basis of estimated profitability. Assuming that the most profitable sites will be developed first, this ranking will provide a unique ordering of sites to be brought "on line." Such information is already in demand to facilitate planning and development efforts. 
Table 5.3

Distribution by State of Low Temperature Geothermal

Resources Which Pass Initial Technological Screening

\begin{tabular}{|c|c|c|}
\hline State & Site & $\begin{array}{l}\text { Estimated Supply } \\
\text { Potential, MBtuh }\end{array}$ \\
\hline Arizona & $\begin{array}{l}\text { Gillatd H.S. } \\
\text { Eagle Creek H.S. } \\
\text { Coolidge H.S. } \\
\text { Coffers H.S. } \\
\text { Cat Tank } \\
\text { Safford Area } \\
\text { Castle H.S. } \\
\text { Yuma } \\
\text { Littleton } \\
\text { Wilcox } \\
\text { Casa Grande (North) } \\
\text { Casa Grande (South) }\end{array}$ & $\begin{array}{r}70 \\
82 \\
117 \\
30 \\
35 \\
22 \\
110 \\
156 \\
160 \\
29 \\
120 \\
114\end{array}$ \\
\hline Colorado & $\begin{array}{l}\text { Craig Warm Water } \\
\text { Roub H.S. } \\
\text { Steamboat Springs } \\
\text { Hot Sulphur Springs } \\
\text { Idaho H.S. } \\
\text { Glenwood H.S. } \\
\text { South Canyon H.S. } \\
\text { Colonel Chinn H.S. } \\
\text { Hartsell H.S. } \\
\text { Brown Canyon Thermal } \\
\text { Poncha H.S. } \\
\text { Don K Ranch } \\
\text { Mineral H.S. } \\
\text { Shaws Warm Spring } \\
\text { Dutch Crawley } \\
\text { Pagosa Springs } \\
\text { Wagon Wheel Gap } \\
\text { Cebolla H.S. } \\
\text { Orvis } \\
\text { Duray } \\
\text { Lemon } \\
\text { Rico } \\
\text { Pinkerston } \\
\text { Tripp \& Trimble }\end{array}$ & $\begin{array}{r}21 \\
20 \\
54 \\
27 \\
50 \\
16 \\
4 \\
3 \\
17 \\
37 \\
54 \\
30 \\
41 \\
4 \\
8 \\
15 \\
22 \\
37 \\
3 \\
20 \\
18 \\
60 \\
7 \\
20\end{array}$ \\
\hline Nevada & $\begin{array}{l}\text { Cherry Creek H.S. } \\
\text { Hot Pot Bloosom } \\
\text { Mineral H.S. } \\
\text { Hot Springs Point } \\
\text { Warm Springs } \\
\text { Sou H.S. } \\
\text { Elko H.S. }\end{array}$ & $\begin{array}{r}78 \\
32 \\
7 \\
8 \\
10 \\
9 \\
44\end{array}$ \\
\hline
\end{tabular}


Table 5.3 (cont.)

\begin{tabular}{|c|c|c|}
\hline Nevada (cont.) & $\begin{array}{l}\text { Sodaville Springs } \\
\text { Walley H.S. } \\
\text { Hind's H.S. } \\
\text { Carson Lake } \\
\text { Wilson H.S. } \\
\text { Eightmile Flat } \\
\text { Wellington }\end{array}$ & $\begin{array}{r}40 \\
116 \\
110 \\
35 \\
85 \\
35 \\
63\end{array}$ \\
\hline New Mexico & $\begin{array}{l}\text { Radium Springs } \\
\text { Ojo Caliente } \\
\text { Gila H.S. (Below Bridge) } \\
\text { Gila H.S. (Middle Fork) } \\
\text { Montezuma H.S. } \\
\text { Mamby's H.S. } \\
\text { Turkey Creek } \\
\text { Las Alturas } \\
\text { Berino-Mesquite } \\
\text { Ponce De Leon } \\
\text { T or C } \\
\text { W. Mesa - Black Mountain } \\
\text { Derry Warm Spring } \\
\text { Guadalupe Spring } \\
\text { Hot Well } \\
\text { San Ysidro } \\
\text { Hueco-S. Tularosa } \\
\text { Aleman } \\
\text { Sandiego Mts. }\end{array}$ & $\begin{array}{r}141 \\
141 \\
63 \\
14 \\
141 \\
90 \\
34 \\
129 \\
129 \\
40 \\
25 \\
98 \\
27 \\
128 \\
104 \\
104 \\
66 \\
116 \\
134\end{array}$ \\
\hline Utah & $\begin{array}{l}\text { Joseph H.S. } \\
\text { Red Hill H.S. } \\
\text { Crystal H.S. } \\
\text { Abraham H.S. } \\
\text { Wasatch H.S. } \\
\text { Monroe H.S. } \\
\text { Ogden H.S. } \\
\text { Stinking Springs } \\
\text { Meadows Springs } \\
\text { Hooper H.S. } \\
\text { Utah H.S. } \\
\text { Becks H.S. } \\
\text { Crystal H.S. }\end{array}$ & $\begin{array}{r}153 \\
147 \\
147 \\
136 \\
130 \\
130 \\
117 \\
117 \\
110 \\
110 \\
99 \\
92 \\
92\end{array}$ \\
\hline
\end{tabular}




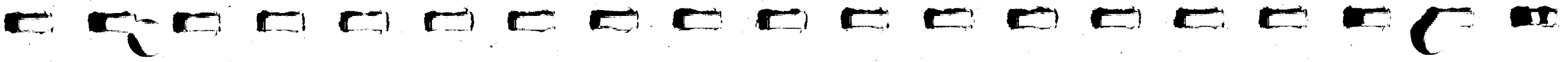

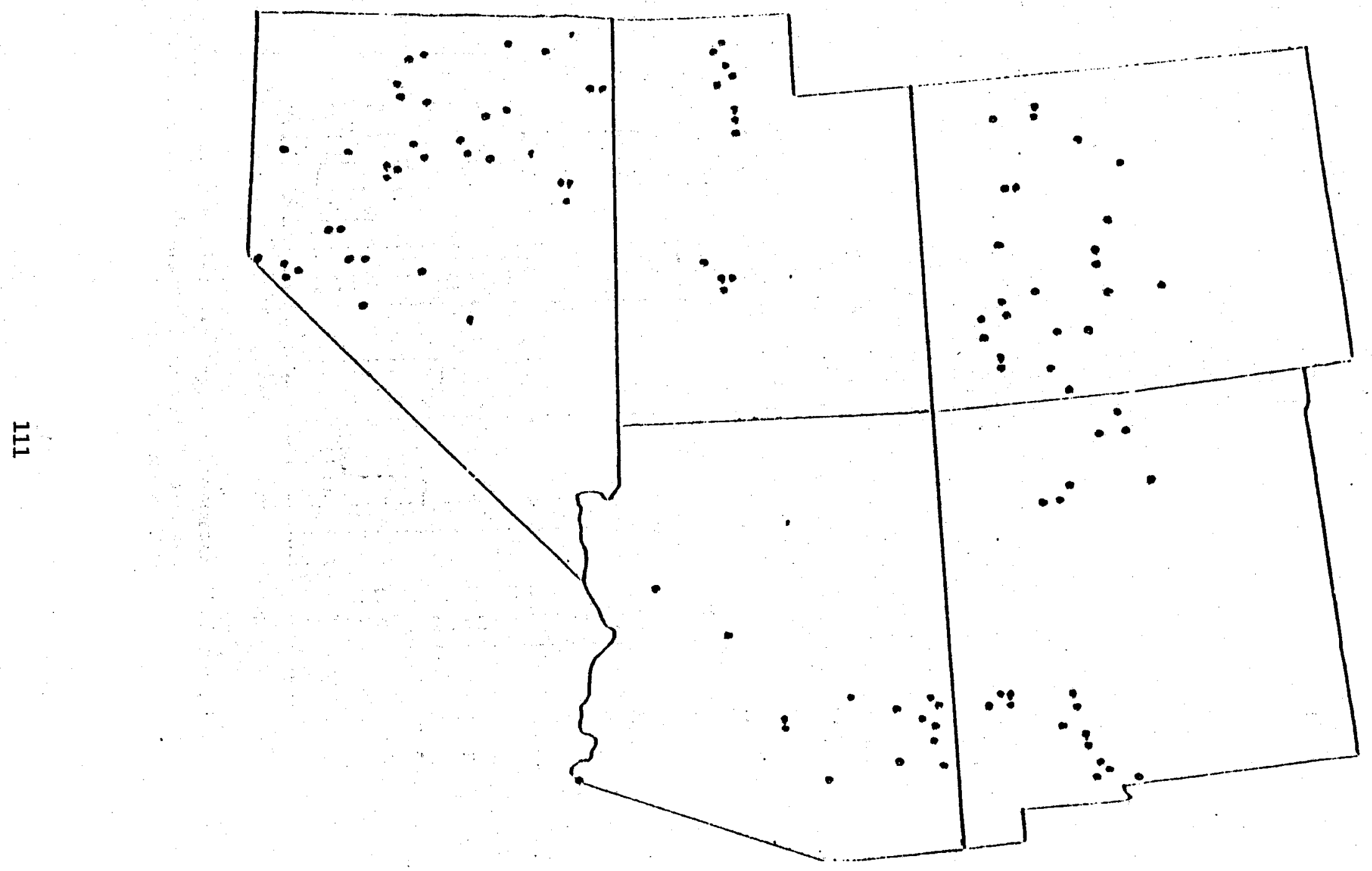

Figure 5.2 ... Technologically Feasible Low Temperature Sites in Southwestern Region 


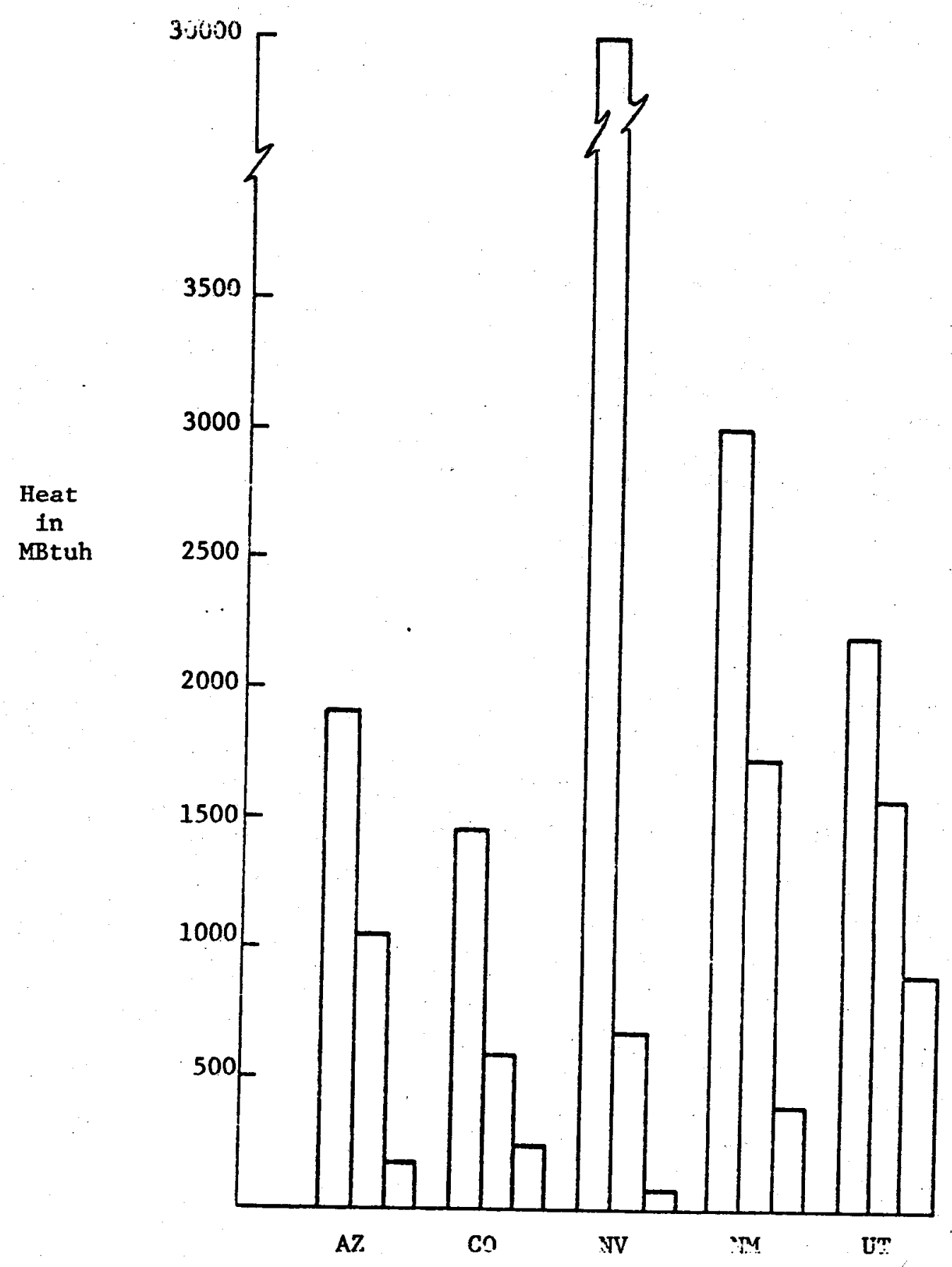

Figure 5.3 Estimated Energy Potent lal of Low Temperature Geothermal Energy before and after Technological and Economic Screening 
The calculation of a site specific internal rate of return is invaluable for yet another reason. By altering the values of selected variables and parameters within the model, the sensitivity of the rate of return to a number of pertinent factors can be determined, In the following pages, the results of such simulation exercises are presented.

\subsection{Simulation Results}

Simulation experiments with GIRORA have yielded a number of interesting and highly informative results. Three exercises were undertaken. First, a baseline scenario was proposed, and the resulting internal rate of return was estimated. This might be considered the case of a hypothetical geothermal developer working on a hypothetical geothermal resource site. The second exercise consisted of conducting sensitivity analysis. Changes in selected parameters of the model were proposed, and the resulting impacts upon the internal rate of return were measured. Finally, several market scenarios were proposed and the rates of return were forecasted. An "Optimistic" and a "Pessimistic" scenario were specificed based upon selected values of key determinates of $R$. The purpose of this exercise was to define, insofar as possible, practical limits to the bounds of potential geothermal resource development.

The Baseline Case

The baseline case depicts a geothermal resource being harnessed to provide space heating. Table 5.4 summarizes the values specified for all manual inputs and major choice and parametric model varlables.

A geothermal resource with a temperature of $100^{\circ} \mathrm{C}$ is assumed to be the candidate resource. It is located five miles from a population center of 5,000 persons for whom space heating is to be provided. The load factor of the unit is assumed to be 0.6 and the price of natural gas with which geothermal energy must compete is $\$ 3.00 / 10^{6}$ BTU. As for the geothermal producers, an investment tax credit rate of 0.12 is assumed; a royalty rate of 0.15 is assumed; the depletion allowance is zero; and the cost of debt capital is 8.5 percent. Finally, a debt equity ratio of $0.7 / 0.3$ is assumed.

The estimated rate or return for this baseline case is $11.0 \%$. Under the conditions specified, therefore, the prospects for space heating appear to be encouraging. Accordingly, the results of the sensitivity analysis become increasingly important, since they will reveal which factors might prove most influential in altering the internal rate of return on investment. 
TABLE 5.4

The Baseline Case Values

\begin{tabular}{|l|c|}
\hline Parameter or Variable & Base Case Value \\
\hline Temperature & $100^{\circ} \mathrm{C}$ \\
Distance & 5 miles \\
Population & 5,000 \\
Load Factor & 0.6 \\
Price of Natural Gas (\$/10 $\left.{ }^{\mathrm{BIU}}\right)$ & $\$ 3.00$ \\
Investment Tax Credit Rate & 0.12 \\
Royalty Rate & 0.15 \\
Depletion Allowance & 0.0 \\
Producer Bond Rate & 0.085 \\
Equity Capital Share & 0.3 \\
\hline Internal Rate of Return (R) & $11.0 \%$ \\
\hline
\end{tabular}


The Sensitivity Analysis

The values of the physical, geophysical and policy factors specified in Table 5.4 are variables in this model. Each of these factors exerts impacts upon the rate of return which are, for the most part, clearly defined but quantitatively unspecified. For the sake of conventence, these factors have been grouped into several classes. The first class includes the geophysical foactors, and the second class includes policy variables and parameters. The role of the geophysical factors in influencing $R$ will be examined first.

Consider the ramifications of varlations in resource temperature upon the estimated rate of return. In this analysis, the temperature span considered ranges from $80^{\circ}$ to $150^{\circ} \mathrm{C}$. The differing values of $\mathrm{R}$ at each temperature are illustrated in Figure 5.4.

The changes in resource temperature clearly exert only minimal impacts upon R. If all other parameters and variables considered are maintained at their base case values, the rate of return is 11 percent at $80^{\circ} \mathrm{C}$, and it rises to just over 12.5 percent at a temperature of $150^{\circ} \mathrm{C}$. Such a finding, that lower temperature resources generate nearly as high a return as the hotter resources is encouraging given the the abundance of relatively lower temperature anomalies in the Southwest.

Consider next the importance of the distance to the market as a determinant of the internal rate of return. Given the potentially large size of the transmission expense, changes in distance can be expected to exert substantial impacts upon R. Figure 5.5 depicts the effects of differences in distance between 0 and 25 miles when all other base case values are held constant. In order to maximize the information provided, the estimated rate of return is plotted against the resource temperature. In this manner, the interactive impacts of changes in distance and temperature become evident.

The distance over which geothermal fluid must be transported strongly invluences $R$ values for a given resource site. For example, at distance of 5, 15, and 25 miles, the rate of return falls from 12.75 to 10.0 to -0.25 percent at $120^{\circ} \mathrm{C}$. In the case of a user who is located on site (distance $=0$ ), an estimated 21.5 percent return would be earned. For space heating purposes, therefore, the distance between the resource and the user is of major importance in determining the financial return on investment in geothermal energy development.

The third geophysical parameter in which we are interested is the population of the district heating unit. Varlations in population will alter both revenues 


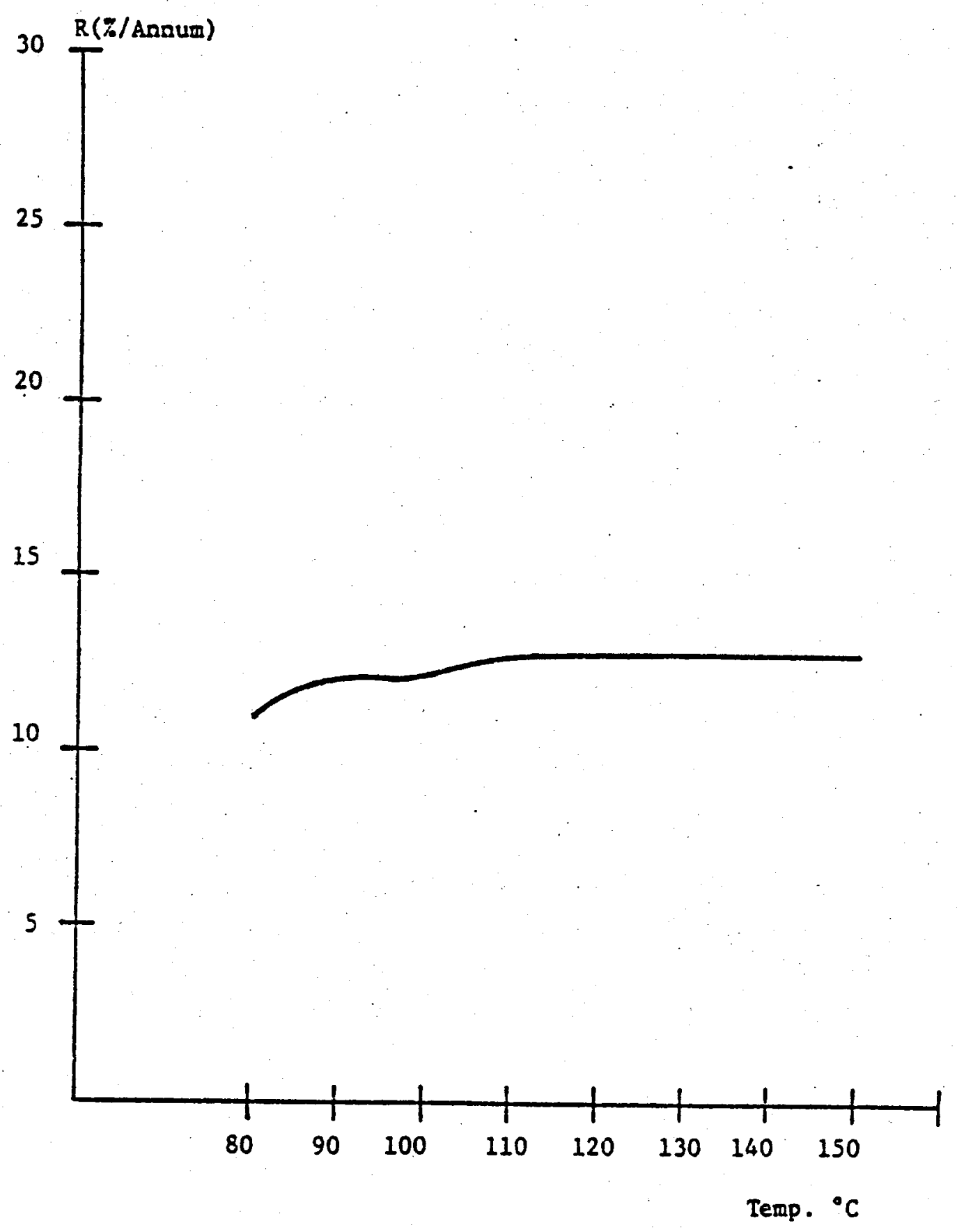

Figure 5.4. Sensitivity of $R$ to Changes in Temperature. 

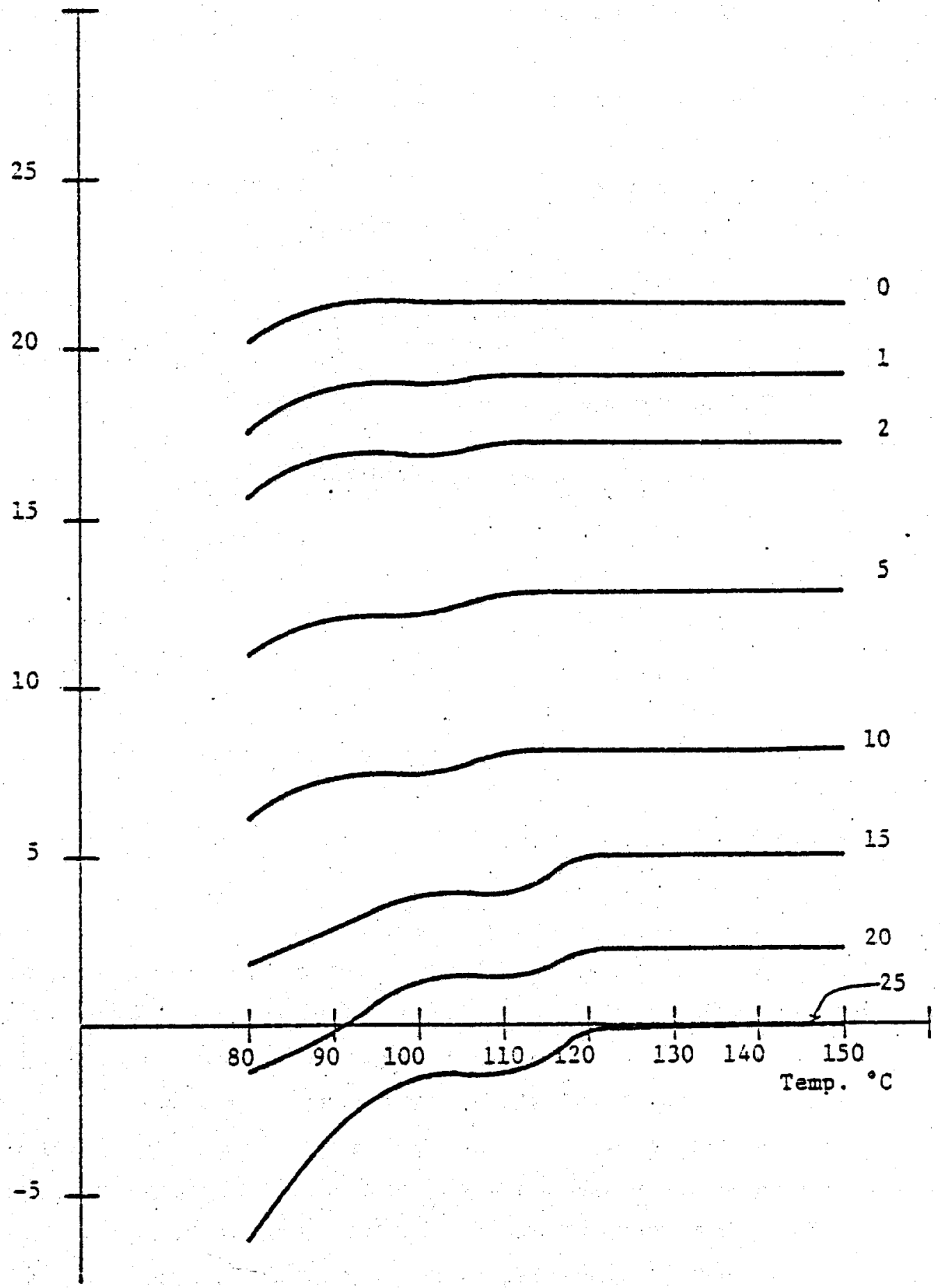

Figure 5.5. Sensitivity of $R$ to Changes in Distance (in miles) 
earned and investment costs sustained. To clarify the net impacts upon $R$, population sizes of $1000,2000,3000,4000,5000,10,000,15,000$, and 25,000 have been proposed. Figure 5.6 summarizes the results for various temperatures between $80^{\circ}$ and $150^{\circ} \mathrm{C}$.

The results are highly informative. Changes in the rate of return are directly related to changes in population at all temperatures. For example, at $120^{\circ} \mathrm{C}$, the return on investment rises from 1000 to 25,000 . These findings indicate that sizeable financial incentives exist for investment in space heating for relatively larger versus smaller communities.

The analysis above of the roles of the physical and geophysical resource characteristics in determining the return on investement in geothermal energy provided clear results: for anomalies with temperatures between $80^{\circ}$ and $150^{\circ} \mathrm{C}$, those which are closer to the largest populations offer the greatest financial incentive. Among the other factors in the model which are of concern are a class of parameters and variables which are, in some sense, policy tools. Some of these have been traditionally employed for stimulating natural resource development. Six policy tools are considered here. These include the royalty rate, the bond rate of the producer, the price of home heating fuels with which geothermal energy must compete, the depleting allowance, the investment tax credit rate, and the system load factor. The role of each of these in determining $R$ is considered below.

The influence of the royalty rate in determining $R$ is ascertained by altering its value from 0.10 to 0.20 . Figure 5.7 presents the results of these calculations Changes in royalty rates appear to exert quite modest impacts upon $R$. A reduction of royalty rates from 0.20 to 0.10 raises the rate of return from 12 percent to 13.75 percent. In and of itself, therefore, changes in the royalty rate do not appear to be of major importance in influencing the rate of return.

Consider next the results of alterations in the bond rate of the producer in revising the internal rate of return. Government loan guarantee programs are frequently considered as a means for insuring a supply of venture capital at a minimum cost. In this manner, reductions in interest charges from such programs reduce the cost of financlal capital, thereby ralsing the internal rate of return.

Figure 5.8 reveals that relatively large changes in the bond rate generate relatively. small absolute variations in the rate of return. For example, at $120^{\circ} \mathrm{C}$, reducing the bond rate from 8.5 percent to 6.5 percent raises the return 
$R(\% /$ Annum $)$

25

$\frac{1}{1}$

20
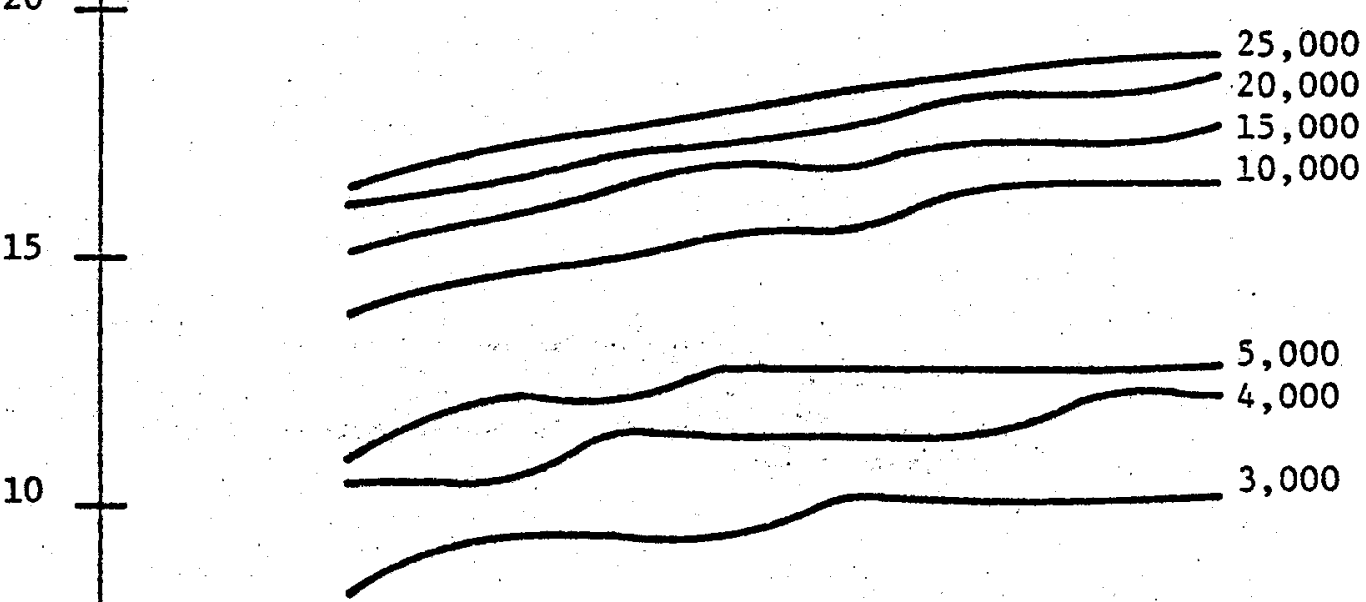

1

15

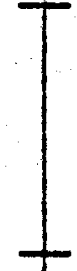

2,000

5

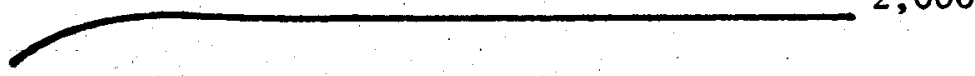

1

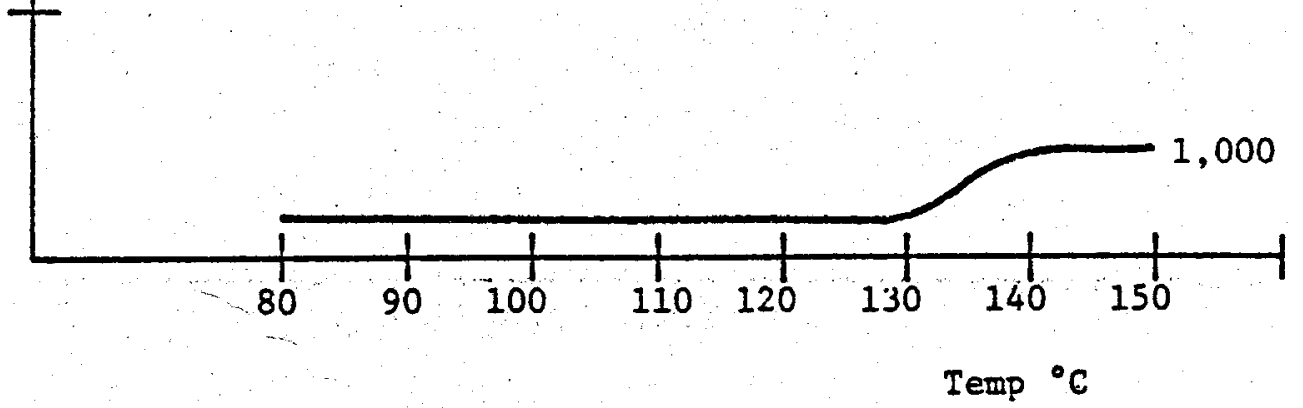

Figure 5.6. Sensitivity of $R$ to Changes in Population 


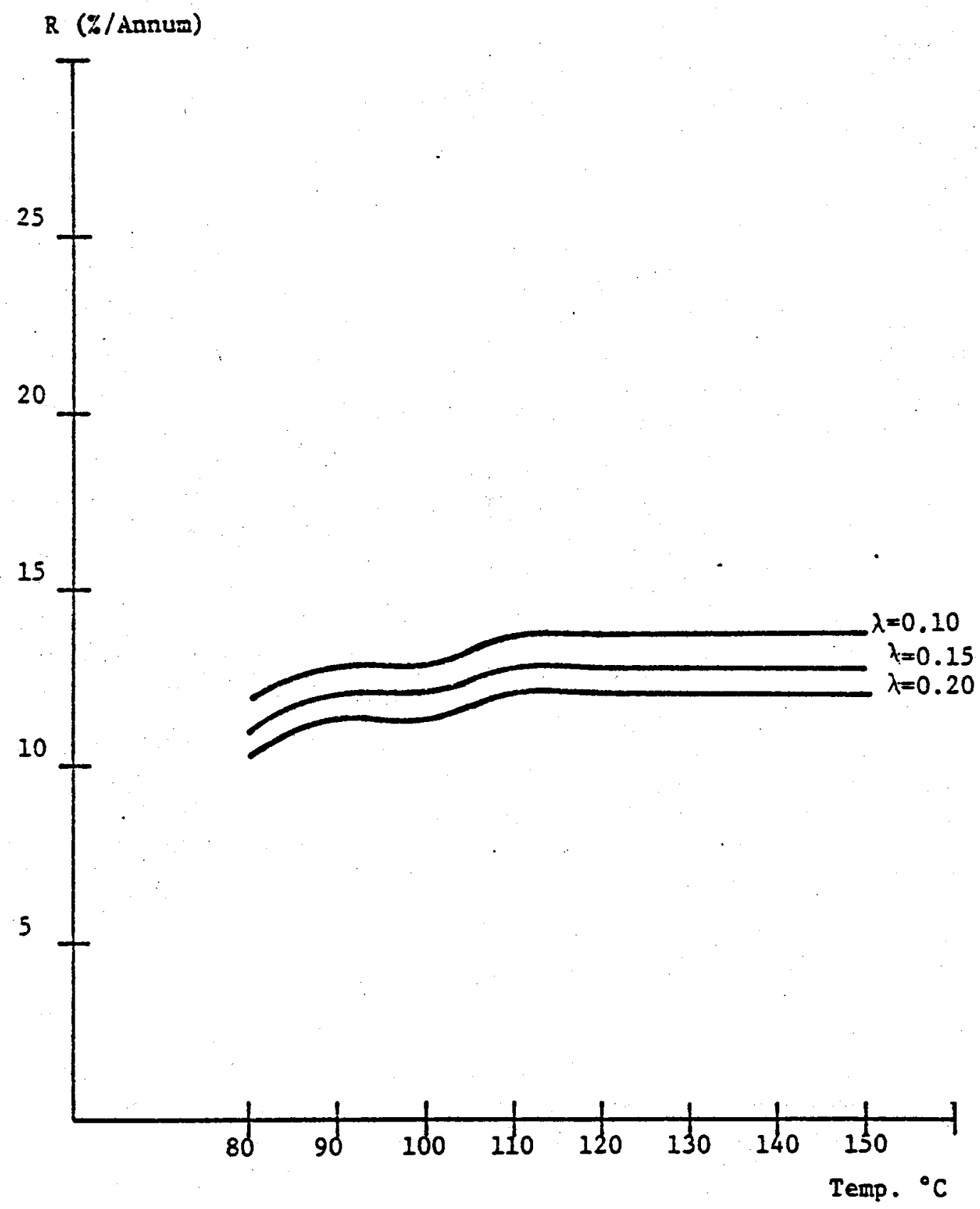

Figure 5.7. Sensitivity of $R$ to Changes in Royalty Rates 


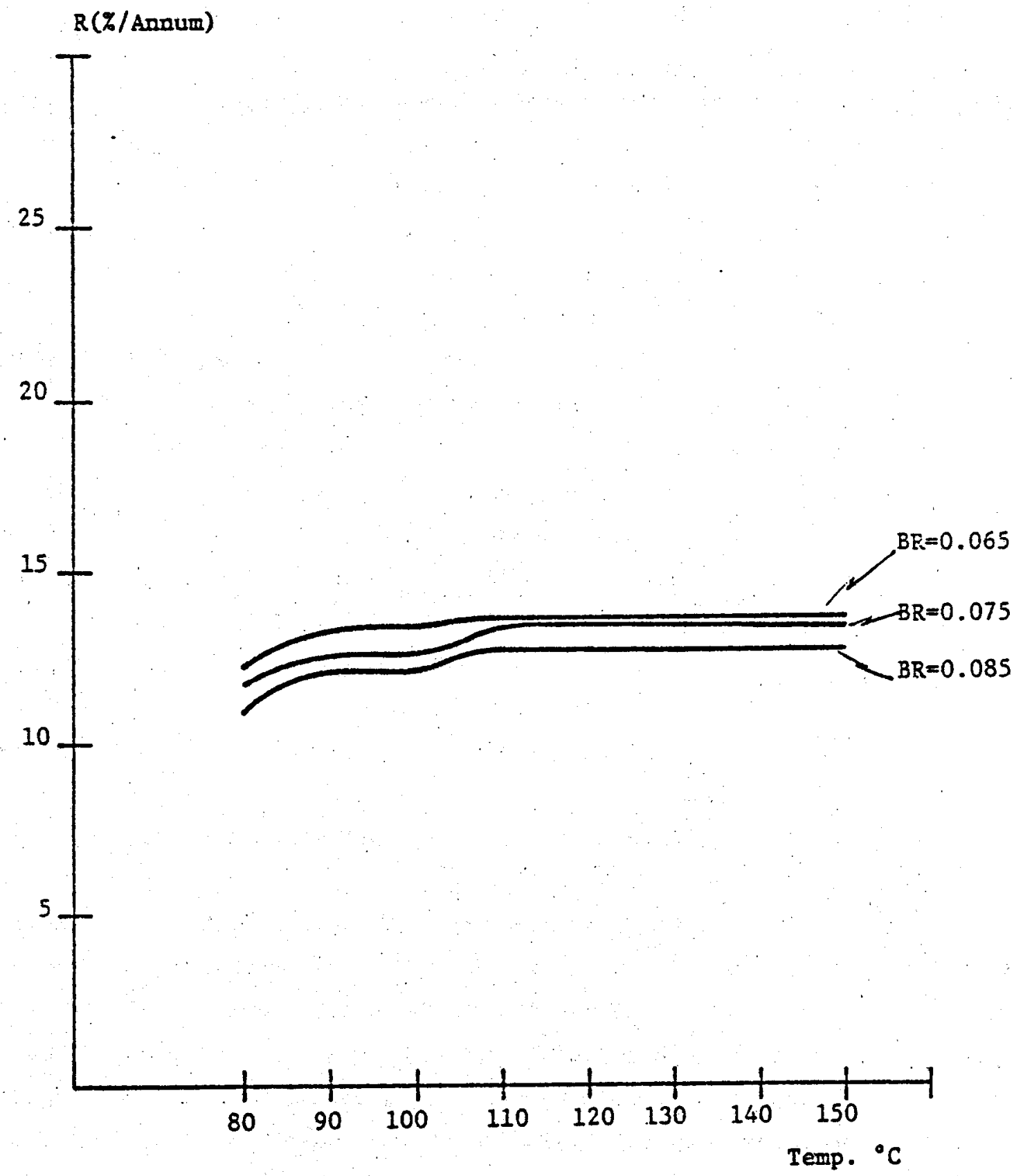

Figure 5.8. Sensitivity of $R$ to Changes in Bond Rate 
from 12.75 to 13.75 percent. Furthermore, the leverage which financial capital rates exert upon $R$ is limited at all temperatures between $80^{\circ}$ and $150^{\circ} \mathrm{C}$. clearly, reductions in the bond rate do enchance the attractiveness of geothermal investment, in the expected manner, but these effects are of relatively minor importance.

A third policy variable is the price of natural gas. This is the space heating fuel with which geothermal energy must compete throughout much of the Southwest. As natural gas prices rise, the potential revenue recoverable from geothermal energy will rise as well. Accordingly, dollar increments in gas prices from $\$ 3.00$ to $\$ 8.00 / 10^{6}$ BTU have been proposed.

Figure 5.9 reveals that increases in the price of competing fuel bear heavily upon the rate of return to geothermal investment. At $120^{\circ} \mathrm{C}$, an increase in natural gas prices from $\$ 3.00$ to $\$ 6.00$ raises the rate of return from 13 percent to 24.5 percent. On average, each one dollar rise in price generates an increase in $R$ of four percentage points. Deregulations of energy prices in the U.S. would clearly provide strong impetus to geothermal energy development.

The depletion allowance is yet another potential policy option which may influence the return to geothermal energy development. The depletion allowance was assumed zero in the base case, and its value was raised to 0.11 and 0.22 in the sensitivity analysis. The results, illustrated in Figure 5.10, are similar to those for the royalty and bond rates. Although the direction of the changes in $R$ are as expected, the magnitude of the absolute change is limited. Increasing the depletion rate from 0 to 0.22 raises the rate of return roughly 2.5 percentage points at all temperatures. By itself, therefore, the depletion allowance offers relatively limited policy potential as a means of improving the profitability of geothermal energy investment.

A final traditional policy variables which is considered is the investment tax credit rate. A range of investment tax rates has been specified between 0.04 and 0.20 . Figure 5.11 verifies that this is also a relatively insignificant factor in affecting the absolute value of $R$. Raising the tax credit rate from 0.04 to 0.20 only increases $R$ by 1.5 percentage points, from 12.25 to 13.75 percent. As in the case of the royalty rate, bond rate and depletion allowances, the tax credit alone is also of little consequence in determining the profitability of low temperature resources.

A parameter in the model which might be loosely consldered a policy option is the load factor. The load factor is a measure of the efficiency of utilization 


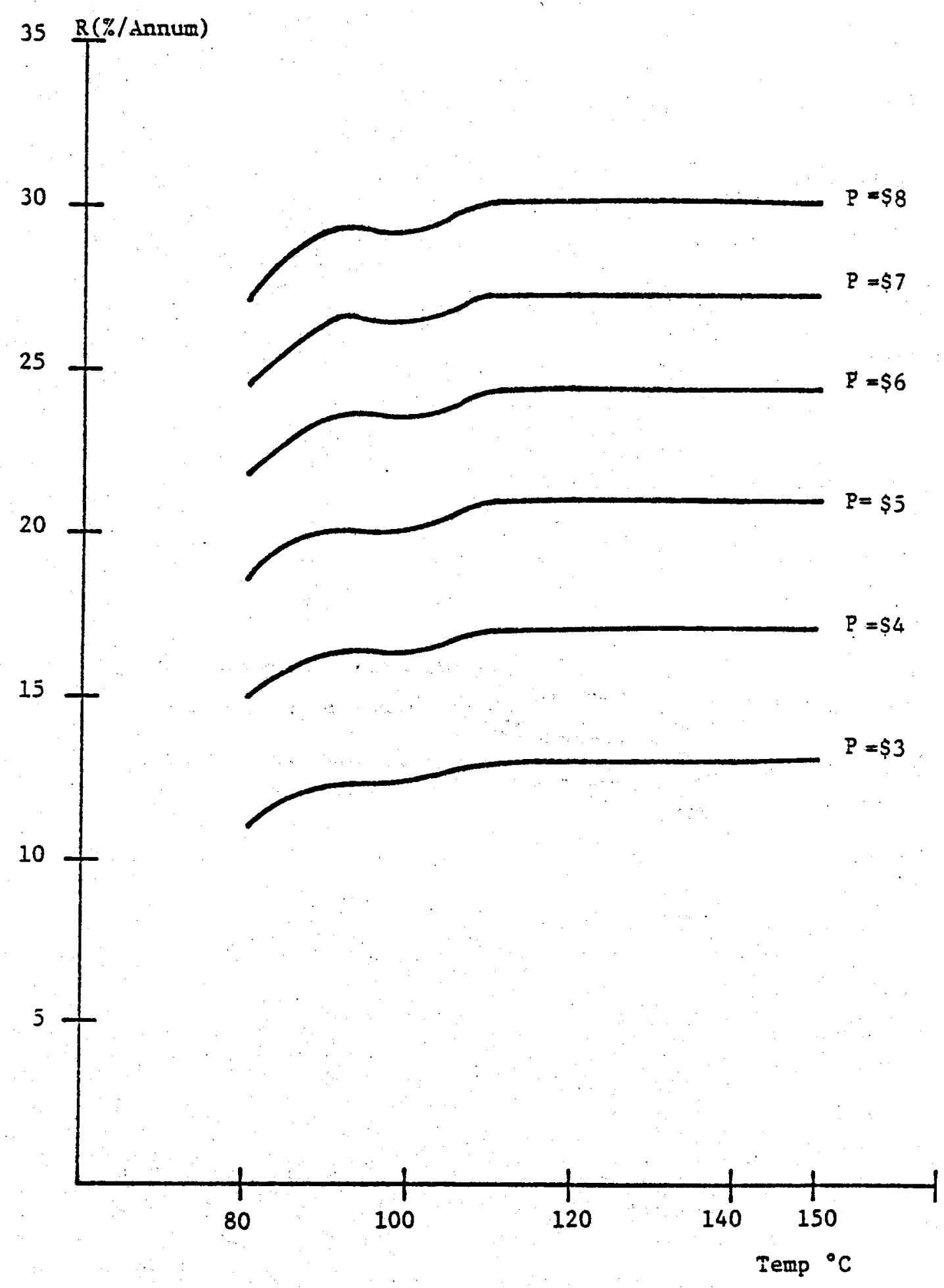

Figure 5.9. Sensitivity of $R$ to Changes in Energy Prices 


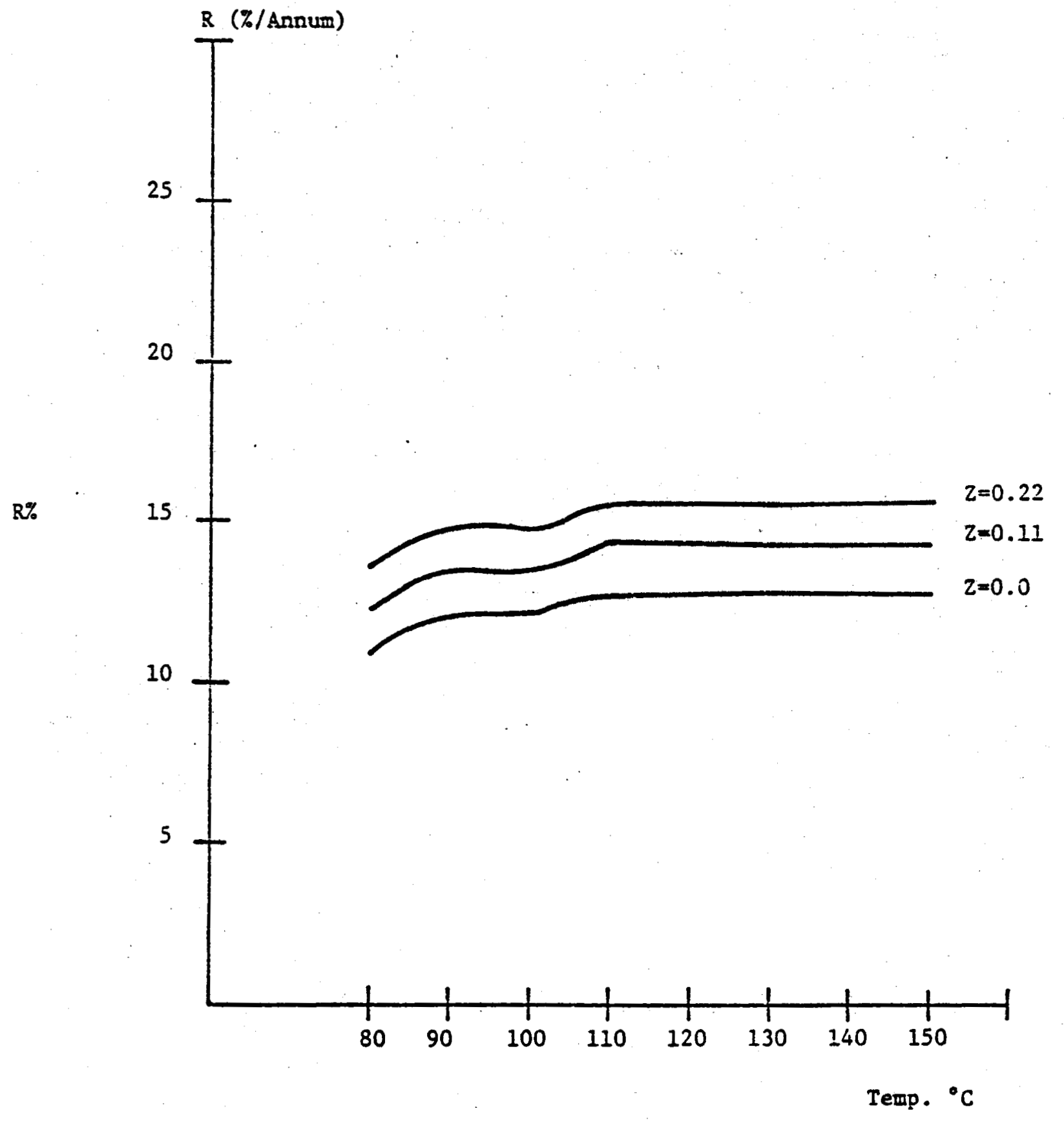

Figure 5.10. Sensitivity of $R$ to Changes in Depletion Allowances 

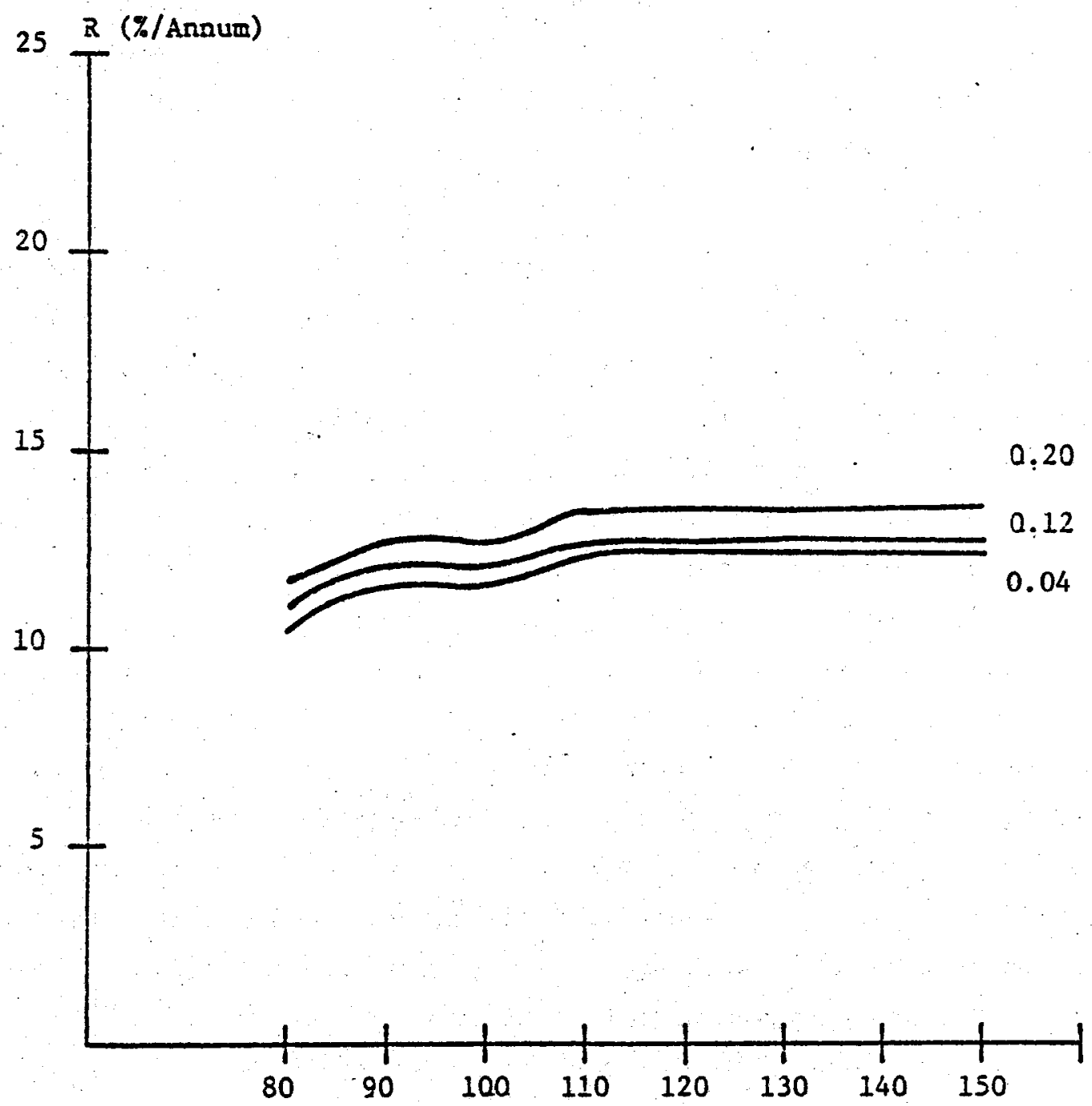

Temp. ${ }^{\circ} \mathrm{C}$

Figure 5.11. Sensitivity of $R$ to Changes in Investment Credits 
of the entire physical plant. For a space heating system of a given capacity, the greater or lesser the load factor, the greater or lesser will be the revenues earned; and the greater or lesser the revenues earned for a given investment outlay, the more or less profitable the investment will be. Although the load factor has not been a traditional policy tool, increases in system load factors are subject to policy manipulation.

Figure 5.12 illustrates the impacts of variations in the user load factor at $120^{\circ} \mathrm{C}$, the rate of return for load factors of $0.5,0.6,0.7$, and 0.8 are 10.5 percent, 12.75 percent, 15 percent, and 17.25 percent respectively. Thus, raising the load factor by 40 percent rates $R$ by roughly 70 percent, a highly favorable trade-off. Insofar as the load factor potential may vary from community to community, these findings suggest that the fullest appreciation should be granted the load factor.

\subsection{Scenario Forecasts}

In the sensitivity analysis above, the impacts of altering a single variable or parameter value were calculated. A more meaningful analysis could be provided if a number of properties of the base case scenario could be varied simultaneously. This exercise would provide valuable infomration on two counts. First, it would elucidate the interactive impacts upon $R$ of several variables or parameters; and second, if the complete set of policy factors are altered simultaneously, the results would infer the full potential of public policy in influencing the profitability of investment in geothermal energy.

Accordingly, Pessimistic and Optimistic forecasting scenarios were prepared. Each scenario consisted of a designated set of policy variable values, with all other values assuming their base case magnitudes. The Pessimistic scenario posited an energy market in which policy conditions are relatively hostile to geothermal energy development. In return the Optimistic scenario pictured an environment which is relatively receptive to geothermal development. The differences in the return on investment between each case provide a measure of the potential of public policy for influencing geothermal energy development.

The scenario values specified for the six policy varlables are presented in Table 5.5. The estimated internal rates of return between the scenarios differ darmatically at all temperatures as seen in Figure 5.13. In the Pessimistic setting, with circumstances generally hostile to development $R$ is 9.5 percent at $120^{\circ}$. At the same temperature in the Optimistic scenario, $R$ is a healthy 50 percent. Quite evidently, the combined efforts of all of the policy variables 


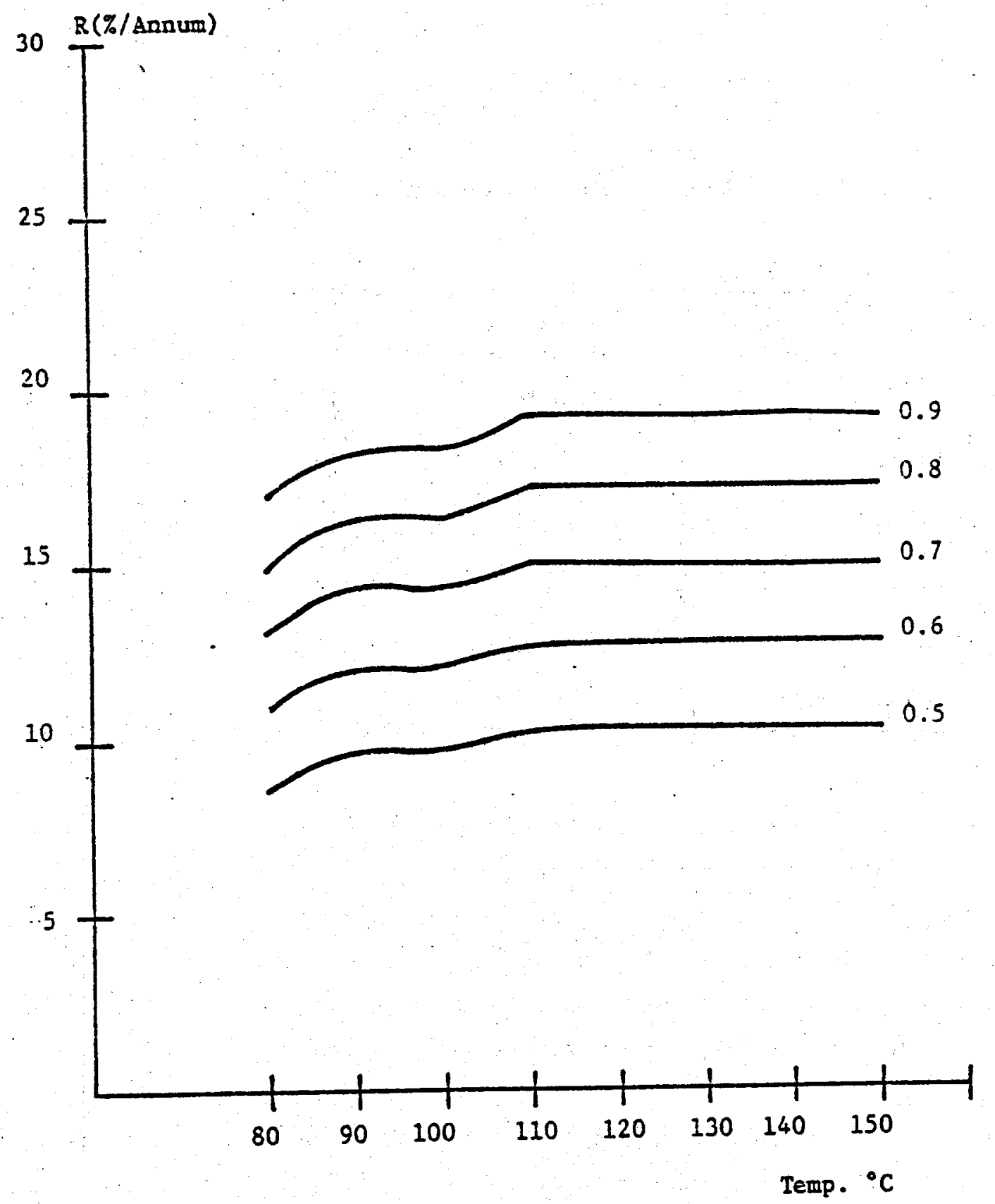

Figure 5.12. Sensitivity of $R$ to Changes in Load Factor 
TABLE 5.5

Optimistic and Pessimistic Scenarios

\begin{tabular}{|l|c|c|}
\hline Parameter or Variable & Pessimistic & Optimistic \\
\hline Load Factor & 0.5 & 0.9 \\
Price $\left(\$ / 10^{6}\right.$ BTU) & $\$ 3.00$ & $\$ 8.00$ \\
Royalty Rate & 0.2 & 0.1 \\
Tax Credit & 0.0 & 0.2 \\
Bond Rate & 0.085 & 0.065 \\
Depletion Allowance & 0.0 & 0.22 \\
\hline
\end{tabular}


a

C

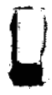

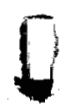

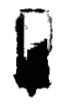

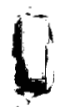

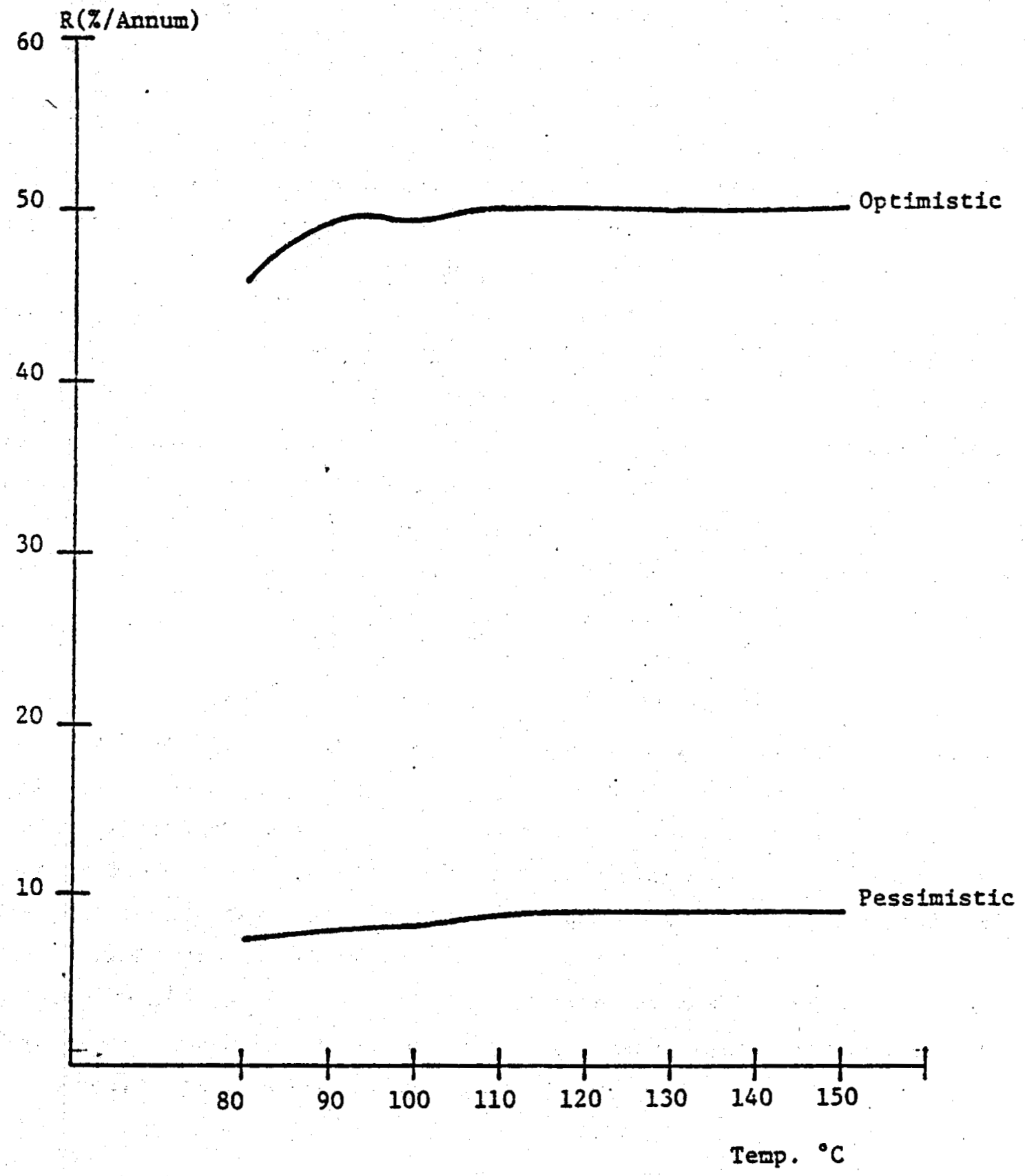

Figure 5.13. Estimated $\mathrm{R}$ for Optimistic and Pessimistic Scenarios 
considered in Table 5.5 are sufficient to generate a large range of possible return on investment. This finding suggests that a carefully orchestrated $\mathrm{mix}$ of policies is capable of inducing space heating applications of geothermal energy on a much broader basis than would otherwise occur.

\subsection{Summary of Simulation Results}

A simulation model has been developed which evaluates the financial feasibility of harnessing geothermal energy for district space heating. The output of the model consists of an estimated internal rate of return for any specific geothermal anomaly. This rate of return is the discount rate which equates present values of estimated net revenues earned with investment costs incurred throughout the investment life of a geothermal reservoir. Ceteris paribus, the greater the estimated internal rate of return, the more finanically attractive geothermal energy becomes for direct heating applications.

For a hypothetical geothermal anomaly, 1.e., a baseline reservoir, sensitivity analysis has revealed a number of important findings. First, the geophysical characteristics of low temperature resources, including the reservoir temperature, the distance to market, and the market size, collectively impose severe constraints upon the development of geothermal resources. Specifically, unless a space heating district of good size is located quite near to a relatively "hot" geothermal reservoir, the internal rate of return will be very low or even negative.

A second finding relates to the effectiveness of the traditional policy tools for enhancing the financial return to geothermal energy development. By and large, most of the policy options considered, including the royalty and investment tax crdit rates, the depletion allowance, and the cost of capital, are of 1imited individual effectiveness in raising the internal rate of returns. Increases in alternate fuel prices and geothermal plant load factors are the exceptions.

Several contrasting market scenarios were proposed, and the rates of return for each were estimated. The purpose of this exercise was to identify the range of possible returns given a most favorable and a least favorable set of circumstances. The results indicate that under such market extremes, effectively combined policy initiatives and efficient load factors may generate moderate improvements in rates of return.

5.6 Scenario Forecasts of Low Temperatures Geothermal Energy Potential in the Southwest

The modeling analysis presented above has provided experience factors for the expected profitability of a hypothetical low temperature geothermal resource 
which has been harnessed for district space heating. The findings (i) present a "ballpark" estimate of expected profitability under certain conditions; (ii), identify the release or retention of a number of factors as determining profitability; and (iii), evaluate the effectiveness of public policy in altering profitability. All of these finds are relevant, however, only for a hypothetical service.

The profitability of geothermal resources which are actually located in the Southwest may now be examined. Those resources which passed the technological screening (Table 5.3) are of greatest concern. Ceteris paribus, the most profitable among these will be developed first and the least profitable will be developed last; those resources which will not earn some minimum return will. not be developed at all. GIRORA-Nonelectric will differentiate the former from the latter.

For each of the technologically feasible sites, an internal rate of return will be estimated. The return will be unique to each site, calculated on the basis of its temperature, distance to market, and market population. The minimum acceptable return has been designated as 12 percent. This is the return frequently allowed non-profit, publicly regulated enterprises, and it is considered the minimum acceptable figure for a privately financed business.

The geothermal resources which are expected to earn in internal rate of return greater than or equal to 12 percent are presented in Table 5.6. The number is relatively sma11: of the 82 candidate sites, only 30 ( 36 percent) will earn at least 12 percent. Alternatively considering potential of the original 5602 only 2071 ( 37 percent) successfully pass the economic screening. Thus, only one-third of the geothermal sites (and one-third of the potential MBtuh) which survived the technological screening will generate a minimum acceptable return on investment.

On the basis of the technological and economic screening exercises, several geothermal supply scenarios may be proposed. The first of these depicts the gross energy potential (MBtuh) of the low temperature resources located in the Southwest. The second scenario presents the expected energy potential of the technologically usual resources, as defined earlier. The final scenario measures the energy potential of geothermal resources subject to the technological and economic screenings. Each of these scenarios provides an increasingly realistic appraisal of the true potential of low temperature geothermal energy in the Southwest. 
Table 5.6

Distribution by State of Low Temperature Geothermal Resources Which Pass Technolgical and Economic Screening

\begin{tabular}{|c|c|c|}
\hline State & Site & $\begin{array}{l}\text { Estimated Supply } \\
\text { Potential, MBtuh }\end{array}$ \\
\hline Arizona & $\begin{array}{l}\text { Gillard H.S. } \\
\text { Safford Area } \\
\text { Yuma } \\
\text { Littleton } \\
\text { Casa Grande (North) } \\
\text { Casa Grande (South) }\end{array}$ & $\begin{array}{r}24 \\
22 \\
116 \\
160 \\
18 \\
24\end{array}$ \\
\hline Colorado & $\begin{array}{l}\text { Idaho H.S. } \\
\text { Poncha H.S. } \\
\text { Don K Ranch } \\
\text { Pagosa Springs } \\
\text { Lemon } \\
\text { Rico } \\
\text { Pinkerton }\end{array}$ & $\begin{array}{r}50 \\
54 \\
30 \\
15 \\
18 \\
60 \\
7\end{array}$ \\
\hline Nevada & $\begin{array}{l}\text { Cherry Creek H.S. } \\
\text { E1ko H.S. } \\
\text { Walley Hot Springs }\end{array}$ & $\begin{array}{r}30 \\
40 \\
116\end{array}$ \\
\hline New Mexico & $\begin{array}{l}\text { Radium Springs } \\
\text { Montezuma H.S. } \\
\text { Las Alturas } \\
\text { T or C } \\
\text { Hot Well } \\
\text { Sandiego Mountains }\end{array}$ & $\begin{array}{r}25 \\
30 \\
129 \\
25 \\
40 \\
134\end{array}$ \\
\hline Utah & $\begin{array}{l}\text { Crystal H.S. } \\
\text { Wasatch H.S. } \\
\text { Ogden H.S. } \\
\text { Stinking Springs } \\
\text { Hooper H.S. } \\
\text { Utah H.S. } \\
\text { Becks H.S. } \\
\text { Crystal H.S. }\end{array}$ & $\begin{array}{r}147 \\
130 \\
117 \\
117 \\
110 \\
99 \\
92 \\
92\end{array}$ \\
\hline
\end{tabular}


The scenarios are illustrated in Figures 5.14 and 5.15. The former summarizes the MBtuh potential by state, and the latter identifies the resources which pass both screenings. The summary table, Table 5.7 , conveys a sobering impression. On1y 6 percent of the regional low temperatures sites, providing 6 percent of the MBtuh in the Southwest, survive both screening processes. 


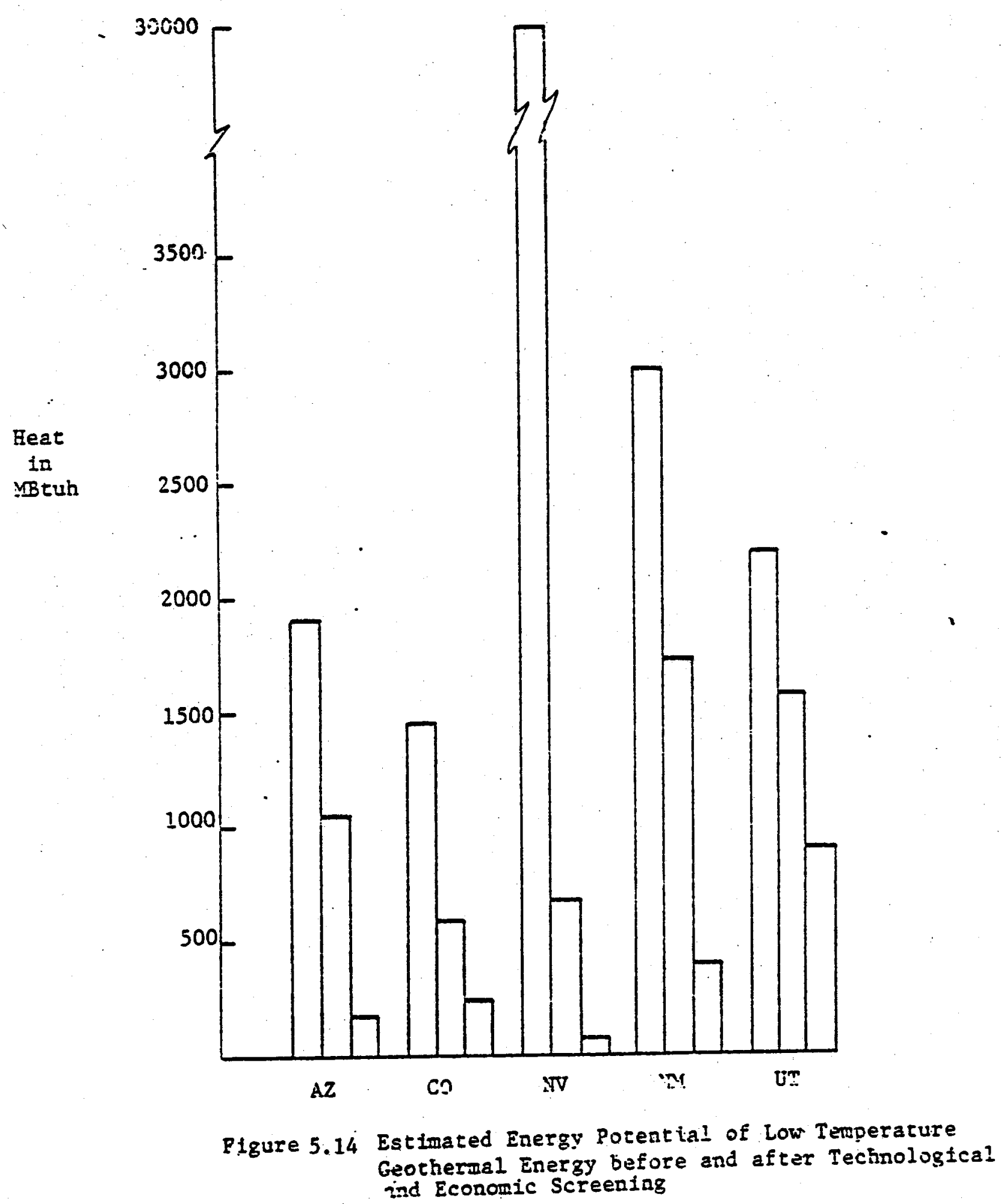




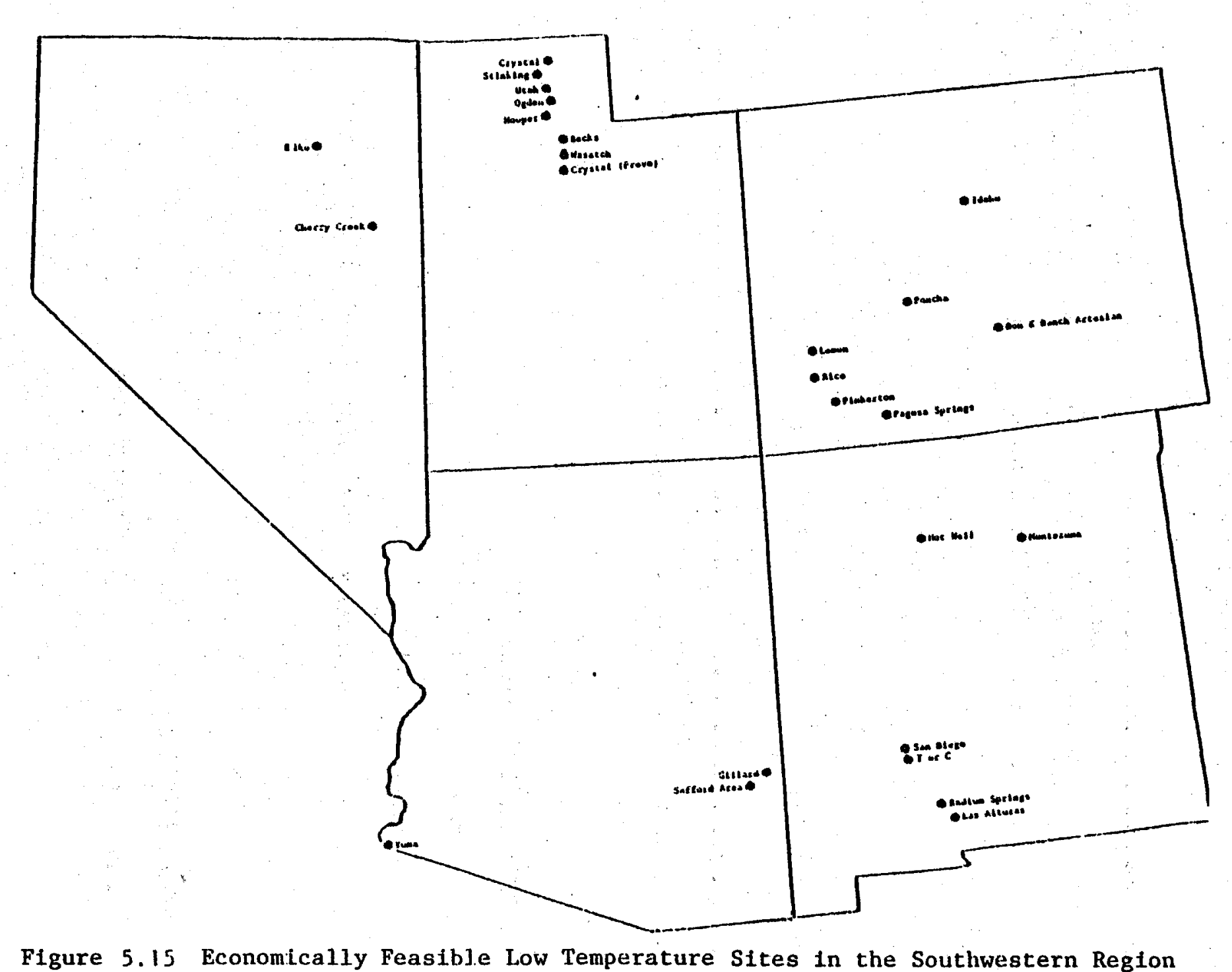


Table 5.7

Sumary Table of Technological and Economic Fessibility of Low Temperature Geothermal Resources in the Southwest

\begin{tabular}{|l|c|c|c|c|c|c|}
\hline \multirow{2}{*}{ State } & \multicolumn{2}{|c|}{ Total } & \multicolumn{2}{c|}{$\begin{array}{l}\text { Technological } \\
\text { Feasibility }\end{array}$} & \multicolumn{2}{c|}{$\begin{array}{l}\text { Econowic } \\
\text { Feasibility }\end{array}$} \\
\cline { 2 - 7 } & $\begin{array}{l}\text { No. of } \\
\text { Sites }\end{array}$ & $\begin{array}{l}\text { Avallable } \\
\text { Eear MBtuh }\end{array}$ & $\begin{array}{l}\text { No. of } \\
\text { Sites }\end{array}$ & $\begin{array}{l}\text { Eeat } \\
\text { MBtuh }\end{array}$ & $\begin{array}{l}\text { So. of } \\
\text { Sites }\end{array}$ & $\begin{array}{l}\text { Heat } \\
\text { MBtuh }\end{array}$ \\
\hline Arizona & 40 & 1892 & 12 & 1045 & 6 & 364 \\
Colorado & 45 & 1460 & 24 & 588 & 7 & 234 \\
Nevada & 328 & 30423 & 14 & 672 & 3 & 186 \\
New Mexico & 46 & 2969 & 19 & 1724 & 6 & 383 \\
Utah & 45 & 2201 & 13 & 1573 & 8 & 904 \\
\hline Total & 504 & 38945 & 88 & 5602 & 30 & 2071 \\
\hline
\end{tabular}

Technological Feasibility:

Temperature: $65^{\circ} \mathrm{C} \leq \mathrm{I} \quad<150^{\circ} \mathrm{C}$

Population: . 1000

Distance: 50 miles for single population center

Economic Feastbility:

Rate of Return $\geq 12 \%$ from GIRORA 


\section{CHAPTER VI}

\section{DATA BASE AND REGIONAL PROGRAM PROGRESS MONITOR}

The computing support described here has been provided by the Regional Program Progress Monftor (RPPM) Group of the Physical Science Laboratory (PSL) of New Mexico State University (NMSU). This support falls into two categories. The first includes the work connected with design, development, implementation, and validation of the geothermal data base, which is the first phase in achieving the goal of a computerized Regional Program Progress Monitor for the project. The second category encompasses the computing required for various economic and scientific investigations conducted by the Core Team.

Soon after the project was started, the state teams were requested to gather information about their resources and send it to the Core Team. To ald in recording the data, a Resource Area Data Sheet (Figure 6.1) and a Drilling Data Sheet (Figure 6.2) were distributed to the state teams. While data were being gathered by the state teams, the core team was considering the question of data storage. It was decided that geothermal data which would be used regularly in calculations and reports should be put in computer storage. The remaining data would be kept on file until the demand for it increased to a point that would justify electronic storage. By mid-1977 interactive (conversational) terminals, such as the IBM 2741, were avallable in some work areas at NMSU. These allowed quick computer response in jobs which could be processed using the APL computer language. Consequently, this particular language was adopted as standard for use on short geothermal data processing jobs.

\subsection{Market Area Determination}

In November and December 197.7, the accomplishment of market studies required that the number of people living within $50 \mathrm{miles}$ of certain geothermal sites be determined. A computer file was created which contained population center information consisting of city name, county, state, population, latitude, and longitude. Most of the data were obtained from U. S. Census reports; some position information was obtained from atlases. Distance were calculated using the APL functions shown in Appendix 3 of this report.

Thus, the approximate number of people living within a specified distance of a site could be calculated. Repeated studies were made using various dis: tances. The recurring demand for such information established the need to keep the "city and population" tables in computer storage. 
SOUTHWEST REGIONAL

GEOTHERMAL O/R PROJECT

\section{RESOURCE AREA DATA SHEET}

Common Name:

County

tocation

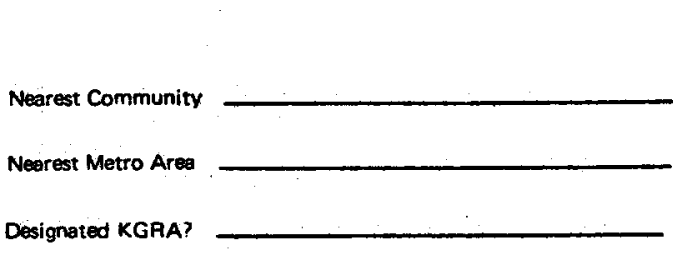

Leasing Status:

Location

Surface

Ownership

Lessor:
Population

Population

by (Agency)
Project 1.D. No.

State

Township/Section

Lot./Long

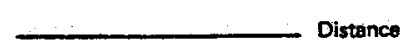

Distance

Date
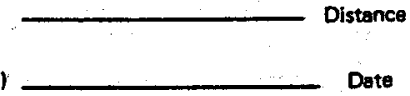
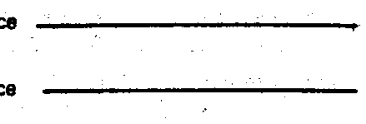

Lesseo:

\section{Information Source}

Person Compiling

Agency

Information Source:

Reliability Assessment:

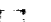

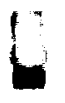<smiles></smiles> 
Drilling Data Sheet No.'s:

\section{Environmental Aspects:}

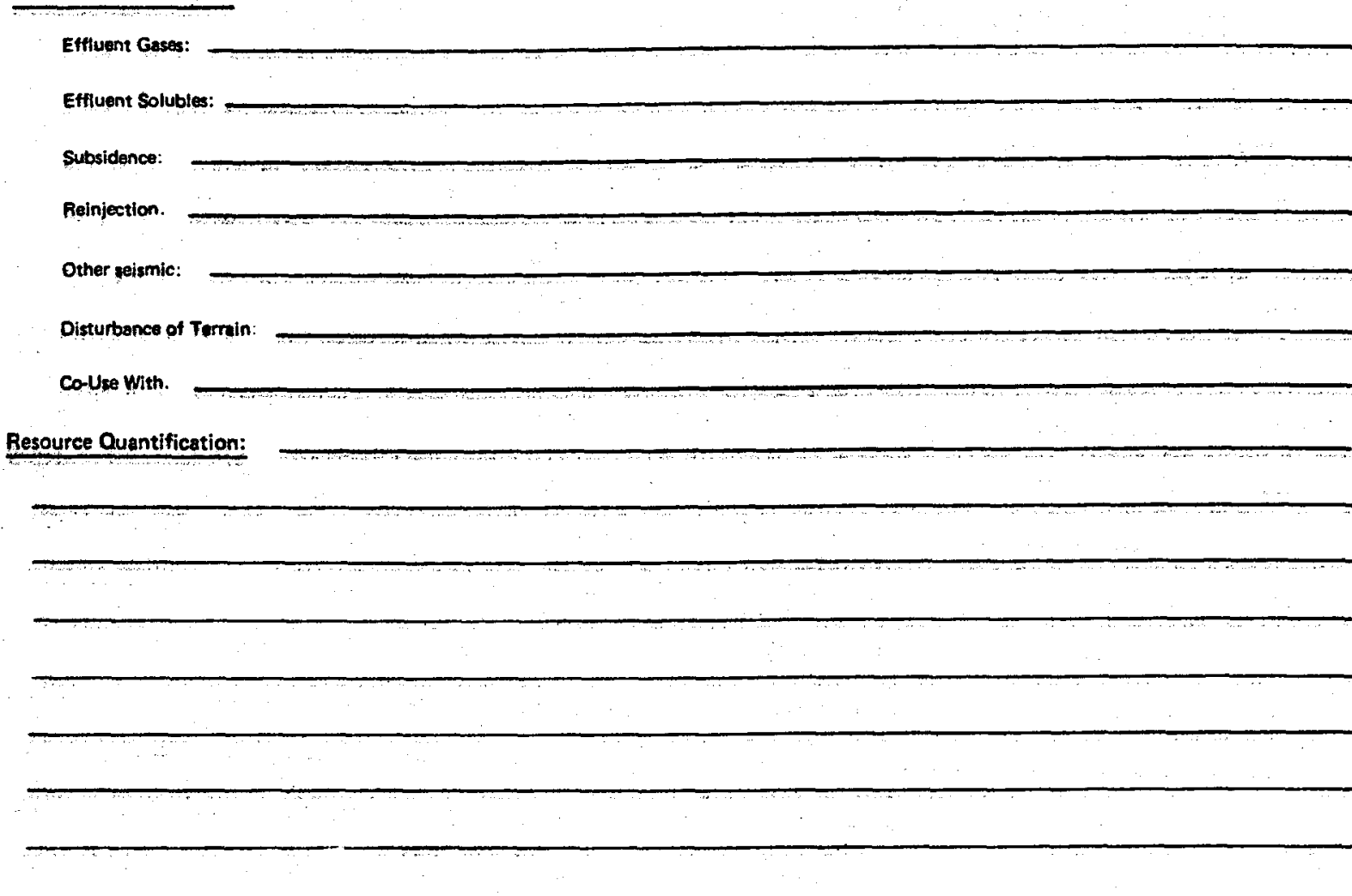

\section{Probable Available Energy:}

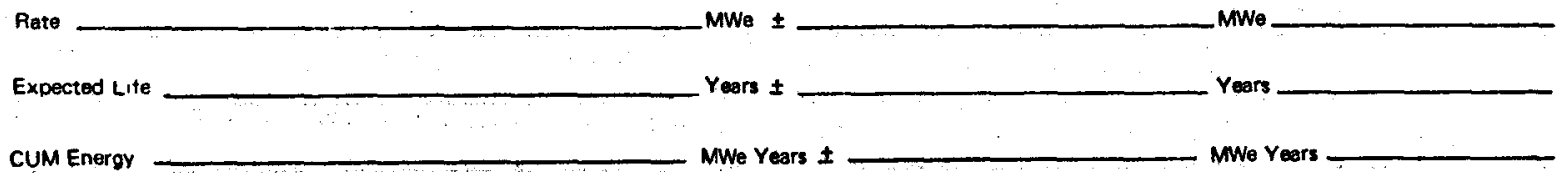

\section{Distance to:}

Nearest Power Transmission Line

Nearest Use Point:

Development Status/Schedule:

Figure 6.1 Resource Area Data Sheet (Continued) 
SOUTHWEST REGIONAL

GEOTHERMAL O/R PROJECT

DRILLING DATA SHEET

Well Name/No.

\section{Plesource Area Name/No.}

Location

County

Operato

Drilling: Dism,
Classification:

Open
Project 1.D. No.

State

deep, through downhole conditions of

Finds:

Energy Quality: Temp

$\pm$

Flow Rate

$\pm$

Pressure

$\pm$

By Test

By Calc

Estimatod Lifetime:

Effluent Quality:

Gases (Composition, 4 )

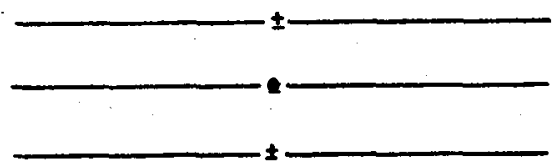

$100 ; / 8 k w$

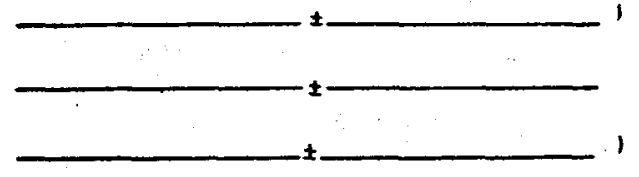

Solubles Suapended Sollids IComponition or PPM .\%1:

$(\mathrm{ko} / \mathrm{kw})$

Figure 6.2 Drilling Data Sheet 
Status: Drilling in Progress $\square$

Producible $\square$ in production (Date)

Completed

From (Source)

Suspended (Date)

Drilling Contractor/address

Cost of drilling:

Adjacent Drilling:

Name/No.

Project I. D. No.

Notes:

\section{Information Source}

Person Compiling

Information Source:

Reliability Assessment

Figure 6.2 Drilling Data Sheet (Continued) 


\subsection{Data Base Design}

Also in November and December a tentative format for geothermal site information was adopted and data were entered as APL files into computer storage through the terminals. The format included basic site information such as name, location, reservoir volume, and temperature. Using APL commands and functions it was easy to manipulate the data and make useful calculations. Current demand was the primary factor in determining what should go into the data base. In January, estimates of recoverable energy were calculated for each hydrothermal site and results, which indicated sites with good potential for development, were sent to state teams to help them in writing site scenarios. This job utilized practically all of the data in the geothermal site file. The equations for calculation of stored heat, electric potential, and thermal potential (recoverable energy) were obtained from the U. S. Geological Survey Circular 726. The formatting of the report was done with APL and typing took place at the terminal under computer control.

The geothermal data base is relatively small. The SITE relation, which contains all of the geothermal site information, consisted of approximately 250 geothermal sites and about a dozen domains (data fields) for each site in January. In March at the quarterly meeting in Reno, Nevada, an explanation of of the data base structure was made to the state teams and consultants, and samples of the data base were displayed. Later in March new data provided by the state teams were entered in the data base. Then the entire geothermal site portion of the data base was arranged into tables, reproduced, and copies were sent to state teams and Core Team investigators for comments and verification. As a consequence, the state teams sent in additional data which enabled correction of the entries already in the data base.

A complete description of the entire data base was begun in April, continued into May and was published as a 62 page volume called the RPPM Data base. This report lists all of the data in the three divisions of the data base. The report also explains how information may be retrieved from the data base using a terminal connected to the New Mexico State University computer. The report was distributed to the state and core teams during the fourth quarterly meeting of the project in Las Cruces, NM, on May 31 and June 1, 1978. A copy of the report is included as Appendix 3 in this report.

\subsection{The Data Base Management System}

In 1977 a data base management system called Educational Data Base System (EDBS) was obtained by the NMSU Computing Center from the University of Toronto. 
EDBS used the APL language and files so it appeared to be well suited for geothermal data base management. However, EDBS proved to be too slow in retrieving information from the data base. It was not possible at that time to determine whether the computer system or EDBS was responsible for the delays. The use of EDBS for the geothermal data base was postponed. Instead, some APL functions such as 'GET', which is described in Appendix 3, were used for retrieval and update purposes.

\subsection{Leasing and Drilling Information}

Since leasing and drilling information is of great importance in estimating future sites development, it should be incorporated into the data base. To put all such data into a data base would require a substantial amount of manpower, which would be justified only if the data were used frequently in development scenarios. Detailed leasing data has not been needed thus far by project analysts and as a consequence it has not yet been entered into computer storage. Alternate designs for including lease data are now being considered. One approach is to create a new relation, based on townships, giving detailed information about leases near each geothermal site. Similar methods are being considered for drilling data.

\subsection{Data Base Functions}

Many API functions have been developed especially for the geothermal project. The following pages in this chapter contain listings of these functions together with explanations of how they work, their input and output, and their limitations. More information about the functions can be obtained from the Core Team. 
Group Name: UIIIITIGROUP

tis Name: 310733401 2תت3

Group Description: These fuactions are designed to ass13t in many applic3:102s. They are of two t7pes, those tritran axpressiy for the pro$j$ act and those found in edte packages in public workspacas is the occ (indicated by as asterisk).

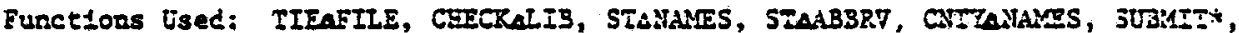
STATLS*, JOE*, AI, DUMP, SESHAPE, RATEI, DATE, SORT.

Variables Used: EIIAPRT

\section{Function Nase: TIEAFILE}

Glcba? Vartables Esed: cone

Global Vartables Created: none

Local Vartables: In (input as described below)

IN (output as dascribed below)

Input: A right argument, IN, containing the library number and name of itIs to be 21 ed. This argument (a vector) uust resemble a sow in the expicit resule of system iunction DFLIB, le:

$\begin{array}{ll}\text { colum } & \text { lescription } \\ 1 & \text { biank } \\ 2-10 & \text { library number } \\ 12 & \text { blank } \\ 12-22 & \text { Etie name }\end{array}$

Outpur: An explfcit restle, IN, a scalar. I ts 3 O lf the itia couid sot ba tiad; if the ille was tied, $Z$ is the tis number.

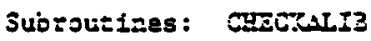

Calling Routines: TiRKET

Function tiare: GiECKar

Global Vartablas Ised: cone

Global Varzabies Creared: acne 
Local Variables: Fi (input as described below)
\[ \text { (output as described below) } \]

Input: See Input descriotion for function TIEAFIiE in this group.

Output: th explfcte result, $x$, a scalar. $X$ is a -1 if the file doesn't exist. $X$ Is a 0 if the EIIe exist3, but is not tied. X Is the fila tie number if the file is tied.

Subroutlaes: cone

Ca11:2g Routines: TIEAFILE

Spectal Codins:

iise

sodinz commencs

2

If file exists, $X$ will be 0 ; otherwse, $X$ will be -1 .

4

$X$ is assigned the fila tie number.

5

If illa was not tied, $X$ will be an empty vector or a zesult of line 4 .

6 File noc tied, so reassign $X$ to oe 0.

Funceton Name: STANAMES

Globa1 Variables toed: Codes

Global Vartables Creasad: 2

Local Jarlables: cone

Input: A matrix of rumiters; for one state aame it could be used as Eollows:

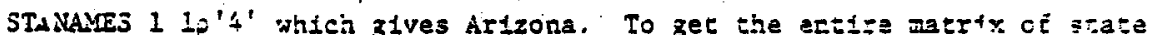

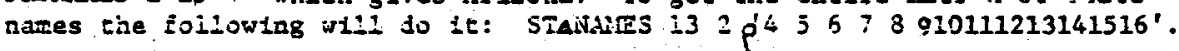

Output: Ni1l be one or howdver many the first dinension of the atrix is.

Subrout1aes Used: noae.

Special Cod12g; none.

\section{Furceton Vame: SƯMIT*}

Isput: A right argliment, $x$, a vector contalalig card irages (tioy neeiz' = be 80 characters) separated by carriage returns, racresenting a job deck.

Output: ds explicit result, $R$, concalalng the neme of the job subni=sed. 
Global Variables ised: CODES

Glooal varlables Creaced: 2

Local Variables: none

Inpue: A matrix of numbers. For Naw Yexico the function could ie isec as follows: 5TABBRV 1 le ' 7 '. To get the entire ratrix of stace abbravlations: STA ABBRV $132 e^{\prime} 45$ ' 7 B 910111213141516'.

Outfut: itll be ore or however many the first dimension of the aatrix is. Subroutices Used: noce

Special Coding: aone 
Group Name: MARKETGRCUP

WS Vame: 310733401 PJIB

Group Descriftion: For user docuwentatisa, zefer to the vartabla yiprargon in this group. The user routines are MARKET and MARKETSTAIUS. The group can be divided into swo subsets: those routines written specifically for the $0 / R$ profect effort and those routines avallable from varlous editing packages (notab1y, 501 SESDIT) 10 pubitic workspaces at the UCC (Ihese are noted below with an asterisk).

Furcelons Used: MARKET IIBAFIIE CHECKALIB STAABBRV CNTYANAMES SUBMIT* MARKETSTATUS STIIUS* JOE*.

Varlables tsed: MARRETHOW, SMTMSG MKTDMP

\section{FUNCTION NAME: MARKET}

Input: Rerer to user documentativn variable, MARKETHOW, in this group.

Output: Elther a sumary of output directed to terminal or a detail oi output directed to the line printer at VCC. This detafl is dimped throuzh an API file called 'MKTOUT' wiscin must consaln approxinately 100,000 by:es or unused file space.

Subroutines: TIEAFILE, CHECZALIB, STAABBRV, CNTYANAMES, SUBMIT, STATUS.

Calling routines: none.

Special Coding:

Iine

9

13

15

$13-19$

20

25

$26-27$ coding comments

If user doesn't request a detall dump, the next few operations are unnecessary.

If the MKrouT ifle is not empty, request fintructicns.

If the user requests the file so be srased, fall through and drog all components.

If the user requests the 11 a be left as is, changs OMP condition to false and PRISTM to trie.

Reserve a component for the fob sumary.

S1nce we have 2 tamp domains EIEMP and VIDND, we must combine them lato $i$.

Elfminata frow input those sites and temps which don't meec input criteria. 
Iine

29

$30-36$

$37-38$

39

$40-50$

47

51

32-6j

60

$\dot{j} \boldsymbol{i}-\mathbf{j} \tilde{0}$

70

71-74

75

$79-50$

$31-93$

94

$55-97$

98

99

100

$10:$

102 coding coments

If no slies restite sklp processing.

formac sumary

Reac approprtate sise iacitude and iongitude.

Construct a rectangular boundary arourd the sics.

Construet a flle of citfes within this rectangular boundary.

If no citles found within boundaries in the state, don'te tery and change pop. to numerte forrs.

If no cities are found withti this rectangular boundary, skip ahead.

Interuediace rasulis of the calculations to determine the straight ine distance between the sibe and each cicy within the rectangular boundary.

MI Is that distance rounded to the nearest gile.

Elfintrate thosa cities not within the spectifad radius.

If no cities within radius, skip ahead.

format sumary

If nc dump requested, gkIp ahezd.

If there is more than one county name in CST, skip ahead; else, reshape a single name into a ratrix.

Eornat detail

sppend format detail.

Conpress the last processed site and 1ts temp Exom the Input.

IE sltes ranata, go back; else,

If no cimp reg̣lestad. skip ahead.

seplace reserved comporent with sumsary.

Subalt the pregran to dump the detasl output.

Append fob number of dump cato end of ilie. 
Ine

103

104 coding coments

Caleck dump job status.

If no sumary, skip anead.

\section{Function Vame: MARXISTATSS}

Global Variables Used: JOB (contains job nama)

Global Vartables Created: none.

Local Variables: I (Ele number of outpur itle)

Function Descrfption: This function is used to report the curreat status of the fob which prints the detail output at the ICC.

Input: No arguments:

Output: A statis message.

Subroutines: IIEFIE, SaITS

Calling Routines: nene

Special Coding:

1ine

coding cominenes

Assign JOB the joo ame as praviously stored in output file.

4

Caeck siatus.

3

Tnte file. 
Group Name: MARKETGROUP and UTILITYGROLP

\section{Eunction Name: CarckallB}

Refer to documentation to UTIITYGROLP.

\section{Funct10n Name: TIEAFIIE}

Refer to documentation in UTIIITYGROUP.

\section{Function Name: STAABBRV}

Refer to documentation in UTIIITGGROUP.

\section{Eunction Name: CNTYOVAMES}

Refer to documentation in UTIIITYGROUP.

Xot3: Although th1s routine actualiy does nothing once colnty cudes are substituted for zames in the file XCIFI ( $I$ II ever), the program needa'c be rewrictan; simply godify this routine to make the conversion Exom code to name.

Function Vame: SUBMTT

Reier to documentation in UTILITIGROU.

Function Name: STATUS

Refer to docimentation in TIIIITYGotr.

Eunc:ion iame: JOB

Refer to documentation in CIIIITYGROCP. 
D CITYS STN

[1]. OPEN 'CTTYY a $*(E T R R O R=1) / L O$

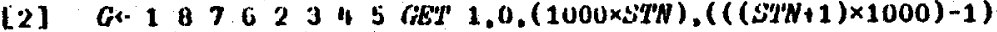

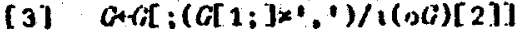

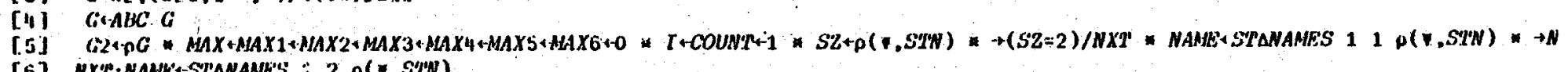

[6] BXP:NAMHESSTANAME'S : 2 p $(Y, S I N)$

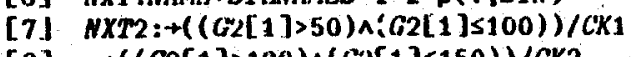

[8] $\rightarrow((G 2[1]>100) \wedge(C 2[1] \leq 150)) / C K 2$

[9] $\rightarrow((G 2[1]>150) \wedge(G 2[1]>200)) / C \times 3$

$[10]+((G 2[1]>200) \wedge(G 2[1] \leq 250)) / C K_{4}$

$[11]+\left((G 2[1]>250) \wedge\left(\left(i_{2}[1] \leq 300\right)\right) / C K 5\right.$

[12] MAX+G21 1]

[13] $\Delta L 1: 21+1 \%$ p ( (30p! 1$)$.NAME, $(10 p ! \cdot))$

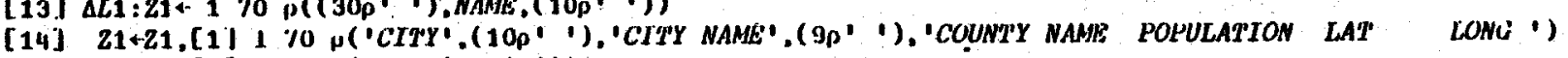

[15] Z1-Z1,[1] $\left.1 \% \rho(1 /)^{\prime},(68 \rho+1)\right)$

[16] CONT:A1+ $15 \rho G[; 15] * A 2+124 \rho G[I ; 5+124] * A 3+112 \rho G[I ; 29+112] * A 4+16 \rho C[I ; 11+16] * A 5+12 p(i[T ; 4849.1$

[17] $A 6+12$ oG $I ; 5051] \times A 7+13 \rho G[T ; 51+13] * A 0+12 \rho G[I ; 5556] \times A R R A Y+A 1, A 2, A 3, A 4, A 5, A G, A 7, A B$

[10] $B Y T T_{1}-15 A 1, X 1,24 A 1, Y 2,12 A 1, X 1, E A 1, X 5,2 A 1, X 1,2 A 1, X 3,3 A 1, X 1,2 A 1$ !

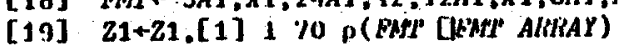

$[20] \quad I+I+1$

[21] $\rightarrow(I \leq M A X) /(C W I$

[22] $21+21.11] 2700^{\circ}$,

[23] ]

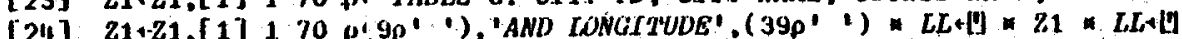

[211] $21+21.110 \times+(M A X 5=0) / C 3 *+(M A X 6=0) / C 4 \times+C 5$

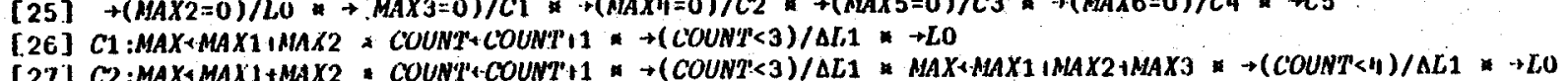

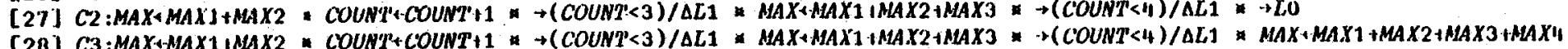

$[29] \rightarrow($ COUNP $<5) / \triangle L 1 *+L O$

[30]

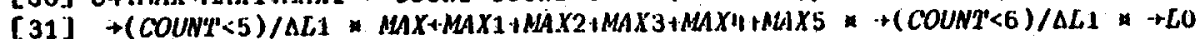




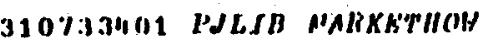

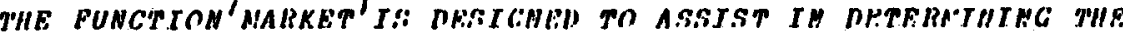

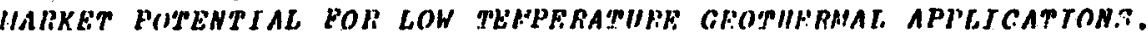

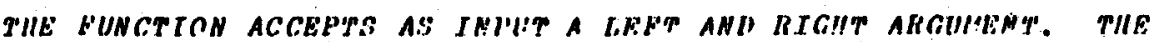

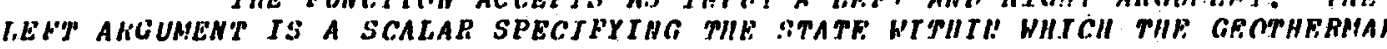
SITE:S ARE LOCATEl). ONLY TIE POLLOHING VALUES ARN VALTI.

$\begin{array}{ll}11 & \text { ARIRONA } \\ 5 & \text { COI.NRADO } \\ 6 & \text { NRYADA } \\ 7 & \text { MEII HEXICO } \\ 8 & \text { UTAII }\end{array}$

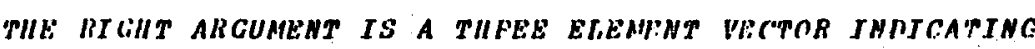

\begin{abstract}
1 RADIU: OF HALKFT AREA IN MITIES

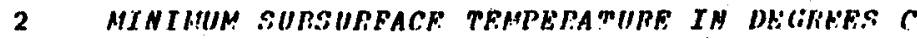

3 MITIAIUM POPIITATION.
\end{abstract}

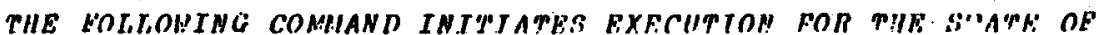

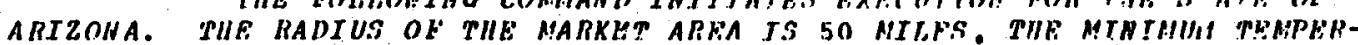

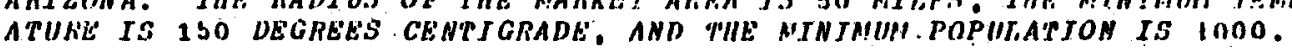

4 RADTUS so 150 1000

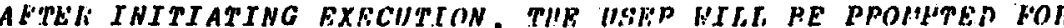

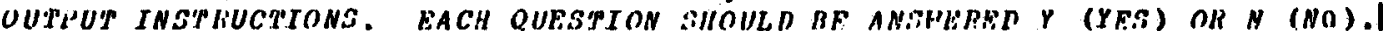
OUIPUIT OPTIONS INCLUDE

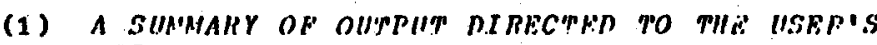
TERM!IHAI,

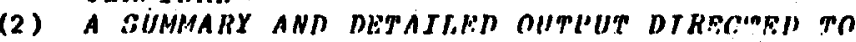

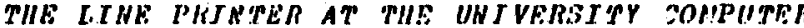
CENTER.

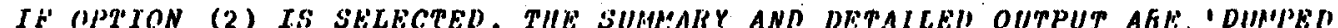

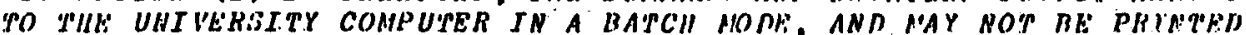
INAB'

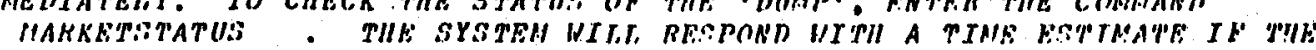

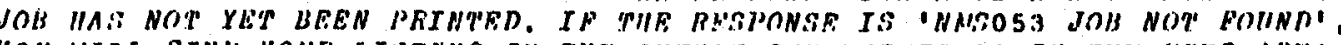

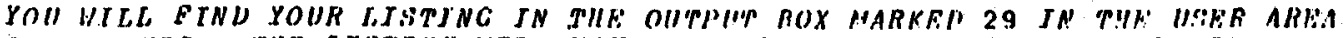

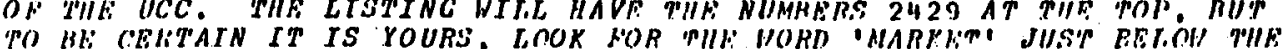

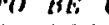


$\checkmark$ STATE MARKET LIMITS

[1] $\quad(1=+/$ STATE $=4.56: 78) / \triangle L 10$

[2] 'INVALID STATE CODE'

[3] $\rightarrow 0$

[4] $\triangle L 10:$ :WS+STN+TIEAFILE ' 310733401 NSITS'

[5] TWS+TWS, CTW-TIEAFILE ' 310733401 NCITY'

[6] $+(3>5 T W+C T W) / 0$

[7] 'PRINT SUMMARY ?' PRTSUM+'Y'=1+0,' !

[8] 'DUMP ?' DMP+' $Y$ ' $=1+$ ', '

[9] $\rightarrow(D M P=0) / \triangle L 30$

[10] OTW+TIEAFILE' 310733401 MKTOUT'

[11] $+(0 \geq O T N) / \triangle L 100$

[12] TNS $T W S, O N W$

$[13]+(0=S O T W[2]-($ SOTN+CFSIZE OTW $)[1]) / \triangle L 25$

[14] MKTMSG

[15] $\rightarrow\left(' E^{\prime} \neq 1+F L A G+\eta_{1} !\right.$ i) $/ \Delta L 12$

[16] [FPROP OTW, -SOTW[2]-SOTW[1]

[17] $\rightarrow \Delta L 25$

[18] $\triangle L 12: \rightarrow\left(' C^{\prime} \neq 14 F L A G\right) / \triangle L 100$

[19] DMP $=$ ORTSUM $1 * \rightarrow \triangle L 30$

[20] $\triangle L 25:(000)$ QFAPPEND OTW

[21] $\triangle L 30: R L I M+L I M I T S[1] * T L I M+L I M I T S[2] *$ PLIM+LIMITS[3]

[22] SITESADRREAD STW,STATE

[23] ETEMP+\&,SITES[; 73747576$]$

[24] MIEMP+1,SITES[; 77.787980$]$

[25] ETEMP[CTEMP] AMTEMP CTTEMP+(ETEMP=0)/1DETEMP]

[26] SITES+(ETEMP $\geq T L I M)+S I T E S$

[27] ETEMP+(ETEMPZTLIM)/ETZMP

[28] (DSTTES)[1]:' STTES'

[29] $-(0=($ DSTTES $)[1]) / \Delta L 100$

[30] SUMMARY+ $273 \circ^{\prime}$

[31] ST+ST $A B B R Y$ SITES[1;1],

[32] SUMMARY+SUMMARY,[1] 173 o'STATE',(200' '),ST,730' '

[33] SUMMARY+SUMMARY,[1] 173 D'MARXET AREA RADTUS MILES', 730' '

[34] SUMARY+SUMMARY,[1] 173 D'MINIMUM TEMPERATURE ',( TLTM),' DECREES C',730'!

[35] SUMMARY+SUMMARY,[1] 473 OMINIMUM POPULATION 47-DTELIM)D' $),\left(2060^{\prime}\right.$ ' ), 'AREA i,90'! 


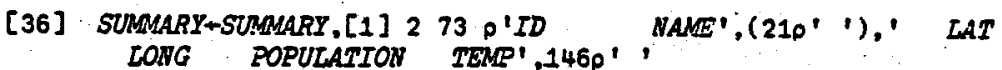

[37] $\triangle L 40: S L A+(2$, SITES[1; 313233$])+(2$, SITES[1; 343536$])+000$

[38] SLO+(2,SITES $[1 ; 37383940])+(2, \operatorname{SITES}[1 ; 414243])+60$

[39] BOULD+(SLA+RLIM+60), (SLA-RLIM+60), (SLO+(RLIM×1.2)+60),(SLO-(RLIM $\times 1.2)+60$ ?

[40] CITIES+ $0640^{\circ}: \times C H \div 4$

[41] $\triangle L 50: X+\square$ TRREAD CTW, CWT

[2] $\left[A+\left(2, X\left[; 6 \begin{array}{lll}6 & 7 & 8\end{array}\right)+(2, X[; 91011])+60\right.\right.$

[43] $L O+(2, X[; 12131415])+(2, X[; 16 \quad 1718])+60$

[44]. $\angle A L O C+([A \leq B O U N D[1]) \wedge(L A \geq B O U N D[2])$

[45] LOLOC+(LOSBOUND[3])^(LO>BOUND[4])

[46] CITIES+CITIES; [1] (LALOCALOLOC) +X

[47] $\rightarrow(0=($ DCITIES $)[1]) / \Delta L 55$

[48] CITIES+(PLIMSe, CITIES $; 19+17])+C I T I E S$

[49] $\triangle L 55: C 2 R+C R+1$

$[50]+(C V 1 \leq 16) / \triangle L 50$

$[51] \rightarrow(0=(0$ CITIES $)[1]) / \Delta L 70$

[52] SLA+SLA+57.29578

[53] SLO+SLO+57.29578

[54] CLA+((2,CITIES[; 678 8])+(2,CITIES[; 910 11])+60)+57.29578

[55] CLO+((2,CITIES[; 12131415$])+(2$, CITIES[; $16 \quad 1718])+E 0)+57.295$ 78

[56] $A+20925831 * B+20854891 * C+0.006768658$

[57] $S R+A *(1-(C \times 1 O S L A) * 2) * 0.5$

[58] $C N+A *(1-(C \times 10 C L A) * 2) * 0.5$

[59] $S X+(205 L A) \times(205 L O) \times S N$

[60] $C X+(20 C T A) \times(20 C L O) \times C N$

[51] $S Y+(20 S L A) \times(10 S L O) \times S H$

[62] $C Y+(20 C L A) \times(10 C L O) \times C H$

[63] $S Z+(10 S L A) \times S W \times(B * 2)+A * 2$

[64] $C Z+(10 C L A) \times C A \times(B * 2)+A * 2$

[65] $\triangle+(((S X-C X) * 2)+((S Y-C Y) * 2)+(S Z-C Z) * 2) * 0.5$

[66] $M I+\Gamma 3957.7719 \times-30 \Delta+20897037$

[67] CITIES+(MI $\leq R L I M)+C I T I E S$

[68] $M I+(M I \leq R L I M) / M I$

[69] $\triangle L 70: P O P+0$

[70] $\rightarrow(0=(\rho$ CITIES $)[1]) / \Delta L 80$

[71] POP+2,CITIES[;19+17] 


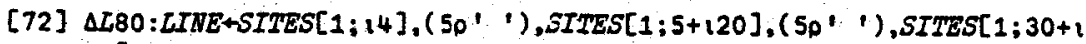
5]

[73] $L T N E+L I N E, N^{\prime},,\left(50^{\prime},\right), S T T E S[1 ; 36+16], W^{\prime},\left(30^{\prime} \cdot\right),((2070)++1 P$ $O P) ;(2 p 90) \pi 1+E T E M P$

[74] SUMMARY +SUMMARY,[1] LINE

$[75] \rightarrow(D M P=0) / \triangle L 90$

[75] $\rightarrow(0=($ CCITIES $)[1]) / \Delta L 87$

[77] NAMES+CITIES[; 39+125]

[78] CST $\triangle S T \triangle A B B R V$ CITIES[;22]

[79] $\rightarrow(2=p p C S T) / \triangle L 85$

[80] CST +12 OCST

[81] $\triangle L 85:$ COUNTY+CNTY ANAMES CITIES[ ; $26+112]$

[82] $M I+(2 D 30) T((D M T), 1) p M I$

[83] $\triangle L 87: D E T A I L+173$ p'PROJECT ID NO. ',SITES[1;14],510' '

[84] ST+,ST $\triangle A B B R V$ SITES $[1 ; 1], '$

[85] DETAIL+DETATL,[1] 173 p'SITE NAME ',SITES[1;5+120],' ' ST, 310' '

[86] DETAIL DETAIL, [1] 173 o'LOCATION

$$
', \text { STTES }[1 ; 36+16], ' W^{\prime}, 35 \rho^{\prime},
$$

[87] DETAIL+DETAIL.[1] 173 p'TEMPERATURE . ',( 2030$) \times 1+E T E M P)$, - DEGREES C',700' '

[B8] DETAIL+DETAIL,[1] 173 D'AREA POPULATION $1,((2 p 70) 7+/ P O P), 55$ $\rho^{\prime} \cdot$

$[89] \rightarrow(0=(\rho C I T I E S)[1]) / \Delta L 89$

[90] DETAILADETAIL.[1] $273 \rho^{\prime}$.

[91] DETATL -DETAIL,[1] $273 \mathrm{p}\left(10 \mathrm{p}^{\prime}\right.$ '), 'CITY',(140' '), 'STATE', (70' ') ' 'COUNTY',(6p' '), 'POPULATION DISTANCE'.730'!

[92] $P O P+(2 p \quad 7 \quad 0) \nabla((p C I T I E S)[1], 1) p P O P$

[93] DETAIL -DETAIL. [1] NAMES,SP,CST,SP, COUNTY,SP, POP, $(S P+(($ NMI $)[1], 5)$ $0^{\prime}$ ') $, M T,((O M T)[1], 4) 0^{\prime}$

[94] $\triangle L 89: D E T A T L$ DFAPPEND OTW

[95] $\triangle L 90: ' E N D$ SITE ',SITES[1;14]

[95] ETEMP $+(0,((0 E T B M P)-1) 01) / E T E M P$

[97] SITES+ $\left(0,((0 S I T E S)[1]-1)_{01}\right)+S I T E S$

[98] $\rightarrow(0<(0 S I T E S)[1]) / \Delta L 40$

[99] $\leftarrow \sim D M P) / \triangle L 95$

[100] SUMMARY OFREPLACE OTN, (DFSIZE OTN)[1]

[101] DUMMY+SUEMTT MKTDMP

[102] DUMMY OFAPPEND OTW

[103] STATUS

$[104] \triangle L 95: \rightarrow($ DRTSUM $=0) / \triangle L 100$

[105] 'POSITION PAPER, THEN RETLRN CARRIACE TO RECEIVE SUMMARY' * DLMM $7+0$

[105] SUMMARY

[107] $\triangle E 100:$ DFUNTIE TWS

$\nabla$ 
$\nabla$ X+CHECKALIB $F N$

[1] $E T T-E T,(22-0 F W)_{0}^{\prime}$ ।

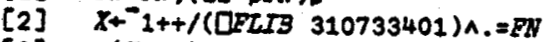

[3] $\rightarrow(x=-1) / 0$

[4] $x+($ [ENAMESA. $=$ FW $) /$ DFWUNS

[5] $\rightarrow(1=0 X) / 0$

[6] $x+0$

7

$\nabla$ TWT-TIEAFILE EW

[1] $2 W+0$

[2] $\rightarrow(-10=C B E C K \Delta E I B \quad F T) / \Delta L 1, \Delta L 2$

[3] 'FILE ',FW' MUST ROT EE TIED' +0

[4] AL1:'EILE',FW, DOESW' 'T EXIST'

[5] $\triangle L 2: F N$ DFSTIE TW+1+[/0, DFWUMS $\nabla$

7 2+CKTY $\triangle$ DAMES CODES

[1] $\nabla$-CODES

MKXTMSG

OUTPUT FILE CONTAINS DATA EROM A RREVTOUS RUN.

OWTER a TO ERASE EXISTING DATA,

C TO CORTINUE UTTH ONLY A PRITIED SUMAARY, OR RETURN CARRIAGE TO EWD EXECUTION.

$\nabla R+S U B M I T X$

[1] R+JOB+DSUBMIT $X$

$\nabla$ Z+STATUS

[1] 2 2+[HASPIW('I';12+'SD'', JOB) 
$/ / * * G P N 0001 L, 585-65-2429-0, M A A R E E T$

II EXSC FILEPRT

- EILE 310733401 MKTOUT

$C E \sqrt{E} C T$

- SELECT ALL

จ MARKETSTATUS:2WT

[1] TW+TIEARILE ' 310733401 MKTOUT'

[2] $\rightarrow(T W \leq 0) / 0$

[3] JCB+DFREAD $W,(D F S I Z E T W)[2]-1$

[4] : STATUS

[5] QFINTIE TW

$\nabla 2+10 B ; 0 R X$

[1] $\square R X+1[R M+1$

[2] $\rightarrow(2 \times \square N C \text { JOB' })_{D N G}$

[3] $\rightarrow(\sim(00 \mathrm{OOOB}) \in \quad 0$ 1)ONG

[4] $\rightarrow(\sim \wedge / J O B \in C A V) \circ N G$

[5] $\quad\left(\Lambda /{ }^{\prime},=J O B\right) \cap N G$

[6] $Z+J O B:+0$

[7] WG:'JOBNAME ERROR' $*$

$\nabla Z+S T \triangle A B B R V$ CODES

[i] $Z+1620^{\prime} \quad$ AZCOWWWCATDKANBOKORTXWY'

[2] $2+z\left[\left(2,\left(((p \text { CODES })[1], 1)_{0} ! !\right)\right.\right.$, CODES $\left.) ;\right]$ 
Group Nama : DBGROUP

wS Name. 310733401 PJIB

This group allows simple retrieval of data from the RPPM Database. Using the GET function a retrieval Eay search a maximum of two domains, (provided one domaiz is to as specified by che second element of $i=32$ of the GET Eurction. Rafer to user documencacion for that function.)

For detained axampies of the use of these iunctions, refar to the user manual.

Cser functions are OPEN, CLOSE. GET.

IFTS: OPEN CLOSE GE: EDITRELAAME VCRIFYACCESS

)VARS: RELATION contains a valld relation name for use by ocher functions. ERROR a variable which should be checked after each latabase operation performed within a user's function. If a database function terminates normaily with a database error message, execulion of che user Eunction sinould be hal ted as results are unpredictabie.

ERROR - I if an exror was detacted. ERROR = O if no erzor was detected.

........................

Eunction Yare: OPEN Group Name: DBGROUP

Input: a righe argureat RELIAME containing the name of the ralacion to be accessed.

Output: aone

Global vars used: ERROR, RELATION

Giubal vars created: none

tocal vars: IiES a vec sor (or scaiar) of tis numbers

Subrcutizes: EDITRELAANE

VERIFYACCESS

Call:5.8 Foutines: none

coding correses

Line

i set ERROR condition to true; if executica is terminated be sore the 2 end of program then ERROR cerdition rill be true.

2-4 if user hasn't been ziven acsess to the dasa element dic:sonary,

5-7 if tie nurbers 99 or 100 ate in use, ead.

9 check for valid relation name

io check for proper access rights (type 0 access is read onl $j$ )

1i-i2 (1f lavalid relation nare o: acess 3 ijtets rot granted) untle data elerent dicionary and and

15 no extor has been de zected thri this polnt, so ER3OR sonóftion is felse 
Function name: Close

Input: none

Global vars used: auna

Local vars: none

Calling rouclines: none

Output: none

line coments

1-3 if ille tle numbers 99 and 100 are not $1 n$ use it is assuned

4 no relation

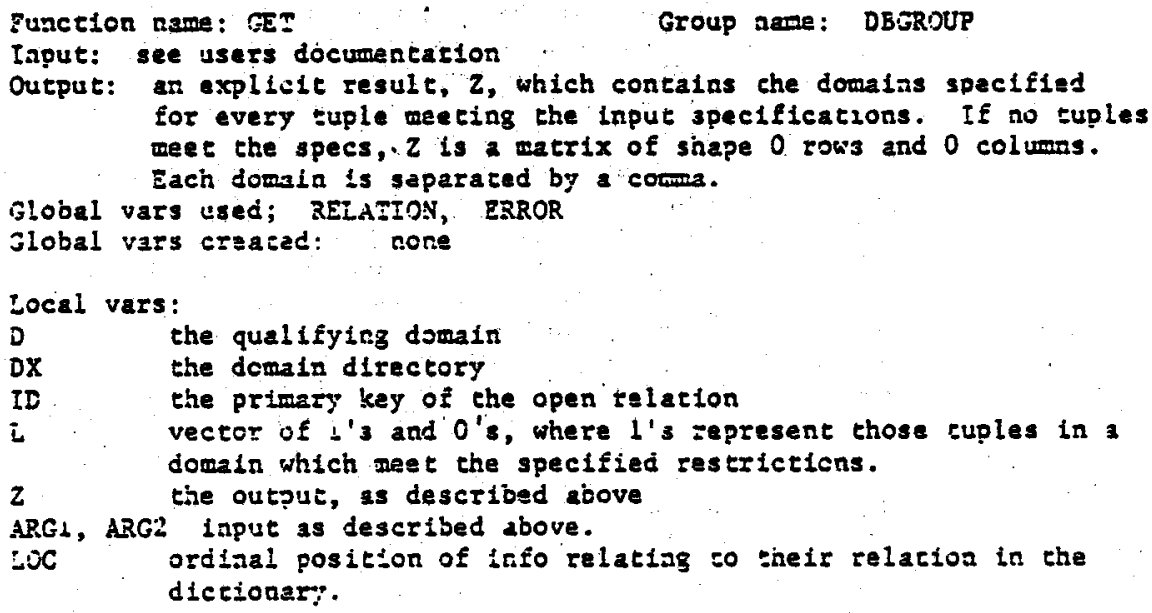

Subroutines: VERIFYACCESS

Calling rourines: none 
Function name: GET (continued)

\section{Line}

1

intefalize result

coding coment

2 set ERROR condition to true so that if execucion terminates

duriag edieing, an ERROR condition will be indicated.

3 If read only access is not approved, end; If LOC is zFater than zero, it represents che ordinal bocation of lafo relacing to this relaction it the dictionary.

4-5 reshape the left argurent into a vector if is isn't already. 6 read dorain information of the epen relation

7-9 if an invalid domain was iacluded in the left argument, and. 10-12 if az inval id staie coce or not anough elements lacluded in

15 If the qualifying domain is not valid, ent.

16 if execulion has reached this point, it is assumed no error condition will occur, so ERROR is sec to false (actually a workspace full condicion ray occur diring iurther processing, buc chis error cannot go undetected and the user will not benefit from secting the ERROR flag to true if the condsion did occur).

17 read end convert qualifying tomais to numeric data.

i3 I is assizred a logisal vector, where ones incicate $=D$ 's mee:Ang specifled reguizerers.

if no cuples meet qualifications, end.

if no restristions by state, skip the next section. read ID domain, convert to numeric data.

$L$ is reassigned to be one only where originaliy one and where ID's also meec specifled restrictions.

initialize result.

assign resuic

zemove trailing comas 
Input: none

Output: I If selidite is a valid celacion neme, O tf not;

$z$ is an expllate resuit containing this value.

5

Global vars used: REL NAME

Globai vars creaced: nore

Loc3l vars: none

Subroulines: nore

Calling rousines:

OPEN

Lise $\therefore$ coding coments

3. reassiga RELAANe to taclude library nimbu: and reassemble the

41 Iesules of DFNAME and

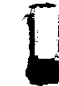

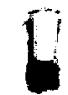

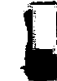

1

i

1

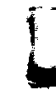

1

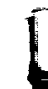




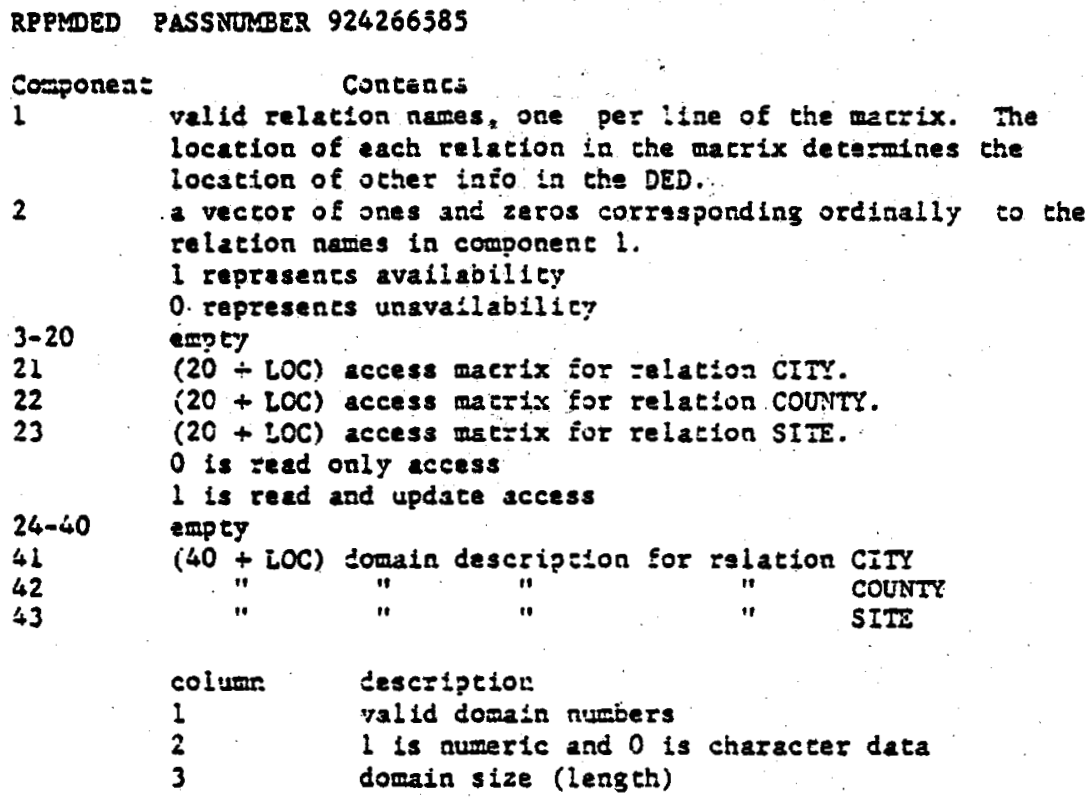




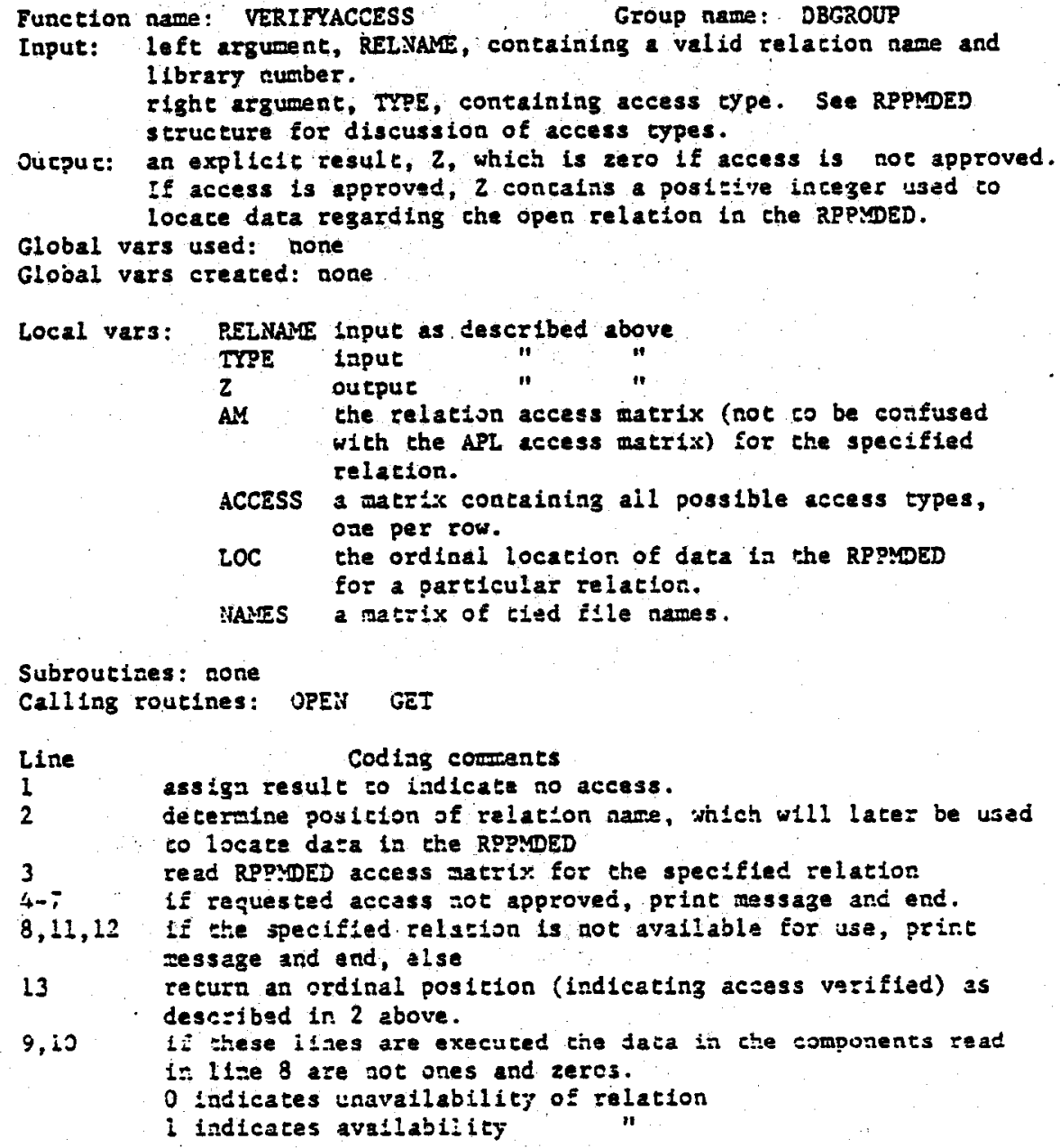


$\nabla$ OPEN RELWAME;TIES

[1] ERROR+1

[2] $\rightarrow\left(1=+/(\right.$ CELTB 310733401 $) \Lambda_{0}=1310733401$ RPFMEED $\left.\cdot 1\right) / \Delta L 10$

[3]. 'WO, ACCESS BOT APRROVED'

[4] $\rightarrow 0$

[S] $\triangle L 10:+(0=+/ 99100$ ETIES+DFWUMS $) / \triangle L 20$

[6] 'WO, MMRROPER USE OF TIE MTMBER 99, 100 OR A RELATION IS ALREADY OREN'

[7] $\rightarrow 0$

[8] $\triangle L 20: ' 310733401$ RFPNDED' QFSTIE 99924266585

[9] $\rightarrow(0=E D$ ITRELNANE $) / \triangle L 25$

[10] $\rightarrow(0<R E L N A M E$ VERIFYACCESS 0)/AL3O

[11] $\triangle L 25:$ :QFUTTIE 99

[12] $\rightarrow 0$

[13] $\triangle L 30:$ RELNAME CESTIE 100,924266585

[14] RELATION+RELNAME

[15] $B R R O R+0$

\section{CLOSE}

[1] $\rightarrow(2=+/ 99100$ e[FWUMS $) / \Delta L 10$

[2] 'NO RELATION OPEN'

[3] $\rightarrow 0$

[4] $\triangle L 10:$ CPUNTE 99100

V Z+EDITRELITAME

[1] RRETURNS 1 IF RELWAME IS A VALTD RELATION RAME

[2] A O IF INVALTD

[3] RELNAME+224' 310733401 ',11+RELNAME.110' '

[4] $\rightarrow(1=2+/(\square F R E A D 991924266585) \wedge .=R E L N A N E[11+111]) / 0$

[5] 'MOT A VALID RELATION MAME'

$\nabla$ 
$\nabla 2+A R G 1$ GET $A R G 2 ; 0 ; D \% ; I F ; L ; L O C$

$[4]$

$\triangle L 5: \rightarrow(C K$ OQAFC1)/AL.1?

$A R G 1+1 \cap A R G 1$

[s]

[6]

[7]

[8]

[9] 
QVERIFYACCESS[Q]D

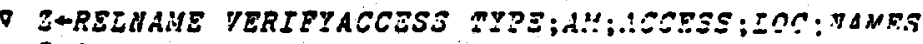
$3+0$ EDC+( MAMESA . =RELMAME[11+i11])/2(ONAMES+DFREAD 99,1,924266585)[1] $A M+\square E R E A D \quad 39,(20+L C C), 924266585$ $\rightarrow(T Y P E \leq A L A[(A M[; 1]=D A T[1]) /:(D A A)[1] ; 2]) / \triangle L 20$ ACCESS+ 26 D'READ UPDATE' 'WO. ', ACCESS[TYPE+1:],' ACCESS NOT APPROVED' $\rightarrow 0$

$\triangle L 20: \rightarrow(0)=(0 F R E A D \quad 99,2,924265585)[L O C]) / \triangle L 30, \triangle L 40$

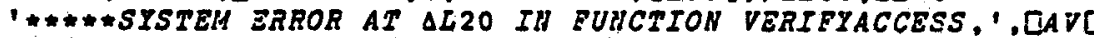
157].' NOTIEY DATABASE ADMIUISTRATOR'

[10] $\rightarrow 0$

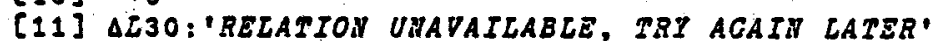

[12] $\rightarrow 0$

[13] $\triangle 240: 3+2 O C$.

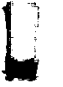

5
$\Rightarrow$ 


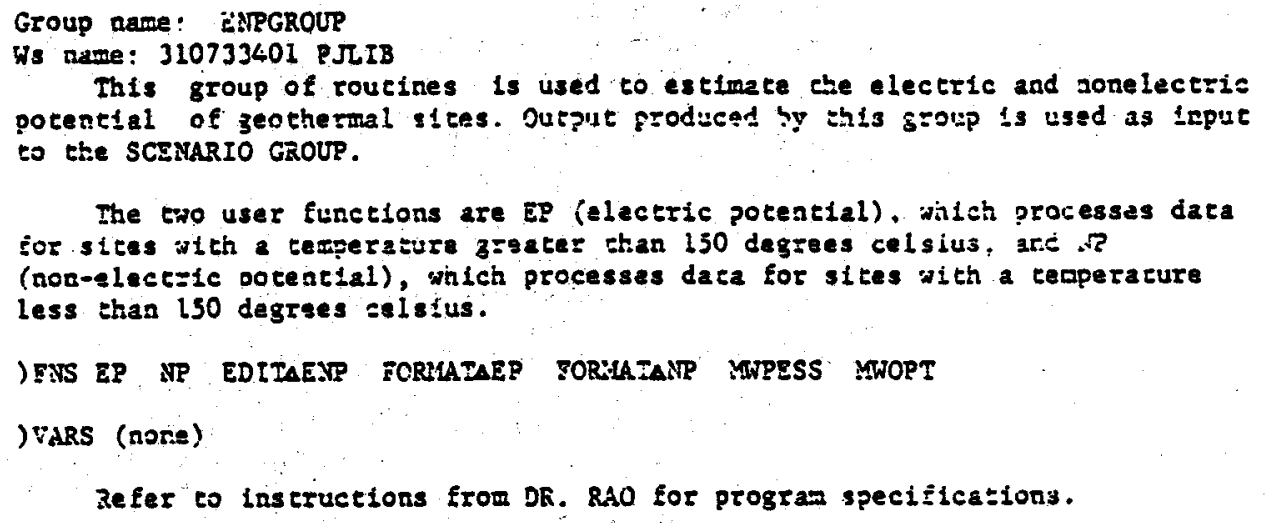

aefer to instructions from DR. RAO for progran specifications. 
Function name: EP

Group name: EAPGROUP

Inpuc: requiree a right argument, $X$, which is a character matrix of at least one row and 36 coluens.

$\begin{array}{ll}\frac{\text { Columins }}{1-4} & \frac{\text { Eield name }}{\text { sife id }} \\ 5 & \text { filler } \\ 6-25 & \text { site name } \\ 26 & \text { filler } \\ 27-32 & \text { reservoir volume in cubic kilome ters } \\ 33 & \text { E\$ller } \\ 34-36 & \text { temperature in degrees celsius }\end{array}$

Output: produces an explicic resule in character watrix form which may be assigned to a variable name. This result is a iable concairing site Id, site name, egrperature, raservolt volume, negawact equivalent (MWE) for 20 years, WWE pessimistic estimate, MWE optinistic estimate. The opeinistic and pessimistic estimste for MWE are used as input to Eunctions in the SCEXARIO GROUP.

For information reguarding source formulas, refer to program specifications from Dr. Rao.

Global vartables ised: none

Globel yartables created: none

Local variables:

$x$

2

SID

SINAME

I

RV

ER

ERI

$Q$

MEIOL

w30

5

Miro

INTP

Subroutires:

EDIIAENP

PORMATAE:

IITOPT

MUPESS

inpus as described above output as descrlbed above

site Id

sise name

temperature in degrses celsius

reservoli volune- if not known, use default

value of 2.25 cubic k1loceter3.

recovery factor.

racovery factor index

calorias

negawat centuries

regawares for $2 C$ years

number of sites la inpir

megawact estimate optimistic

megawate escizate pessimisic

eciss input

Formats out put

calculates optiniscic WE estinate

calculates pessimistic whe estiate

Calling routines: none 
Function aame: $\mathrm{VP}$

Group name: ENPGROUP

Input: requires $a$ right argument, $X$, which is 2 character matrix of a= least ore =ow and 36 coluns.

Columns Field ame

$1-4 \quad$ si:e ID

3 . Eliler

$6-25$ sice sare

26 it 11 er

27-32 reservoir volume in $\mathrm{su} \mathrm{km}$

33 Eiller

36-36 eamperature, dag $C$

Output: produces an explici= resule in character matrix form which mes be assigned to a vartable rame. This result is a table containing site iD, sfte name, samperature, reservoir volume and megawat equivalent for $30 \mathrm{yrs}$.

Local rars

$x$ input as described above

$z$ outpue

SID 31te ID

SVAAE Sice name

- temp in ciag C

3y reservoir vol

0 thermal potentiai

MwIH30 megawat thermal potential for 30 yrs

$s$ number of sites in inpuc

Subroucines: EDITAEYP FORMATAIR

adies Iapue

formats output

Calling routlnes: sone

jlobal var3: sone 


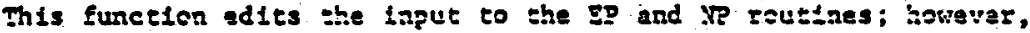
no error checking is performed.

Inpuc: requizes a =ighth argument, $X$. Refier to inpuc description for

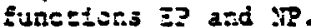

Output: none

Global vars used: none

Global vars created:

$\begin{array}{ll}\text { SID } & \text { SiLe ID } \\ \text { SIAAE } & \text { site name } \\ R V & \text { reservolr vol ume } \\ T & \text { cemperacura }\end{array}$

Subroutines: none

Calling routiaes:

EP, IT

Function rame: iHOPT

Group name: ENEGRC'S

This Fiscion calculates the optinistic megnat: equitalest es inate.

Iaput: reguites a right argument, wiso, which is a numeric vector of megawact equivaleat for 30 years estieated. It concains one element for each site belng processed.

Outpuc: an explicit resule in numerte vector form, sontainirg an opcimistic astirses of pegawate equivalene for ach Mijo valie input.

Global vars used or created: soze

cocsi vers: none

Subroutizes: sone

Calling routises: E?

Coding coments: Line 1. Fach dement of visom is reassigned the vaide -1 so that when adjusted to the next highest j0MN chose values will remain zero. 
Function name: FormataEp

Group name: ENPGROUP

This function formats the output of the ţ? function.

Inpuc requires : cight argument, $X, a$ numertc matz $\$ x$ of at leas ore row and 5 colums.

Columa : Descripclon

i T temperature

2 RV, reservolr vol

3 M 30, megawate estimate For 30 yzs

$4^{\circ}$ MO, optimistic MN estimate

5 MVP, pessimistic WN estimate

Output: an explicit result in character matrix form containing sits

ID, sice name, cemp, reservoir vol, MN30, MWO, Miv.

Global vars used: SID stee ID

Global vars created: none

site name

Local vars: none

Subroutines: none

Calling routines: EP 


\section{Function Slame: EORMaT 4 NP}

Group Same: ENPGroup

Funct1on Description: This function formats the outpur of the XP function.

Input: Requires a right argumeat, $I$, a numeric matrix of at least one row acd 3 colvens.

column

1

2

3

\section{descripeing}

I (temperature)

RV (reservior volume)

MWTa30 (megawatt thernal potential for 30 vears)

output: An explicit result in chrracter satilx form contairing site $\pm d$, site nane, temperature, reserrolis volume, and $\mathrm{WW}$ thermal potential estimates for 30 gears.

Eunction Name: FORMATAIT

Group Name: Encgroup

Global Varlables Creatad:

sone

Local Varlables: none

Subroutines: none

Calling Routines: IP 
Function name: MWPES

Group name - INPGROUP

This function calculates the pessimistic megawate equivalent escimate.

iaput: requires aight argument, $\operatorname{tiw}^{2} 30$, which is a numeric vector of megawatt equivalent for 30 yrs estimates. It contzitss one lement for each site being processed.

Output: an explicit result in nureric rector torn containing an optinistic esefmate of megawatt equivalent for ach vaise input.

Global vars used or created: none

Local vars: MNP an incermediate resul:

Subroutines: none

Calling routines: EP

Coding coments.

Lise 2

eech lement of MWP 10 is reassigned the value -so that when adjusted to the next hignest $50 \mathrm{Mg}$, those values will remain zero.

Line 3 same as llne 2, but for those sites with temperacures less than 200 deg C. 
JGRP ENPAGHOUIS

$\boldsymbol{E P}$

$N P$

BDITAENP

PORNATAEP

PORMATAMP

MHPESS MHOIT

VEPTEIV

Q $2+E P$ X:SID:SNAME ; $T: R V ; E R ; L^{\prime} R I ; Q ; M W 100 ; M W 30 ; S ; H W O ; M W P$ EDITAENP $X$

Kht 0.030 .0250 .02

$E R T+(T \leq 200)+(T \leq 300)+T \leq 300$

$Q+0.6 \times R V \times T-15$

$M W 100+(Q \times E R[E R I]) \div 0.753$

$M W 30+M W 100+0,3$

MWO+NWOPT MW3O

MWPAMWPESS MHO

$X+(S \rho P),(S \rho R V),(S$ QMW 30$),(S \rho M W O),((S+(\rho P), 1) \rho M H P)$

T+PORMAT TAEP $X$

DNP[CI]V

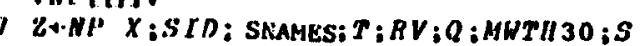

[1] EDTTABNP $X$

[2] $Q+0.06 \times R V \times T-15$

[3] MWTU $30+(R \times 0.25 \times 0.24 \times 1327 * 100)+0.3$

[4] $\quad X+(S \rho T),(S \rho R V),((S+(\rho P), 1) \rho d W T H I 30)$

(5) 2+FORMATANP $X$

VEDTRAENP[C]

D EDITAENP $X$

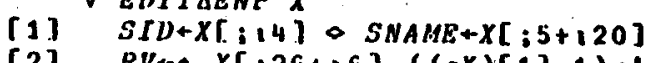

[2] $\quad R V+2, X[, ; 26+10),((\rho X)[1], 1) \rho^{\circ}$

$P+2, X[:: 33+13],((p X)[1], 1) p^{\prime}$ 
VFORMATAEP[O]V

$0,2+$ PORNATAEP $X$

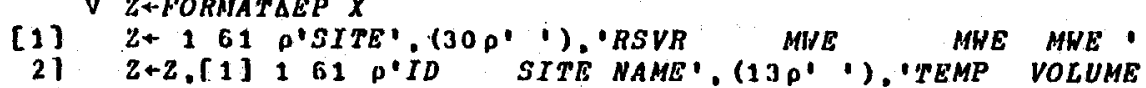

$x+[5,2 P Y, 2,2 I 6,[1 F N P X$

$X+(1 \| A 1, X 2,20 A 1$, DEMT SID,SNAME),$X$

$\nabla$

$z+z,[1] x$

$\stackrel{5}{\mathcal{u}}$

DFORMATANPCDIV

2+FORMATANP $X$

[1] 2* $148 p^{\prime} S I T E !,\left(29 p^{\prime} '\right), Q^{\prime R S V R}$

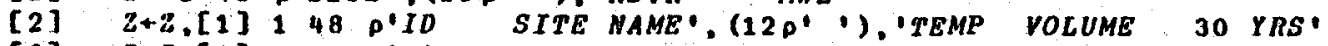

[3] $2+2,[1], 48 \mathrm{O}$ '.

[4] $X+14,2 F 9.2$, DEMT $X$

[5] $X+\left(14 A 1, X 2,20 A 1^{\circ}\right.$ [IPMT SID,SNAKE $), X$

$\nabla$

$z+2,[1] x$

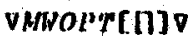

$z+B H O D T$ THW

[1] MW3OL (MW30s0)// MHW 30$]+-0.1$

[2], $2+50 \times 1+L A W 30 \div 50$

DMWPESS[t]J

2+MWPESS HWO; MWP

HWP + $117,762+1,01 \times M W O$

[2] MWP $(M W P \leq 0) / 1$ OMWP ]- 0.1

[3] MWP[ $(P<200) / 1 \rho P]+0.1$

[1] $2+50 \times 1+[M W P+50$ 
Sample Input to EP Function

"OO1.POWER RAMCH AREAS

4002 CLTPTON HOT SPATNGS: 2.50.184

2.25.160

HOT SPRINGS 2.25 .150

5020, COTTONWOOD CREEK JUM, 1.09 .170

5021. CIIATK CR MT PRINCETH, 2.48.200

5022. CIIALK CREEK HRICIIT H, 2.25.170

5023. CHALK CREEK HORTENSE, 2.25,170

5024, CIIALK CREEK HOOLMING, 2.25,170

$6001 . B L O W A H E \| I S$

6002. BRADY HOT SP 30.00 .214

6003.STEAHBOAT SP

12.25 .200

6001.SAN BMIDIO

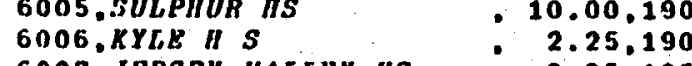

6007.JERSEY VALLEY HS : 2.25.185

$6000 . H O T$ SULPIIUR SP $\quad \therefore 2.25 .180$

6009,IIOT SP NEAR WELLS: $2.25,180$

6010.HOT SP RANCH

$6011 . L K^{\circ}$ il $S$

6012 PINTO 5 . 2.25 .175

6012.PIN⿴囗十 $s$ : 9.50 .175

OO13. OREAT HOILINC M $S$ : 25.00.170

6014,LEACH IIS $, 10.00,170$

6015.PERNLEY IIS : $2.25,170$

6016,BALTAZOR IIS $\quad \because 3.00,170$

$6017.5 O D A$ LAKE $\quad 12.50 .165$

$6018, S T I L I, W A T E R \quad 25.00 .165$

$6019 . S M I T I I C R H E K$ VALLEY $2.25,160$

. $2.25,155$

GO20. WABUSKA IIS

6021. NEKDLE ROCKS $\quad 3.00 .150$

6022.BLACK ROCK DESERT • 2.25 .150

$\begin{array}{lr}6023, D I X I E \text { VALLEY HS } & 3.00 .150 \\ 7001, \text { VALLES CALDERA } & 130.00 .240\end{array}$

7002,LIGHTNING DOCK $\quad 2.25 .170$

7003,LWR SAN PRANCISCO HS: 2.25 .150

$7004, K I L H O U R N E$ IIOLE

BO01, ROOSEVELT HS

8002, COVE KORT-SULPHURDAL, $22.50,200$

8003, TIIERMO HS : $2.25,185$ 
Sample Output of EP. Function

\begin{tabular}{|c|c|c|c|c|c|c|}
\hline $\begin{array}{l}S I T E \\
I D\end{array}$ & SITR NAME & TEMP & $\begin{array}{l}\text { RSVRR } \\
\text { VOLUME }\end{array}$ & $\begin{array}{l}M W E \\
30 \text { YRS }\end{array}$ & $\begin{array}{l}\text { MWE } \\
\text { OPT }\end{array}$ & $\begin{array}{l}\text { MWE } \\
\text { PESS }\end{array}$ \\
\hline 001 & POWER RANCH AREAS & 184 & 2.50 & 22.44 & 50 & \\
\hline 002 & CLIPTON HOT SPRINGS & 160 & 2.25 & 17.33 & 50 & \\
\hline 4003 & VERDE HOT SPRINGS & 150 & 2.25 & 16.14 & 50 & \\
\hline 5020 & COTTONWOOD CREEK JUM & 170 & 1.09 & 8.97 & 50 & \\
\hline 5021 & CHALK CR MT PRINCETN & 200 & 2.48 & 24.37 & 50 & \\
\hline 5022 & CHALX CREEK WRIGHT H & 170 & 2.25 & 18.53 & 50 & \\
\hline 5023 & CIIALK CREEK HORTENSE & 170 & 2.25 & 18.53 & 50 & \\
\hline 5024 & CIIALK CREEK WOOLMING & 170 & 2.25 & 18.53 & 50 & \\
\hline 6001 & BKOWAWE HS & 240 & 42.00 & 627.49 & 650 & 550 \\
\hline 6002 & BRADY HOT SP & 214 & 30.00 & 396.41 & 400 & 300 \\
\hline 6003 & STEAMBOAT SP & 210 & 16.00 & 207.17 & 250 & 150 \\
\hline 6004 & SAN EMIDTO & 200 & 2.25 & 22.11 & 50 & \\
\hline 6005 & SULPHUR HS & 190 & 10.00 & 92.96 & 100 & \\
\hline 6006 & KYLF HS & 190 & 2.25 & 20.92 & 50 & \\
\hline 6007 & JERSEY VALIEEY HS & 185 & 2.25 & 20.32 & 50 & \\
\hline 6008 & UOT SULPUUR SP & 180 & 2.25 & 19.72 & 50 & 0 \\
\hline 6009 & HOT SP NEAR WELLS & 180 & 2.25 & 19.72 & 50 & \\
\hline 6010 & HOT SP RANCH & 180 & 2.25 & 19.72 & 50 & 0 \\
\hline 6011 & LEE $\| \mathrm{S}$ & 17.5 & 2.25 & 19.12 & 50 & 8 \\
\hline 6012 & PINTO HS & 175 & 7.50 & 63.75 & 100 & \\
\hline 6013 & GREAT BOILING $\| S$ & 170 & 25.00 & 205.84 & 250 & 0 \\
\hline 6014 & LEACH HS & 170 & 10.00 & 82.34 & 100 & 0 \\
\hline 6015 & FERNILYY HS & 170 & 2.25 & 18.53 & 50 & \\
\hline 6016 & BALTSAZOR US & 170 & 3.00 & 24.70 & 50 & $c$ \\
\hline 6017 & SODA LAKE & 165 & 12.50 & 99.60 & 100 & c \\
\hline 6018 & STILLWATER & 165 & 25.00 & 199.20 & 200 & \\
\hline 6019 & SMITH CRELK VALEEY & 160 & 2.25 & 17.33 & 50 & 0 \\
\hline 6020 & WABUSKA HS & 155 & 2.25 & 16.73 & 50 & c \\
\hline 6021 & NEEDLE ROCKS & 150 & 3.00 & 21.51 & 50 & \\
\hline 6022 & BLACK ROCK DESLRT & 150 & 2.25 & 16.14 & 50 & 0 \\
\hline 6023 & DIXIK VALLEY IIS & 150 & 3.00 & 21.51 & 50 & 0 \\
\hline 7001 & VALLES CALDERA & 240 & 130.00 & 1942.23 & 1950 & 0 \\
\hline 7002 & LITGIINING DOCK & 170 & 2.25 & 18.53 & 50 & 0 \\
\hline 7003 & LWR SAN BRANCISCO IIS & 150 & 2.25 & 16.14 & 50 & \\
\hline 7004 & KTLBOURNE HOLE & 155 & 2.25 & 16.73 & 50 & 0 \\
\hline 8001 & ROOSEVELT US & 250 & 0.00 & 124.83 & 150 & 50 \\
\hline BOO2 & COVE FORT-SULPIIUI & 200 & 22.50 & 221.12 & 250 & 150 \\
\hline 8003 & TIIERMO US & 185 & 2.25 & 20.32 & 50 & 0 \\
\hline
\end{tabular}


Group Name: SCEAARIOGROUP

dS Name: 310733401 PJLIB

Group Description: This group of routines provides a graphlesi representation of eegariats on line for each pear, 1982 through 2022, for 3 3iazis stice or for a group s: sites. The user functions are SCEidzio, wicich accepts oniy a single stie as ineut, and ACGREGAIE, whith processes a zroup of sites. dil 5 scaces are required. AGGREGATE aiso caicuiates annual tocals of Iega:vatts on ilne for each 3 ta:e inciuded in input and a grand total.

Functioas Ised: ACGREGATE, GRAPH, READSTIE, SCEMAREO, STLVAMES, STIEIIELITE, SRREAD, SCEMARIOKIESDER, FORYAAT.

7ariailes lised: aone

\section{Function Vame: AGGREGATE}

Input: Requires a leitt argment, IYPE, concaling eicher the characters 'OPTIMISTIC' or 'PESSIIISTIC: It also requires a right argunent, $\mathrm{r}$, which

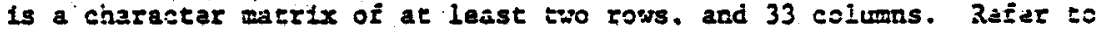

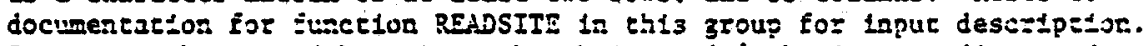
inpue must je $30=: e c$ by stace, though $t t$ seecin' $\tau$ be in sseending or desceading orier; Input must also contain 3ites in zora than ore scace.

Output: Produces a character matrdx cuncaiaing a seport of processing witein is appendect to as APL file t1ed with the tis number. 1. This fille should contain at least 75,000 bytes for an input daca sat containinz 60 sites. aach page of the report contaizs 135 solums and a maximum of 51 lizes, and is appended as a separate component of the file. then the princed repore is reduced to $74 \%$ of orlzinal size, it is suitable for $8: 12$ by 11 inch paper.

Globai Varlables Used: none

Global Var1ables Created: norie

Local Variables:

TYPE

$\mathbf{x}$

2

STAI

SIT

SAT
Input as tescrtbed above.

Input as described above.

Output as described above.

State annuai total of regawates on 112re (MHOL) as a 40 eirment vector.

State socal Mtor as. i scalar.

Region ansual rotal swoi as a to elemeat vectur. 
Region total is a scalar.

STTS

State totals swol as a 5 element vector, one for each state.

Sar

Site annual total wNoL as 340 element vector.

SID

Site ID currenty jeing orocessed.

OLDSID

Last sica ID processed.

LIVE

Last lige on curtant page of output.

$M$

Megawate equivalant estimate for current sita.

START

SNAME

Subroutines: FORMAT, READSITE, SITETIMELIVE

Calling Routines: none

Special Coding:

Ine

$$
1-6
$$

7

8

$9-10$

11

12

i3

$14-1 ?$

18

19 coding commencs

Inftalization

Read site data.

Frocess jitz data.

Accummulate cotals.

Read next sice data.

If rexi stte is is same state as last sfita repeat $8-11$, else

Format state totals.

Accutulate regfor cotals, and refnitialize state totais.

If last sita has been processed, jegin firal Estmatting operattons, ise

If the currert page of outpur contaias onit the ieader, do not print the Jeit state name, as it has already beer $p=i z t e d$, bur repeat 8-19.

Print next state name. 
line

21

$22-24$

25

26

coding soments

Repeat 8-18.

Begin final forwat operations.

Append final page.

Indlcate to user nomal terimition of execuston.

\section{Function Nare: SCEMARIO}

Globa: Variable Used: aone

Globel Vartables Crested: none

Local Variables:

$x$

$\mathbf{z}$

$S=D$

Ssivide

WW
Input as described above.

Output as described above.

Site ID

Si:2 zame

Megawatt equivalent est1mate.

Input: Reçuizes a right argument, $X$, thish is a sharacter matrix of exactly

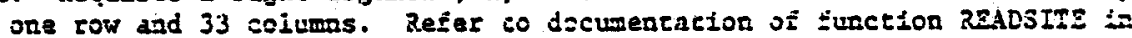
this zroup tox tnput cescriptions.

Output: th explicit resuit, 2 , waich is a ciaracter aat:ix coztaining a report of processing.

Subroutires: SITETINEIINE

Caling Routines: anne

\section{Eunction Jane: GR.PH}

Global Parlables lised: none

Glooal Varisbies Crested: tone

Local Variajoles:

$\sqrt{x}$

$x$

2
Input as described below.

Input as descrlbed bslow.

Cusput as described telow. 

row in ting input is to be expanded.

Input: A right argument, $x$, which is a matrix of ones and zeros, having at least one row, and 40 colums. Jash colume represents a year betreen 1932 and 2021. Each row represents a 50 . Jegawate gecthermal plant; each

$I$ in a row Indicates a year in witich that plant is generating elactract a zero, a year in which it is not. A ieft argument, $\mathbb{N}$, which la i sirgie character. This character will replace each one in the matrix, $\pi$, while 3 blank will replace each zero.

Output: An explicit resule, $z$, containing a graphical represencation or nagzwatts on line and where during the 40 year period, 1982-2021. The ottput is a character matrix of any number of rows and 100 coivuns.

Subroutines: none

Calling Rout_nes: SITETIMELINE

Function Name: READSIIE

Global Variables Usad: SID, OLDSID

Giobal Varlables Crasted: SNAME, MW, START

Local Varlables: nene

Input: No argurents.

Outpur:- No explicir result, or printed oltput. The function operites on a slobai rariabie, $x, 3$ atrix of at least wo rows, and 33 columis.

Selung

Lescripeion

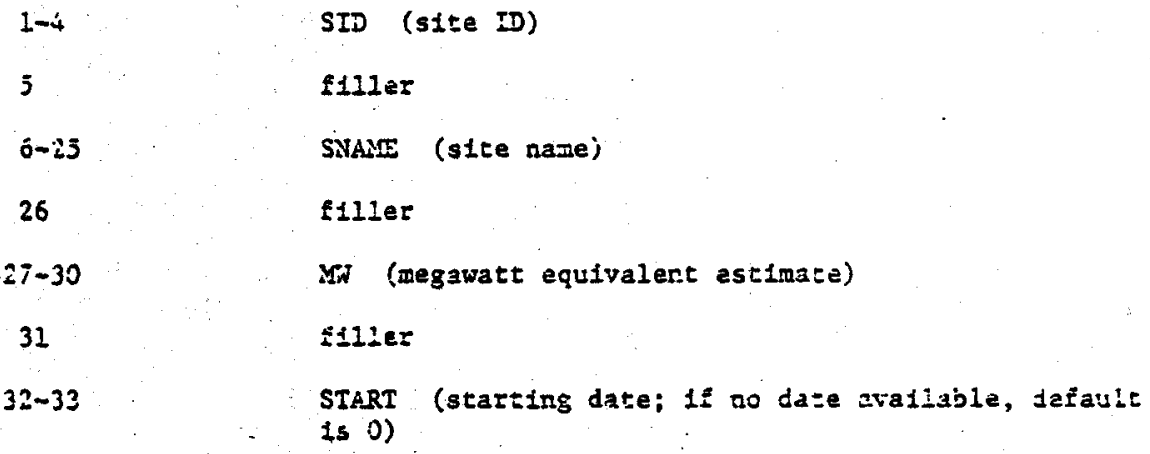


Subroutines: none

Calling Rout1nes: AGGREGATE

\section{Eunction Name: STANAMES}

Global Varlables Used: sone

Global Tariables Created: none

Local Variables:

$\begin{array}{ll}\text { CODES } & \text { Laput as described below } \\ z & \text { output as bescribed below }\end{array}$

Input: I right argument, CODES, a character watrix of at least one row, and exactly 1 colum. Each element of codes must be one of the characters $4,5,6,7,3$. Ho error shecking is performed.

Dutpit: in explicte result, 2 , In character matriz form, of at least one ror and exact $1 \%$ io selumes with 23 many rows as che input. Each row conzaits an underscored name of a scate in the Southwest Region correspording to tize appropriate state code in the input.

Subroutines: aone

Calling routInes: AGGREGATE, SCEALAROHEADER

\section{Function Name: SITETIMETIVE}

Globai Varlabies Used: SiveluE

Global Varlables Creaced: SAI (stce annual totai)

Loce: Tistables:

71

MIT

$z$

I
A matrix of ones and zeros; refer to inpit jesczipstor of the rlghe argunent of the finction GRAPH in this 3roup.

Input as described below.

Output as desirtbed below.

Graphical representacion of negawatts on lire; refer to output description of finctien GRAFH ta this group.

Stbroutires: SPREAD, GRAPH

Dalling Routines: SCENARIC, AGGREGAIE 
Input: A right argument, MW, a scalar estimate of segawat equivalent.

Output: An expllc1t result, $Z$, in character watrix form, which inciudes site nane, a graphic representation of megawates on line during the 40 year perfod 1982 through 2021, and an annual total oi negawates on line.

Special Coding:

line

2

$3-4$

5

6 coding comments

Site annual total is assigned the value or the odd subscripts of $Z 1$ sumed through the columins (the odd subscripts represent the even zumber yd yaars from 1982 ehrough 2021).

Formal- site name and graph.

If $\mathrm{MW}$ is less chaz or equal to 0 , there is no zeed to priat a site annual total line, so, erd, else.

Formal site annual total.

Function Name: SPREAD

Global Variablas used: START

Global Varlables Created: none

Local Vartables:

MWE

Input as described below.

$z$

PIV

$\mathrm{PT} / \mathrm{R}$

DELAY

APL

APLY

SCAED
Output as described below.

No. of 50 zez3wate plants needed, ziven Input.

No: or $50 \mathrm{MW}$ plants needed per year.

Xo. of years fron 1982 until a plants begins producrion.

Actual planes productig.

Actual piants producing during the eurrent yeas.

A vector indicating deiay between places, after the ilrst begins procucing.

Input: A right argumeat, WhE, a scalar to estinate megawatt aquivalent.

Output: An explictt result, $z$, a matrix of ones and zeros representing megawatts on line. Rafer to input descripetion for function GRAPH in this group. 
Subroutines: none

\section{Call108 Rout1nes: SIIEIMIEIINE}

Special Coding:

\section{Iine}

1

2

3

3

12

13

15

\section{coding couments}

Megarat equivalent divided by 30 megawatts is aumber of plants needed.

If start date not spectfled, zererate

A ranciom number and calculace a scart date.

If plants reeded is less than 1 , end.

If actual plants equal plants needed or if the delay is greater than 40 years (in which case it wor' pear in outpur), end; else

If actual plants for the current year is isss than plants needed for the current yeai, add another, else Increase the delay, and add anotiner plant.

\section{Function Vame: SCENARIOBEADER}

Global Vartabls used: SID, IZPS

Global Tariables ireated: bone

Local Variabies: $\Xi$ (output as descrabed below)

Input: acne

Outple: Ait explicit sesuiz, 2, a sastix of 8 rows, 135 columb containing tae report neader.

Subroutzaes: STARAAES

Calling ROUTZZAS: AGERZGATE, FORYAT

\section{Function Name: FORMAT}

Global Variabies used:

LIVE

3

SID

OLDSID
Last lige on current page.

Curzezt page. 
Global Variables Created: none

Local Variables: none

Input: A right argument, $X, a$ character matrix of at least one row and exactly 135 columas. The matrix may contain any portion of the output report.

Cutput: Adds the input to the current page unless the page will tha bave zore than 30 11nes. In this case, the surrent page is appended. A new page coaplece with header, is begun and the input is added to the nex current page.

Subroutines: SCEIARIOIRADER

Calling Reutines: AGGREGATE

Special Coding:

ine

1

2

3

4

6

12

\section{coding comments}

If adding input to current page would push the current page over 50 lines, fall cinrough.

Append currens page.

If last site has been processed, prepare report header for ilial sumary, else,

Replace current page with header.

If zext site is not in same state, doa't acid cont'D to header.

ddd Input to current page. 


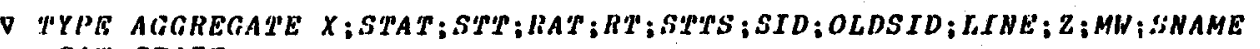
:SAT;START

$S T A t+S T P+R T+0$

$s T+S+10$

$R A T+020$ PO $* S I D+X[1 ; 14]$

L. IUEE+O

L+ $0135 D^{\prime}$ COLDSID+10000'

FORMAT SCENARTOHEADER

READSITE
ALIO:FORMAT SITETIMETINE MW

$\triangle L 10: F O R M A T$
$S T P+S T T^{2}+M H W$

[10] SPAT+GTAT+SAT

[11] READSITE

[12] $\rightarrow((1+O L D S T D)=1+S I D) / \triangle L 10$

[13] PORMAT $4135 \rho\left(35 \rho^{\prime}\right),\left(1000^{\prime} 1\right),\left(8 \rho^{\circ} 1\right)$. STATE TOTALS'.

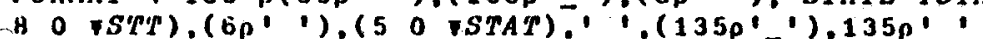

$[14] R T+R T+S T T$

[15] RAT+RAT,[1] STAY

[16] SUTS+STPS,STT

[17) $\quad S T A T+3 T P+0$

$[10] \rightarrow\left(11=+/ S I D=10000^{\circ}\right) / \Delta L 20$

[19] $\rightarrow((p Z)[1] \leq 8) \backslash A L 10$

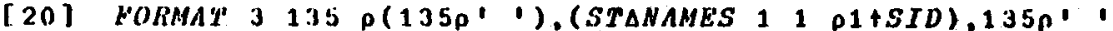

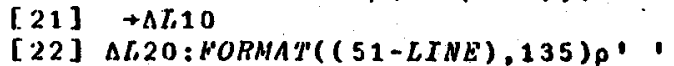

[22] AL20:HORMAT((51-LINE),135)P' $57 p^{\prime}$, , 5 O 0 RAT

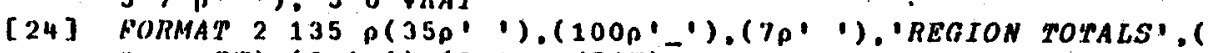

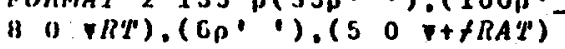

[25] Z IIPAPPEND

[26] 'DONE' 


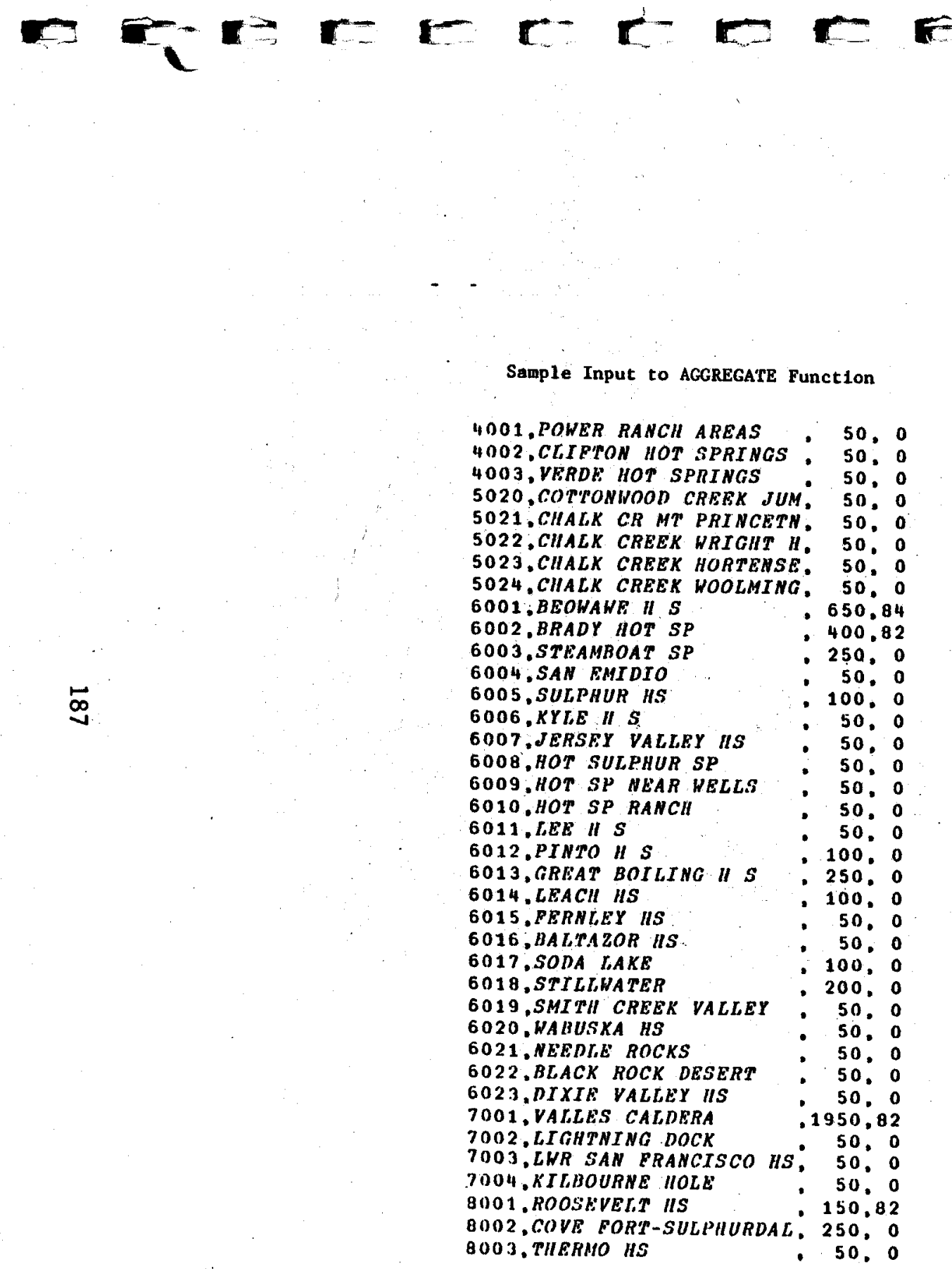


TSCEMARIOLZJP

" Z+SCEWARIO X;SID; SHAUE: :HW

[1] $5 I E+X[14] \cdot S H A U E+X[5+120] \cdot U W+2 X[28+14]$

[2] Z+SCEIIARIOHEADER [3], Z+Z,[1] STIETIUELINE $\mathrm{MW}$ TGRAPR[S]D

$\nabla 2+i$ GRAPR $Y ; k_{i}: X ; Y$

[1] $z+(0, X+(0, A)[1])_{0}, 1, Y+1$

[2] $\Delta L 10:[Y+32[1+y=2 \times[Y+2]$

[3] $z-z,[1](\pi, X) \in M[: Z]$

$[4] \quad y+y+1$

$[5] \quad+(\eta \leq(0 \%)[2]) / \Delta L 10$

$[i] \quad z+(1, A)[1+1=\varnothing 2]$

TREADSITELCIO

$\nabla$ READSITE

[1] $\rightarrow((0 X)[1]>0) / \Delta L 10$

$[2 j$ SID 190001

[3] $\rightarrow 0$

[4] $\triangle E 10: O L D S I D+S I D * S[D+X[1 ; 14]$

[5] SRAME+X[1;5+120]: $14 \%+2 X[1 ; 26+14]$

[5] $5 T A R T+2 X[1 ; 3233]$

[7] $X-(0,((0 X)[1]-1) 01)+X$

5

PSTABALESLE]V

7 3+STANA:OSS CODES

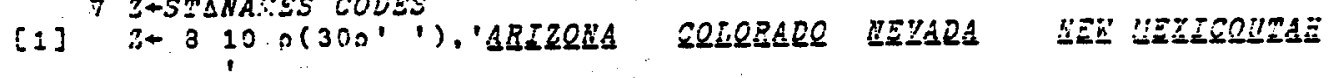

[z], $z+z\left[\left(2,((\operatorname{coCODES})[1], 2) 0^{\prime} 1\right)\right.$, CODES $\left.):\right]$ 
$\nabla$ FORMAT $X$

[1] $\rightarrow((\rho X)[1] \leq 51-L I N E) / \triangle L 10$

[2] 2 QFAPPEND 1

[3] $\rightarrow\left(4=+/ S I D=10000^{\prime}\right) / \Delta L 5$

[4] 2+SCENARIOHEADER

[5] LINE+(

[6] $\rightarrow((1 \uparrow O L D S I D) \neq 1 \uparrow S I D) / \triangle L 10$

[7] $2[7 ; 12+18]+'\left(\right.$ CONT' $\left.^{\prime} D\right) '$

[8] $\rightarrow \triangle L 10$

[9] $\Delta L 5: Z+Z[26 ;]$

[10] $2[4 ; 5+19]+1$,

[11] LINE+6

[12] $\triangle L 10: Z+Z,[1] X$

[13] LINE+LINE+( $\rho X)[1]$

$\nabla$

$\nabla$ Z+SPREAD MWE;PLN;PLNY;DELAY;APL;APLY;SCHED

[-1] $\quad P L N+M W E \div 50$

[2] $\rightarrow(S T A R T \neq 0) / \triangle L 5$

[3] START\&83+?4

[4] $\triangle L 5: D E L A Y+S T A R T-82$

[5] $P L N Y+\Gamma P L N \div 40-D E L A Y$

[6] $Z+040$ ०0

[7] SCHED+ $34,27 \rho 3$

[8] $\quad \rightarrow(P L N<1) / 0$

[9] $A P L+A P L Y+C$

[10] $\triangle L 10: Z+Z,[1] 140 \rho(D E L A Y \rho 0),(30 p 1), 10 p 0$

[11] $A P L+A P L+1 * A P L Y+A P L Y+1$

[12] $\rightarrow((A P L=P L N) \vee(D E L A Y \geq 40)) / 0$

[13] $\rightarrow(A P L Y<P L N Y) / \triangle L 10$

[14] $A P L Y+0$

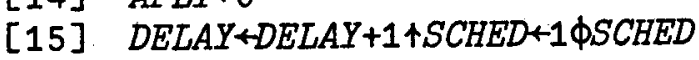

[16] $\rightarrow \triangle L 10$

$\nabla$ 
$\nabla 2+$ SITETIMELINE $M W ; Z 1 ; Y$

[1] Z1+SPREAD MW

[2] $S A T+50 \times(++21)[(2 \times 120)-1]$

[3] Z Z (( $\left.(\rho Y)[1], 35) \rho S N A M E,(80 \mp M W),((\rho Y)[1] \times 35) \rho^{\prime} '\right), Y+1>1$ GRAPH Z1

[4] $Z+Z,[1] 1135 \rho^{\prime}$ '

[5] $\rightarrow(M W \leq 50) / 0$

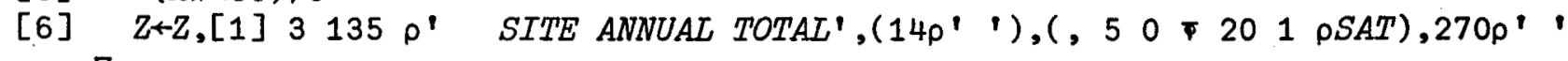
$\nabla$

STIE ANNUAL TOTAL',(14p" $),(, 50 \% 201$ pSAT),270p"

$\nabla Z+S C E N A R I O H E A D E R$

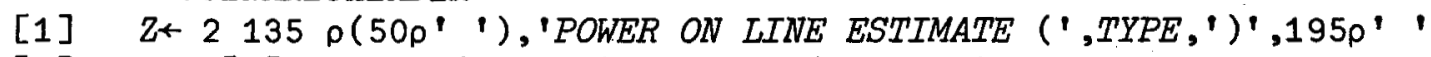

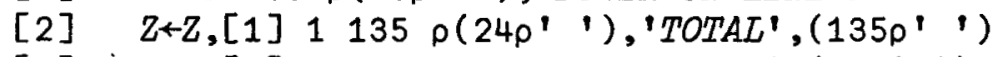

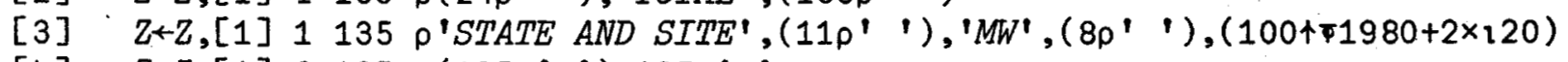

[4] $Z+Z,[1] 2135 \rho\left(135 \rho^{\prime}, '\right), 135 \rho^{\prime}$ '

[5] Z+Z,[1] $2135 \rho(S T \triangle N A M E S 11 \rho 1 \uparrow S I D), 270 \rho^{\prime}$ ' $\nabla$ 
16, IABI.B7, CreYY and COUN'LYS are so very simllar that they will all be explalued liere.

Input: A right argument, 'ST'N', contalns the state number on which the searching ls to be done in the fllics to get the desiced output. The flles that are used for the ce he dity searehtng are: sira, ciry and chuNy . The first three functions use the sro flle and the last function uses the COUNTY ftle.

output: The output is listed out in equivalent portions such that each page has an equivalent number of lines. The output to formatted in colums containing

Information depending on the function used. TABLES gives cEOTHERMAL SITE LOCATIONS.

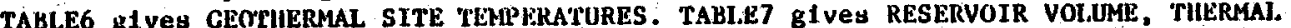

GRADIENT, DISSOLVED SOLIUS and FLOWRATE. CITYS gIVes CITY ID, CITY NAME, COUNTY NAME, POPUIATION, LATITUDE and LONGTTUDE. COUNTYS gives COUN'YY ID and COUNTY MAME.

SUBROUTINES USED: ABC, EUITRGLNAME, GET, OPEN, SIANAMES, VERIYYACCESS.

VARIABLES USED: RELATION 
Z Z1+TMLLES STW

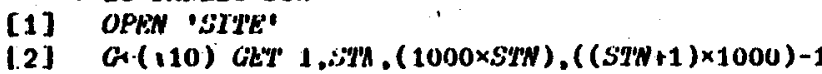

[3] GAABC G

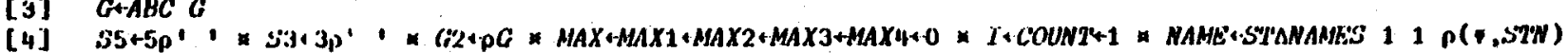

$[4] \quad \rightarrow((C 2) 11>50) \wedge(G 2[1] \leq 100)) / C K 1$

$[6]+((62[1]>160) \wedge((6)[1] \leq 150)) / C K_{2}$

[7] $\rightarrow(($ G2 1$]>150) \wedge(G 2[1] \leq 200)) / C K 3$

[8] MAX+(i2[1]

[9] $A L 1: Z 1+170 \mathrm{p}\left(\left(3.3 \mathrm{p}^{\circ} 1\right), \mathrm{NAMF},\left(10 \mathrm{p}^{\circ}\right.\right.$ ')

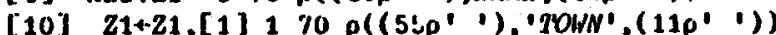

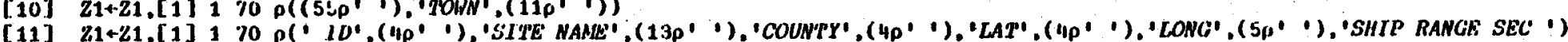

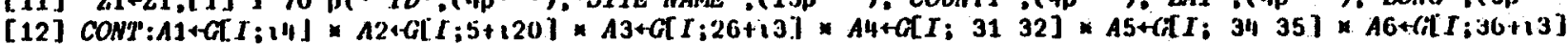

$[12] C O N P: A 1+G T ; 11] \times A 2+G[I ; 5+120] \times A 3+G[I ; 26+13.1 \times A 4+C A I ; 3132] \times A$

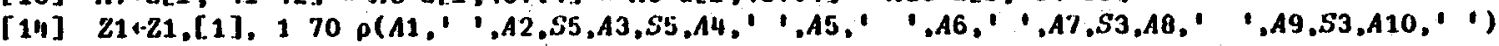

[15] $[+I+1 * \rightarrow(I \leq M A X) / C O M$

$[16] 21+21[1] 270 \mathrm{c}^{\prime}$ '

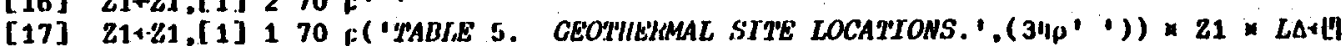

$[10] \rightarrow(\operatorname{MAX} 2=0) / L 0 \times+($ MAXY $=0) / C 1 \times \rightarrow($ MAXY $=0) / C^{2} \times+C 3$

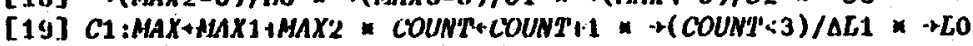

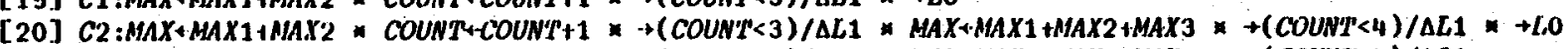

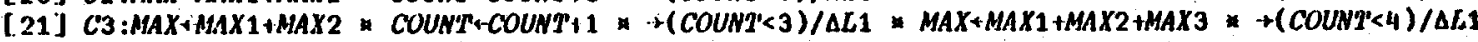

[22] MAX+MAX1+MAX2+MAX3+MAX $4 *(C O U N 2<5) / \triangle L 1 \times+L 0$

[23] CK1:MAX'MAX1+([(G)[1]:2)) $\times+(\operatorname{MAX1}=(L(G 2[1]+2))) / C H 1 * M A X 2+M A X 1-1 \times+\triangle L 1$

$[2 " 1] C H 1$ : $M A X 2+M A X 1$ * $+\wedge L 1$

[25] CK2:MAX+AIAX1+(l(G2[1]+3)) $\quad+(\operatorname{MAX} 1=(L(G 2[1]+3))) / C H 2$

$[20]+((M A X 1-(G 2[1] 13))>0.4) / C H 3 \times M A X 2+N A X 1 \times M A X 3+M A X 1-1 *+\triangle L 1$

[27] CII2:MAX24MAX3+MAX1 $* \rightarrow \Delta L .1$

[28] CII3:MAX2+HAX3+HAX1-1 + "AL1

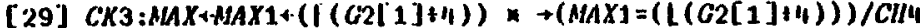

$[30] \rightarrow(((M A X 1-(C 2[1] 14))=0.75),((M A X 1-(C 2[1]+4))=0.5)) / K 1, K 2$ * MAX2+MAX1 MAX3+HAXM+AAX2-1 * $\rightarrow$ LL1

[31] K1:MAX $4+M A X 3+M A X X 2+M A X 1-1 \times+\Delta L 1$

[32] K2:MAX'J+MAX2+MAX1 NAX'1MAX1-1 $\rightarrow A L 1$

[33] CIII: MAXIN MAXX3+NAX2 $M A X 1 * \rightarrow A L 1$

[311] LOO:[N'IINI'TE 100

V 
V Z1बTABLK" STH

[1] OHEN 'SII't'

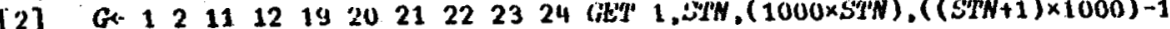

(3) $C \leftrightarrow A B C G$

[4] Gati:(G[1:]×1,1)/2(oG)[21]

$[6] \rightarrow((C 2[1]>50) \wedge((i 2[1] \leq 100)) / C K 1$

[.) $\rightarrow((c 2[1]]>100) \wedge(C 2[1] \leq 150)) / C K 2$

[.8] $\rightarrow((C 2[1]>150) \wedge((j 2[1] \leq 200)) / C K 3$

[9] $M A X+G 2[1]$

[10] $\triangle L 1: 21+170 \rho\left(\left(30 p^{\prime} '\right)\right.$, HAHE $\left._{0}\left(10 \rho^{\prime} \cdot\right)\right)$

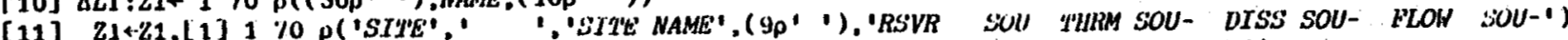

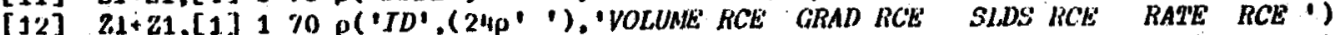

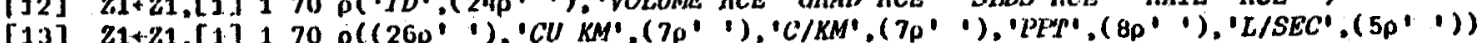

[14]

$[15] A 6+12 \rho G[T ; 3637] * A \% 13 p\left(f[I ; 37+13] * A B+12 p G[I ; 4142] * A 9+13 p G\left[I_{;} 42+13\right] * A 0 * 12 \rho G[I ; 4647]\right.$

$[16] A R K A Y+A 1, A 2, A 3, A 4, A 5, A 6, A^{7}, A 8, A 4, A 0$

[17] $M M P_{4}-14 A 1, X 1,20 A 1, X 1,6 A 1, X 1,2 A 1, X 3,3 A 1, X 2,2 A 1, X 4,3 A 1, X 2,2 A 1, X 1,3 A 1, X 3,2 A 1, X 2$

[18] $21+21,[1] 170 \mathrm{p}\left(\mathrm{MHI}^{\prime}\right.$ [W'MP' ARRAY

$[19] I+I+1$

$[20] \rightarrow(I \leq M A X) / C O N I$

[20]

21]

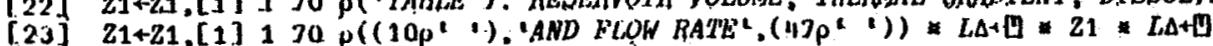

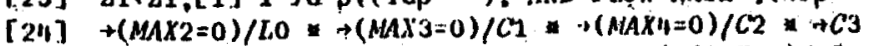

[25] C1:MAX + MAX1+MAX2 COUNI'+COUNT $11 \rightarrow($ COUNT $<3) / A L 1 * L O$

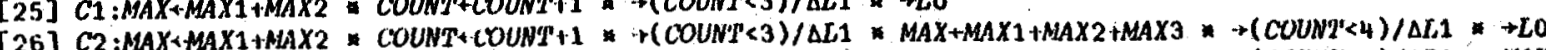

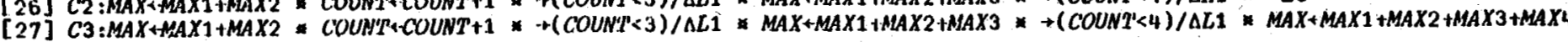

[28] $\rightarrow($ COUNT $<5) / \Delta L 1 * \rightarrow L O$

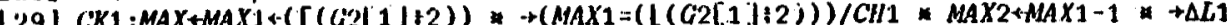

[.30] CIL1:MAX2 + MAX1 $\rightarrow \Delta L, 1$

[31] CK2:MAX +AAAX1+([(C2[1]:3)) $\rightarrow(\operatorname{MAX1}=(1(C 2[1]: 3))) / C H 2$

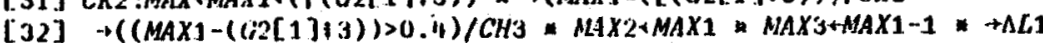

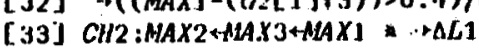

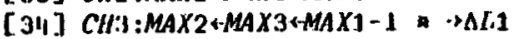

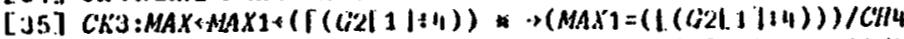

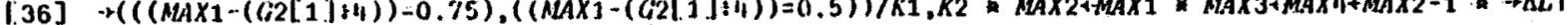

[3] 37] K1:MAX11+MAX3+MAX2+MAX1-1* * $\rightarrow L 1$

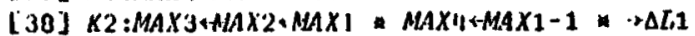

[39] CIII: MAX4+AAX $3+M A X 2+M A X 1 * \rightarrow \triangle L 1$

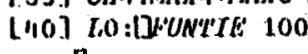
$\nabla$ 


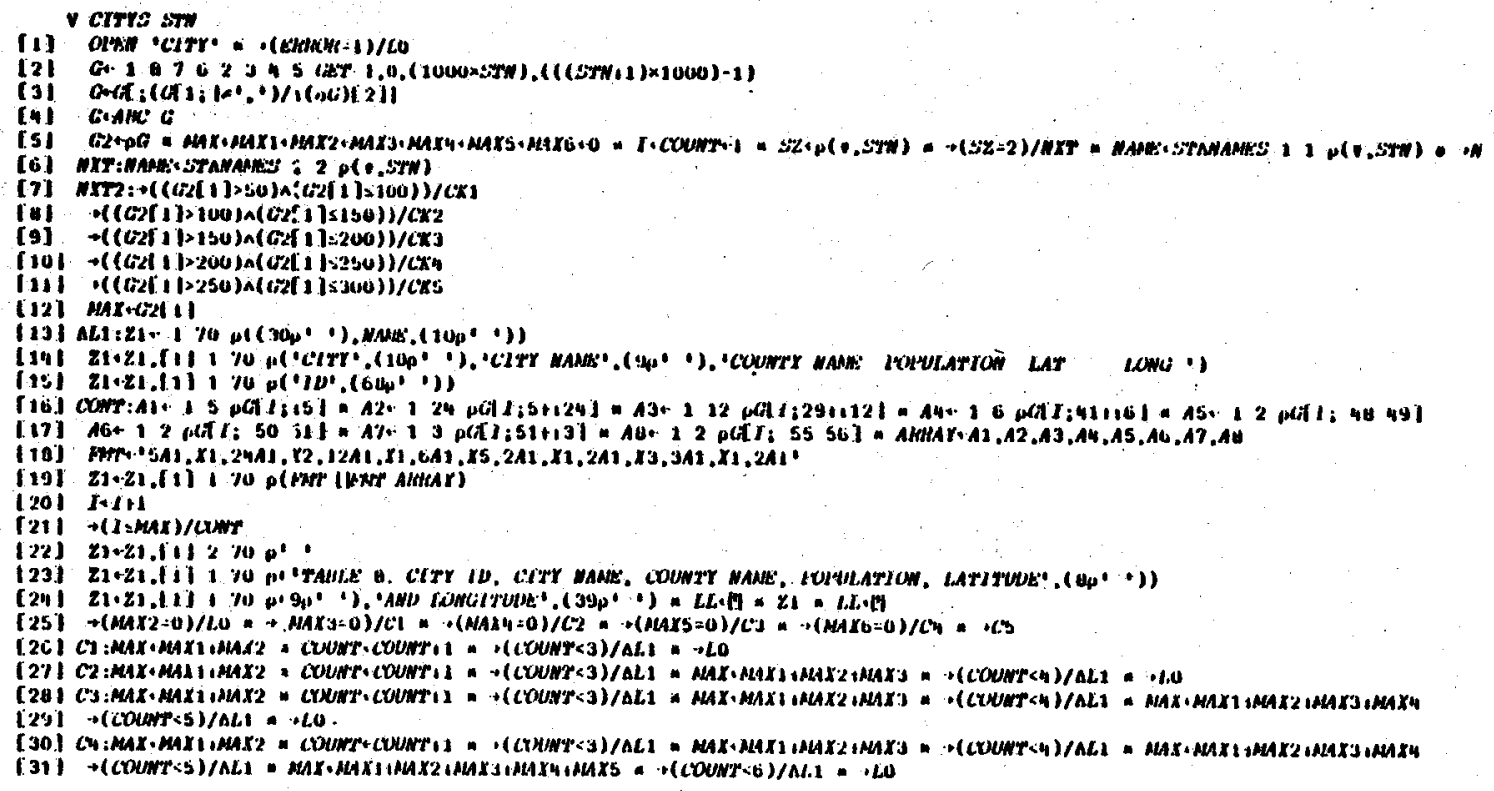




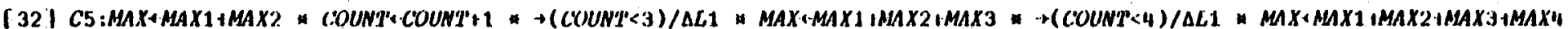

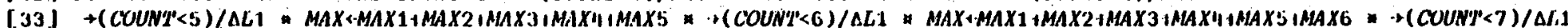

$\lfloor$ III! $\rightarrow$ L, O

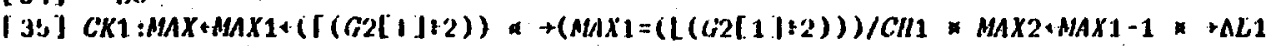

(1) 36$)$ CH1:MAX2+MAX1 $\rightarrow \triangle L 1$

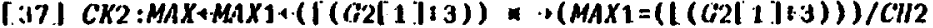

[38] $\rightarrow((\operatorname{MAX} 1-(C 2[1 \mid 13))>0.4) / C / 13 \times M A X 2+M A X 1 * M A X 3 \times M A X 1-1 * \rightarrow A L 1$

[39] C112:MAX2+NAX3rMAX] $\rightarrow \Delta L 1$

[110] CIII3:MAX2+HAX3+MAX1-1 * $: A L 1$

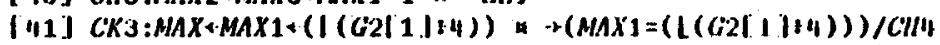

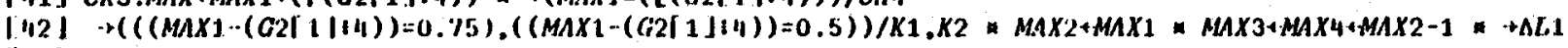

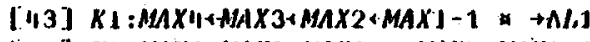

[14] K2:MAX3+MAX2 MAX1 MAX"1 + MAX1-1 +AL1

[155] CIIII:MAX4+AIAX34AUX24MAXI $* \rightarrow A L 1$

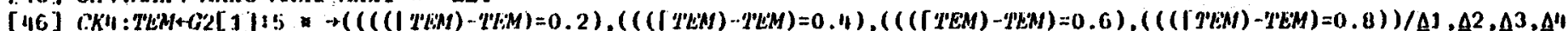

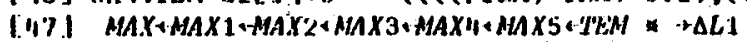

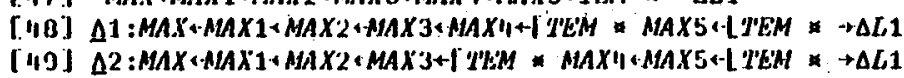

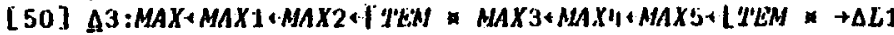

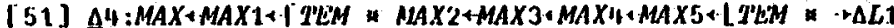

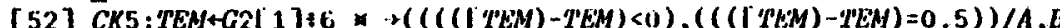

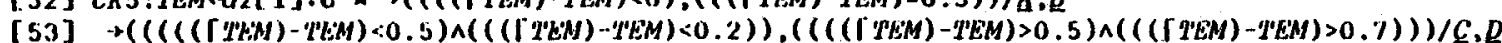

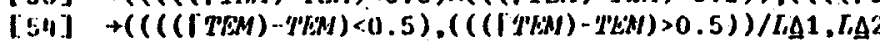

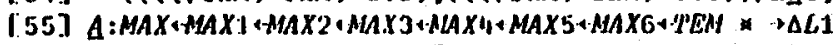

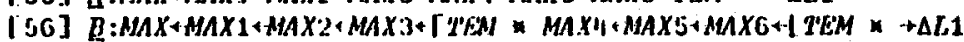

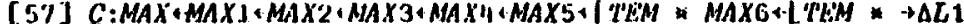

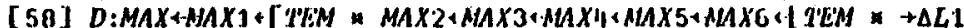

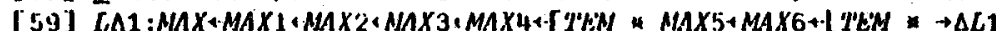

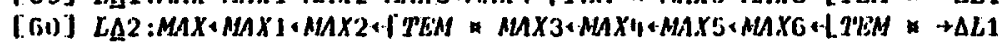

[61] LO:I EUNISL: DHNUAS

$\nabla$ 
$\nabla$ COUNTYS STW

[.1] OCBN 'COUWTY' (BLHOR=1)/LO

[2] Ga- $12 G E 71,0,(100 \times S T W),(((S T+N 1.1) \times 100)-1)$

[.3] $\operatorname{coc}[;(G[1 ;]=0 ;) / 1(p(f)[2])$

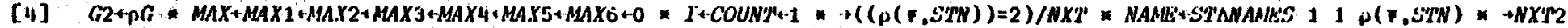

[.5] NXT:NAME+STANAMES; 12 o(T,STN)

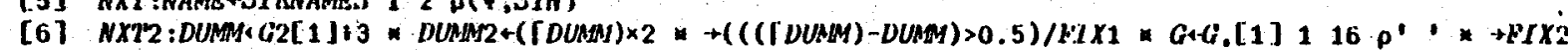

[6]

[a] $\operatorname{PIX2:} \cdot((G 2[1]>15 C) \wedge(G 2[1] \leq 300)) / C K 1$

[9] $\rightarrow((62[1]>300) \wedge((62[1] \leq 450)) / C K 2$

$[10]+\left(\left(C_{2}[1]>450\right) \wedge(C 2[1] \leq 600)\right) / C K 3$

$[11]+((C 2[1]>600) \wedge((\div 2[1] 5 / 50)) / C K 4$

$[12] \rightarrow((02[1]>\% 50) \wedge(02[1] \leq 900)) / C K 5$

[13] MAX+[DUMM

[14] $\triangle L 1: 21+170 \rho\left((30)^{\prime} !\right)$,NAME, (10p! '))

[15] $21+Z 1,[1]$ 1 70 o('COUNYY COUNIY NAME । 1)

$[16.1 \% 1+21,[1] 1 \%$ ('ID', 20p' '),'।

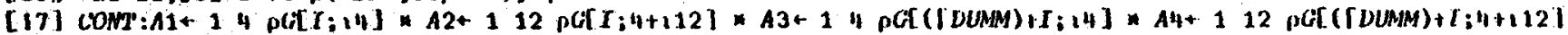

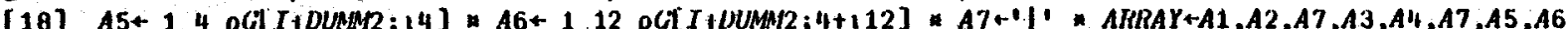

$[19] F M P+14 A 1, X 4,12 A 1, X 2,1 A 1, X 2,4 A 1, X 1,12 A 1, X 2,1 A 1, X 2,4 A 1, X 4,12 A 1$ '

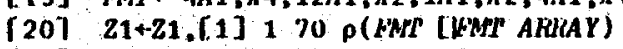

[21] $I+I+1$

[22] $\rightarrow($ I SMAX $) /$ CONI

[23] $Z 1+21,[1] 270 \rho^{\prime}$

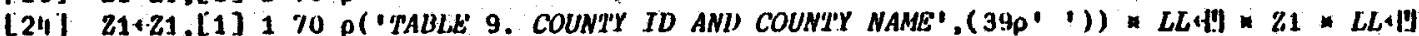

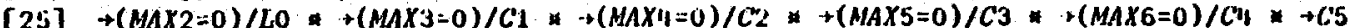

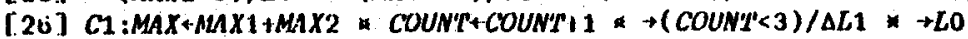

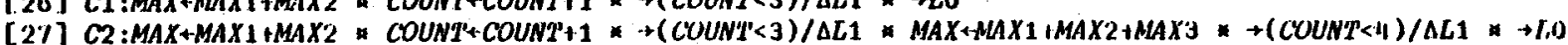

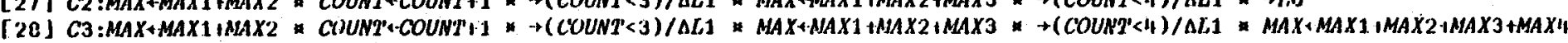

[29] $\rightarrow($ COUNT $<5) / \triangle L I *+L U$

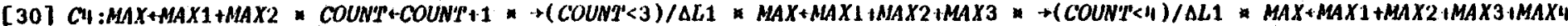

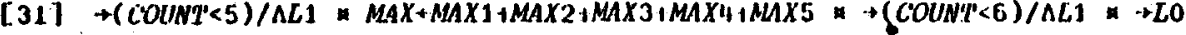




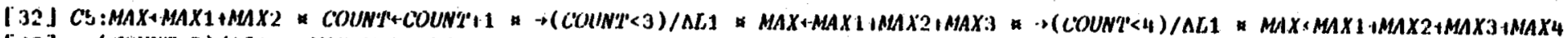

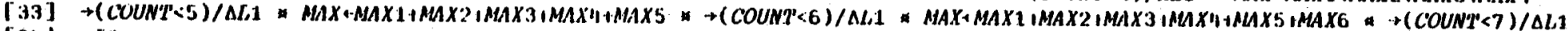

[311] $\rightarrow$ LO

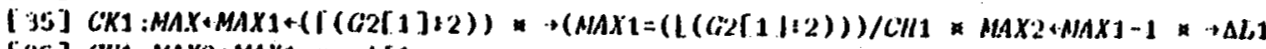

[.36]. CIII:MAX2+MAX1 $\rightarrow M L 1$

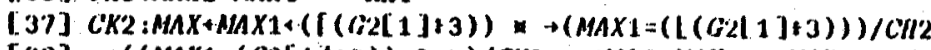

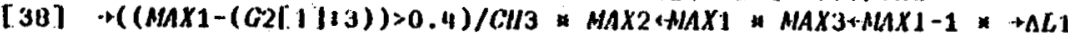

[39] CIII2:MAX2 MAX3 MAX1 * $-A C 1$

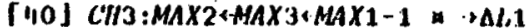

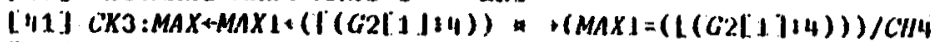

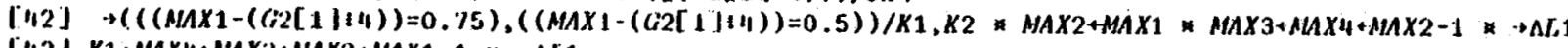

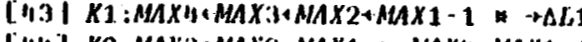

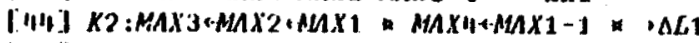

1451 CIII :NAXX+MAX:M+MAX2,MAX1 * $* \Delta L 1$

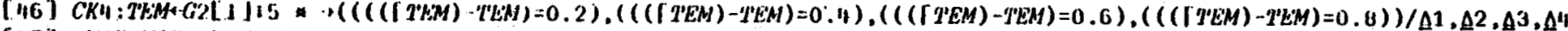

[.17] MAX+MAX1+MAX2+MAX3+MAXU+MAXS+1E'M $\rightarrow \triangle L L 1$

[1.8] Q1:MAX+MAX1+MAX2+MAX3+MAXY+FT'M * MAX5 +LI'E'N * $\rightarrow \triangle L 1$

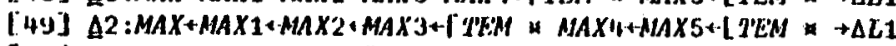

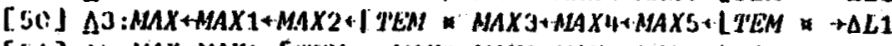

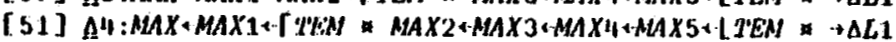

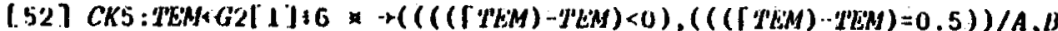

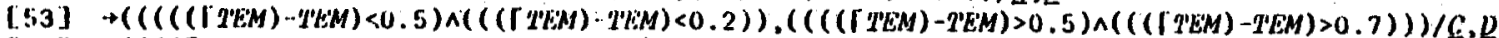

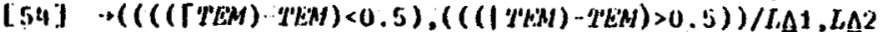

I.55] A:MAX+MAX] +MAX2+NAXX MAXI+ MAXX +MAX6+ TEM $\rightarrow \triangle L 1$

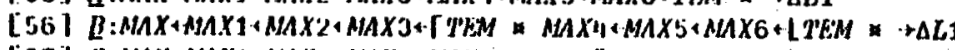

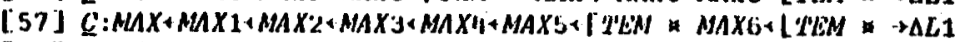

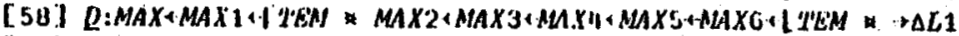

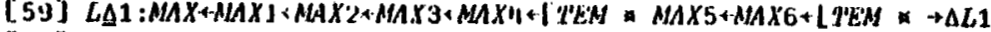

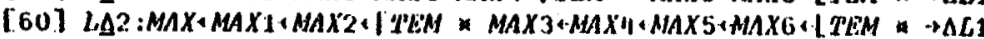

[61] I,0:[L'UNITIE' IIENIMT; 


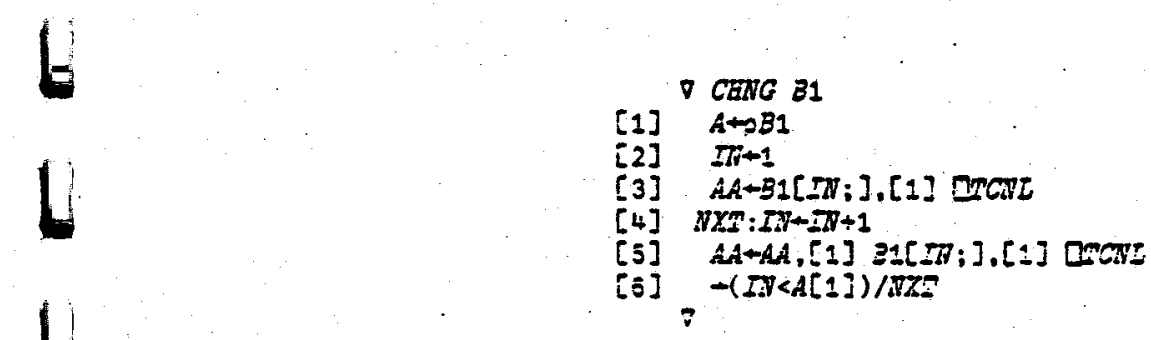

Euncelon ane: CONG

spout: A variable is matrix forn which this function will change inco a vector so that it cap be subnitted to the bigh speed printer. output: a vector of whatever lengeh it is needed to be, the variable alase is at. STBROTINES: מose

VARTABLES: AH 
$\nabla$ MB-RENOTE MC

[1] $2 R+D C$

[2] $2 k+, 14$

[3] $\quad M 2+(Q H=1(1) \vee(Q H=!) !) \vee(Q M=1-1)$

[4] QM[:2/10QK]+',

[E] $43-Q R+Q H 4$

Fusction name: Rrupt

Input: A matrix chat has bypheas, or parexthesis in Its contents wtich are to be renoved.

outpuc: a matrlx without byphess, or parexthes 1s.

SUBROUTINES: nORE

TARIABIES: 20Re 
REFERENCES

1. First Annual Report, Geothermal Energy Research,Development and Demonstration Program, Energy Research and Development Administration, ERDA 77-9, Apri1, 1977.

2. United States Geological Survey Circular 726, 1975.

3. Birsic,R.J., The Geothermal Steam Story or a Hot Tip from Mother Earth, Published by R.J. Birsic, June 1974 .

4. Reistad, G.M., Analysis of Potential Non-Electric Applications of Geothermal Energy and their Place in the National Economy, Lawrence Livermore Laboratory, UCRL 51747, February 1973.

5. Status Report: Geothermal Program Definition Project, (Part II: Geothermal Energy Development Status) Jet Propulsion Laboratory, Apri1 1975.

6. Sacarto, D.M., State Policies for Geothermal Development, National Conference of State Legislatures, November 1976.

7. Johnson, L.R., Simons, G., and Peterson, J., Energy Supply and Environmental Impacts- Unconventional Energy Sources, Study Module III - B, Northwest Energy Policy Project, 1977.

8. U.S. ERDA, A Bibliography, Geothermal Resources, Exploration, and Exploitation, July 1976.

9. U.S. DOE, Lega1 and Institutional Impediments to Geothermal Energy Energy Resource Development: A Bibliography, January 1978.

10. Hlatt, W.E., Jr., Unconventional Energy Sources, In Balmer et al., Northwest Energy Policy Project, 1977

11. Balmer, D.G., Mattersdorf, G.H., Kelley, K.R., and Foote, J.H., Institutional Constraints and opportunities, Report on Tasks 4-7, Study Module V-B, Northwest Energy Pollcy Project, 1977.

12. Brewer, W.A., and Lee, K.N., Institutional Constraints and opportunities, Report on Tasks 1-3, Stydy Module V-A, Northwest Energy Pollcy Project, 1977.

13. Schuller, C.R., Schilling, A.H., Cole, R.J., and Simon, G.D., Legal, Institutional and Political Problems in Producing Electric Fower from Geothermal Resources in California, Battelle Human Affairs Research Center, Richland, Washington, August 1976. 
14. Raschen, R., and Cook, W.S., Exploration and Development of Geotherma1 Resources, Conservation Division, Office of the Area Geothermal Supervisor, U.S. Geological Survey, Menlo Park, California, 1976.

15. Vollintine, L., and Weres, 0., Public Opinion Concerning Geothermal Development in Lake County, California, Lawrence Berkeley , aboratories, March 1976.

16. Vollintine, L., and Weres, 0., Public Opinion in Cobb Valley concerning Geothermal Development in Lake County, California, Lawrence Berkeley Laboratories, June 1976.

17. U.S. DOE, Solar, Geothermal, Electric and Storage Systems ProgramSummary Document for Fiscal Year Year 1979, March 1978.

18. Institutional Barriers Panel, First Report to Interagency Geothermal Coordinating Council, July 1976.

19. Institutional Barriers Panel, Second Report to IGCC, December 1976.

20. Institutional Barriers Pane1, Draft Report of Minutes of Meeting of Apri1 5, 1977, May 1977.

21. U.S. DOI Memorandum of Understanding for Geothermal Program, June 15, 1976.

22. Streamlining Taskforce of Interagency Geothermal Coordinating Council, Program and Objectives of the Interagency Geothermal Streamlining Task Force, June 1978.

23. Davidson, R., Geothermal Energy Prospectus in the Western States, Special Report to the Governors, Western Governers Regional Energy Policy office, May 1976.

24. Harric, R.C., Technical Status Report of the Geothermal Policy Project, National Conference of State Legislatures, March 1978.

25. Arizona Team of the Southwest Regional Geothermal Development Operations Research Project, Final Report, July 1978.

26. Colorado Team of the Southwest Regional Geothermal Development Operations Research Project, Final Report, July 1978.

27. Neyada State Team of the Southwest Regional Geothermal Development Operations Research. Project, Final Report, July 1978.

28. New Mexico Team of tje Southwest Regional Ceothermal Development Operations Research Project, Final Report, July 1978.

29. Utah State Team of the Southwest Regional Geothermal Development Operations Research Project, Final Report, July 1978. 
30. Mount, T.C., Chapman, L.D., and Tyrrel1, T.J., Electricity Demand in the United States: An Econometric Analysis, Oak Ridge National Laboratories, Oak Ridge, 1973.

31. Taylor, L.C., The Demand for Electricity: A Survey, The Bell Journal of Economics, 6:1, 74-110.

32. Johnston, J., Econometric Methods, McGraw Hill Book Co., N.Y., 1972.

33. Anderson, K.P., Sales and Load Growth of Participating Companies, Arizona Nuclear Power Project, 1974-1978, National Economic Research Association, New York, 1976.

34. Edison Electric Institute., Report on Economic Growth in the Future., New York, N.Y., 1976.

35. Barnes, B.B., Contributions of Emerging Technologies-Geothermal Energy, Federal Energy Administration, February 1977.

36. Chiang, C.W., and Hardy, Brain., Geothermal Space Heating for LowIncome Houses at Edgemont, S.D., Geothermal Resources Counc1l Annual Meeting, ( May 1977).

37. Reistad, G.M., Potential for Non-Electrical Applications of Geothermal Energy and their Place in the National Economy, Proceedings of Second United Nations Symposium on the Development and Use of Geothermal Resources, Vol 3, San Francisco, Calif., May 20-29, 1975, pp 2127.

38. Kunze, J.F., and Richardson, A.S., National Program Definition study for the Non-Electrical Utilization of Geothermal Energy, Idaho Falls, Idaho: Aerojet Nuclear Company, Idaho National Engineering Laboratory, June 1975.

39. Lineau, Paul J., OIT Adds a New Building to its Geothermal Heating System, Geo-Heat Utilization Center Quarterly Bulletin, Vol. 1, No. 2 , October 1975 .

40. Lineau, Paul J., Geoheat Utilization Center Established at Oregon Institute of Technology, Geo-Heat Ut1lization Center Quarterly Bulletin, Vol. 1, No. 1, May 1975.

41. Lund, J.W., The Utilization and Economics of Low Temperature Geothermal Water for Spapc Heating, Eleventh Intersociety Energy Conversion Engineering Conference Proceedings, 12 September 1976. 
DISTRIBUTION

\begin{tabular}{|c|c|c|c|}
\hline Organization & Location & Attention & Copies \\
\hline $\mathrm{DOE} / \mathrm{DGE}$ & Washington, DC & R. Oliver & 4 \\
\hline DOE/ALO & Albuquerque, NM & D. Denham & 2 \\
\hline DOE/ INEL & Idaho Falls, ID & R. Chappe11 & 10 \\
\hline REGIONAL ADVISORS & & & \\
\hline $\begin{array}{l}\text { Nat' } 1 \text { Conf. of State } \\
\text { Legislatures }\end{array}$ & Denver, Co & R. Harris & 1 \\
\hline $\begin{array}{l}\text { Rocky Mtn Mineral } \\
\text { Law Foundation }\end{array}$ & Boulder, CO & G. Vranesh & 1 \\
\hline Dept, of Intertor & Denver, CO & R. Sanchez, Jr. & 1 \\
\hline $\begin{array}{l}\text { Energy Research } \\
\text { Institute }\end{array}$ & Provo, UT & P. Larson & 1 \\
\hline Amax Exploration Inc. & Denver, $\mathrm{CO}$ & W. Dolan & 1 \\
\hline Phillips Petroleum Co. & De1 Mar, CA & C. Berge & 1 \\
\hline Union $011 \mathrm{Co}$. of $\mathrm{Ca}$. & Los Angeles, CA & J. Robinson & 1 \\
\hline Smith Too1 Co. & Irvine, $\mathrm{CA}$ & J. Kingsolver & 1 \\
\hline Nevada Power Co. & Las Vegas, NV & J. Arlidge & 1 \\
\hline Bank of Montrea1-Ca. & San Francisco, CA & J. Woods & 1 \\
\hline $\begin{array}{l}\text { Hydrothermal Energy } \\
\text { Corporation }\end{array}$ & Los Angeles, CA & D. Atkinson & 1 \\
\hline Project Consultant & Denver, $\mathrm{CO}$ & R. Meyer & 1 \\
\hline STATE TEAMS & & & \\
\hline $\begin{array}{l}\text { Solar Energy Research } \\
\text { Commission }\end{array}$ & Phoenix, AZ & F. Mancini & 2 \\
\hline Colorado Geo. Survey & Denver, CO & R. Pear1 & 2 \\
\hline Department of Energy & Carson City, NV & N. Clark & 2 \\
\hline N.M. Energy \& Minerals & Santa Fe, NM & G. Carlson & 2 \\
\hline State Engr's. Office & Salt Lake City, UT & S. Green & 2 \\
\hline
\end{tabular}


DISTRIBUTION (Continued)

\begin{tabular}{|c|c|c|c|}
\hline Organization & Location & Attention & Copies \\
\hline Mitre Corporation & McLean, VA & S. Goldstein & 1 \\
\hline $\begin{array}{l}\text { Science Applications } \\
\text { Inc. }\end{array}$ & La Jolla, CA & J. Welgand & 1 \\
\hline JHU/APL & Laure1, MD & F. Paddison & 1 \\
\hline $\begin{array}{l}\text { Four Corners } \\
\text { Regional Commission }\end{array}$ & Albuquerque, NM & K. Dotson & 25 \\
\hline $\begin{array}{l}\text { New Mexico Energy and } \\
\text { Minerals Department }\end{array}$ & Santa Fe, MM & G. Carlson & 45 \\
\hline $\begin{array}{l}\text { New Mexico Energy } \\
\text { Institute }\end{array}$ & Las Cruces, NM & A. Starkey & 45 \\
\hline Idaho Energy Office & Bolse, ID & M. Montgomery & 2 \\
\hline $\begin{array}{l}\text { Montana Dept. of } \\
\text { Natural Resources }\end{array}$ & Helena, MT & R. Breuning & 2 \\
\hline University of Wyoming & Laramie, WY & E. Meyer & 2 \\
\hline $\begin{array}{l}\text { South Dakota Office } \\
\text { of Energy Policy }\end{array}$ & Pierre, SD & M. Hohmann & 2 \\
\hline $\begin{array}{l}\text { North Dakota Energy } \\
\text { Office }\end{array}$ & Bismarck, ND & D. Connor & 2 \\
\hline
\end{tabular}


APPENDIX 1

\section{SUMMARY OF GEOTHERMI ALGORITHM - ELECTRIC USES (GIRORA-ELECTRIC)}

The model which follows posits the very simpie economic idea that an investment should be made if the present value of all net income streams is equal. to the investment required to generate ther when discounted at an interest rate appropriately high. ${ }^{1}$ If the amount of an investment is known, and the net income streams are known, the rate-of-return can be calculated. This model attempts to calculate the internal rate-of-return to a producer from a geothermal field for which electricity production is planned. This model can easily be nodified to fit any type of energy production from a geothermal field.

The basic equation is of the simple form for discounting cash flows:

$$
\text { Investment }=\sum_{t=1}^{T}\left(\text { Net Income } \text { I }_{t}\right)(1+R)^{-t}
$$

where Net Income = (Total Revenues) - (Total Operating Cost) - (Taxes)

Total Revenues $=$ (Price) (Quantity Output)

Total Operating Cost $=A$ Percentage of Investment

R: Rate-of-Return

$t:$ Each year, $t=1,2, \ldots, \mathrm{T}$.

T: Expected life span of the Investment

However, this rather fundarental notion is modified somewhat in GIRORAElectric due to the fact that some investments are made throughout the life of the project and thus must also be discounted to the present for proper evaluation. This yields the equation,

$$
\sum_{t=1}^{T}\left(\text { Investment }_{t}\right)(1+R)^{-t}=\sum_{t=1}^{T}\left(\text { Net Income }{ }_{t}\right)(1+R)^{-t}
$$

For a discussion of this principal, see Fred R. Glahe Macroecononics (New York Harcourt, Brace, Jovanich, Inc., 1973), pp. 91-95 
which reduces to

$$
\sum_{t=1}^{T}\left(\text { Investment }_{t}\right)(1+R)^{-t}=0
$$

If we set $(1+R)^{-1}=b$, then

$$
\sum_{t=1}^{T}\left(\text { Investment }_{t}-\text { Net } \text { Income }_{t}\right)^{t}=0
$$

Equation (1.4) is a polynomial with $T$ roots. Assuming a monotonic function there will be one real (non-imaginary) root (b) which permits a solution for the equation. This root can be found iteratively by Newton's technique. ${ }^{2}$ Fortunately, GIRORA-Electric has generated only monotonic functions.

GIRORA-Electric simulates all investment, revenue, and cost flows for a specified resource site, and inputs the flows to equation (1.3) and solves for R.

Investment, revenue and cost flows are divided into two sectors, a geothermal developer sector, and an electric utility sector. The geothermal developer's revenues are operating costs as perceived by the electric utility. The electric utility demand for geothermal fluid (or steam) is derived from the demand for electricity. Once a quantity of electricity has been specified, given resource characteristics, the quantity of fluid or steam is automatically specified. The price of the geothermal energy is the highest price consistent with the competitive price of electricity and the electric utility's regulated rate-of-return (both which are assumed to be known). The description of GIRORA-Electric begins with a description of the Electric Utility Sector.

\section{Electric Utility Sector}

The model first identifies the principal components of cost to the electric utility for each year ( $t$ ) of electricity production: capital costs (CC ${ }_{t}$ ), For a description of the mathematical technique involved, see C. C. T. Baker, Dictionary of Mathematics, (New York City, Hart Publishing Co, , 1966), p. 206. 
operating costs $\left(O M C_{t}\right)$, incoue taxes $\left(\operatorname{ITX}_{t}\right)$, property taxes $\left(\mathrm{PTX}_{t}\right)$, and energy $\operatorname{costs}\left(E N C_{t}\right)$

Capital costs are a function the investment (K) required for a specified level of capacity in kilowatts (CAP).

$$
K=(C A P)(C A P C)
$$

CAPC: capacity cost in dollars per $\mathrm{KW}$; an infut parameter

Capital costs are also a function of the regulated return to equity (ER), the bond rate (BR), the debt to equity ratio, and depreciation $\left(D E P R_{t}\right)$.

$$
\begin{aligned}
& E=(E K)(R)(E R),(\text { equity costs), } \\
& D=(D K)(K)(B R),(\text { debt costs), } \\
& \text { DEPR }_{t}=\left(D_{t}\right)(R), \quad \text { (depreciation), }
\end{aligned}
$$

and therefore

$$
C C_{t}=E+D+D E P R_{t}
$$

where, EK: equity share of capital; an input parameter,

DK: debt share of capital; an input parameter

$$
\begin{gathered}
(E K=1-D K) \\
D E P_{t} \text { : depreciation rate in year } t ; \\
D E P_{t}(T+1-t) / \sum_{t=1}^{T} t,
\end{gathered}
$$

where $T$ is the length of time for electricity production. The model provides for a fast write-off option.

Operating costs are a function of total investment and escalate through time.

$$
\begin{aligned}
& O M C_{t}=\left(O C_{t}\right)(K) \\
& O C_{t}=(O C B)(1+O \dot{C})^{t} \\
& O C_{t}: \text { operating percent of investment in year } t \text {; Input variable } \\
& O C B: \text { base rate; input variable, } \\
& O \dot{O C}: \text { escalation rate; input variable }
\end{aligned}
$$


Likewise, property taxes are a function of investment.

$$
P T X=(P T P)(K) \text {. }
$$

PTP: property tax rate; input varlable

Before income taxes are calculated, total revenues must be known. They are, of course, a function of the price of electricity $\left(P E_{t}\right)$ and the quantity of electricity $(Q E)$, which is a function of plant capacity. $P E_{t}$ is specified as an exogenous busbar price of electricity which is determined by the market and escalates over time.

$$
P E_{t}=(P B)(1+\dot{P})^{t}
$$

PB: Base busbar price of electricity; input variable.

$\dot{P}$ : escalation factor; input variable

$\mathrm{QE}=(\mathrm{CAP})(8760)(\mathrm{LF})(\mathrm{I}-\mathrm{UF})$

LF: Plant factor; an input variable,

UF: Plant use of power; an input variable.

Income taxes and energy costs must be determined simultaneously, because the price of the geothermal energy $\left(\mathrm{PHW}_{t}\right.$ ) is an element of both and moreover, $\mathrm{PHW}_{t}$ is the output of the utility sector for the model. The quantity of geothermal energy is determined by electricity plant requirements.

$$
\begin{aligned}
& \mathrm{QHW}=(\mathrm{CAP})(8760) \cdot(\mathrm{LF}) \\
& \mathrm{ENC}_{\mathrm{t}}=\left(\mathrm{PHW}_{\mathrm{t}}\right)(\mathrm{QHW}) \\
& \operatorname{ITX}_{t}=\{\operatorname{TXRT}\}\left\{\left[\left(P E_{t}\right)(Q E)\right]-\left[O M C_{t}\right]-[P T X]-\left[E N C_{t}\right]-[D]\right. \\
& \left.-\left[\operatorname{DEPR}_{t}\right]\right\}-\left\{[\mathrm{CRRT}]\left[\mathrm{K}_{t=1, t=2, t=3,}\right]\right\}
\end{aligned}
$$

TXRT: income tax rate; input variable

CRRT; Investment tax credit rate; input variable

Therefore,

$$
\begin{aligned}
\text { PHW }_{t}= & \frac{(\mathrm{TXRT})\left(\mathrm{DEPR}_{t}\right)+(\mathrm{CRRT})\left(\mathrm{K}_{t=1, t=2, t=3,}\right)-\left(\mathrm{CC}_{t}\right)}{(\mathrm{QHW})(1-\mathrm{TXRT})} \\
& +\frac{\left(\mathrm{PE} \mathrm{t}_{t}\right)(\mathrm{QE})-\left(\mathrm{OMC}_{t}\right)-(\mathrm{PTX})}{(\mathrm{QHW})}
\end{aligned}
$$


The price of energy in year ( $t$ ) from (15) and the quantity of energy from (12), that is, $E N C_{t}$ (equation 1.17), become total revenue for the geothermal energy producer.

\section{Geothermal Energy Producer Sector}

We will recall equation (1.17) ENC $_{t}$ for the producer, $\mathrm{REV}_{j}$, or total revenues.

$$
\mathrm{REV}_{j}=\mathrm{ENC}_{t}
$$

First, a discussion of the time period involved is necessary. The producer's time horizon is different from that of the electric utility. The years $t$ are elements of $T$, while the years $\mathrm{j}$ are elements of $\mathrm{J}$. $\mathrm{J}-\mathrm{T}=\mathrm{PPY}$, the "pre-production years." PPY is composed of two periods. The exploration period (EXP) and the development period (DVP), and thus EXP+DVP=PPY. Thus, the determinative direction is $E X P+D V P+T=J$. EXP is the period during which only exploratory wells are drilled. The development period begins with the drilling of the first production well.

The producer's activity is modeled somewhat differently from the utilities because the output of the simulation is a rate of return on the producer's equity. Thus, the first order of business is to determine what the level of the investment is in each year of the project. The producer's investment (PNV $j$ ) is a share of the total investment in year $J\left(P P R_{j}\right)$.

$$
\begin{aligned}
& P N V_{j}=(E P K)\left(P K K_{j}\right) \\
& P K K_{j}=\left(L N V_{j}\right)+\left(D N V_{j}\right)+\left(I D C_{j}\right)+\left(O P N V_{j}\right)
\end{aligned}
$$

EPK: Equity portion of capital; an input variable, $\mathrm{LNV}_{j}$ : Leasing investment in year $j$, in $\$$, DNV ${ }_{j}$ : Drilling investment in year $j$, in $\$$, $\mathrm{IDC}_{j}$ : Interest cost during construction in year $j$, in $\$$, $\mathrm{OPNV}_{j}$ : Other producer investments in year $j$, in $\$$, 
Total investment by the producer, cumulative to year $j$ is

$$
\mathrm{PK}_{j}=\sum_{\substack{j=0 \\ \mathrm{PKR}_{i}}}
$$

We will first describe the calculation of each element of PKR $_{j}$, beginning with DNV $_{j}$.

$\mathrm{DNV}_{j}=\left[\left(\frac{\mathrm{NPW}_{j}}{\mathrm{PSS}}\right)(\mathrm{ADDP})(\mathrm{CPFP})\right]+\left[\left(\frac{\mathrm{NIW}}{\mathrm{ISS}}\right)(\mathrm{ADDI})(\mathrm{CPFI})\right]$

$\mathrm{NPW}_{j}$ : New producing wells in year $j$.

PSS: Production Well Success ratio,

CPFP: Cost per foot, producing wells,

$N W_{j}:$ New injection wells in year $j$,

ISS: Injection well success ratio ( $=1$ usually),

ADDI: Average depth of injection wells,

CPFI: Cost per foot of injection wells.

The calculation of the elements of $\mathrm{DNV}_{j}$ is shown below.

$N P W_{j}=R P W_{j}-R P W_{j-1}$

$R P W_{j}$ : required producing wells, $R P W_{j}=0$ when $j<E X P+1$.

$R P W_{j}=\frac{R F R}{F R}$

FR: Flowrate in $1 \mathrm{~b} / \mathrm{hr}$ per producing we11,

$\mathrm{RFR}_{\text {CAP }}$ : required flowrate for rated capacity in $1 \mathrm{~b} / \mathrm{hr} .^{3}$

(CAP is stated here in $\mathrm{MW}$, not $\mathrm{KW}$, and is net of UF.)

$\operatorname{RFR}_{50}=1374.912 \mathrm{e}^{-0.01379 \text { (TEMP) }}$

$\operatorname{RFR}_{100}=2667.012 \mathrm{e}^{-0.01372 \text { (TEMP) }}$

3 Bechtel Corporation, Advanced Design and Economic Considerations for Commercial Geothermal $\frac{\text { Power }}{\text { California }}, \frac{\text { Plants at Heber and Niland, California. SAN-1124-2, San Francisco, }}{1977 .}$ 


$$
\begin{aligned}
& R F R_{150}=3959.226 e^{-0.013655 \text { (TEMP) }} \\
& R_{20 R_{20}}=5251.44 \mathrm{e}^{-0.01359 \text { (TEMP) }}
\end{aligned}
$$

Temperature decline is estimated, and resulting need for increased flow rate, thus producing wells, is modeled in the following way:

$$
\begin{aligned}
& \text { Temp }=\frac{T_{0}}{360}\left[358.344 e^{-0.00144(\text { Time) }}\right], \text { for CAP }=50 \mathrm{MW} \\
& \text { Temp }=\frac{T_{0}}{360}\left[357.474 \mathrm{e}^{-0.00233 \text { (Time) }}\right], \text { for CAP }=100 \mathrm{MW}
\end{aligned}
$$

$$
\text { Temp }=\frac{T_{0}}{360}\left[357.12 e^{-0.00322(\text { Time) }}\right] \text {, for CAP }=150 \mathrm{MW}
$$

Temp $=\frac{T_{0}}{360}\left[357.769 \mathrm{e}^{-0.00411 \text { (Time) }}\right]$, for CAP $=200 \mathrm{MW}$

$\mathrm{T}_{0}: \quad$ downhole temperature of brine in ${ }^{\circ} \mathrm{F}$, an input variable.

$$
N I W_{j}=R I W_{j}-R I W_{j-1}
$$

$\mathrm{RIW}_{j}$ : required injection wells in year $j$.

$R I W_{j}=R P W_{j}(P I R)^{-1}$

PIR: required ratio of producing wells to injection wells, in year $j$, an input varlable.

After initlation of power generation, $\mathrm{NPW}_{j}$ and $\mathrm{NIW}_{j}$ will generally take on a value of 0 or 1 , but are arbitrarily allocated during DVP.

The remaining elements of $\mathrm{PKK}_{\mathrm{j}}$ are discussed below:

$\left.\operatorname{LNV}_{j}=\left[(D P A C)(A C P W)\left(N W_{j}\right)\right]+[D P A C)(A C I W)\left(N I W_{j}\right)\right]$

DPAC: dollars per acre leasing cost; input variable, ACPW: acres per producing well; Input variable, ACIW: acres per Injection well; input variable.

$\mathrm{OPNV}_{j}=\operatorname{EXPN}_{n}+\mathrm{PIPN}_{j}+\mathrm{ONV}_{j}$

EXPN $_{j}$ : exploration investments, year $j$, 


$$
\begin{aligned}
& \operatorname{PIPN}_{j}: \text { piping investments, year } j \text {, } \\
& \mathrm{ONV}_{j} \text { : other investments, year } j \text {. } \\
& \operatorname{EXPN}_{j}=f(\operatorname{EXPN}) \\
& \text { EXPN }=(E X D)(C A P) \\
& \text { EXD: dollars per unit of capacity (electric needed for } \\
& \text { exploration, on average; input variable. } \\
& j>\operatorname{EXP}, \operatorname{EXPN}_{j}=0
\end{aligned}
$$

EXPN: total exploration investment in $\$$

(Note: $\operatorname{EXPN}=\sum_{j=0}^{\operatorname{EXP}} \operatorname{EXPN}_{j}$, where the distribution function is chosen arbitrarily)

$$
\operatorname{PIPN}_{j}=(P I P)\left(D_{j}\right)
$$

PIP: average percentage of drilling investment required for piping and similar field developments.

$$
\begin{aligned}
& O N V_{j}=\left(O P E_{j}\right)\left(D N V_{j}\right) \\
& O P E_{j}=(O P E B)(1+O P)^{j}
\end{aligned}
$$

Equations (137) and (1.38) calculate estimate additional investments in field development which are related to drilling expenses.

$$
\begin{aligned}
& I D C_{j}=[B R][D P K]\left[\sum_{i=0}^{j} L N V_{i}+\sum_{i=0}^{j} D N V_{i}+\sum_{i=0}^{j} O P N V_{i}\right] \\
& I D C_{j}=0 \text { for } j>P P Y . \\
& D P K: \text { debt portion of capital; DPK }=1-\text { EPK. }
\end{aligned}
$$

Thus, total revenues and all elements of investment have been calculated. What remain are uncapitalized elements of cost. OMCP $_{j}$ are operating and other current outlays.

$$
\mathrm{OMCP}_{j}=\left[\left(\mathrm{OCP}_{j}\right)\left(P K_{j}\right)\right]+\left[(B R)\left(\mathrm{PK}_{j}\right)(\mathrm{DPK})\right]+\left[\mathrm{PTXP}_{j}\right]
$$


$\mathrm{OCP}_{j}=(O C P B)(1+O C P)^{j}$

$O C P_{j}:$ operating percentage of investment outlay,

OCPB : base percentage; input variable,

o $\dot{C} \dot{P}$ : escalation factor.

$\operatorname{PTXP}_{j}:$ property taxes.

$\operatorname{PTXP}_{j}: \quad(P T P P)\left(\mathrm{PK}_{j}\right)$

PTPP: property tax rate; Input variable.

Income taxes are as follows:

$$
\begin{aligned}
\operatorname{ITXP}_{j} & =\{\operatorname{TXRT}\}\left\{\left[\left(\operatorname{REV}_{j}\right)(1-\lambda)(1-Z)\right]-\text { OMCP }_{j}-\left[(Y)\left(\text { DNVD }_{j}\right)\right]\right\} \\
& \left.-\left\{[\text { CRRT }]\left[(1-Y) \sum_{i=j-2}^{j} \operatorname{DNV}_{i}\right)\right]\right\} \\
\operatorname{DNVD}_{j} & =\sum_{i=1}^{j} \operatorname{DNV}_{i}\left(\operatorname{DEPRP}_{j-i+1}\right) \\
\operatorname{DEPRP}_{j} & =(D+1-j) / \sum_{j=1}^{D} j
\end{aligned}
$$

D: period chosen for depreciation; input variable

$\lambda$ : royalty rate, input variable,

$Y$ : percentage tangible investment, input variable,

2: depletion allowance, input variable,

$\mathrm{DNWD}_{j}$ : depreciation allowance in year $j, \$$

DEPRP $_{j}$ : depreciation rate in year $j$. Program contains fast writeoff option.

Finally, the model solves for $R$, the rate of return to equity for the geothermal energy producer from the Jth degree polynomial given by

$$
\sum_{j=1}^{J}\left\{\left[\left(\operatorname{REV}_{j}\right)(1-\lambda)-\left(\mathrm{OMCP}_{j}\right)-\left(\operatorname{IXXP}_{j}\right)\right]\right\} e^{-R j}=0
$$

The $R$ thus solved is one criterion for ranking geothermal resource sites and for comparing the outcomes of policy variable changes. 

APPENDIX 2

A DISTRICT SPACE HEATING MODEL - GIRORA: NONELECTRIC

To find the commercial feasibility of a geothermal resource for district heating, an internal rate of return model is developed, which is labeled as GIRORA-NONELECTRIC.

GIRORA NON-ELECTRIC is a simple but powerful simulation model which evaluates the economic potential of low temperature hydrothermal geothermal resources for district space heating. The model also provides a means for measuring the estimated economic impacts of varlations in a number of policy variables and site speciflc geophysical variables. In composite, these findings present an empirical collage which proves rlchly productive in evaluating the potential of low temperature geothermal energy.

GIRORA NON-ELECTRIC will be considered in detall below. The primary output of the model is an estimated measure of profitability for a geothermal producer developing a given geothermal resource site. On this basis, an ordinal ranking of low temperature sites in Region 4 can be compiled with respect to expected profitability. Such a ranking provides a best guess listing, ceteris paribus, of which sites might be expected to come "on Iine" and in what order they will be developed.

While a number of analytical models similar to the model described herein are being developed, each of the current generation is dependent upon the original GEOCITY model developed by Bloomster, et. al., at Batelle Pacific Northwest Laboratories ${ }^{1}$. Unfortunately for most analysts Interested in broad regional study, GEOCITY may be too elegant. "GEOCITY is an offshoot of the GEOCOST program. . ." a highly technical and extremely detailed $\overline{1}$ Bloomster, C. H., Fassbender, L. L. and McDonald, C. L. Geothermal Energy: Potential for District and Process Heating Applications in the U.S. An Economic Analysis. Battelle Paciflc Northwest Laboratories, Richiand, Washington, August 1977. 
simulation model which describes the development of high temperature resources for generating electricity ${ }^{2}$. As a result, GEOCITY might be more appropriately described as an engineering description of a district heating model than as a financial feasibility model.

For a broader research thrust with which little proprietary data or detailed district heating plans are avallable, many properties of GEOCITY : are redundant. Given the objectives of the present analysis, therefore, a simpler more functional model is necessary. Accordingly, Geothermal Internal Rate of Return Algorithm (GIRORA) has been developed.

From an analytical perspective, GIRORA NON-ELECTRIC is a discounted cash flow model which simulates required investments, revenues, and operating outlays for each year of the investment life of a geothermal anomaly. The model iterates for the internal rate of return which equates the suns of investment costs incurred with net revenues, discounted to the present. In simple terms, the model calculates $R$ (internal rate of return) from

$$
\sum_{t=1}^{T} \text { Investments }(I+R)^{-t}=\sum_{t=1}^{T} \text { Net Revenues }(1+R)^{-t}
$$

$T$ : Each year of the period, $t=1, \ldots T$

Simulating the life of an investment through $T$ years results in a $T$-th order polynomial which is solved iteratively by Newton's method of approximation for a unique real root, $R$. This root is a measure of the expected profitability of an investment. Ceteris Paribus, the greater the present value of all net revenues or the lowest cost of all investments throughout the productive life of a resource, the higher is $R$, and vice versa.

- Bloomster, C. H., Huber, H. D. and Walter, R. A. User Manual for GEOCOST: A Computer Model for Geothermal Cost Analysis; Vols. $1 \& 2$, Battelle Pacific Northwest Laboratories, Richland, Washington, 1975-1976. 
The heart of the simulation model is an expanded version of equation (2.1).

$$
\begin{aligned}
& \sum_{t=1}^{T} I N V(1+R)^{-t}=\sum_{t=1}^{T}\left(R E V_{t}-T C_{t}-T X_{t}\right)(1+R)^{-t} \\
& I N V: \quad \text { Equity Investment by project developers } \\
& R E V_{t}: \text { Total revenues in year } t . \\
& T C_{t}: \quad \text { Variable costs in year } t . \\
& T X_{t}: \quad \text { Taxes in year } t . \\
& R: \quad \text { Discount rate of internal rate of return. } \\
& t: \quad \text { Each year of project, } t=1, \ldots T \text {. }
\end{aligned}
$$

The remainder of the model Identifies explicitly each element of equation (2.2). Beginning on the left side of the equation and working to the right,

$$
\mathrm{INV}=(\mathrm{EK})(\mathrm{TNV})
$$

EK: Equity portion of capital.

TNV: Total Investment.

Equation (2.3) Indicates that the return to risk capital is of primary concern, since the return on debt capital will be specified by a bond rate.

Total investment costs include drilling investment, leasing costs, plant Investment, and interest paid during construction. During the early years of a geothermal resource Investment, i.e. during the pertod of resevoir exploration and development and plant construction, investment cost is the sum of all of the four components above. Thereafter, during the actual operation of the space heating system, total investment is the sum of drilling, leasing, and interest expenses. Thus,

$$
\begin{aligned}
& \mathrm{TNV}_{t}=D N V_{t}+L N V_{t}+I D C_{t}+P L V_{t}, t=E X P+D V P+C O N \\
& T N V_{t}=D N V_{t}+L N V_{t}+I D C_{t}, t \neq E X P+D V P+C O N
\end{aligned}
$$




$$
\begin{aligned}
& \mathrm{DNV}_{t}=\text { Drilling investment costs in year } t, \$ \\
& \text { LNV }_{t}=\text { Leasing Inves tment cost in year } t, \$ \\
& \text { PLV = Plant investment cost for transmission and distribution } \\
& \text { system, \$ } \\
& I D C_{t}=\text { Interest during construction in year } t, \$ \\
& \text { EXP = Exploration period in years, input variable } \\
& \text { DVP = Development period in years, input variable } \\
& \text { CON = Plant construction period in years, input variable }
\end{aligned}
$$

Each of the four components of the capital investment is estimated individually. The first is the drilling investment. Driling investment is a function of the number of geothermal production and injection wells required, the average depth of production and injection wells, and the cost per unit depth of proudction and injection wells.

$$
\begin{aligned}
& D_{t}=\left(\frac{N P W_{t}}{P S S}\right)(A D D P) \quad(C P F P)+\left(\frac{N I W}{I S S}\right) \quad(A D D I) \quad(C P F I) \quad(2.5) \\
& \mathrm{NPW}_{t}=\mathrm{New} \text { production wells to be drilled in year } t \\
& \text { PSS = Production well success ratio; input variable, } \\
& \text { ADDP = Average depth of production well in feet; input } \\
& \text { variable, } \\
& \text { CPFF = Drilling cost per foot of production well, } \$ \text {, } \\
& \text { input variable, } \\
& N W_{t}=\text { New injection wells to be drilled in year } t \text {, } \\
& \text { ISS = Injection well success ratio; input variable, } \\
& \text { ADDI = Average depth of infection well in feet; input } \\
& \text { variable, } \\
& \text { CPFI = Drilling cost per foot of Injection well, \$, } \\
& \text { input variable. }
\end{aligned}
$$

The number of production wells required is dependent upon the amount of hot water required to meet the space heating system demand and the flow rate of each production well. 


$$
\begin{aligned}
& \mathrm{RPW}=\mathrm{HWLBH} / \mathrm{FR} \\
& \mathrm{RPW}=\text { Required number of production wells to be drilled, } \\
& \mathrm{HWLBH}=\text { Hot water required to meet system demand, } 1 \mathrm{bs} / \mathrm{hr}, \\
& \mathrm{FR} \quad=\text { Flow rate of the production well, } 1 \mathrm{bs} / \mathrm{hr} \text {; input variable. }
\end{aligned}
$$

In return, the amount of hot water that is required to meet the demand of the space heating system is jointly dependent upon the estimated peak heat demand (PED) of the user and the usable heat (TD) from the avallable water. In the case of the former, the hot water required is assumed to be 75 percent of the amount necessary to supply peak heat demand, with the remaining 25 percent supplied by conventionally fueled backup units. Thus ${ }^{3}$

$$
\text { HWL BH }=0.75[\mathrm{PHD} / \mathrm{TD}]
$$

When estimating peak heat demand, the user mix or the percent of the population residing in single family dwelling units versus multiple family dwelling units is specified. In addition, the non-restdential demand is assumed to be 50 percent of residential demand.

$$
\begin{aligned}
& \text { PHD }=1.5[2.016(\Omega)+0.914(1-\Omega)] \text { [POP/3] [DEGD] } \\
& \text { DEGD }=\text { Heating degree days }\left({ }^{\circ} \mathrm{F}\right) \text { of the commity } \\
& \text { POP }=\text { Population of the comunity; input } \\
& \Omega \quad=\text { User mix }(0.0<\Omega<1.0) \\
& T D=\text { Usable temperature from the avallable hot water }
\end{aligned}
$$

As the hot water is transported from the resource site to the demand site, there will be a decline in temperature of hot water proportional to the distance. In addition, the usable temperature also depends on the downhole temperature of the hot water at the source. 4

3E. F. Wehlage, The Bastcs of Applied Geothermal Engineering, Geothermal Information Services, California, 1976.

${ }^{4} E$ G \& G Idaho Inc., The Potential for Utilizing Geothermal Energy in Reconstructed Sugar City, Idaho, TREE-116, January 1977. 


$$
\begin{aligned}
& \mathrm{TD}=-75.41+0.7142(\mathrm{TEMP}-\mathrm{DIST}) \\
& \text { TEMP = Downhole temperature of hot water at source, }{ }^{\circ} \mathrm{F} \text {; } \\
& \text { input variable, } \\
& \text { DIST = Distance from resource to the population center, } \\
& \text { miles; input variable. }
\end{aligned}
$$

Neither the temperature nor the flow rate is assumed to decline through time. Accordingly, once the production and injection wells are drilled at the beginning of the project, they are assumed adequate to support the estimated demand throughout the project iffe.

$$
\begin{aligned}
& N P W_{t}=R P W \quad t=1 \\
& N P W_{t}= \quad t>1 \\
& N I W_{t}= N P W_{t} \quad / P I R \\
& P I R= \begin{array}{l}
\text { Necessary production well to injection well ratio; } \\
\text { input variable. }
\end{array}
\end{aligned}
$$

The second component of investment expenditures is the leasing investment. Leasing investment is a joint function of the acreage. required for production and injection wells and the leasing cost per acre.

$$
\begin{aligned}
& L N V_{t}=(D P A C)(A C P W)\left(N_{t}\right)+(D P A C)(A C I W)\left(N I W_{t}\right) \\
& \text { DPAC = Leasing cost, \$ per acre; input variable, } \\
& A C P W=\text { Required acreage per production well; input } \\
& \text { vartable, } \\
& A C I W=\text { Required acreage per injection well; input } \\
& \text { variable. }
\end{aligned}
$$

The third component of investment cost necessary for the development of a low temperature geothermal resource is the plant investment cost. Plant investment consists of two components. The first is transmission investment, the costs incurred in transporting geothermal hot water from the supply site to the point of demand. The second component is distribution investment, which consists of costs incurred in distributing geothermal water to individual demand units. 


$$
\begin{aligned}
& \text { PLV }=\text { TRNV + DINV } \\
& \text { TRNV = Transmission costs, } \$ \\
& \text { DINV = Distribution costs, } \$
\end{aligned}
$$

Each of these two investment expenses is individually explained below.

The transmission cost is a dual function of the transmission line pipe diameter (which is itself directly related to the amount of hot water to be transported) and the distance from the geothermal resource to the population center. This cost includes the expense of schedule 10 international pipe, fittings and valves, $2.5^{\prime \prime}$ insulation, tin shield, labor and trenching, modified expansion loop and miscellaneous costs associated with transmission pipe installation ${ }^{5,6}$. More specifically,

$$
\begin{aligned}
& \text { TRNV }=7.2474+2.699 \text { (TPD) } \times 5280 \times \text { DIST } \\
& \text { TPD }=\text { Transmission Iine pipe diameter, inches } \\
& T P D=6.6+4.04 \times \text { HWLBH } \times 10^{-6}
\end{aligned}
$$

The transmission line pipe diameter is in each case adjusted to the next highest integer.

The distribution investment is a function of the peak heat demand.

$$
\mathrm{DINV}=0.75(115,000 \times \mathrm{PHD} / 3.413)
$$

The final component of investment cost is the interest expense incurred during construction.

5 C. L. McDonald and C. H. Bloomster, The Geoclty Model: Description and Application, Battelle Pacific Northwest Laboratories, Richland, Washington, June 1977.

6 S. S. Elnarsson, Geothermal Space Heating and Cooling, Second U. N. Symposium on the Development and Use of Geothermal Resources, San Francisco, California, 1975. 


$$
\begin{aligned}
& I D C_{t}=[B R]\left[\sum_{j=1}^{t}\left(D N V_{j}+L N V_{j}\right)\right][D K], \\
& t=E N+D V P, \\
& I D C_{t}=[B R] \sum_{j=1}^{t}\left(D N V_{j}+L N V_{j}+P L V_{j}\right)[D K], \\
& t=E X P+D V P+C O N, \\
& I D C_{t}=0, \quad t>E X P+D V P+C O N
\end{aligned}
$$

where

The sum of the present values of all of these four investment costs, Including drilling, leasing, plant investment and interest during construction is equated to the sum of the net revenues earned. Net revenue is defined as gross revenue (REV) less variable expenses (TC) and taxes (TX). Taking each of these items in order,

$$
\begin{aligned}
\mathrm{REV}_{\mathrm{t}}= & (\mathrm{AHD})(8760) \mathrm{P}(1+1)^{\mathrm{t}}(1-\lambda) \\
\mathrm{AHD}= & \text { Average heat demand of the population center, } \\
& \text { in million Btu/hr } \\
\mathrm{P}= & \text { Price of alternate fuel (natural gas), } \\
& \$ \text { per million Btu equivalent; input variable, } \\
\mathrm{I}= & \text { rate of growth of alternate fuel price; input variable, } \\
\lambda= & \text { Royalty rate; input variable } \\
\mathrm{AHD}= & \text { (PHD) (LF) } \\
\mathrm{PHD}= & \text { Peak heat demand of the population center in } \\
& \text { mllion Btu/hr } \\
\mathrm{LF}= & \text { Load factor; input variable }
\end{aligned}
$$

Gross revenue is alrectly related to the average heat demand placed upon the system. In theory, the demand for space heating is extremely variable, both as a diurnal and on an annual basis. As mentioned above, the space heating system is assumed to have installed capacity sufficient to fulfill 75 percent of estimated peak heat demand; the remaining demand is assumed to be supplied by an appropriate backup system. Over a period 
of a year, the space heating system will function at a certain percent of its peak capacity, and this element is defined as the load factor.

Having thus calculated gross revenues, net revenues are gross revenues less operating costs and taxes. Property taxes are assumed proportional to the plant investment. In the case of total cost,

$$
\begin{aligned}
& \left.T C_{t}=\left[O C E_{t}+(B R)(D R)+D E P R D_{t}\right] \times \sum_{j=1}^{t}\left(T N V_{j}-I D C_{f}\right)\right] \text {, } \\
& t=\operatorname{EXP}+\mathrm{DVP} \\
& \left.T C_{t}=\left[O C P_{t}+(B R)(D R)+D E P R D_{t}\right] \times \sum_{j=1}^{t}\left(\operatorname{TNV}_{j}-\mathrm{IDC}_{j}\right)\right] \\
& +\operatorname{PTX}_{t}, t=\operatorname{EXP}+\mathrm{DVP}+1, \mathrm{EXP}+\mathrm{DVP}+2, \ldots, \mathrm{T}(2.20 \mathrm{~b}) \\
& { }^{O C E_{t}}=\begin{array}{l}
\text { Percent of drilling costs which constitutes } \\
\text { operating expenses }
\end{array} \\
& { }^{O C P}{ }_{t}=\begin{array}{l}
\text { Percent of drilling and plant costs which } \\
\text { constitutes operating expenses }
\end{array} \\
& \text { PTX }_{t}=\text { Property taxes during year } \mathrm{T} \\
& \operatorname{PTX}_{t}=\left[P T X R_{t}\right][P L V] \\
& \operatorname{PTXR}_{t}=\text { Property tax rate } \\
& O C E_{t}=C(1+\dot{C})^{t} \\
& \mathrm{OCP}_{t}=\mathrm{PC}(1+\dot{P C})^{t} \\
& \text { C = Base year percentage; input variable, } \\
& \dot{c}=\text { Rate of Increase of } c \text { over time; input variable } \\
& \text { PC = Base year percentage; input varlable } \\
& \overrightarrow{P C} \quad=\text { Rate of increase of PC over time; input varlable } \\
& \text { DEPRD }_{t}=\text { Depreciation for drilling investment in year } t \\
& \operatorname{DEPRD}_{t}=(D+1-t) / \sum_{j=1}^{D} j \\
& \text { D } \quad=\text { period of depreciation for drilling and } \\
& \text { leasing (Input) }
\end{aligned}
$$


Finally, income taxes are computed

$$
\begin{aligned}
& \operatorname{TX}_{t}=\{\operatorname{TXRT}\}\left\{\left[\mathrm{REV}_{t}(1-\mathrm{z})\right]-\left[\mathrm{TC}{ }_{t}-\left(B R \cdot \mathrm{DK}+\mathrm{DEPRD}_{t}\right)\right.\right. \\
& \left.\left(\sum_{j=1}^{t} \mathrm{TNV}_{t}-\mathrm{IDC} \mathrm{t}_{t}\right)\right] \\
& \left.\left.-\left[Y-\left(\text { DEPRD }_{t}\right) \sum_{j=1}^{t} L N V_{j}\right)+\operatorname{DNVD}_{t}+\operatorname{DEPRN}_{t} \cdot \operatorname{PLV}\right]\right\} \\
& \left.-\left\{[\operatorname{CRRT}]\left[(1-Y) \sum_{j=1}^{t} L_{j}+P L V\right\}\right]\right\} \\
& \text { TXRT = Tax rate (Input) } \\
& z \quad=\text { Depletion allowance (Input) } \\
& \mathrm{Y} \quad=\text { Percentage tangible investment (Input) } \\
& D N V D_{t}=A \text { dollar amount for depreclation of drilling } \\
& \text { investment in year } t \\
& \text { DLPRN = Depreciation for plant investment in year } t \\
& \text { CRRT = Investment tax credit rate (Input) } \\
& \operatorname{DNVD}_{t}=\sum_{j=1}^{t} D^{\prime} \cdot D^{\prime} D_{t-j+1} \\
& \operatorname{DEPRN}_{t}=\quad 0, \quad t \leq \mathrm{PPY} \\
& =(N+P P Y+1-t) / \sum_{j=1}^{N}, \quad t>P P Y
\end{aligned}
$$

N = Depreciation period for plant; input variable

All of the approprlate terms in equation (2.2) are now known, except for $R$. Any variables which have not been identified are manual inputs to the simulation model. Equation (2.2) is a polynomial of order $T$, and it is solved iteratively for a value of $R$. 
APPENDIX 3

THE GEOTHERMAL RPPM DATABASE

The Regtonal Program Progress Monitor (RPPM) Database was created for the ReglonaI Operations Research Program for Development of Geothermal Energy in the Southwest United States, ERDA Contract No. EG-77-S043992.

The Database has been Implemented on the IBM System/360 at the New Mexico State University (NMSU) Computer Center. The APL language has been used in file cefinition, update, retrleval and formatting. Use of APL as the host language permits interactive access to the Database from core team offices throughout the MMSU campus.

The Database contains no classified or proprietary data. Since the Database is designed to meet Profect needs, it is likely to be modified in the future as Project requirements change. This report describes the Database as of May 5, 1978. The status of the Database at any time may be determined by contacting the Core Tean at NMSU.

This report was prepared by John Nance, Roy Heath and Pat O'Dea of the Physical Sclence Laboratory, New Mexico State University.

\section{DATABASE STRUCTURE}

The RPPM Database consists of three relations: SITE, CITY and COUNTY. The SITE relation contains data on approximately 350 geothermal locations in the five state Southwest Region. The data has been collected from a varlety of sources. A source code has been provided for each data 1tem, where source might be of importance. A description of sources and source codes may be found in Table 4.

The EITY relation contains data on apfroximately $1000 \mathrm{U}$. S. cities in or near the Southwest Region. The population data was complled from the 1970 Report of the Bureau of the Census. It includes al1 incorporated places with a population greater than 500 persons and all unincorporated places with a population greater than 1500 persons. The London Times Atlas was the primary source for latitude and longitude.

The COUNTY relation contains approximately 450 countles in or near the Southwest Region. 
DOMAIN

NUMBER

DOMAIN

UNITS

FIEID

* $1 \quad$ **Site ID

$-$

Site Name

-

-

* 3 County Code

* 4

Latitude

Degrees North

Latitude

Longitude

Minutes North

Degrees West

Minutes West

Township

Range

Section

-

-

$-$

Reservolr Volume

Source of Reservolr Volume

Substrface Temperature

Source of Subsurface Temp

Surface Temperature

Source of Surface Temp

Estimated Temp (Swanberg)

Neasured Telm (Swanberg)

Thermal Gradient

20

$* 21$

22

$* 23$

24

Source of Thermal Gradient

Dissolved Solids

Source of Dissolved Sollds

Flowrate

Source of Flowrate

cubic kilometers

-

degrees Celsius

-

degrees Celsius

SIZE

Table 1. Contents of the SITE F1le (Relation)

DONAIN

DOMAIN

UNITS

FIELD

NLEABER

**City ID

Latitude

Latitude

Longitude

Long1tude

Population

County Name

C1ty Name

$\begin{array}{cc}\text { - } & \mathbf{5} \\ \text { Degrees North } & \mathbf{2} \\ \text { Minutes North } & 2 \\ \text { Degrees West } & 3 \\ \text { Minutes West } & 2 \\ - & 6 \\ - & 12 \\ - & 25\end{array}$

Table 2. Contents of the CITY File (Relation)

*Indicates a valid qualifying domain

**Indicates primary key 
DOMAIN

NUMBER

* 1

2
DOMAIN

**County ID

County Name
FIELD

UNITS

SIZE

4

12

Table 3. Contents of the COUNTY File (Relation)

*Indicates a valld qualifying domain

**Indicates primary key

SOURCE

CODE

1 U. S. Geological Survey, Circular 726

2 Dr. C. Swanberg, or NMSU Dept. of Earth Sciences

3 MITRE

4. Arizona State Team

5. Colorado State Team

6 Nevada State Team

7 New Mexico State Team

8 Vtah State Team

9 U. S. Dept. of Energy

10 NOAA

11

12

13

14

15

16

17

18
New Mexico Energy Institute GEOTHERM Database

W. K. Summers, or New Mexico Bureau of Mines and Mineral Resources

U. S. Bureau of the Census Report for 1970

U. S. Bureau of the Census Update 1976

London Times Atlas

U. S. Geologlcal Survey - Waring

Stone \& Mizell, or New Mexico Bureau of Mines and Mineral

Resources

Table 4. Source codes used in the RPPM Database 


\section{DATABASE ACCESS}

The RPPM Database may be accessed through terminals comunicating with the System/360 at the NMSU Computer Center. Access requires approval of the Ceothermal Operations kesearch Project Director, and use of a private APL workspace. Access irom a public worispace is not perifited.

Presentiy, users are permitted to retrieve data, but not modify it. Update operations may be performed only by the Database Administrator.

\section{DATA RETRIEVAI}

The APL routines necessary for data retrleval are found in the workspace 310733401 RPPM. After signing on to a private API workspace, execute the foliowing command.

$$
\text { )LOAD 31073340I RPPM }
$$

A description of commands follows.

\section{OPEY 'reiation name'}

The OPIN comand must be executed before any retrievals are attempted. Or.'5 one relation may be "open" at once. Valld relation names are SITE, CIMY, and CCYNTY. Refer to the preceding section, DATABASE STRUCTURE (Tables $i, 2$ and 3), for a detafled description of each relation.

\section{BFZ1 GET arg?}

The GEI command actualiy retrleves data from the Database. It may be executed oniy after an OFEN command has been issued. It accesses only the curzentiy "open" relation.

Argl is a numerical list of domains being retrieved. It may include any domain number or comblnation of domain zumoers.

Arg2 ¿s a Four element numeric vector. Element one is the number of the qualifying domain (the domain over which the search is to occur). Only those domains wicin contain numerlc dasa can be searched, and are indicatai in the section DATABASE SInUCTURE. Elerents three and Eour, respectively, provide the lower and upper limits of the search. Elament two restricts the search by state as follows:

$\begin{array}{ll}4 & \text { Arizona } \\ 5 & \text { Colorado } \\ 6 & \text { Nevada } \\ 7 & \text { New Mexico } \\ 8 & \text { itah } \\ 0 & \text { no restriction }\end{array}$


Retrieval examples using GET:

1213 GET 130100200

This command retrieves the Site ID (domain 1), Site Name (domain 2), and Subsurface Temperature (domain 13) for each site in all states (because element 2 of arg2 = 0 ) whose Subsurface Temperature (element 1 of arg2 = 13) Is greater than or equal to 100 and less than or equal to 200 (elements 3 and 4 of arg2).

\section{GET 1172.261000}

This command retrieves Site ID (domain 1), Site Name (domain 2), and Reservoir Volume (domain 11) for each site in New Mexico (element 2 of arg2 = 7) whose Reservoir Volume (element 1 of arg2 = 11) Is greater than or equal to 2.26 and less than or equal to 1000 (elements 3 and 4 of $\arg 2$ ).

\section{GET 36601601}

This command retrieves the Surface Temperature (domain 15) of each site in Nevada whose County Code (element 1 of arg2) is equal to 601 .

To store the results of a retrleval for future processing, the syntax of the GET command may be altered as follows:

$$
\mathrm{X}+\operatorname{argl} \text { GET } \arg 2
$$

where $X$ is a varlable name provided by the user.

\section{CLOSE}

Each "open" relation must be "closed" with the CLOSE command before another may be "opened". It is not necessary to specify the name of the relation to be "closed". 


\begin{tabular}{|c|c|c|c|c|c|c|c|c|c|}
\hline & & $2 k$ & & & & & & & \\
\hline$I D$ & SITE NAME & COUNTY & Le & $\Delta T$ & 20 & & $\begin{array}{l}\text { TOWN } \\
\text { SEIP }\end{array}$ & RANGE & $S E C$ \\
\hline 4017 & AGUA CALIENTE & 407 & 33 & 0 & 113 & 18 & & & \\
\hline 4018 & ARTESIAN $E W$ & 405 & 32 & 43 & 109 & 43 & & & \\
\hline 4026 & ARTESIA AREA & 405 & 32 & 41 & 109 & 42 & & & \\
\hline 4022 & BARNGAN MTW & 414 & 33 & 7 & 113 & 25 & & & \\
\hline 4024 & BOWIE AREA & 402 & 32 & 19 & 109 & 29 & & & \\
\hline 4016 & BUCKBORN AREA & 407 & 33 & 25 & 111 & 42 & & & \\
\hline 4032 & CASA GRANDE & 411 & 32 & 53 & 111 & 45 & $6 S$ & $6 E$ & \\
\hline 4012 & CASTLE ES & 413 & 33 & 59 & 112 & 22 & & & \\
\hline 4008 & CAT TANK & 405 & 32 & 44 & 109 & 23 & & & \\
\hline 4002 & CIIFTON BOT SPRINGS & 406 & 33 & 4 & 109 & $18^{\circ}$ & & & \\
\hline 4007 & COFFERS ES & 408 & 34 & 42 & 113 & 35 & & & \\
\hline 4006 & COOLIDGE ES & 404 & 33 & 10 & 110 & 32 & & & \\
\hline 4013 & COOLIDGE AREA & 411 & 32 & 54 & 111 & 34 & & & \\
\hline 4031 & COOLIDGE & 411 & 33 & 02 & 111 & 35 & $5 S$ & $8 E$ & \\
\hline 4005 & EAGLE CLEEEX E $S$ & 402 & 33 & 3 & 109 & 26 & & & \\
\hline 4029 & ELOY & 411 & 32 & 45 & 111 & 35 & $10 S$ & $8 E$ & \\
\hline 4030 & FLOREMICE & 411 & 33 & 05 & 111 & 18 & $4 S$ & $10 E$ & \\
\hline 4004 & GITIARD ES & 406 & 32 & 58 & 109 & 21 & & & \\
\hline 4015 & EOOKERS ES & 402 & 32 & 20 & 110 & 14 & & & \\
\hline 4011 & $I N D I A N E S$ & 405 & 33 & 0. & 109 & 54 & & & \\
\hline 4000 & JAVELINA PEAK & 405 & 32 & 31 & 109 & 26 & & & \\
\hline 4020 & ENCATS SPA & 405 & 32 & 45 & 109 & 45 & & & \\
\hline 4033 & MALMOTZ & 411 & 32 & 42 & 110 & 35 & $9 S$ & $7 E$ & \\
\hline 4025 & MOBIL $A R E A$ & 407 & 33 & 12 & 112 & 22 & & & \\
\hline 4019 & $M m$ GEABAM & 405 & 32 & 52 & 109 & 45 & & & \\
\hline 4021 & PALOMAS MTS & 414 & 33 & 0 & 113 & 31 & & & \\
\hline 4034 & FAPAGO FARMS & 410 & 31 & 47 & 112 & 19 & $19 S$ & $1 E$ & \\
\hline 4028 & FEOEWIX TEMPE & 407 & 33 & 24 & 111 & 56 & $1 N$ & $4 E$ & \\
\hline 4001 & FOWER RANCE AREAS & 407 & 33 & 17 & 111 & 41 & & & \\
\hline 4014 & RADIUM SPRINGS & 414 & 32 & 44 & 114 & 4 & & & \\
\hline 4010 & SAFFORD AREA & 405 & 32 & 51 & 109 & 34 & & & \\
\hline 4023 & TEEEBA & 407 & 32 & 56 & 112 & 45 & & & \\
\hline 4027 & TOM WIECE WARM SPR & 405 & 33 & 4 & 109 & 59 & & & \\
\hline 4003 & VERDE EOT SPRINGS & 413 & 34 & 22 & 111 & 43 & & & \\
\hline 4035 & NIRIEUF & 408 & 34 & 39 & 113 & 39 & $15 N$ & $3 W$ & \\
\hline
\end{tabular}

IAELE 5. GEOTRERMAL SITE LOCATIONS. 
ID SITE RAME

5047 ANTELOPE BIRDSIE

5005 BRANDS RANCE APTESIA

5025 BROWN CANYON THRML A

5029 CANON CITY EOT SPRIN

5050 CEBOLLA BOT SPRINGS

5016 CEMENT CREEK WS

5021 CHALK CR MT PRINCETN

5022 CHALK CFEEX WRIGET E

5023 CEALK CREEK HOETENSE

5024 CBALK CREEK WOOLHING

5033 CLARK ARTESIAN WELL

5014 COIONEL CEIND EOT WE

5015 CONUWDRUM EOT SERITG

5020 COMTOWWOOD CREER TUM

5002 CRAIG WARM WATER WEL

5039 DEXTER MCINTYRE

5032 DON $K$ RANCE ARIESIAN

5010 DOTSETO WARM SPRINGS

5054 DUNION GEYSR PARADIS

5041 DUTCE CROWTY STINKNG

5008 ELDORADO

5043 EOFF ARTESIAN WELL

5031 ELORENCE ARIESIAN WE

5030 FREMONT NATATORTUM

5061 FULL W WIDER WARM SP

5011 GLEWWOOD EOT SPRTWGS

5019 BARTSELL BOT SERINGS

\begin{tabular}{|c|c|c|c|}
\hline COUNTY & IA & $4 T$ & LOI \\
\hline 540 & 37 & 45 & 107 \\
\hline 529 & 40 & 42 & 106 \\
\hline 508 & 38 & 39 & 106 \\
\hline 522 & 38 & 26 & 105 \\
\hline 526 & 38 & 16 & 107 \\
\hline 526 & 38 & 50 & 106 \\
\hline 508 & 38 & 44 & 106 \\
\hline 508 & 38 & 44 & 106 \\
\hline 508 & 38 & 44 & 106 \\
\hline 508 & 38 & 43 & 106 \\
\hline 551 & 38 & 15 & 104 \\
\hline 515 & 38 & 52 & 107 \\
\hline 549 & 39 & 1 & 106 \\
\hline 508 & 38 & 49 & 106 \\
\hline 541 & 40 & 30 & 107. \\
\hline 511 & 37 & 18 & 105 \\
\hline 522 & 38 & 10 & 105 \\
\hline 519 & 39 & 38 & 107 \\
\hline 517 & 37 & 46 & 108 \\
\hline 504 & 37 & 2 & 106 \\
\hline 507 & 39 & 56 & 105 \\
\hline 504 & 37. & 11 & 107 \\
\hline 522 & 38 & 25 & 105 \\
\hline 522 & 38 & 28 & 105 \\
\hline 555 & 38 & 18 & 105 \\
\hline 523 & 39 & 33 & 107 \\
\hline 547 & 39 & 1 & 105 \\
\hline
\end{tabular}

TOWN

SEIP RANGE SEC

$40 N \quad 2 W \quad 1$

9N $81 W \quad 31$

$51 N \quad 8 E \quad 23$

18S $\quad 70 \mathrm{~W} \quad 31$

$46 N \quad 2 W \quad 4$

$14 S \quad 84 W \quad 18$

15S $78 \mathrm{~W} \quad 19$

$15 S \cdot 79 W \cdots 24$

$15 S \quad 79 W \quad 24$

15S $\quad 79 \mathrm{~W} \quad 24$

21S $65 \mathrm{~W} \quad 1$

$14 S: 92 W \cdot 14$

$12 S \quad 85 \mathrm{~W} \quad 16$

$14 S: 79 \mathrm{~W} 21$

6N $91 \mathrm{~W} \quad 1$

$35 N \quad 11 E \quad 8$

$22 S \quad 68 \mathrm{~W} \quad 5$

5S $\quad 87 W \quad 12$

$41 N \quad 11 W \quad 32$

$32 N \quad 2 E \cdot \quad 18$

1S $\quad 71 W \cdot 25$

$34 N \quad 1 W \quad 7$

19S $68 W \quad 7$

185 4OW 26

6S $89 W \quad 9$

$12 S \quad 75 W \quad 8$

TABLE 5. GEOTHERMAE SITE LOCATIONS. 


\begin{tabular}{|c|c|c|c|c|c|c|c|c|c|}
\hline & & COLO & & & & & & & \\
\hline ID & SITE NIAME & COUNTI & LA & $1 T$ & LOL & & $\begin{array}{l}\text { TOWN } \\
\text { SEIP }\end{array}$ & RANGE & $S E C$ \\
\hline 5007 & EAYSTACX BUTTE WWW & 507 & 40 & 6 & 105 & 14 & $2 \pi$ & $70 \mathrm{~W}$ & 33 \\
\hline 5006 & BOT SULPEUR SPRINGS & 525 & 40 & 5 & 106 & 7 & $1 N$ & $78 W$ & 3 \\
\hline 5009 & IDAEO EOT SPRIWGS & 510 & 39 & 44 & 105 & 31 & $4 S$ & $73 W$ & 1 \\
\hline 5001 & JUNIPER & 541 & 40 & 28 & 107 & 57 & $6 \pi$ & $94 \pi$ & 16 \\
\hline 5053 & LEMON EOT SPRING & 557 & 38 & 01 & 108 & 3 & $44 N$ & $11 W$ & 34 \\
\hline 5034 & MINERAL BOT SPRITGS & 555 & 38 & 10 & 105 & 55 & $45 \pi$ & $9 E$ & 12 \\
\hline 5051 & ORVIS EOT SPRING & 546 & 38 & 8 & 107 & 44 & 45.7 & $8 W$ & 22 \\
\hline 5052 . & OURAY BOT SPRINGS & 546 & 38 & 1 & 107 & 40 & $44 N$ & $7 W$ & 31 \\
\hline $5044^{\circ}$ & PACOSA SPRIWGS & 504 & 37 & 16 & 107 & 1 & $35 \pi$ & $2 W$ & 13 \\
\hline 5013 & PEWNI AVALANCEE ES & 549 & 39 & 14 & 107 & 13 & $10 S$ & $88 W$ & . \\
\hline 5058 & PINKERTON & 534 & 37 & 27 & 107 & 48 & $37 \pi$ & $9 W$ & 25 \\
\hline 5026 & EONCEA EOT SPRINGS & 508 & 38 & 30 & 106 & 5 & $49 N$ & $8 E$ & 15 \\
\hline 45 & RAINBOW EOT SPRING & 540 & 37 & 31 & 106 & 57 & $38 N$ & $1 W$ & 9 \\
\hline 5017 & RANGER WARM SPRING & 526 & 38 & 49 & 106 & 52 & $14 S$ & $85 W$ & 22 \\
\hline 5018 & REODES WARM SPRING & 547 & 39 & 10 & 106 & 4 & $10 S$ & $78 W$ & 24 \\
\hline 5057 & RICO & 517 & 37 & 42 & 108 & 2 & $40 N$ & $11 N$ & \\
\hline 5003 & ROUT ES & 554 & 40 & 34 & 106 & 51 & $7 N$ & $84 W$ & 18 \\
\hline 5037 & SAND DUNES SWIMMING & 502 & 37 & 47 & 105 & 51 & $41 N$ & $10 E$ & 27 \\
\hline 5036 & SEAWS WAFM SPRING & 555 & 37 & 45 & 106 & 19 & $41 N$ & $6 E$ & 33 \\
\hline 5012 & SOUTE CANYON EOT SRR & 523 & 39 & 33 & 107 & 24 & $6 S$ & SOW & 2 \\
\hline 5038 & SFLASBIAVD EOT WATER & 502 & 37 & 29 & 105 & 51 & $38 N$ & $10 E$ & 34 \\
\hline 5004 & STEAMBOAT SPRIWGS & 554 & 40 & 29 & 106 & 50 & $6 N$ & $84 W$ & 17 \\
\hline 5059 & TRIPP AND TRIMBLE WS & 534 & 37 & 23 & 107 & 51 & $36 N$ & $9 W$ & 10 \\
\hline 5035 & VALLEY VIEW HOT SPRI & 555 & 38 & 12 & 105 & 49 & $46 N$ & $10 E$ & 36 \\
\hline-6 & WAGON WHEEL GAP ES & 540 & 37 & 41 & 106 & 50 & $41 \pi$ & $1 E$ & 35 \\
\hline & WELLSVITLE SWISSVALE & 508 & 38 & 29 & 105 & 55 & $49 N$ & $10 E$ & 18 \\
\hline 5049 & WUANITA BOT SPRINGS & 526 & 38 & 31 & 106 & 31 & $49 \pi$ & $4 E$ & 11 \\
\hline
\end{tabular}

TABLE 5. GEOTEERMAL SITE LOCATIONS. 


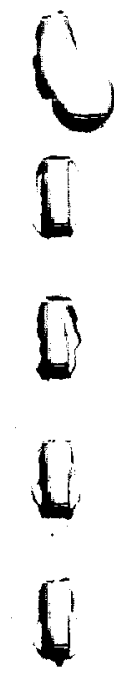

\section{NEVADA}

ID SITE NAME 6063 ALKALI EOT SPRING

COUNTY

6064 ASE SPRINGS

6016 BALTAZOR ES

6040 BARTHOLOMAE

6065 BENWETT SRRINGS

6001 BEOWAWE $B S$

6066 BIG LOCKES SPRIIIG

6067 BIG SPRING

6068 BIG SPRINGS

6022 BLACK ROCK DESERT

6069 BLUE EAGLE SPRIWGS

6070 BOILING SPRING

6071 BORAX SPRING

6059 BOWERS E $S$

$6058 B 06$ E $S$

6002 BRADY BOT SP

6072 EROOKS SPRING

6073 BRUFEEYS BOT SPRINGS

6031 BUFEALO VALLEY ES

D036 EUTTE SPR

6074 BUTTERFIELD SPRINGS

6075 CEIN SPRINGS

6076 CALIENTE EOT SFRING

6077 CARSON HOT SFRITGS

6078 CHARNOCK BIG BLUE

6030 CHERRY CR $B S$

6079 CHIMNEY SPRINGS.

6080 COLLAR AND ELBOW SPR

6081 CRISTAL FOOL

6082 CRYSTAL SPRINGS

6025 DARROUGHS HS

6083 DELMUES SPRTNG

6084 DETILS BOLE

6056 DIANA PUNCE BOWL

6023 DIXIE VALLEY ES

6024 DOUBLE ES

6026 DYKE $\exists S$

6044 ELRO ES

5085 EMIGRAMT SPRINGS

6086 FAIREANKS SPRING

6015 FERNLEY ES

TAELE 5. GEOTEERMAL SITE LOCATIONS. 


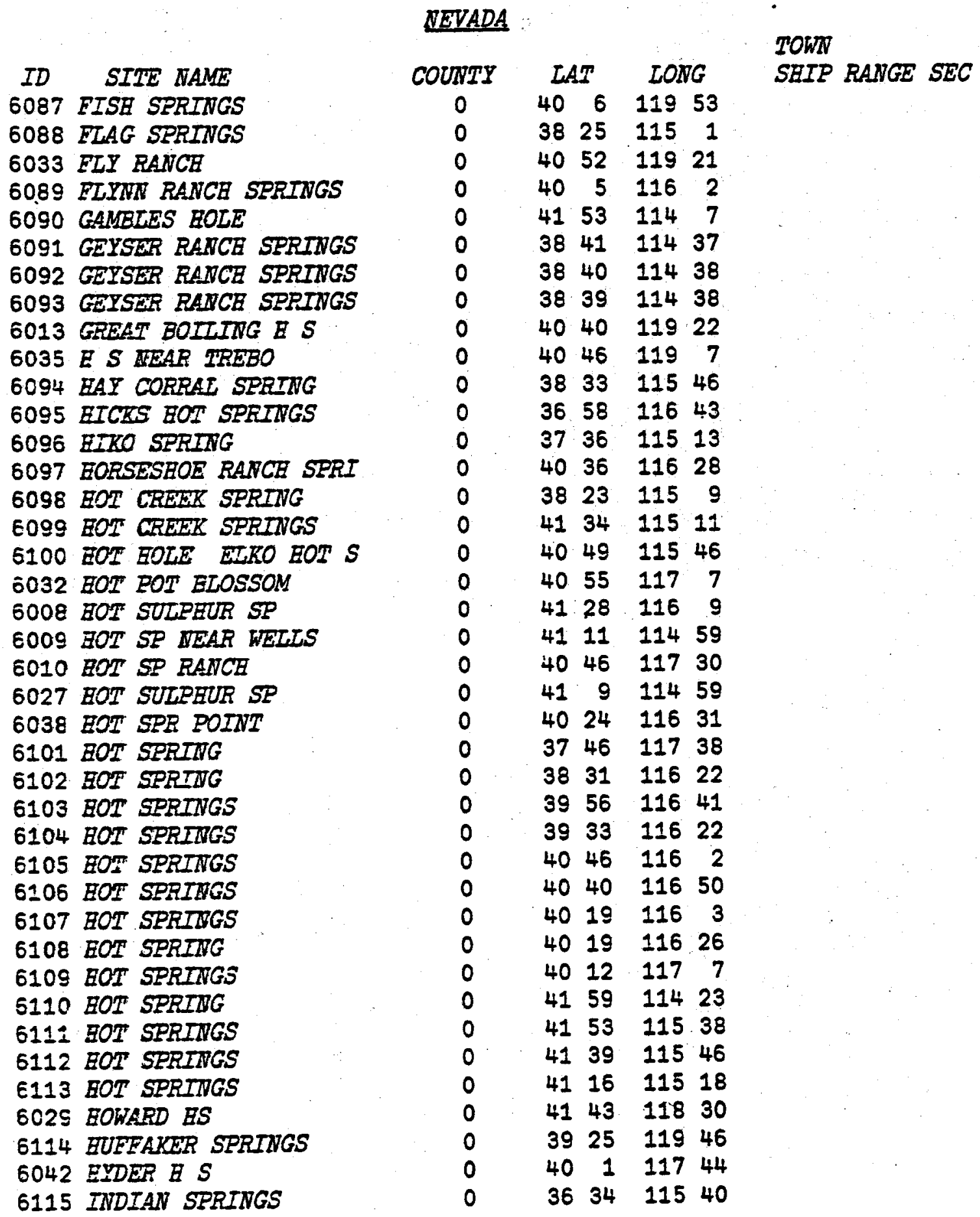

TABLE 5. GEOTEERMAL SITE LOCATIONS. 
ID SITE NAME

6116 IZZENBOOD RANCR SPRI

6117 JACK RABBIT SPRING

6007 JERSEY VALLEY ES

6118 JOEN SALVIS HOT SRRI

$6119 \mathrm{KATE}$ SPRING

6006 KYLE HS

6120 LACKAWANNA SPRINGS

6121 ZALTON EOT SPRINGS

6014 LEACH ES

5011 LEE E $S$

6122 LONGSTREET SPRIWG

6049 LOIERR RAVCR

6123 MACFAREAND EOT SPRIN

6124 MADSE SPRINGS

6125 MCCOY SPRINGS

6126 MCGILL SPPING

6034 IITERAE SAN JACINTO

6050 EOWTE WEVA ES

6127 MOON RTVER SPRING

6128 HOORES RANCE SPRTNGS

6:29 MOORMAN SFEING

6130 MOUND SPRIUGS

5131 MUD SPRINGS

6132 MUD SPRINGS

6133 MUDDY SPRING

6039 NEAR GOLCONDA

6051 NEAR CARLIN

S053 MEAR RUEY MARSE

6021 WEEDLE ROCKS

S055 NEVADA ES

6061 NILE SPR

6134 PANACA SPRING

6135 PEARL EOT SPRTWGS

6012 ZINTO E $S$

5136 ROINT OF ROCKS SPRTI

6060 POTTS RANCI $E S$

6137 DRESTON SERINGS

6138 EIZZI RANCH HOT SPRI

6139 ROGERS SPRING

6004 SAN EMIDIO

\section{COUNT
0}

0

0

0

.

0

0

0

0

0
0

0
0

0

0
0

0

0

0

0

0

0

0

0

0

0

0

0

0

0

0

0

0

0
0

0

0

0

0

0

\section{IAT}

$40 \quad 55 \quad 116.54$

$\begin{array}{llll}36 & 23 & 116 & 17\end{array}$

$\begin{array}{llll}40 & 11 & 117 & 29\end{array}$

$\begin{array}{lllll}39 & 53 & 114 & 54\end{array}$

$\begin{array}{llll}38 & 33 & 115 & 32\end{array}$

$\begin{array}{llll}40 & 24 & 117 & 53\end{array}$

$\begin{array}{llll}39 & 17 & 114 & 52\end{array}$

$\begin{array}{llll}39 & 31 & 119 & 54\end{array}$

$40.36 \quad 11739$

$\begin{array}{llll}39 & 13 & 118 & 43\end{array}$

$\begin{array}{llll}36 & 28 & 116 & 20\end{array}$

$\begin{array}{llll}40 & 3 & 117 & 35\end{array}$

$\begin{array}{llll}41 & 3 & 118 & 43\end{array}$

$\begin{array}{llll}36 & 9 & 115 & 54\end{array}$

$\begin{array}{llll}40 & 5 & 117 & 36\end{array}$

$\begin{array}{llll}39 & 25 & 114 & 47\end{array}$

$\begin{array}{llll}41 & 47 & 114 & 43\end{array}$

$\begin{array}{llll}39 & 38 & 114 & 48\end{array}$

$\begin{array}{llll}38 & 21 & 115 & 11\end{array}$

$\begin{array}{llll}39 & 49 & 115 & 37\end{array}$

$\begin{array}{lllll}38 & 36 & 115 & 8\end{array}$

$\begin{array}{llll}40 & 19 & .117 \quad 4\end{array}$

$\begin{array}{llll}39 & 38 & 118 & 11\end{array}$

$\begin{array}{llll}40 & 39 & 119 & 23\end{array}$

$\begin{array}{llll}36 & 43 & 114 & 43\end{array}$

$\begin{array}{llll}40 & 58 & 117 & 30\end{array}$

$\begin{array}{llll}40 & 42 & 116 & 8\end{array}$

$\begin{array}{llll}40 & 14 & 115 & 25\end{array}$

$40 \quad 9 \quad 11940$

$\begin{array}{llll}38 & 54 & 119 & 25\end{array}$

$\begin{array}{llll}41 & 56 & 114 & 5\end{array}$

$\begin{array}{llll}37 & 48 & 114 & 23\end{array}$

$\begin{array}{llll}37 & 49 & 117 & 29\end{array}$

$\begin{array}{llll}41 & 21 & 118 & 47\end{array}$

$\begin{array}{llll}36 & 24 & 116 & 16\end{array}$

$\begin{array}{llll}39 & 5 & 116 & 41\end{array}$

$\begin{array}{llll}38 & 55 & 115 & 5\end{array}$

$4147 \quad 115 \quad 55$

$\begin{array}{llll}35 & 29 & 116 & 19\end{array}$

$\begin{array}{llll}40 & 24 & 117 & 25\end{array}$

TABLE 5. GEOTHERMAL SITE LOCATIONS. 


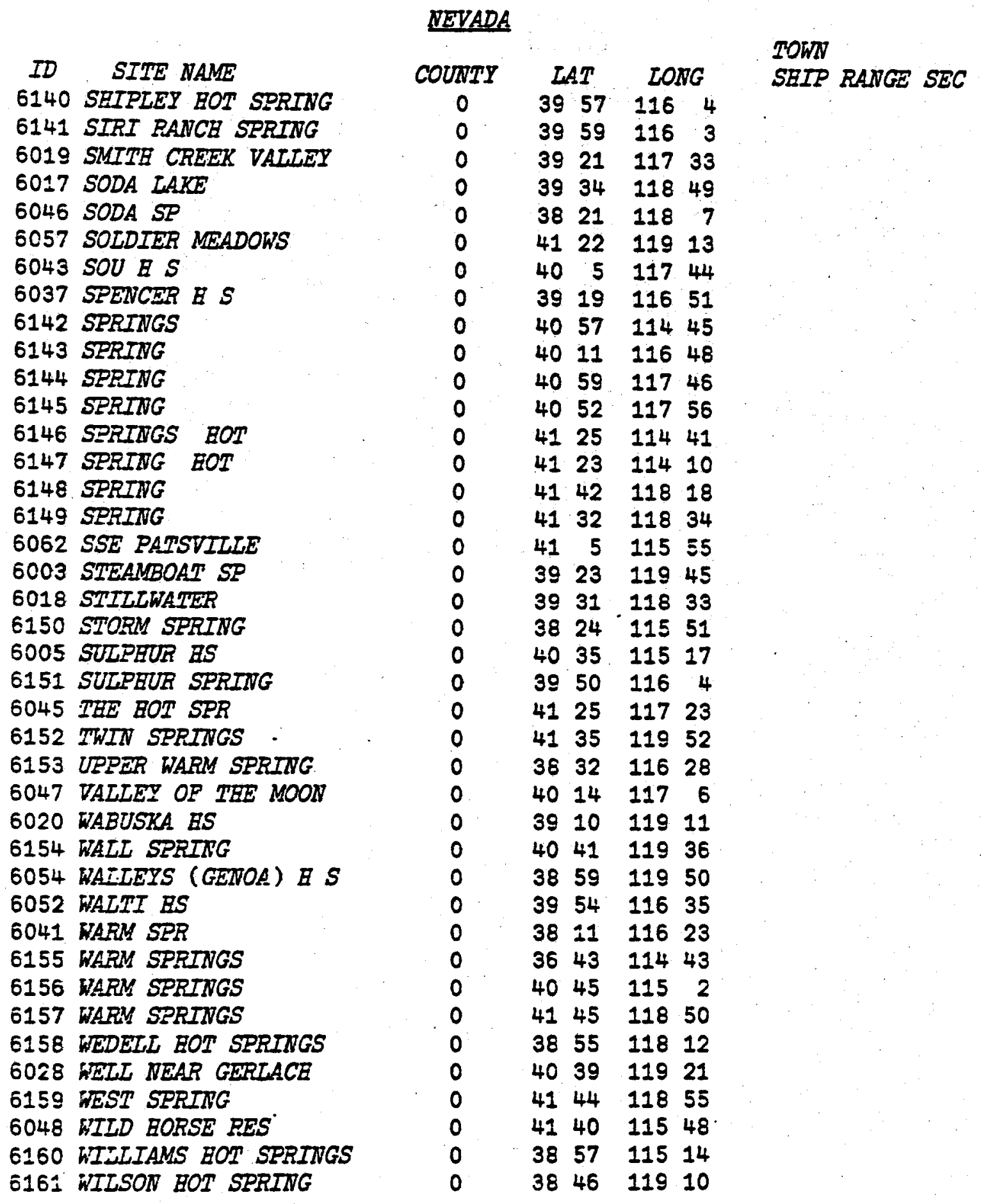

TABLE 5. GEOTHERMAL SITE LOCATIONS. 
NEW MEXICO

ID SITE NAME
7044 ALEMAN
7018 BERINO - MESQUITE
7049 CARNE
7029 CLIFF AREA
7027 CLOSSON
7040 CROCKER
7033 CROWNPOINT AREA
7030 DERRY WARM SPRING
7021 E SAN AUGUSTIN PLAIN
7023 FAYWOOD ES
7041 FREIBORN CANYON
7047 GALLTNAS CREEK
7046 GARTON WELL

7010 GILA BS-BELOW BRTDGE 7011 GILA BS-MLDDLE FORX

7013 GILA BS-DOC CAMPBELL 7025 GILA BS-URR MDL ERK

7035 GUADALUPE SP

7048 EATCEET NOUNTAIN

7036 BOT WELL

7038 BUECO-S TULAROSA BAS

7004 KILBOURNE BOLE

7017 IAS ALTURAS

7042 LAS PALOMAS

7002 LIGETNING DOCK

7003 LWR SAN FRANCISCO ES

7014 MAMBI'S ES

7007 MC CAULEY SP (JEMEZ)

7045 MCKINLEY WEST

7019 UTMRRES ES

7012 MONTEZUMA BS

7050 NELMAN SO PAC RR

7034 WORTEEAST OF PREWITT

7009 OJO CAIIENTE

7028 PLAYAS VALLEY

7020 PONCE DE LEON

7008 RADIUM SPRINGS

7043 RINCON EAST

7005 SAN ANTONIO ES (JEME

7039 SAN JUAN BASIN

7037 SAN YSIDRO

7031 SEDILLO SPEING

7006 SPENCE SP (JEMEZ)

$7024 T$ OR $C$

7032 TOBATCEI AREA

7015 TURKEY CREEX

7022 UPR SAN FRANCISCO BS

7001 VALLES CALDERA

7026 W MESA-BLACK MNIDN

7016 WRITE SANDS

COUNTY
727
707
716
709
732
727
717
727
728
709
702
725
717
709

702

702

702

723

712

723

719

707

707

707

712

702

729

723

717

709

725

719

717

721

712

729

707

707

723

724

723

728

723

727

717

709

702

723

707

707

\section{EAI}

0.0

329

0. 0

3253

$35 \quad 15$

00

$35 \quad 42$

3248

$34 \quad 41$

3233

00

00

$0 \quad 0$

3310

3314

3312

$\begin{array}{ll}33 & 17\end{array}$

3536

00

3545

$32 \quad 3$

3158

3216

00

328

3315

$\begin{array}{ll}36 & 32\end{array}$

35.47

3550

3245

$35 \quad 39$

00

3526

3618

31.50

$36 \quad 19$

3230

$0 \quad 0$

3547

0.0

3532

34.2

$\begin{array}{ll}35 & 47\end{array}$

338

3555

337

3350

3553

328

3220

\section{LONG}

00

10640

00

10835

10819

00

1088

$107 \quad 17$

10733

108

00

00

00

10813

10814

10813

$108 \quad 17$

1078

00

10540

10610

10657

10642

00

10850

10853

10541

10641

10830

10750

10517

00

10753

1063

$108 \quad 37$

10536

10656

00

10641

00

10650

10656

10641

$107 \quad 15$

10835

10829

10848

10632

10652

10625
TOWN

SEIP RANGE SEC

$15 S 2 W$

$24 S: 7 W$

$115 \quad 1 E$

7S $21 W$

$17 N \quad 15 E$

$18 S$. $8 E$

$32 S \quad 16 W$

$14 S \quad 5 W$

$18 N \quad 16 W$

$26 S \quad 8 E$

$19 S \quad 2 W$

$24 N \quad 18 W$

TABIE 5. GEOTHEPMAL SITE LOCATIONS. 3-13 


\begin{tabular}{|c|c|c|c|c|c|c|c|c|c|}
\hline$I D$ & SITE NAME & COURTY & If & $4 T$ & LOA & & $\begin{array}{l}\text { TOWN } \\
\text { SEIP }\end{array}$ & RANGE & $S E C$ \\
\hline 8007 & $A B R A B A M \quad E S$ & 812 & 39 & 37 & 112 & 43 & $14 S$ & $8 W$ & 10 \\
\hline 8015 & BECKS ES & 818 & 40 & 47 & 111 & 56 & $1 N$ & $1 W$ & 14 \\
\hline 8044 & EIG WS & 823 & 40 & 52 & 112 & 36 & 15 & $7 W$ & 8 \\
\hline 8033 & BLUE WS & 802 & 41 & 50 & 112 & 24 & $13 N$ & $5 W$ & 29 \\
\hline 8025 & CASTILLA ES & 825 & 40 & 3 & 111 & 32 & $9 S$ & $4 E$ & 18 \\
\hline 8037 & COMO ES & 815 & 41 & 5 & 111 & 40 & $4 N$ & $3 E$ & 31 \\
\hline 8002 & COTE FORT-SULPHURDAL & 814 & 38 & 36 & 112 & 33 & $25 S$ & $6 W$ & \\
\hline 8021 & CRAILER ES & 825 & 40 & 28 & 111 & 53 & $5 S$ & $1 W$ & 25 \\
\hline 8006 & CEYSTAL ES & 818 & 40 & 30 & 111 & 55 & $4 S$ & $1 \mathrm{~W}$ & 11 \\
\hline 8016 & CRYSTAE E.S. & 802 & 41 & 40 & 112 & 5 & $11 N$ & $2 W$ & 24 \\
\hline 8041 & DIAMOED FORK WS & 825 & 40 & 5 & 111 & 22 & 85 & $5 E$ & 14 \\
\hline 8030 & EISE SPEINGS & 812 & 39 & 52 & 113 & 25 & $11 S$ & $14 W$ & 23 \\
\hline 8031 & GANDI & 814 & 39 & 27 & 113 & 58 & $15 S$ & $19 \bar{W}$ & 31 \\
\hline 8042 & COSHEW ES & 825 & 39 & 57 & 111 & 51 & $10 S$ & $1 E$ & 8 \\
\hline 8038 & RANTSVILLE & 823 & 40 & 38 & 112 & 31 & $2 S$ & $6 W$ & 16 \\
\hline 8026 & EATTOA ES & 814 & 38 & 51 & 112 & 30 & $22 S$ & $6 W$ & 35 \\
\hline 8013 & EOOPER ES & 829 & 41 & 9 & 112 & 12 & $5 N$ & $3 W$ & 27 \\
\hline 8036 & JOEHSOWS WS & 821 & 38 & 36 & 112 & 15 & $25 S$ & $3 W$ & 27 \\
\hline $\begin{array}{l}8004 \\
8022\end{array}$ & $\begin{array}{l}\text { JOSEPE ES } \\
\text { JAVEREIT ES }\end{array}$ & $\begin{array}{l}821 \\
827\end{array}$ & $\begin{array}{l}38 \\
37\end{array}$ & $\begin{array}{l}38 \\
13\end{array}$ & $\begin{array}{l}112 \\
113\end{array}$ & $\begin{array}{l}11 \\
16\end{array}$ & $\begin{array}{l}25 S \\
41 S\end{array}$ & $\begin{array}{r}4 W \\
13 W\end{array}$ & $\begin{array}{l}23 \\
25\end{array}$ \\
\hline 8028 & EINCOLN FOINT WS & 825 & 40 & 1 & 111 & 50 & $8 S$ & $1 E$ & 3 \\
\hline 8012 & MEADOW ES & 814 & 38 & 50 & 112 & 31 & $22 S$ & $6 W$ & 26 \\
\hline 8018 & LTDWAY ES & 826 & 40 & 31 & 111 & 28 & 35 & $4 E$ & 26 \\
\hline 8009 & LONROE( COOPER) ES & 821 & 38 & 31 & 112 & 12 & $25 S$ & $3 W$ & 10 \\
\hline 8032 & MORGADSS WS & 823 & 40 & 24 & 112 & 25 & $5 S$ & $5 W$ & 9 \\
\hline 8010 & OGDEN ES & 829 & 41 & 14 & 111 & 58 & $6 N$ & $1 W$ & 23 \\
\hline 8027 & RADIUM DOTSOR) HS & 801 & 38 & 13 & 112 & 55 & 305 & $9 W$ & \\
\hline 8005 & FED EILC ES & 821 & 38 & 38 & 112 & 6 & $25 S$ & $3 W$ & 11 \\
\hline 8040 & RICEFIETD WS & 821 & 38 & 45 & 112 & 5 & $23 S$ & $3 W$ & 26 \\
\hline 8001 & ROOSEVETT ES & 801 & 38 & 30 & 112 & 49 & $26 S$ & $9 W$ & 34 \\
\hline 8039 & EUSSETS WTS & 823 & 40 & 22 & 112 & 27 & $5 S$ & $5 W$ & 17 \\
\hline 8019 & SARATOEA ES & 825 & 40 & 28 & 111 & 53 & $5 S$ & $1 W$ & 25 \\
\hline 8029 & SPLIT MOURTATH WS & 824 & 40 & 27 & 109 & 15 & 45 & $24 E$ & 16 \\
\hline 8043 & SIEREIEG SPR & 820 & 39 & 12 & 111 & 32 & $19 S$ & $2 E$ & 4 \\
\hline 8011 & SIINKING SPR & 803 & 41 & 35 & 112 & 14 & $10 N$ & $3 W$ & 10 \\
\hline 8003 & TPEERMO ES & 801 & 38 & 11 & 113 & 12 & 305 & $9 W$ & 21 \\
\hline 8020 & UDDY ES & 802 & 41 & 51 & 112 & 9 & $13 N$ & $3 W$ & 23 \\
\hline 8024 & UAWAMED BS & 802 & 41 & 50 & 114 & 7 & $11 N$ & $19 W$ & 11 \\
\hline 8014 & UFAE ZES & 829 & 41 & 24 & 112 & 2 & $7 N$ & $2 W$ & 14 \\
\hline 8023 & DEYO BS & 827 & 37 & 19 & 113 & 42 & $40 S$ & $16 W$ & 7 \\
\hline 8034 & WARM SPR & 802 & 41 & 48 & 113 & 35 & $12 \pi$ & $15 W$ & 19 \\
\hline 8035 & WARM SPR-UTAE LAKE & 825 & 40 & 14 & 111 & 46 & 75 & $1 E$ & 5 \\
\hline 8008 & WASATCE BS & 818 & 40 & 45 & 111 & 55 & $1 N$ & $1 W$ & 25 \\
\hline 8017 & WILSON BS & 812 & 39 & 55 & 113 & 26 & $10 S$ & $14 W$ & 33 \\
\hline
\end{tabular}

\section{UTAB}

TABIE 5. GEOTBERMAL SITE LOCATIONS. 


\begin{tabular}{|c|c|c|c|c|c|c|c|}
\hline \multirow{3}{*}{$\begin{array}{l}\text { SITE } \\
\text { ID }\end{array}$} & \multirow[b]{2}{*}{ SITE NAME } & \multicolumn{4}{|c|}{ - - - TEMPERATURE IN DEGREES } & \multicolumn{2}{|c|}{ EL } \\
\hline & & $\begin{array}{l}\text { SUBSUR- } \\
\text { SACE }\end{array}$ & $\begin{array}{l}\text { SOU- } \\
R C E\end{array}$ & SUREACE & $\begin{array}{l}S O U- \\
R C E\end{array}$ & $\begin{array}{l}C S \\
E S T\end{array}$ & $\begin{array}{l}C S \\
M E A S\end{array}$ \\
\hline & AGUA CALIENTE & 0 & & 0 & & 0 & 46 \\
\hline 4018 & ARTESIAN $E W$ & 0 & & 0 & & 0 & 44 \\
\hline 4026 & ARTESIA AREA & 0 & & 0 & & 0 & 33 \\
\hline 4022 & BARNGAN MEN & 0 & & 0 & & 0 & 39 \\
\hline 4024 & BONIE AREA & 0 & & 0 & & 0 & 36 \\
\hline 4016 & BUCKEORN AREA & 0 & & 0 & & 0 & 49 \\
\hline 4032 & CASA GRANDE & 24 & 4 & 0 & & 0 & 0 \\
\hline 4012 & CASTIE $B S$ & 0 & & 0 & & 105 & 0 \\
\hline 4008 & GAT TENKR & 0 & & 0 & & 115 & 0 \\
\hline 4002 & CLIFTON EOT SPRINGS & 0 & & 0 & & 160 & 0 \\
\hline 4007 & COFEERS ES & 0 & & 0 & & 120 & 0 \\
\hline 4006 & COOLEDGE ES & 0 & & 0 & & 120 & C \\
\hline 4013 & COOEIDGE AREA & 0 & & 0 & & 0 & 61 \\
\hline 4031 & COOEIDGE & 42 & 4 & 0 & & 0 & 0 \\
\hline 4005 & RAGLE CREER $E S$ & 0 & & 0 & & 130 & 0 \\
\hline 4029 & ELOY & 27 & 4 & 0 & & 0 & 0 \\
\hline 4030 & ELORETPCE & 28 & 4 & 0 & & 0 & 0 \\
\hline 4004 & GILIARD ES & 0 & & 0 & & 140 & 0 \\
\hline 4015 & ECOKERS ES & 0 & & 0 & & 0 & 50 \\
\hline 4011 & IDDIAN $B S$ & 0 & & 0 & & 105 & 0 \\
\hline 4009 & JAVETINA PEAR & 0 & & 0 & & 110 & 0 \\
\hline 4020 & IUCATS SPA & 0 & & 0 & & $\cdot 0$ & 42 \\
\hline 4033 & MAMANOTE & 32 & 4 & $0^{\prime}$ & & 0 & 0 \\
\hline 4025 & MOEII AREA & 0 & & 0 & & 0 & 35 \\
\hline 4019 & WT GRAEAM & 0 & & 0 & & 0 & 44 \\
\hline 4021 & PALOMAS MISS & 0 & & 0 & & 0 & 42 \\
\hline 4034 & PAPAGO FAPUS & 31 & 4 & 0 & & 0 & 0 \\
\hline 4028 & PHOEIVIX TERME & 34 & 4 & 0 & & 0 & 0 \\
\hline 4001 & POWER RATCH AREAS & 0 & & 0 & & 184 & 0 \\
\hline 4014 & RADIUM SFRINGS & 0 & & 0 & & 0 & 53 \\
\hline 4010 & SAFEORD AREA & 0 & & 0 & & 110 & 0 \\
\hline 4023 & IFEEBA & 0 & & 0 & & 0 & 38 \\
\hline 4027 & IOM WIECE WARM SPR & 0 & & 0 & & 0 & 32 \\
\hline 4003 & WERLE HOT SRRIWGS & 0 & & 0 & & 150 & 0 \\
\hline 4035 & WIXIEUP & 22 & 4 & 0 & & 0 & 0 \\
\hline
\end{tabular}

TABLE 6. GEOTEERMAL SITE TEMPERATURES. 
COLORADO

\begin{tabular}{|c|c|c|c|c|c|c|c|}
\hline \multirow[b]{2}{*}{ SITE } & \multirow[b]{2}{*}{ SITE NAME } & \multicolumn{4}{|c|}{----TEMPERATURE IN DEGREES } & \multicolumn{2}{|c|}{ CEISIUS--....- } \\
\hline & & $\begin{array}{l}\text { SUBSUR- } \\
\text { FACE }\end{array}$ & $\begin{array}{l}\text { SOU- } \\
R C E\end{array}$ & SURFAC & $\begin{array}{l}\text { SOU- } \\
R C E\end{array}$ & $\begin{array}{l}C S \\
E S T\end{array}$ & $\begin{array}{l}C S \\
M E A S\end{array}$ \\
\hline 5047 & ANTELOPE BIRDSIE & 44 & 5 & 32 & 5 & 0 & 32 \\
\hline 5005 & BRANDS RANCE ARTESIA & 49 & 5 & 0 & 5 & 0 & 42 \\
\hline 5025 & BROWN CANYON TERMU A & 100 & 5 & 25 & 5 & 0 & 25 \\
\hline 5029 & CANON CITY BOT SPRIN & 50 & 5 & 40 & 5 & 0 & 40 \\
\hline 5050 & CEBOLLA HOT SPRINGS & 60 & 5 & 39 & 5 & 135 & 0 \\
\hline 5016 & CENENT CREEK WS & 45 & 5 & 0 & 5 & 0 & 26 \\
\hline 5021 & CFALK CR MT PRINCETN & 200 & 5 & 50 & 5 & 120 & 0 \\
\hline 5022 & CRALK CREEK WRIGET $B$ & 170 & 5 & 69 & 5 & 0 & 0 \\
\hline 5023 & CEALK CREEX EORTEWISE & 170 & 5 & 82 & 5 & 0 & 0 \\
\hline 5024 & CEALK CREEK WOOLLMTNG & 170 & 5 & 39 & 5 & 0 & 0 \\
\hline 5033 & CLARK ARTESIAN WELL & 40 & 5 & 25 & 5 & 0 & 25 \\
\hline 5014 & COLONEL CEINI EOT WE & 51 & 5 & 42 & 5 & 80 & 0 \\
\hline 5015 & CONUNDRUM EOT SPRING & 45 & 5 & 35 & 5 & 0 & 38 \\
\hline 5020 & COTTONWOOD CREEL JUM & 170 & 5 & 52 & 5 & 105 & 0 \\
\hline 5002 & CRAIG WARM WATER WEL & 55 & 5 & 39 & 5 & 90 & 0 \\
\hline 5039 & DEXTER MCINTYRE & 35 & 5 & 20 & 5 & 0 & 20 \\
\hline 5032 & DON $K$ RANCE ARTESIAN & 45 & 5 & 28 & 5 & 110 & 0 \\
\hline 5010 & DOTSERO WARM SERINGS & 39 & 5 & 32 & 5 & 0 & 32 \\
\hline 5054 & DUNTON GEYSR PARADIS & 50 & 5 & 42 & 5 & 0 & 44 \\
\hline 5041 & DUTCE CROWLY STINKNG & 65 & 5 & 27 & 5 & 0 & 70 \\
\hline 5008 & ELDORADO & 35 & 5 & 25 & 5 & 0 & 26 \\
\hline 5043 & EOFF ARTESIAN WELL & 50 & 5 & 39 & 5 & 0 & 39 \\
\hline 5031 & FLORENCE ARTESIAN WE & 42 & 5 & 28 & 5 & 0 & 28 \\
\hline 5030 & FREMONT NATATORIUM & 43 & 5 & 35 & 5 & 0 & 36 \\
\hline 5061 & FULL $N$ WIDER WARM SP & 0 & 0 & 0 & 0 & 0 & 18 \\
\hline 5011 & GLEWWOOD BOT SPRINGS & 65 & 5 & 33 & 5 & 130 & 0 \\
\hline 5019 & BARTSELL BOT SPRINGS & 70 & 5 & 48 & 5 & 105 & 0 \\
\hline
\end{tabular}

TABLE 6. GEOTEERMAL SITE IEMMERATURES. 


\section{SI}

5007 EAYSTACK BUTTE WWW

5006 HOT SULPEUR SPRINGS

5009 IDAEO BOT SPRINGS

5001 JUNIPER

5053 LEMON BOT SPRING

5034 MINERAL HOT SPRINGS

5051 ORVIS BOT SPRING

5052 OURAY HOT SFRINGS

5044 PAGOSA SPRINGS

5013 PENWY AVALANCEE ES

5058 PINKERTON

5026 PONCEA HOT SPRINGS

5045 RAINBOW HOT SPRING

5017 RANGER WARM SPRIWG

5018 RBODES WARM SPRING

5057 RICO

5003 ROUT BS

5037 SAND DUNES SWIMRING

5036 SHAWS WARM SPRING

5012 SOUTH CANYON EOT SPR

5038 SFLASELAND BOT WATER

500\%' STEAMBOAT SPRINGS

5059 TRIPP AND TRIMBLE WS

5035 VALLEY VIEW BOT SPRI

5046 WAGON WEEEL GAP BS

5027 WELISVILLE SWISSVALE

5049 WUANITA HOT SPRITGS

COLORADO

-..--TEMPERATURE IN DEGEEES CELSIUS-....-

SUBSUR- SOU- SURFACE SOU-

FACE RCE

40

75

80

63

43

70

75

80

80

75

50

145

45

45

35

63

138

75

45

75

75

70

58

50

115

40

135

\section{5}

\section{5}

5

5

5

5

5

5

5

5

5

5

5

5

5

5

5

5

5

5

5

5

5

5

5

5
28

42

33

35

32

60

52

59

46

43

29

55

40

26

0

39

57

44

30

47

40

29

40

34

52

30

78
5

5

5

5

5

5

5

5

5

5

5

5

5

5

5

5

5

5

5

5

5

. 5

5

5

- 5

5
CS CS

EST MEAS

$0 \quad 28$

$\begin{array}{rr}95 & 0 \\ 120 & 0\end{array}$

$0 \quad 38$

$140 \quad 0$

$105 \quad 0$

$105 \quad 0$

$0 \quad 69$

$140 \quad 0$

$150 \quad 0$

$100 \quad 0$

$140 \quad 0$

$0 \quad 40$

$\begin{array}{ll}0 & 27\end{array}$

$0 \quad 25$

$140 \quad 0$

1450

$160 \quad 0$

$130 \quad 0$

$105 \quad 0$

$160 \quad 0$

$120 \quad 0$

$110 \quad 0$

$0 \cdot 37$

$140 \quad 0$

033

TABLE 6. GEOTIERRAL SITE TENPERATURES. 


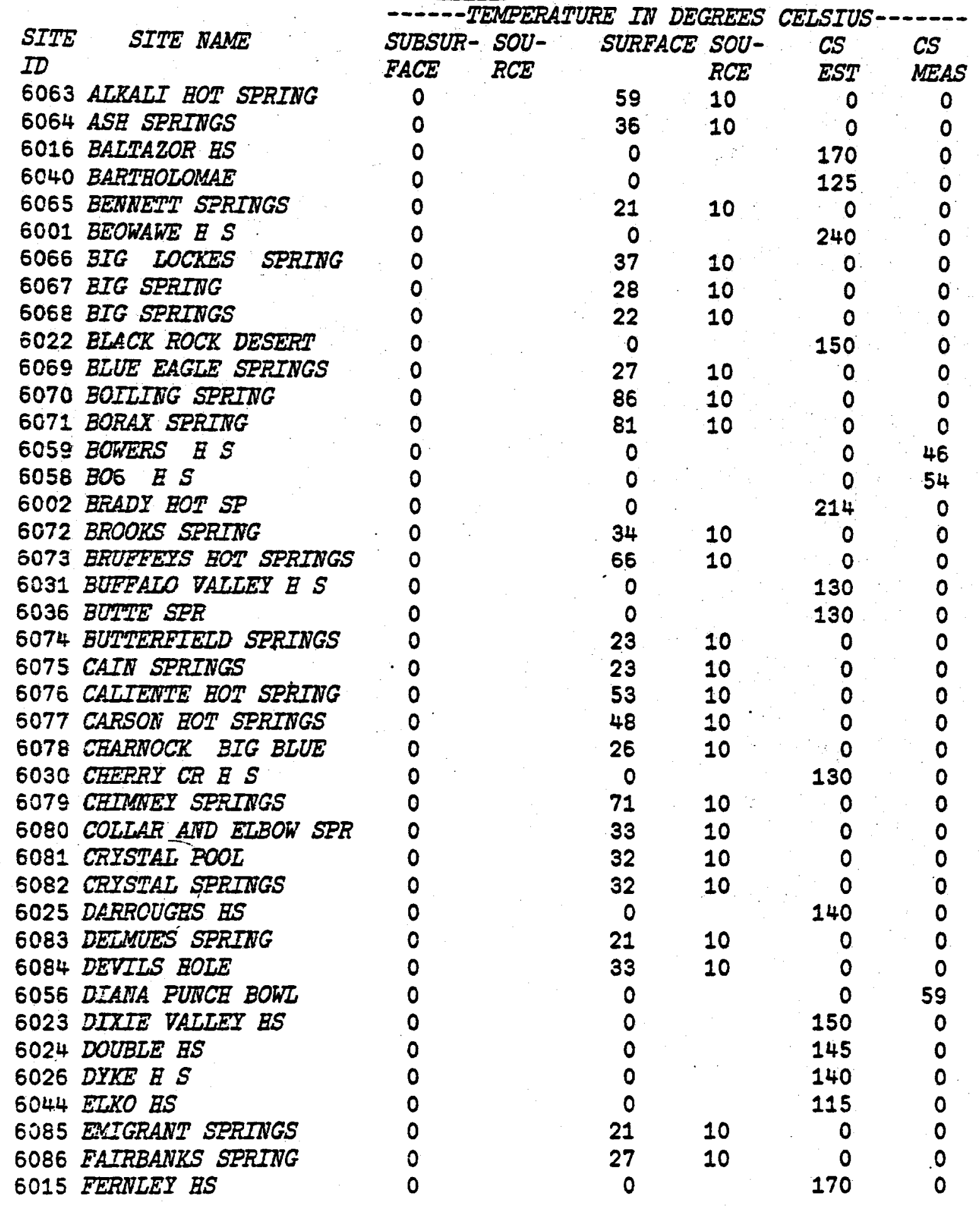

TABLE 6. GEOTHERMAL SITE TEUPERATURES. 


\begin{tabular}{|c|c|c|c|c|c|c|c|}
\hline & & & 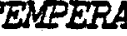 & $I$ & 2 & 916 & \\
\hline $\begin{array}{l}\text { SITE } \\
I D\end{array}$ & SITE NAME & $\begin{array}{l}\text { SUBSUR- } \\
\text { FACE }\end{array}$ & $\begin{array}{l}\text { SOU- } \\
R C E\end{array}$ & SUREACE & $\begin{array}{l}\text { SOU- } \\
\text { RCE }\end{array}$ & $\begin{array}{l}C S \\
E S T\end{array}$ & $\begin{array}{l}C S \\
M E A S\end{array}$ \\
\hline 6087 & FISE SPRINGS & 0 & & 22 & 10 & 0 & 0 \\
\hline 6088 & FLAG SPRIDGS & 0 & & 23 & 10 & 0 & 0 \\
\hline 5033 & FLY RANCE & 0 & & 0 & & 130 & 0 \\
\hline 6089 & ELYIN RANCE SPRINGS & 0 & & 25 & 10 & 0 & 0 \\
\hline 6090 & GAMELES EOLE & 0 & & 43 & 10 & 0 & 0 \\
\hline 6091 & GEYSER RANCE SPRINGS & 0 & & 21 & 10 & 0 & 0 \\
\hline 6092 & GEYSER RANCE SPRINGS & 0 & & 21 & 10 & 0 & 0 \\
\hline 6093 & GEYSER RANCE SPRINGS & 0 & & 21 & 10 & 0 & 0 \\
\hline 6013 & GREAT BOILTWG ES & 0 & & 0 & & 170 & 0 \\
\hline 6035 & E S MEAR TREBO & 0 & & 0 & & 130 & 0 \\
\hline 6094 & EAY CORRAL SPRING & 0 & & 37 & 10 & 0 & 0 \\
\hline 8095 & EICKS EOT SPRINGS & 0 & & 43 & 10 & 0 & 0 \\
\hline 6096 & EIKO SPRIRG & 0 & & 32 & 10 & 0 & 0 \\
\hline 6097 & BORSESBOE RADCE SPRI & 0 & & 57 & 10 & 0 & 0 \\
\hline 6098 & BOT CREER SFRING & 0 & & 33 & 10 & 0 & 0 \\
\hline 6099 & EOT CREEK SPRINGS & 0 & & 67 & 10 & 0 & 0 \\
\hline 6100 & BOT BOLE EHEO EOT $S$ & 0 & & 33 & 10 & 0 & 0 \\
\hline 6032 & EOT POT BLOSSOM & 0 & & 0 & & 130 & 0 \\
\hline 6008 & BOT SULPEUR SP & 0 & & 0 & & 180 & 0 \\
\hline 6009 & EOT SP NEAR WELIS & 0 & & 0 & & 180 & 0 \\
\hline 6010 & EOI SP RANCE & 0 & & 0 & & 180 & 0 \\
\hline 6027 & EOT SULPEUR SP & 0 & & 0 & • & 140 & $\underline{0}$ \\
\hline 6038 & EOT SPR FOIWT & 0 & & 0 & & 125 & 0 \\
\hline 6101 & EOT SPRING & 0 & & 71 & 10 & 0 & 0 \\
\hline 6102 & EOT SPRING & 0 & & 82 & 10 & 0 & 0 \\
\hline 6103 & EOT SPRINGS & 0 & & 82 & 10 & 0 & 0 \\
\hline 6104 & BOT SPRTWGS & 0 & & 40 & 10 & 0 & 0 \\
\hline 6105 & BOT SPRINGS & 0 & & 36 & 10 & 0 & 0 \\
\hline 6106 & BOT SPRINGS & 0 & & 55 & 10 & 0 & 0 \\
\hline 6107 & BOT SPRINGS & 0 & & 26 & 10 & 0 & 0 \\
\hline 5108 & EOT SERING & 0 & & 85 & 10 & 0 & 0 \\
\hline 6109 & EOT SPRINGS & 0 & & 53 & 10 & 0 & 0 \\
\hline 6110 & EOT SPRING & 0 & & 30 & 10 & 0 & 0 \\
\hline 6111 & EOT SPRIWGS & 0 & & 39 & 10 & 0 & 0 \\
\hline 6112 & BOT SFRINGS & 0 & & 54 & 10 & 0 & 0 \\
\hline 6113 & ZCT SPRTIGS & 0 & & 49 & 10 & 0 & 0 \\
\hline 6029 & BOWARD ES & 0 & & 0 & & 130 & 0 \\
\hline 6114 & BULFAKER SPRIINGS & 0 & & 34 & 10 & 0 & 0 \\
\hline 6042 & EYDER $E S$ & 0 & & 0 & & 120 & 0 \\
\hline 6115 & INDIAN SPRINGS & 0 & & 25 & 10 & 0 & 0 \\
\hline
\end{tabular}

TABLE 6. GEOTESRMAL SITE TEMPERATURES. 


\section{NEVADA}

-.---TEMPRERATURE IN DEGREES CELSTUS-------

\begin{tabular}{|c|c|c|c|c|c|c|c|}
\hline $\begin{array}{l}\text { SITE } \\
\text { ID }\end{array}$ & SITE NAME & $\begin{array}{l}\text { SUBSUR- } \\
\text { FACE }\end{array}$ & $\begin{array}{l}\text { SOU- } \\
\text { RCE }\end{array}$ & SURFACE & $\begin{array}{l}\text { SOU- } \\
R C E\end{array}$ & $\begin{array}{l}C S \\
E S T\end{array}$ & $\begin{array}{l}C S \\
M E A S\end{array}$ \\
\hline 6116 & IZZENEEOOD RANCE SPRI & 0 & & 28 & 10 & 0 & 0 \\
\hline 6117 & JACK RABBIT SPRING & 0 & & 27 & 10 & 0 & 0 \\
\hline 6007 & JERSEY VALLEY ES & 0 & & 0 & & 185 & 0 \\
\hline 6118 & JOEN SALVIS BOT SPRI & 0 & & 65 & 10 & 0 & 0 \\
\hline 6119 & KATE SRRING & 0 & & 22 & 10 & 0 & 0 \\
\hline 6006 & KYLE ES & 0 & & 0 & & 190 & 0 \\
\hline 6120 & LACKAWANNA SPRINGS & 0 & & 34 & 10 & 0 & 0 \\
\hline 6121 & LAWTON EOT SPRINGS & 0 & & 33 & 10 & 0 & 0 \\
\hline 6014 & LEACE ES & 0 & & 0 & & 170 & 0 \\
\hline 6011 & LEE $B S$ & 0 & & 0 & & 175 & 0 \\
\hline 6122 & LONGSTREET SPRING & 0 & & 27 & 10 & 0 & 0 \\
\hline 6049 & LOWER RANCEE & 0 & & 0 & & 100 & 0 \\
\hline 6123 & MACFARLAND EOT SPRIN & 0 & & 76 & 10 & 0 & 0 \\
\hline $6 \pm 24$ & MANSE SPRITGS & 0 & & 23 & 10 & 0 & 0 \\
\hline 6125 & MCCOY SPRINGS & 0 & & 48 & 10 & 0 & 0 \\
\hline 6126 & MCGILE SPRING & 0 & & 28 & 10 & 0 & 0 \\
\hline 6034 & NINERAL SAN JACINTO & 0 & & 0 & & 130 & 0 \\
\hline 6050 & MONTE NEVA BS & 0 & & 0 & & 0 & 79 \\
\hline 6127 & MOON RIVER SPRING & 0 & & 33 & 10 & 0 & 0 \\
\hline 6128 & MOORES RANCE SRRINGS & 0 & & 21 & 10 & 0 & 0 \\
\hline 6129 & MOORMAIV SREING & 0 & & 37 & 10 & 0 & 0 \\
\hline 6130 & MOUND SPRITIGS & 0 & & 43 & 10 & 0 & 0 \\
\hline 6131 & MUD SPRINGS & 0 & & 21 & 10 & 0 & 0 \\
\hline 6132 & MUD SRRINGS & 0 & & 75 & 10 & 0 & 0 \\
\hline 6133 & MUDDY SPRING & 0 & & 32 & 10 & 0 & 0 \\
\hline 6039 & NEAR GOLCONDA & 0 & & 0 & & 125 & 0 \\
\hline 6051 & DEAR CARLIN & 0 & & 0 & & 0 & 79 \\
\hline 6053 & WEAR RUBY MARSB & 0 & & 0 & & 0 & 65 \\
\hline 6021 & WEEDLE ROCKS & 0 & & 0 & & 150 & 0 \\
\hline 6055 & MEVADA ES & 0 & & 0 & & 0 & 61 \\
\hline 6051 & RILE SPR & 0 & & 0 & & 0 & 43 \\
\hline 6134 & PANACA SPRING & 0 & & 31 & 10 & 0 & 0 \\
\hline 6135 & PEARL EOT SPRIWGS & 0 & & 43 & 10 & 0 & 0 \\
\hline 6012 & FINTO E S & 0 & & 0 & & 175 & 0 \\
\hline 6136 & POINT OE ROCKS SRRID & 0 & & 33 & 10 & 0 & 0 \\
\hline 6060 & POTTS RANCE E $S$ & 0 & & 0 & & 0 & 45 \\
\hline $61 \equiv 7$ & PRESTON SPRIWGS & 0 & & 22 & 10 & 0 & 0 \\
\hline 6138 & RIZZI RANCE EOT SPRI & 0 & & 43 & 10 & 0 & 0 \\
\hline 6139 & ROGERS SPRING & 0 & & 28 & 10 & 0 & 0 \\
\hline 6004 & SAN EMIDIO & 0 & & 0 & & 200 & 0 \\
\hline
\end{tabular}

TABLE 6. GEOTEERMAL SITE TEMPERATURES. 


\section{SITE SITE NAME}

ID

6140 SHIPLEY EOT SPRING

6141 SIFI RANCE SPRING

6019 SMITH CREEK VALIEI

6017 SODA LAKE

6046 SODA SP

6057 SOLDIER MEADOWS

6043 SOU ES

6037. SPENCER $B S$

6142 SPRINGS

6143 SERING

6144 SPRING

6145 SFRTNG

6146 SFRINGS BOT

6147 SPRING HOT

6148 SPRING

6149 SPRING

6062 SSE PATSVILLE

6003 STEAMBOAT SP

6018 STILLWATER

6150 STORM SPRING

6005 SULPEUR ES

6151 SULPEUR SPFING

6045 TEE EOT SPR

6152 TWIN SPRINGS

6153 UPDER WARM SPRTNG

6047 VALLEY OF TEE MOON

6020 WABUSKA ES

6154 WALL SPRIFG

6054 WALLEYS (GEROA) E S

6052 WALTI ES

6041 WARM SPR

6155 WARM SPPITES

6156 WARM SPRTIIGS

6157 WARM SRRIIGS

6158 WEDELL EOT SPRINGS

6028 WELL NEAP GERLACE

6159 WEST SPRING

6048 WILD EORSE RES

6160 WILLIALS HOT SPRINGS

5161 WILSON BOT SERING
NEVADA

-.---TEMPERATURE IN DEGREES CELSIUS-...-.-

SUBSUR- SOU- SURFACE SOU- CS CS

FACE RCE

$R C E$

EST MEAS

0

0

41

30

10

10

$0 \quad 0$

\section{0}

165

105

$0 \quad 54$

115

125

10

10

10

10

10

10

10

10

39

0

0

0

29

0

23

0

21

33

0

0

28

0

0

0

32

18

44

62

0

42

0

53

84

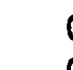

$0 \quad 0$

$0 \quad 0$

$0 \quad 0$

$0 \quad 0$

$0 \quad 0$

$0 \quad 0$

$0 \quad 0$

$0 \quad 0$

$0 \quad 41$

210

165

10

0

190

10

0

110

10

10

$0 \quad 0$

$0 \quad 0$

100

155

10

$0 \quad 0$

$0 \quad 61$

$0 \quad 72$

120

10

10

10

$0 \quad 0$

$0 \quad 0$

10

$0 \quad 0$

10

135

0

100

10

10

0

TABLE 6. GEOTHERMAL SITE TEMPERATURES. 
NEW MEXICO

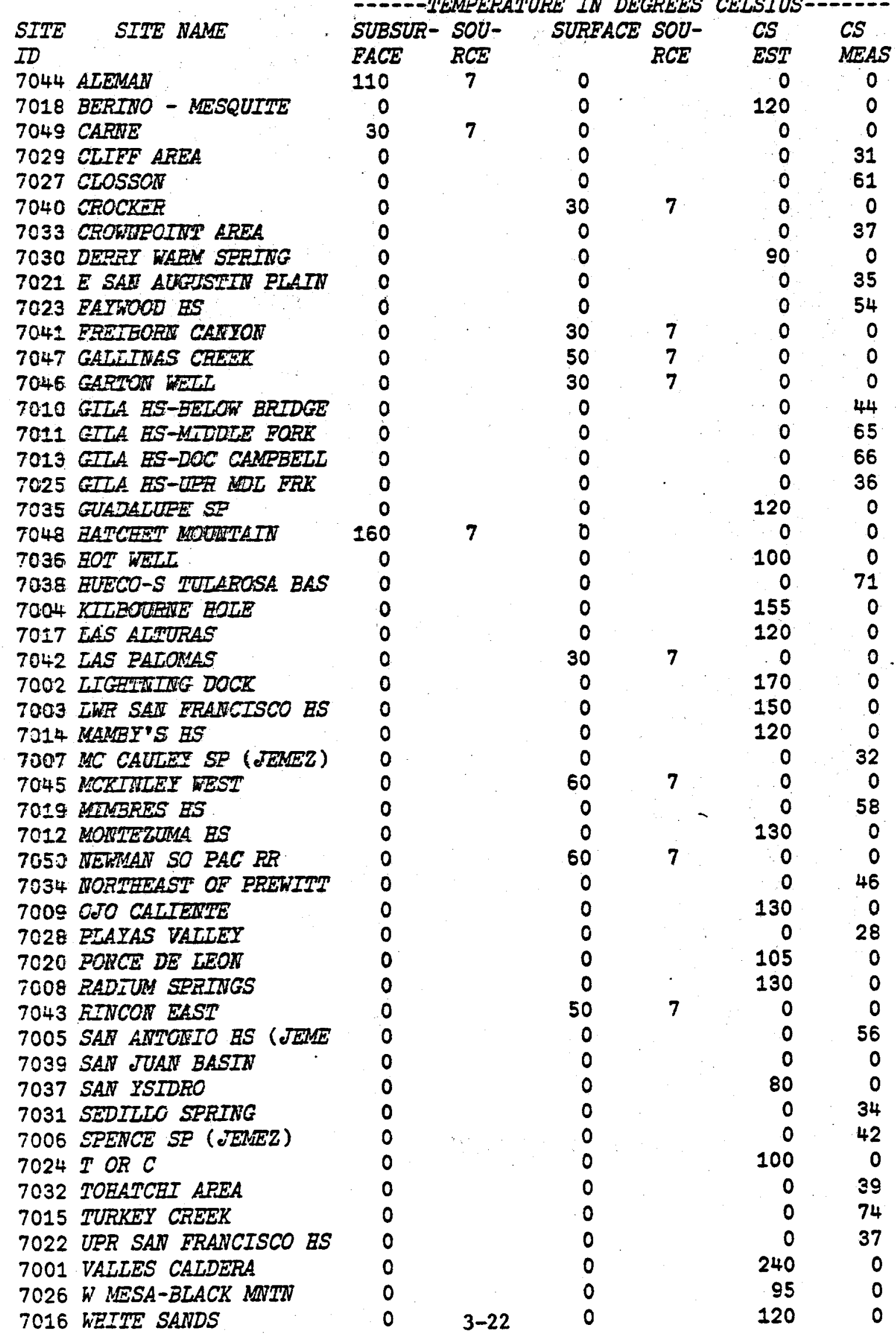


$b$

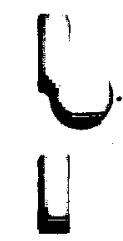

SITE SITE NAME
ID
8007 ABRABAM BS
8015 BECES BS
8044 BIG WS

UTAE

-.--TEMPERATURE IN DEGREES CELSIUS-.....-

SUBSUR- SOU- SURFACE SOU- CS CS

FACE RCE RCE EST MEAS

\section{0}

0

$125 \quad 0$

$90 \quad 0$

8033 BLUE WS

0

$0 \quad 18$

8025 CASTILLA HS

$0 \quad 27$

8037 CONO ES

$0 \quad 40$

8002 COVE FORT-SLTPEURDAL

$0 \quad 25$

8021 CRATER ES

$800 E$ CRISTAL ES

3016 CRYSTAL E.S.

8041 DIAMOHD FORK WS

8030 EISE SFRITGS

B031 GAADI

8042 GOSHEX WS

8038 GRAWTSVILEE

8026 EATTOW ES

8013 EOOPER ES

8036 JOERSOLES WTS

8004 JOSEPE ESS

8022 LATERKTI ES

8028 IIRCOLW FOINT WS

8012 MEADON ES

8018 MTDWAY ES

8009 MONROE (COOPER) ES

8032 HARGAITS WS

8010 OGDEN ES

8027 RADILM(LOISON) ES

8005 RED EILI ES

8040 RTCHFIELD WS

S001 ROOSEVELT RS

8039 RUSSELS WTS

8019 SARATOGA ES

8029 SPEIT WOUTTEIN WS

8043 STERETIV SPR

8011 STIFETITG SPR

8002 THERLO ES

8020 UDDI ES

8024. CTEAIED ES

8014 UTAE ES

8023 VEYO ISS

8034 WARM SPR

8035 WAFN SPR-UTAE LAKE

8008 WASATCE ES

3017 WILSON BS

TABLE o. GEOTHERMAL SITE TEMPERATURES. 


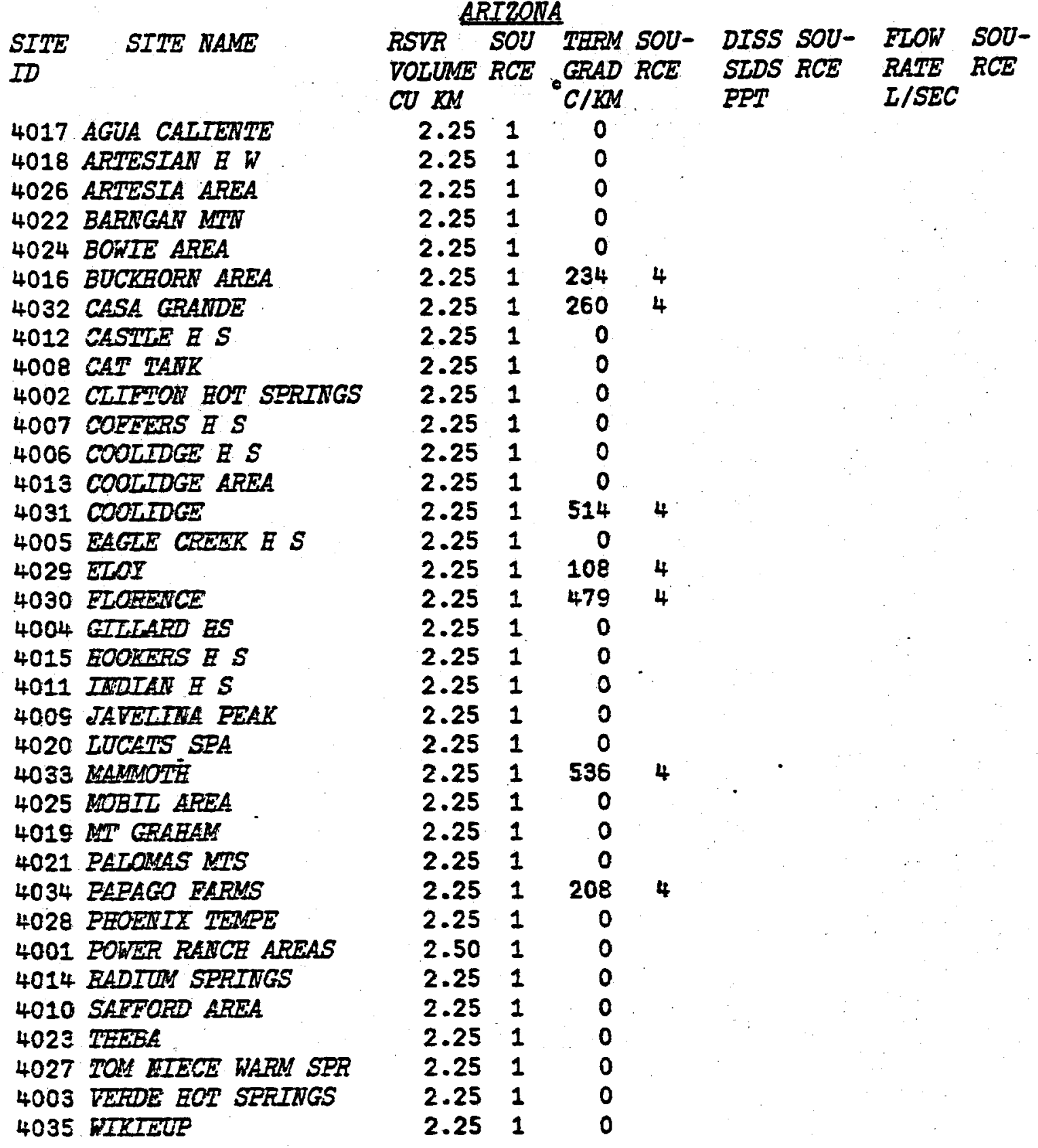

TAEEE 7. RESERVOIR VOLUME, THBRMAL GEADIEWT, DISSOLVED SOLIDS AND FLOW RATE 


\begin{tabular}{|c|c|c|c|}
\hline $\begin{array}{l}\text { SITE } \\
\text { ID }\end{array}$ & SITE NAME & $\begin{array}{l}\text { RSVR } \\
\text { VOLUME } \\
\text { CU KM }\end{array}$ & $\begin{array}{l}S O U \\
R C E\end{array}$ \\
\hline 047 & ANTELOPE BIRDSIE & .94 & 5 \\
\hline 70 & BRANDS RANCE ARTESIA & .06 & $\sqrt{3}$ \\
\hline 25 & BROWI CANYON TERML A & 3.82 & 5 \\
\hline 25 & CANON CITY HOT SPRIN & .04 & 5 \\
\hline 050 & CEBOLLA ROT SPRINGS & .73 & 5 \\
\hline 016 & CERENT CREEK WS & .13 & 5 \\
\hline 021 & CEALK CR MT PRINCETN & 2.48 & 5 \\
\hline 022 & CEALK CREEK WRIGET $H$ & 2.25 & 1 \\
\hline 023 & CHALK CREEK BORIETSE & 2.25 & 1 \\
\hline 024 & CHAIK CREEK WOOLMING & 2.25 & 1 \\
\hline 5033 & CLARK ARTESIAN WELL & .17 & 5 \\
\hline 014 & COLONEL CEINN EOT WE & .24 & 5 \\
\hline 015 & CONUNDEUM HOT SPRING & .18 & 5 \\
\hline 020 & COITONWOOD CREEK JUM & 1.09 & 5 \\
\hline 002 & CRAIG WARM WATER WEL & .51 & 5 \\
\hline 039 & DEXTER MCINTYRE & .95 & 5 \\
\hline 5032 & DON $K$ RANCB ARIESIAN & .59 & 5 \\
\hline 5010 & DOTSERO WARM SPRINGS & .17 & 5 \\
\hline 054 & DUNTON GEYSR PARADIS & .37 & 5 \\
\hline 041 & DUTCE CRONLY STINENG & .24 & 5 \\
\hline 008 & ELDORALO & .28 & 5 \\
\hline 5043 & EOFE ARTE & 2.25 & 1 \\
\hline 5031 & FLORENCE ARTESIAN h & .16 & 5 \\
\hline 5030 & EREUONT NATATORIUM & .17 & 5 \\
\hline & FULE $N W I$ & 2.25 & 1 \\
\hline 01 & GLENWOOD HOT SPRINC & .26 & 5 \\
\hline 019 & EARTSELL EOT SPRINGS & .34 & 5 \\
\hline
\end{tabular}

TABLE 7. RESERVOTR YOLUME, THERMAL GRADIENT, DISSOLVED SOLIDS AND FLOW RATE 


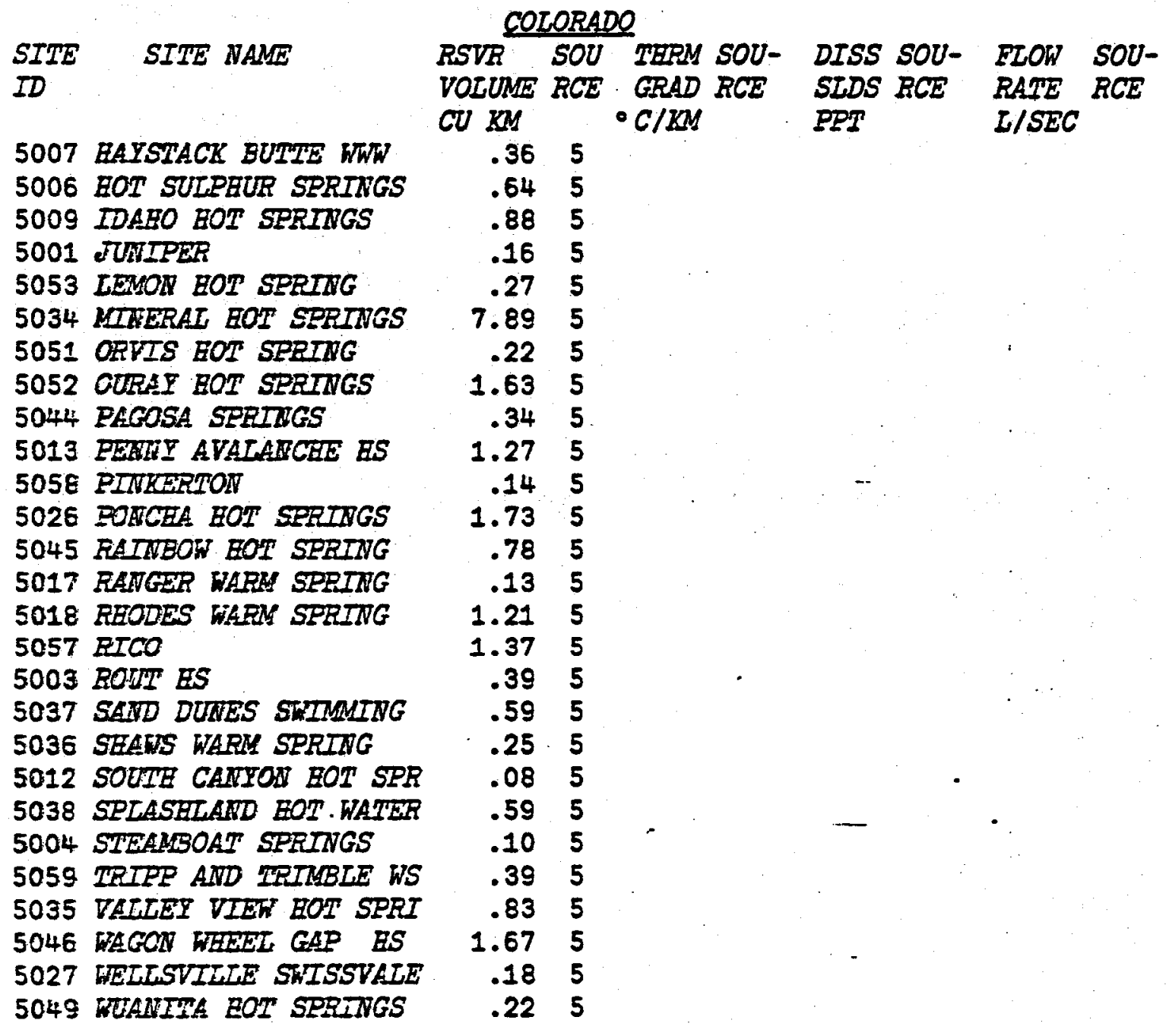

TAELE 7. RESERVOIR VOLUME, TRERMAL GRADIENT, DISSOLVED SOLTDS AND FLON RATE 


\section{SITE SITE NAME ID}

6063 ALKALI HOT SPRING

6064 ASH SPRINGS

6016 BALTAZOR HS

6040 BARTHOLOMAE

6065 BENNETT SPRTIPGS

6001 BEOWAWE E S

6066 BIG LOCKES SFRING

6067 BIG SPRING

6058 BIG SPRINGS

6022 BLACK ROCK DESERT

6069 BLUE EAGLE SPRTNGS

6070 BOILITE SPRIRG

5071 BORAI SPRING

6059 EOWERS E $S$

6058 B06 BS

6002 BRADY EOT SP

6072 EROOKS SPRING

6073 BRUEFEYS BOT SERINGS

6031 BUEFALO TALLEY $E S$

5036 BETIE SFR

6074 EUTTERFTELD SPRINGS

6075 CAIN SPEITISS

6076 CALIENTE HOT SPRING

6077 CARSON HOT SPRINGS

6078 CRARNOCK BIG BLUE

5030 CEERRY CR II $S$

6079 CEIMMEI SPRTMGS

6080 COLLAR AND ELBOW SPR.

6081 CRYSTAL FOOL

6082 COYSTAL SPRTIGS

6025 DARROUGHS HS

6053 DELMUES SPPING

6084 DEVILS BOLE

6056 DIANA PUNCH BOWL

6023 DIXIE VALEET ES

6024 DOUBLE IS

$602 E$ DYKE E $S$

6044 ELRO HS

6085 ETITGRADT SPRINGS

6086 FATRBANKS SPRING

6015 FERNLEY BS
NEVADA

RSTR SOU

VOEUME RCE

CU KM

2.251

2.251

3.001

2.251

2.251

$42.00 \quad 1$

2.251

2.251

2.251

2.251

2.251

2.251

2.251

2.251

4.001

30.001

2.251

2.251

10.001

2.251

2.251

2.251

2.251

2.251

2.251

2.251

2.251

2.251

2.251

2.251

2.251

2.251

2.251

2.251

3.001

20.001

2.251

3.001

2.251

2.251

2.251
TERM SOU- DISS SOU- FLOW SOUGRAD RCE SLDS RCE RATE RCE $\begin{array}{lll}{ }^{\circ} C / S M & \text { DPT }\end{array}$

TABLE 7. RESERVOIR VOLUME, THERMAE GRADIENT, DISSOLVED SOLIDS AND FLOW RATE 


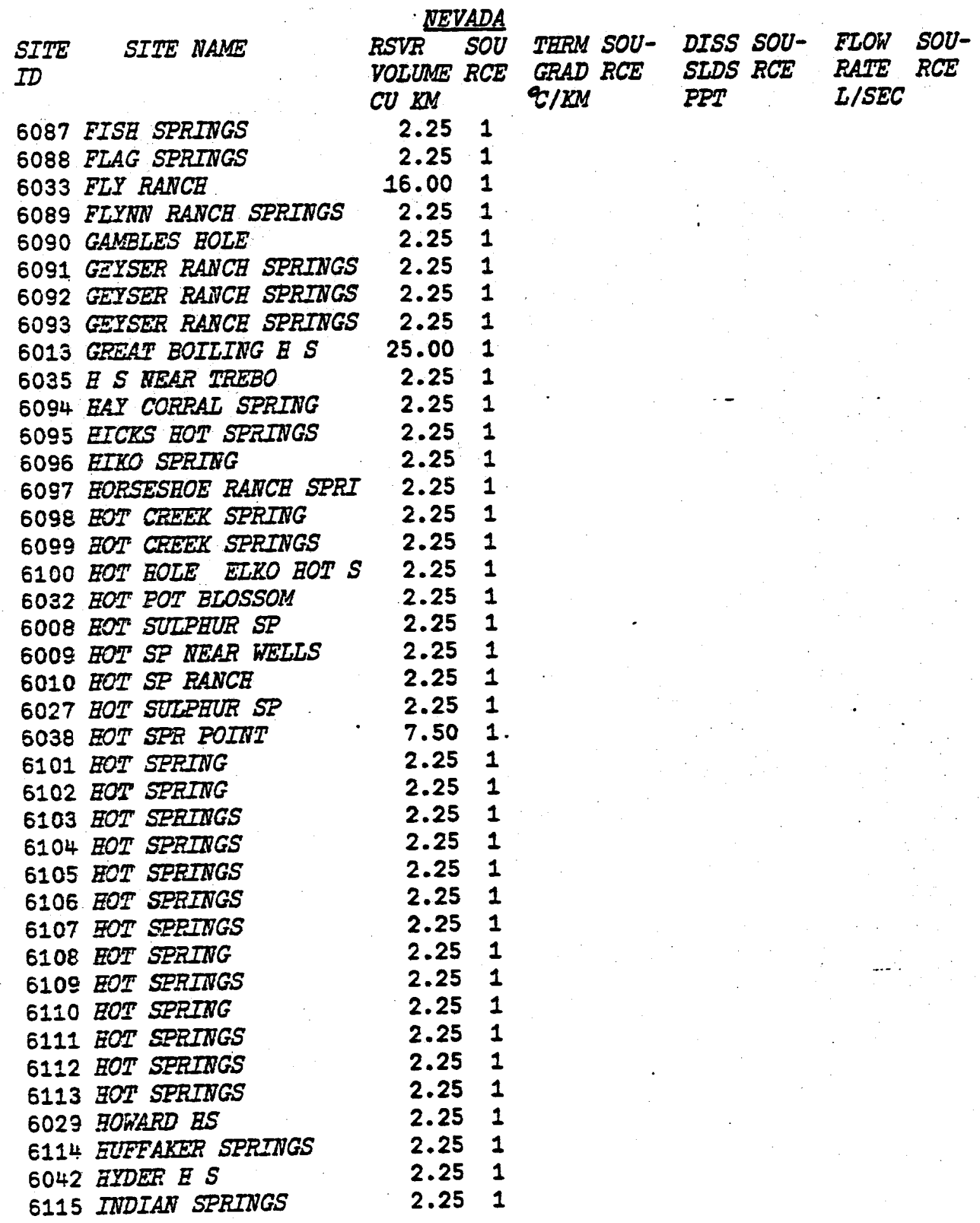

TABLE 7. RESERVOIR VOLUME, TEERMAL GRADIENT, DISSOLVED SOLTDS AND FLOW RATE 


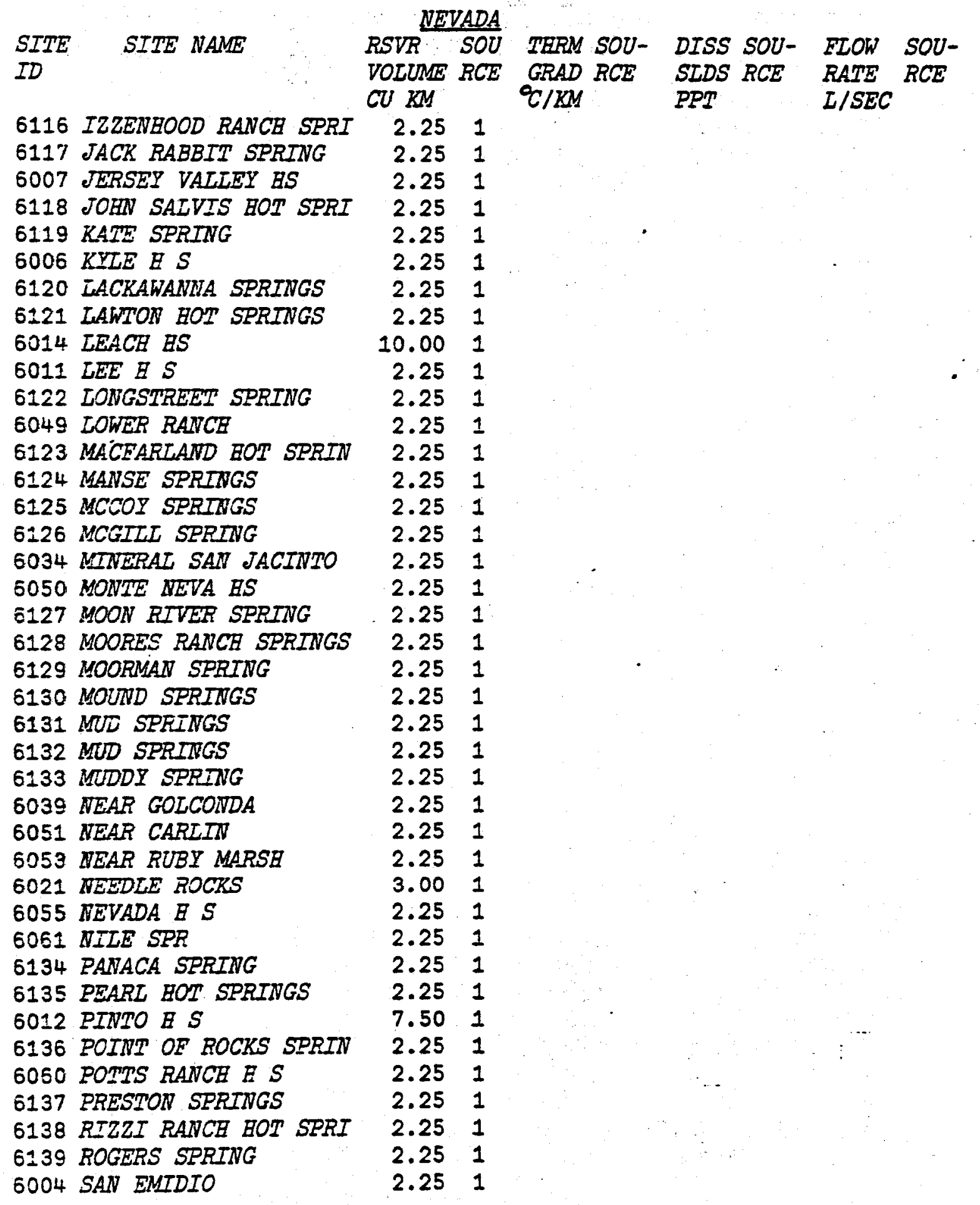

TA $\bar{B} L E$ 7. RESERVOIR VOLURE, THERMAL GRADIENT, DISSOLVED SOLIDS AND FLOW RATE 


\begin{tabular}{|c|c|c|c|c|c|c|c|}
\hline \multirow[b]{2}{*}{$\begin{array}{l}\text { SITE } \\
\text { ID }\end{array}$} & & \multicolumn{2}{|c|}{ NEVADA } & & \multirow{3}{*}{$\begin{array}{l}\text { DISS SOU- } \\
\text { SLDS RCE } \\
\text { PPT }\end{array}$} & \multirow[b]{2}{*}{$\begin{array}{l}\text { FLOW } \\
\text { RATE } \\
\text { L/SEC }\end{array}$} & \multirow[b]{2}{*}{$\begin{array}{l}\text { SOU- } \\
\text { RCE }\end{array}$} \\
\hline & SITE NAME & $\begin{array}{l}R S V R \\
\text { VOLUME } \\
\text { CU KM }\end{array}$ & $\begin{array}{l}\text { SOU } \\
R C E\end{array}$ & $\begin{array}{l}T R R M \text { SOU- } \\
\text { GRAD RCE } \\
Q / K M M\end{array}$ & & & \\
\hline 6140 & SEIPLEY BOT SPRING & 2.25 & 1 & & & & \\
\hline 6141 & SIRI RANCE SPRING & 2.25 & 1 & & & & \\
\hline 6019 & SLITE CREEK VALLEY & 2.25 & 1 & & & & \\
\hline 6017 & SODA LAKE & 12.50 & 1 & & & & \\
\hline 6046 & SODA SP & 2.25 & 1 & & & & . \\
\hline 6057 & SOLDIER MEADOWS & 12.00 & 1 & & & & 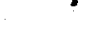 \\
\hline 6043 & SOU E S & 2.25 & 1 & & & & \\
\hline 6037 & SPERCER E $S$ & 2.25 & 1 & & & & \\
\hline 6142 & SPEIMGS & 2.25 & 1 & & & & \\
\hline 6143 & SPRING & 2.25 & 1 & & & & \\
\hline 6144 & SPRIMG & 2.25 & 1 & ' & & & - \\
\hline 6145 & SPRING & 2.25 & 1 & & & & \\
\hline 6146 & SERIKGS EOT & 2.25 & 1 & & & & \\
\hline 6147 & SFRTIG EOT & 2.25 & 1 & & & & \\
\hline 6148 & SERING & 2.25 & 1 & & & & \\
\hline 6149 & SPRIMG & 2.25 & 1 & & & & \\
\hline 8062 & SSE EATSVILLE & 2.25 & 1 & & & & \\
\hline 6003 & STEAMBOAT SP & 16.00 & 1 & - & & & \\
\hline 6018 & STILLWATERR & 25.00 & 1 & & & & \\
\hline 6150 & STORM SPRING & 2.25 & 1 & & & & \\
\hline 6005 & SULPEUR BS & 10.00 & 1 & -- & - & & \\
\hline 6151 & SELPEUR SPRING & 2.25 & 1 & & & & \\
\hline 6045 & TEE EOT SRR & 2.25 & 1 & & & & \\
\hline 6152 & TWIN SPRINGS & 2.25 & 1 & & & & \\
\hline $6 \pm 53$ & UPPER WAFM SRRING & 2.25 & 1 & & & & \\
\hline 6047 & VALEEY OF TEE MOON & 2.25 & 1 & & & & \\
\hline 6020 & WABUUSRA ES & 2.25 & 1 & & & & \\
\hline 6154 & WALL SPRING & 2.25 & 1 & & & & \\
\hline 6054 & WALLETS (GENOA) B $S$ & 2.25 & 1 & & & & \\
\hline 6052 & WAETI BS & 3.00 & 1 & & & & \\
\hline 6041 & WARM SPR & 2.25 & 1 & & & & \\
\hline 6155 & WAPM SPRTNGS & 2.25 & 1 & & & - & \\
\hline 6156 & WARM SPRINGS & 2.25 & 1 & & & & \\
\hline 6157 & WARRM SFRINGS & 2.25 & 1 & . & & & \\
\hline 6158 & WEDELL EOT SFRINGS & 2.25 & 1 & & & & \\
\hline 6028 & WELL NEAR GERLACE & 2.25 & 1 & & & & \\
\hline 6159 & WEST SERING & 2.25 & 1 & & & & \\
\hline 6048 & WILD HORSE RES & 2.25 & 1 & & & & \\
\hline 6160 & WILLTAMS HOT SPRINGS & 2.25 & 1 & & & & \\
\hline 6161 & WIISON HOT SPRING & 2.25 & 1 & & & & \\
\hline
\end{tabular}
TABLE 7. RESERVOIR VOLUME, TEERMAL GRADIEWT, DISSOLVED SOLTDS
AND FLOW RATE 


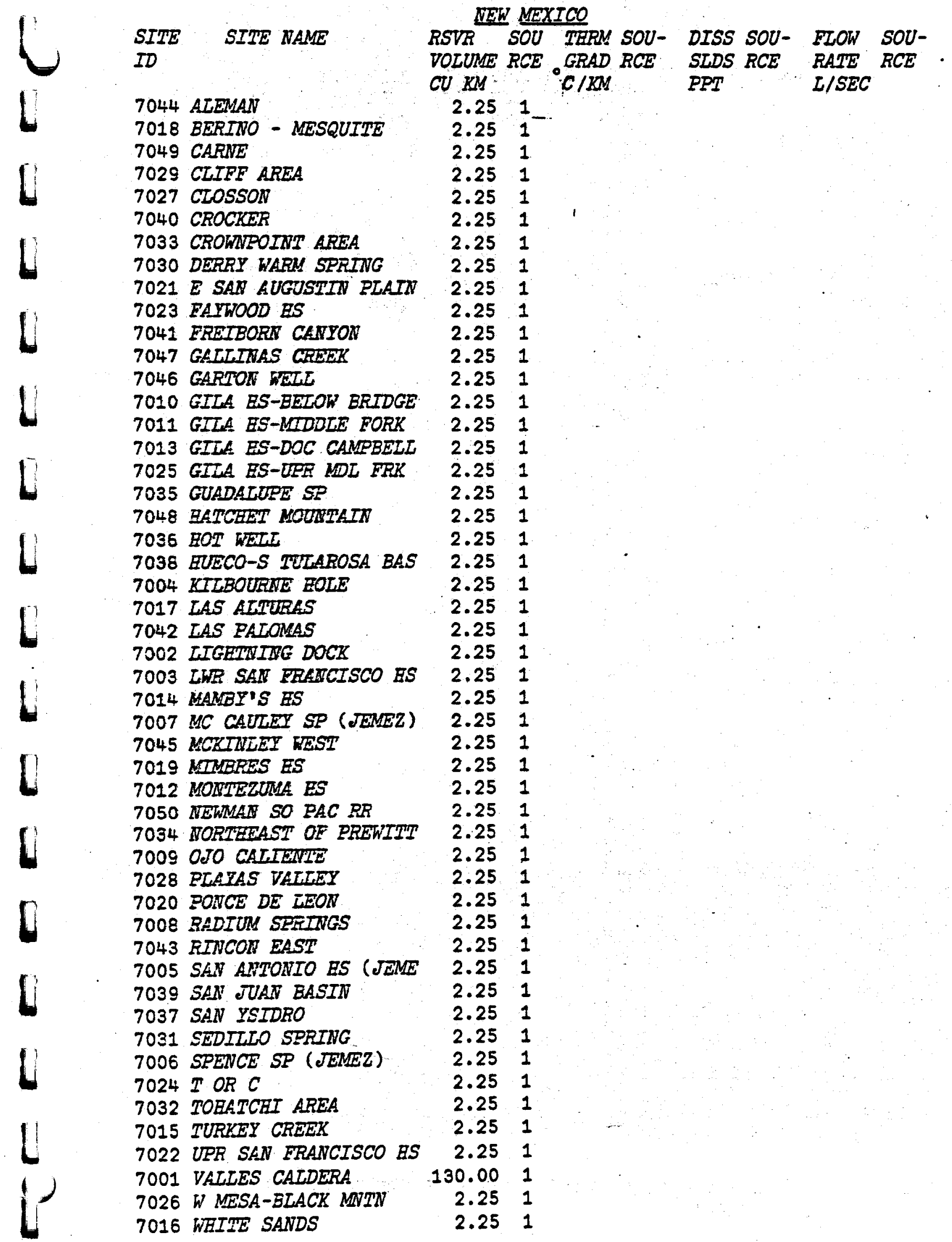

TABEE 7. RESERVOIR VOLUME, TEEEMAI GRADIENT, DISSOLVED SOLIDS AND FTOW RATE 


\begin{tabular}{|c|c|c|c|c|c|c|c|c|c|}
\hline & & UT & & & & & & & \\
\hline $\begin{array}{l}\text { SITE } \\
I D\end{array}$ & SITE NAME & $\begin{array}{l}\text { RSVR } \\
\text { VOLUME } \\
\text { CU KM }\end{array}$ & SOU & $\begin{array}{l}\text { TERM } \\
\text { GRAD } \\
\text { CIIMM }\end{array}$ & $\begin{array}{l}\text { SOU- } \\
\text { RCE }\end{array}$ & $\begin{array}{l}\text { DISS } \\
\text { STDS } \\
\text { PPT }\end{array}$ & $\begin{array}{l}\text { SOU- } \\
\text { RCE }\end{array}$ & $\begin{array}{l}\text { ELOW } \\
\text { RATE } \\
I / S E C\end{array}$ & $\begin{array}{l}\text { SOU- } \\
\text { RCE }\end{array}$ \\
\hline 8007 & ABRABAM ES & 2.25 & 1 & & & & & & \\
\hline 8015 & BECKS ES & 2.25 & 1 & & & & & & \\
\hline 8044 & BIG WS & 2.25 & 1 & & & & & & \\
\hline 8033 & BLUE WS & 2.25 & 1 & & & & & & \\
\hline 8025 & CASTILLA ES & 2.25 & 1 & & & & & & \\
\hline 8037 & COMO ES & 2.25 & 1 & & & & & & \\
\hline 8002 & COVE FORT-SULPEURDAL & 22.50 & 1 & & & & & & \\
\hline 8021 & CRATER ES & 2.25 & 1 & & & & & & \\
\hline 8006 & CRYSTAE ES & 2.25 & 1 & & & & & & \\
\hline 8016 & CRYSTAL E.S. & 2.25 & 1 & & & & & & \\
\hline 8041 & DIAMOND FORK WS & 2.25 & 1 & & & & & & \\
\hline 8030 & FISE SPRTWGS & 2.25 & $\overline{1}$ & & & & & & \\
\hline 8031 & GANDF & 2.25 & 1 & & & & & & \\
\hline 8042 & GOSEET ITS & 2.25 & 1 & & & & & & \\
\hline 8038 & GEADEFSVILEE & 2.25 & 1 & & & & & & \\
\hline 8026 & EATTON ES & 2.25 & 1 & & & & & & \\
\hline 8013 & EOOEER ES & 2.25 & 1 & & & & & & \\
\hline 8036 & JOEHSOWS WS & 2.25 & 1 & & • & & & & \\
\hline 8004 & JOSEPE ES & 2.25 & 1 & & & & & & \\
\hline 8022 & LAVVEREID ES & 2.25 & 1 & & & & & & \\
\hline 8028 & IITCOLW POTWT WS & 2.25 & 1 & & & & & . & \\
\hline 8012 & MEADOW ES & 2.25 & 1 & & & & & & \\
\hline 8018 & MIDWAI ES & 2.25 & 1 & & & & & & \\
\hline 8009 & MONEOE (COOPER) ES & 2.25 & 1 & & & & & & \\
\hline 8032 & MORGANS WS & 2.25 & 1 & & & & & & \\
\hline 8010 & OGEELE ES & 2.25 & 1 & & & & & & \\
\hline 8027 & RADIUHA DOTSON) ES & 2.25 & 1 & & & & & & \\
\hline 8005 & RED EILI ES & 2.25 & 1 & & & & & & \\
\hline 8040 & RICEFIELD WT & 2.25 & 1 & & & & & & \\
\hline 8001 & EOOSEVVETT ES & 8.00 & 1 & & & & & & \\
\hline 8039 & EUSSETS WS & 2.25 & 1 & & & & & & \\
\hline 8019 & SAFATOGA ES & 2.25 & 1 & & & & & & \\
\hline 8029 & SFLIT WOUWTATN WS & 2.25 & 1 & - & & & & & \\
\hline 8043 & STEFIIIRG SPR & 2.25 & 1 & & & & & & \\
\hline 8011 & SIIUZTWF SPR & 2.25 & 1 & & & & & & \\
\hline 8003 & THETHAS IS & 2.25 & 1 & & & & & & \\
\hline 8020 & VDOE ES & 2.25 & 1 & & & & & & \\
\hline 8024 & UWKALEED ES & 2.25 & 1 & & & & & & \\
\hline 8014 & UTAE ES & 2.25 & 1 & & & & & & \\
\hline 8023 & VEIO ES & 2.25 & 1 & & & & & & \\
\hline 8034 & WARH SPR & 2.25 & 1 & & & & & & \\
\hline 8035 & WARM SPP-LTAB IAKE & 2.25 & 1 & & & & & & \\
\hline 8008 & WASATCH HS & 2.25 & 1 & & & & & & \\
\hline 8017 & WILSON BS & 2.25 & 1 & & & & & & \\
\hline
\end{tabular}




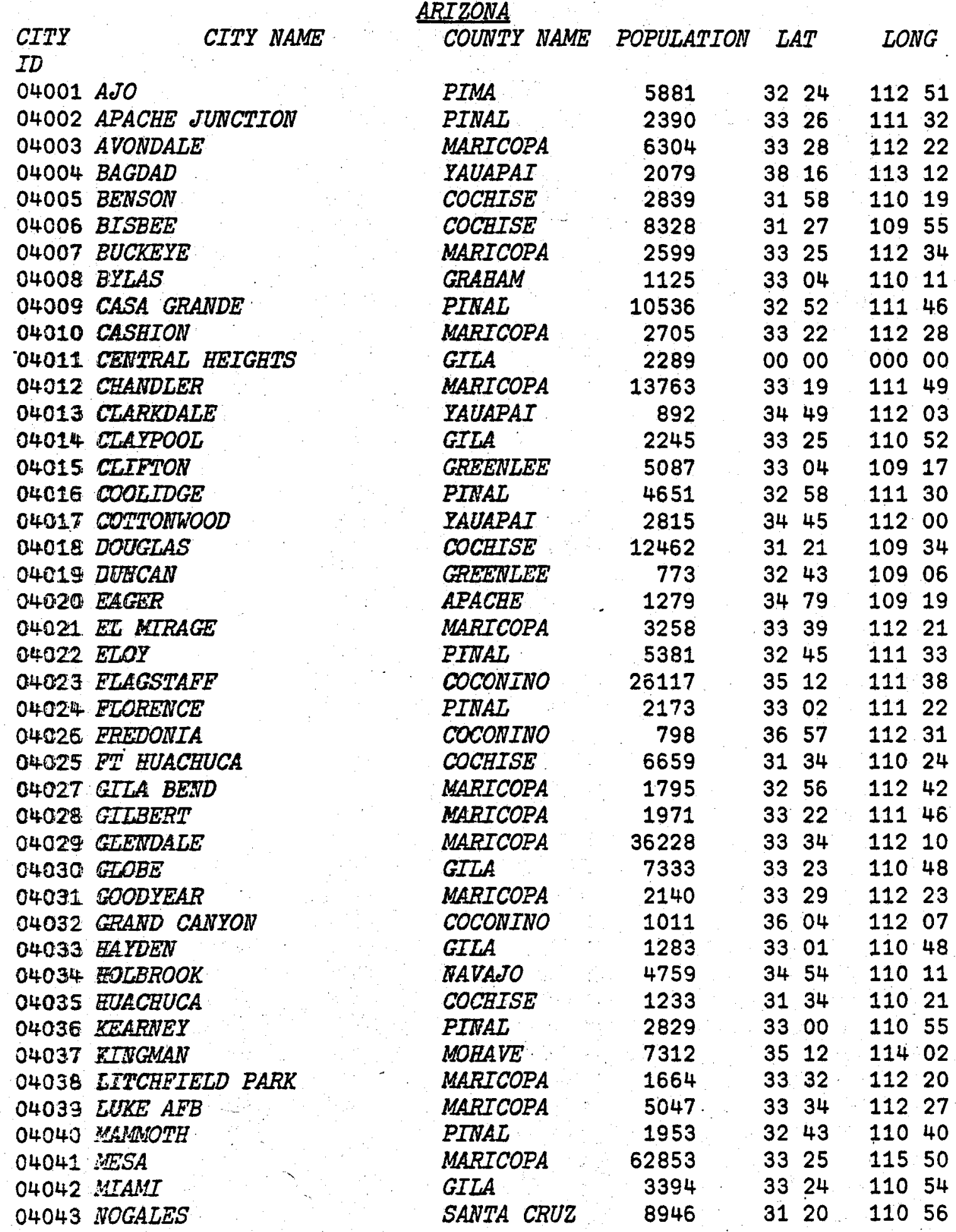

TABLE 8. CITY ID, CITY NAME, COUNTY NAME, POPULATION, LATITUDE AND LONGITUDE 


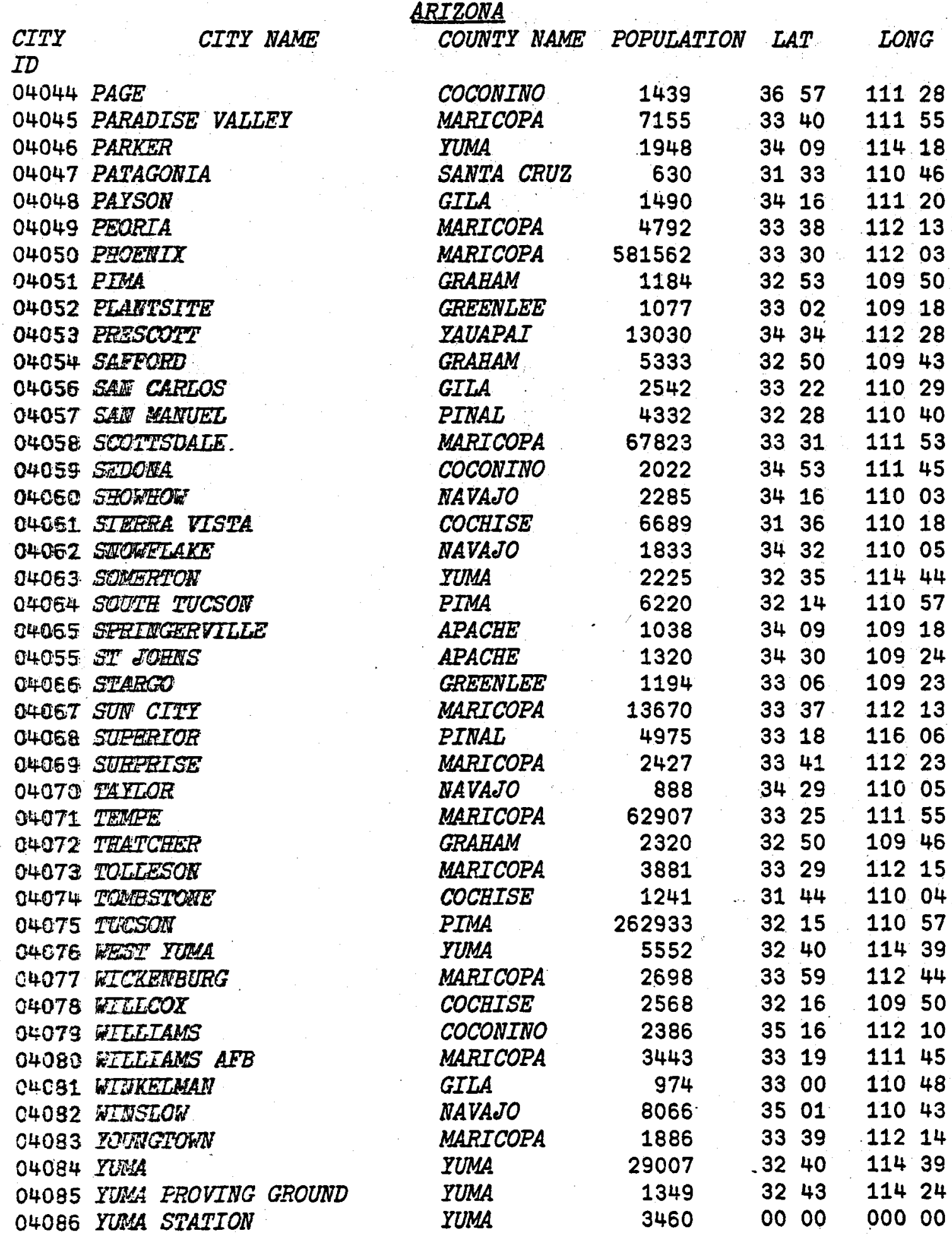

TABLE 8. CITY ID, CITY NAME, COUNTY NAME, POPULATION, LATITUDE AND LONGITUDE 


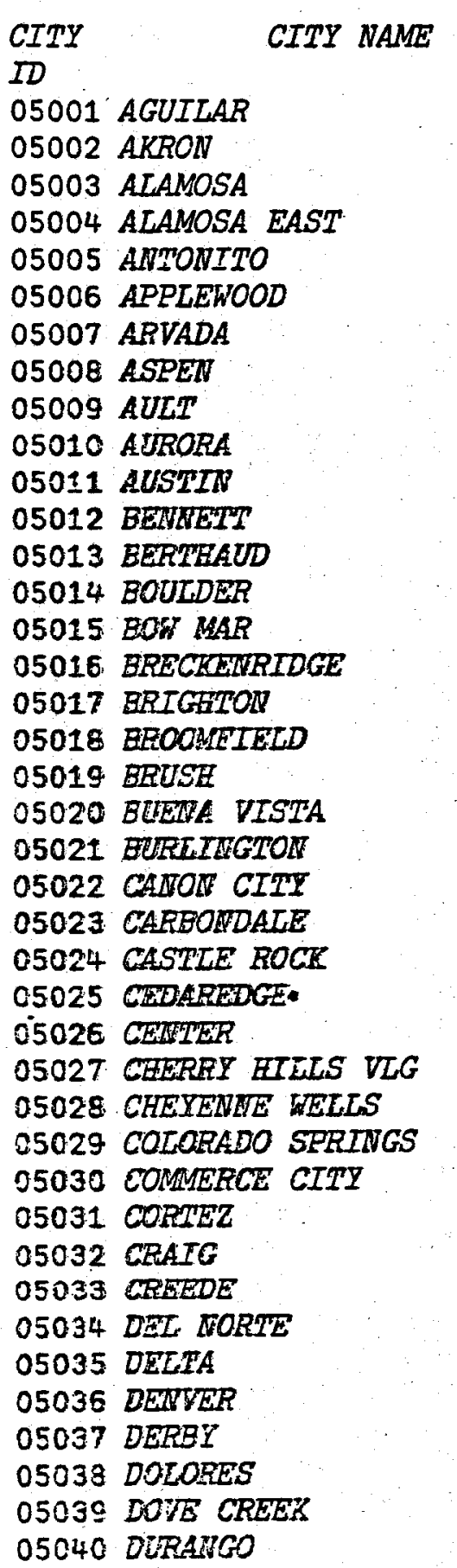

\section{COLORADO COUNTY NAME POPULATION LAT LONG}

$\begin{array}{lrllll}\text { LAS ANIMAS } & 699 & 37 & 25 & 104 & 40 \\ \text { WASHINGTON } & 1775 & 40 & 09 & 103 & 13 \\ \text { ALMOSA } & 6985 & 37 & 28 & 105 & 54 \\ \text { ALAMOSA } & 1040 & 37 & 28 & 105 & 54 \\ \text { CONEJOS } & 1113 & 37 & 04 & 106 & 01 \\ \text { JEFEERSON } & 8214 & 00 & 00 & 000 & 00 \\ \text { JEFEERSON } & 46814 & 39 & 47 & 105 & 07 \\ \text { EITKIN } & 2404 & 39 & 12 & 106 & 49 \\ \text { WELD } & 841 & 40 & 35 & 104 & 44 \\ \text { ARAPAHOE } & 74974 & 39 & 45 & 104 & 50 \\ \text { DELTA } & 1163 & 38 & 47 & 107 & 57 \\ \text { ADAMS } & 613 & 39 & 45 & 104 & 25 \\ \text { EARIMER } & 1446 & 40 & 19 & 105 & 05 \\ \text { EOULDER } & 66870 & 40 & 02 & 105 & 16 \\ \text { ARAPAHOE } & 945 & 39 & 38 & 105 & 03 \\ \text { SUMMIT } & 548 & 39 & 29 & 106 & 03 \\ \text { ADAMS } & 8309 & 39 & 59 & 104 & 50 \\ \text { BOULDER } & 7261 & 39 & 50 & 105 & 07 \\ \text { MORGAN } & 3377 & 40 & 15 & 103 & 36 \\ \text { CHAFFEE } & 1962 & 38 & 44 & 106 & 10 \\ \text { RIT CARSON } & 2828 & 39 & 17 & 102 & 17 \\ \text { FREMONT } & 9206 & 38 & 27 & 105 & 14 \\ \text { GAREIELD } & 726 & 39 & 23 & 107 & 13 \\ \text { DOUGLAS } & 1531 & 39 & 23 & 104 & 53 \\ \text { DELTA } & 581 & 38 & 44 & 107 & 55 \\ \text { RIO GRANDE } & 1470 & 37 & 45 & 106 & 07 \\ \text { ARAPAHOE } & 4605 & 39 & 38 & 104 & 51 \\ \text { CHEYENNE } & 982 & 38 & 48 & 102 & 30 \\ \text { EL PASO } & 135000 & 38 & 50 & 104 & 50 \\ \text { ADAMS } & 17407 & 39 & 50 & 104 & 55 \\ \text { MONTEZUMA } & 6032 & 37 & 22 & 108 & 36 \\ \text { MOFEAT } & 4205 & 40 & 30 & 107 & 33 \\ \text { MINERAL } & 653 & 37 & 52 & 106 & 56 \\ \text { RIO GRANDE } & 1569 & 37 & 40 & 106 & 22 \\ \text { DELTA } & 3694 & 38 & 42 & 108 & 04 \\ \text { DENVER } & 514000 & 39 & 45 & 105 & 00 \\ \text { ADAMS } & 10206 & 00 & 00 & 000 & 00 \\ \text { MONTEZUMA } & 820 & 37 & 28 & 108 & 30 \\ \text { DOLORES } & 619 & 37 & 46 & 108 & 55 \\ \text { LA PLATA } & 10333 & 37 & 16 & 107 & 53 \\ & & & & & \end{array}$

TABLE 8. CITY ID, CITY NAME, COUNTY NAME, POPULATION, LATITUDE AND LONGITUDE 


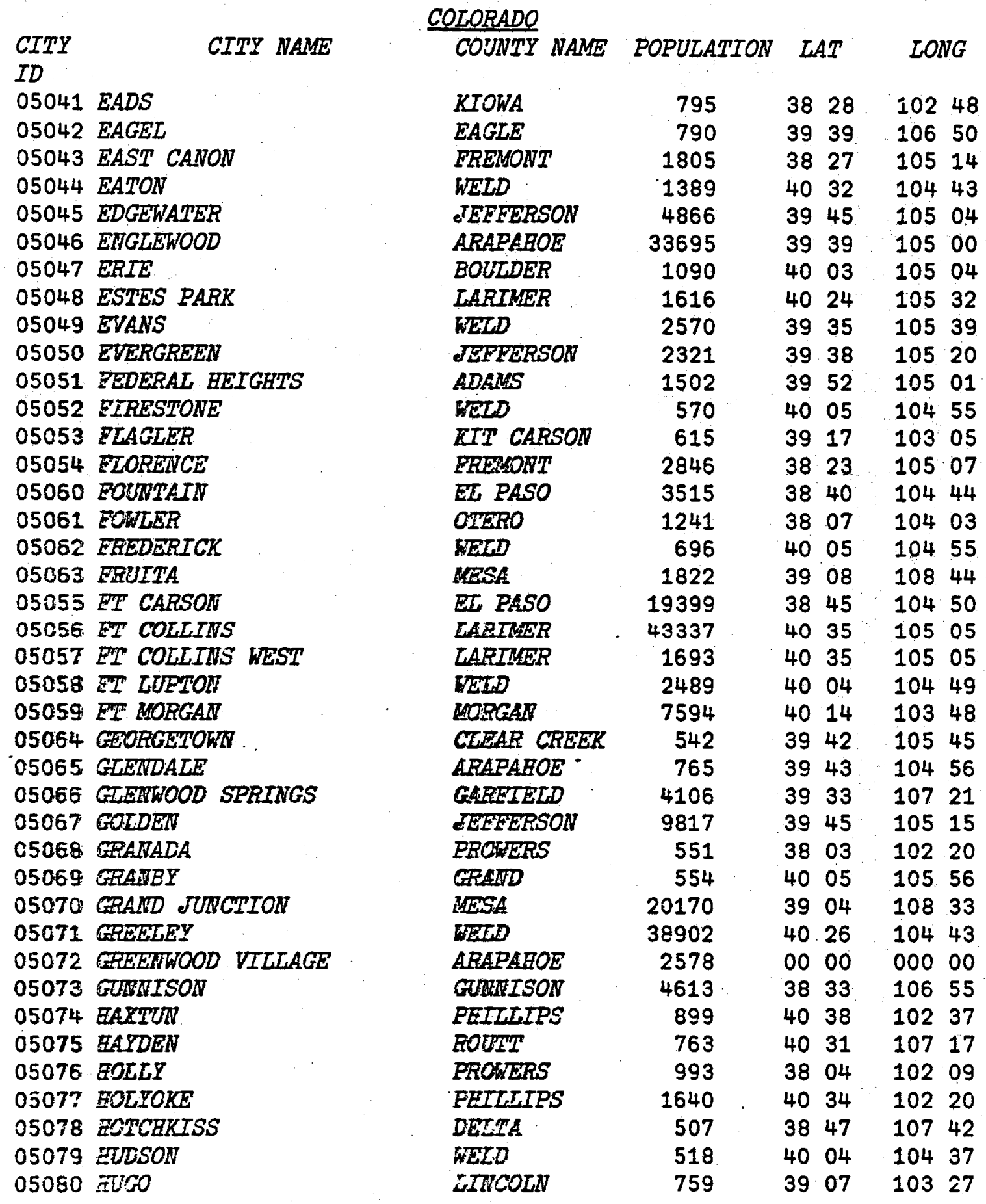

TABLE 8. CITY ID, CITY NAME, COUNTY NAME, POPULATION, LATITUDE AND LONGITUDE 


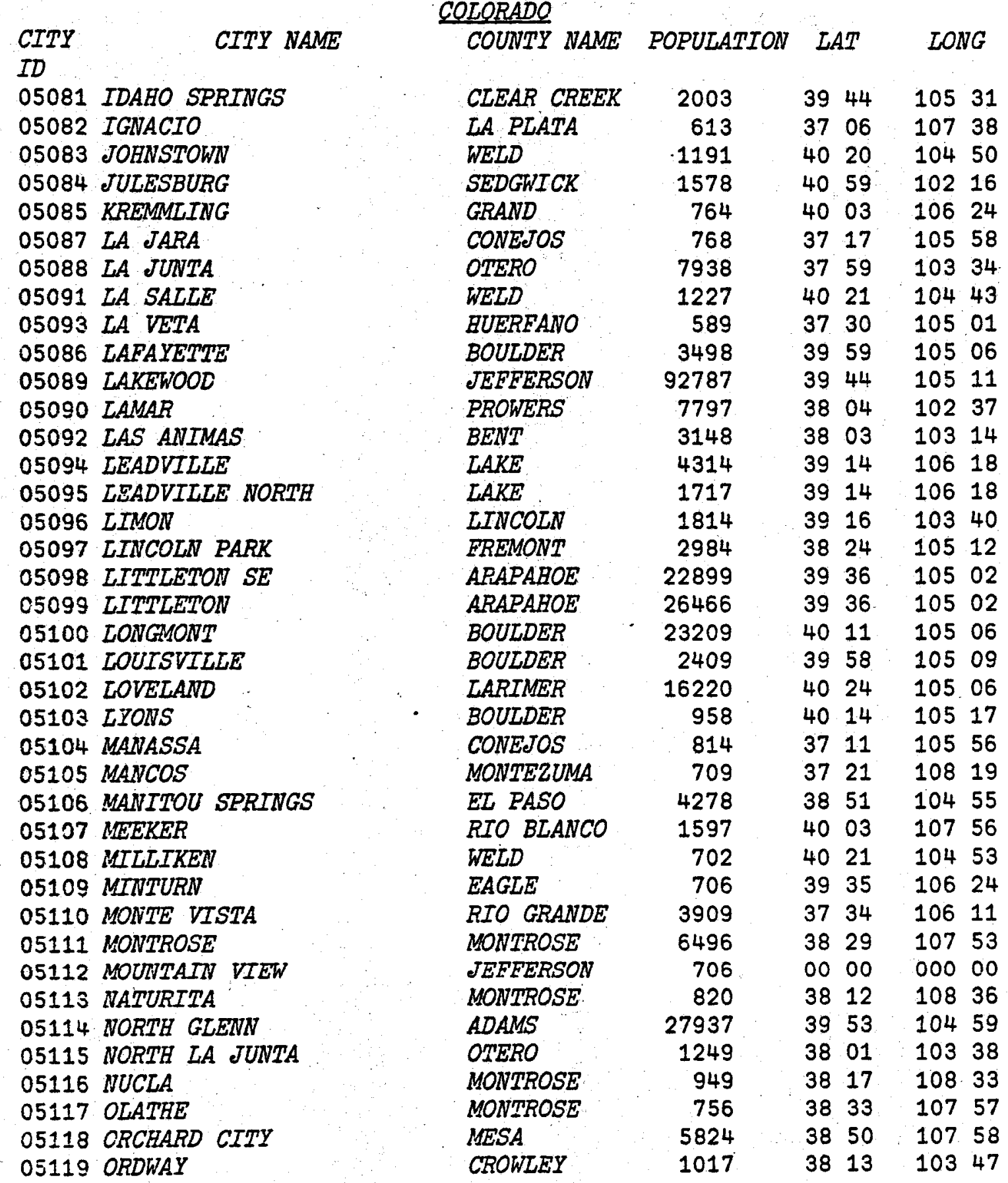

TABLE 8. CITY ID, CITY NAME, COUNTY NAME, POPULATION, LATITUDE AND LONGITUDE 


\begin{tabular}{|c|c|c|c|c|c|c|c|}
\hline & & $1 D O$ & & & & & \\
\hline $\begin{array}{l}\text { CITY } \\
\text { ID }\end{array}$ & CITY NAME & COUNTY NAME & POPULATION & $L$ & $A T$ & LO & $N G$ \\
\hline 05120 & OTIS & WASHINGTON & 521 & 40 & 09 & 102 & 58 \\
\hline 05121 & OURAY & OURAY & 741 & 38 & 02 & 107 & 40 \\
\hline 05122 & PAGOSA SPRINGS & ARCHULETA & 1360 & 37 & 16 & 107 & 01 \\
\hline 05123 & PALISADE & $M E S A$ & 874 & 39 & 05 & 108 & 23 \\
\hline 05124 & PALMER LAKE & $E L$ PASO & 947 & 39 & 07 & 104 & 56 \\
\hline 05125 & -PAONIA & DELTA & 1161 & 38 & 52 & 107 & 35 \\
\hline 05126 & PLATTEVILLE & WELD & 683 & 40 & 13 & 104 & 50 \\
\hline 05127 & PUEBLO & PUEBLO & 97453 & 38 & 17 & 104 & 38 \\
\hline 05128 & RANGELY & RIO BLANCO & 1591 & 40 & 04 & 108 & 48 \\
\hline 05129 & $R E D C L I F F$ & EAGLE & 621 & 39 & 31 & 106 & 22 \\
\hline 05130 & RIFLE & GARFIELD & 2150 & 39 & 32 & 107 & 47 \\
\hline 05131 & ROCKY FORD & OTERO & 4859 & 38 & 03 & 103 & 44 \\
\hline 0.5132 & SAGUACHE & SAGUACHE & 642 & 38 & 05 & 106 & 10 \\
\hline 05133 & SALIDA & CHAFFEE & 4355 & 38 & 33 & 106 & 01 \\
\hline 05135 & SAN LUIS & COSTILLA & 781 & 37 & 03 & 105 & 25 \\
\hline 05134 & SANFORD & CONEJOS & 638 & 37 & 16 & 105 & 55 \\
\hline 05136 & SECURITY-WIDEFIELD & EL PASO & 15297 & 38 & 42 & 104 & 44 \\
\hline 05137 & SHERIDAN & ARAPAHOE & 4787 & 39 & 39 & 105 & 02 \\
\hline 05138 & SHERRELWOOD & ADAMS & 18868 & 00 & 00 & 000 & 00 \\
\hline 05139 & SILVERTON & SAN JUAN & 797 & 37 & 48 & 107 & 40 \\
\hline 05140 & SPRINGEIELD & $B A C A$ & 1660 & 37 & 26 & 102 & 36 \\
\hline 05141 & STEAMBOAT SPRINGS & ROUTT & 2340 & 40 & 28 & 106 & 51 \\
\hline 0.5142 & STERLING & LOGAN & 10636 & 40 & 37 & 103 & 13 \\
\hline 05143 & STRATTON MEADOWS & EL PASO & 6223 & 00 & 00 & .000 & 00 \\
\hline $05 \pm 44$ & STRATTON & KIT CARSON & 790 & 39 & 18 & 102 & 36 \\
\hline 0.5 .145 & TELLURIDE & SAN MIGUEL & 553 & 37 & 57 & 107 & 48 \\
\hline 0.5146 & THORNTON & ADAMS & 13326 & 39 & 57 & 105 & 00 \\
\hline 0.5147 & TRINIDAD & LAS ANIMAS & 9901 & 37 & 11 & 104 & 31 \\
\hline 0.5158 & URAY & YUMA & 1953 & 40 & 05 & 102 & 14 \\
\hline 05148 & WALDEN & JACKSON & 907 & 40 & 43 & 106 & 19 \\
\hline 05149 & WALSENBURG & HUEREANO & 4329 & 37 & 36 & 104 & 48 \\
\hline 05150 & WALSH & $B A C A$ & 989 & 37 & 24 & 102 & 17 \\
\hline 05151 & WELBY & ADAMS & 6875 & 39 & 50 & 104 & 58 \\
\hline 0.5152 & WELLIRGTON & LARIMER & 691 & 40 & 42 & 105 & 01 \\
\hline 05153 & WESTMINSTER & ADAMS & 19432 & 39 & 49 & 105 & 05 \\
\hline 05154 & WESTMINSTER EAST & ADAMS & 7576 & 39 & 49 & 105 & 05 \\
\hline 05155 & WHEAT RIDGE & JEFEERSON & 29795 & 39 & 47 & 10.5 & 13 \\
\hline 05156 & WTNDSOR & KIELD & 1564 & 40 & 28 & 104 & 53 \\
\hline 05157 & WOODLAND PARK & TELLER & 1022 & 39 & 00 & 105 & 04 \\
\hline
\end{tabular}

TABLE 8. CITY ID, CITY NAME, COUNTY NAME, POPULATION, LATITUDE AND LONGITUDE 


$\begin{array}{ll}\text { CITY } & \text { CITY NAME } \\ \text { ID } & \\ 06001 & \text { BABBETT } \\ 06002 & \text { BATTLE MOUNTAIN } \\ 06003 & \text { BOULDER CITY } \\ 06004 & \text { CALIENTE } \\ 06005 & \text { CARLIN } \\ 06006 & \text { CARSON CITY } \\ 06007 & \text { EAST ELY } \\ 06008 & \text { EAST LAS VEGAS } \\ 06009 & \text { ELKO CITY } \\ 06010 & \text { ELY } \\ 06011 & \text { FALLON } \\ 06012 & \text { FALLON STATION } \\ 06013 & \text { GABBS } \\ 06014 & \text { GARDNERVILLE-MINDEN } \\ 06015 & \text { HAWTHORNE } \\ 06016 & \text { HENDERSON } \\ 06017 & \text { LAS VEGAS } \\ 06018 & \text { LOVELOCK } \\ 06019 & \text { MC GILI } \\ \text { O6020 NELLIS AFB } \\ \text { O6021 NORTH LAS VEGAS } \\ 06022 \text { PARADISE } \\ \text { 06023 RENOE } \\ \text { 06024 SPARKS } \\ 06026 \text { SUN VALLEY } \\ 06025 \text { SUNRISE MANOR } \\ \text { O6027 TONOPAH } \\ 06028 \text { VEGAS CREEK } \\ 06029 \text { WELLS } \\ 06030 \text { WINCHESTER } \\ 06031 \text { WINNEMUCCA } \\ 06032 \text { YERRINGTON } \\ \end{array}$

NEVADA

COUNTY NAME POPULATION LAT LONG

$\begin{array}{lrrrrr}\text { MINERAL } & 1579 & 38 & 32 & 118 & 38 \\ \text { LANDER } & 1856 & 40 & 41 & 117 & 07 \\ \text { CLARK } & 5223 & 39 & 59 & 114 & 51 \\ \text { LINCOLN } & 916 & 37 & 36 & 114 & 31 \\ \text { ELKO } & 1313 & 40 & 44 & 116 & 06 \\ \text { ORMSBY } & 15468 & 39 & 10 & 119 & 46 \\ \text { WHITE PINE } & 1992 & 39 & 17 & 114 & 52 \\ \text { CLARK } & 6501 & 36 & 04 & 115 & 03 \\ \text { ELKO } & 7621 & 40 & 50 & 115 & 46 \\ \text { WHITE PINE } & 4175 & 39 & 15 & 114 & 53 \\ \text { CHURCHILL } & 2959 & 39 & 29 & 118 & 47 \\ \text { CHURCHILL } & 1045 & 39 & 25 & 118 & 44 \\ \text { WYE } & 874 & 38 & 44 & 118 & 07 \\ \text { DOUGLAS } & 1320 & 38 & 57 & 119 & 45 \\ \text { MINERAL } & 3539 & 38 & 31 & 118 & 37 \\ \text { CLARK } & 16395 & 36 & 01 & 115 & 00 \\ \text { CLARK } & 125787 & 36 & 10 & 115 & 10 \\ \text { PERSHING } & 1571 & 40 & 12 & 118 & 28 \\ \text { WHITE PINE } & 2164 & 39 & 24 & 114 & 47 \\ \text { CLARK } & 6449 & 36 & 15 & 115 & 03 \\ \text { CLARK } & 36216 & 36 & 15 & 115 & 07 \\ \text { CLARK } & 24477 & 00 & 00 & 000 & 00 \\ \text { WASHOE } & 72863 & 39 & 32 & 119 & 49 \\ \text { WASHOE } & 24187 & 39 & 34 & 119 & 46 \\ \text { WASHOE } & 2414 & 00 & 00 & 000 & 00 \\ \text { CLARK } & 10886 & 00 & 00 & 000 & 00 \\ \text { NYE } & 1716 & 38 & 05 & 117 & 15 \\ \text { CLARK } & 8970 & 00 & 00 & 000 & 00 \\ \text { ELKO } & 1081 & 41 & 08 & 114 & 58 \\ \text { CLARK } & 13981 & 00 & 00 & 000 & 00 \\ \text { EUMBOLDT } & 3587 & 40 & 58 & 117 & 45 \\ \text { LYON } & 2010 & 39 & 00 & 119 & 10\end{array}$

TABLE 8. CITY ID, CITY NAME, COUNTY NAME, POPULATION, LATITUDE AND LONGITUDE 


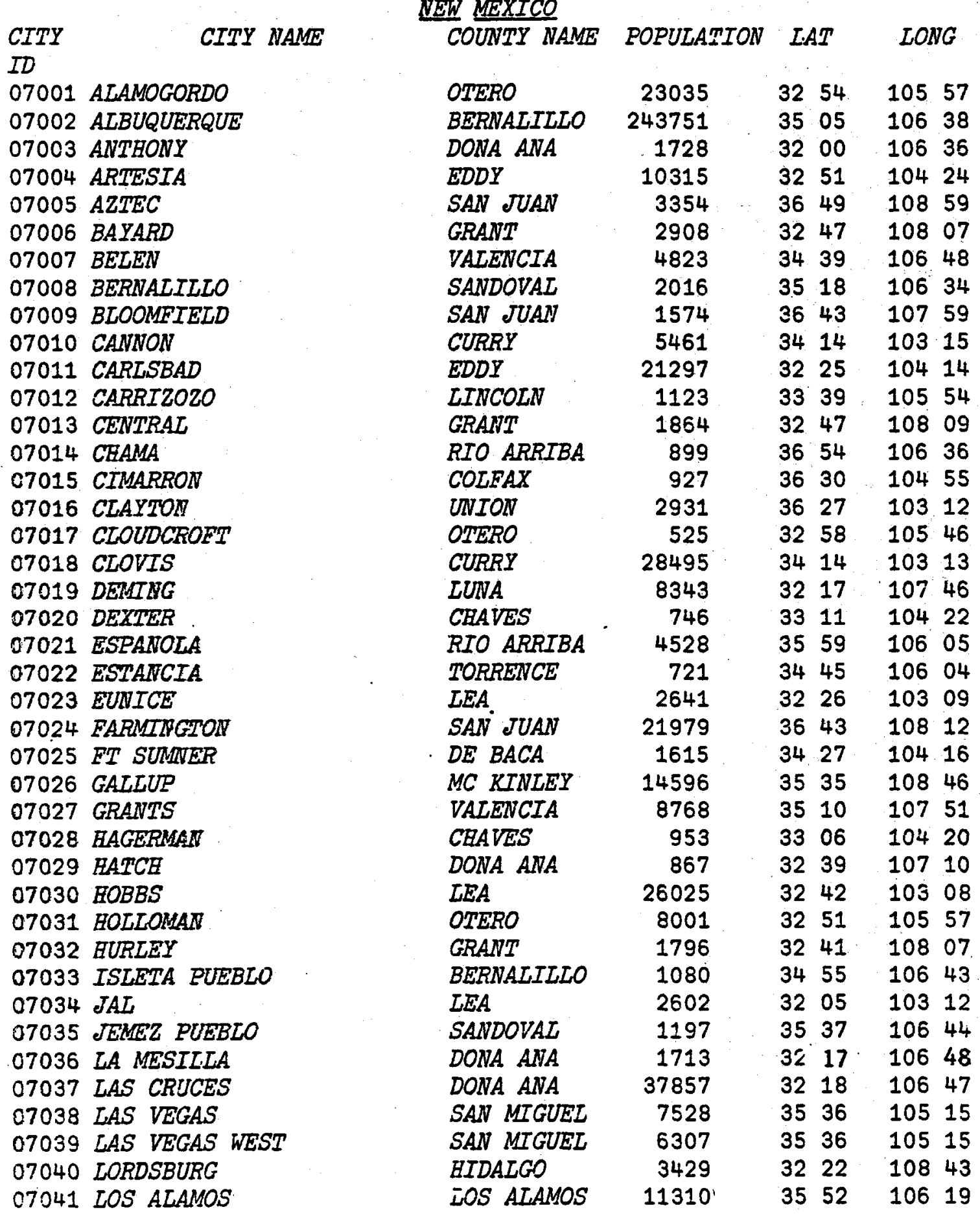

TABLE 8. CITY ID, CITY NAME, COUNTY NAME, POPULATION, LATITUDE AND LONGITUDE 
11

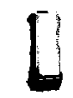

$\Delta$

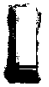

$\checkmark$

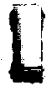

L

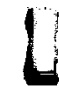

L

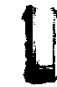

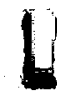

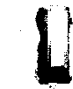

(

CITY.

CITY NAME

07042 LOS LUNAS

07043 LOS RANCHOS DE ALBQ

07044 LOVING *

07045 LOVINGTON

07046 MAGDALENA

07047 MEADOW VISTA

07048 MELROSE

07049 MILAN

07050 MORIARTY

07051 MOUNTAINAIR

07052 NORTH VALLEY

07053 PECOS

07054 PORTALES

07055 QUESTA

07056 RATON

07057 ROSWELL

07058 RUIDOSO

07059 RUIDOSO DOWWS

07061 SAN FELIPE PUEBLO

07060 SANDIA

07062 SANTA EE

07063 SANTA ROSA

07064 SANTO DOMINGO PUEBLO

07065 SILVER CITY

07066 SOCORRO

07067 SOUTH VALLEY

07068 SPRINGER

07069 TAOS

07070 TAOS PEE'BLO

07071 TATUM

07072 TEXICO

07073 TRUTH OR CONSEQUENCES

07074 TUCUMCARI

07075 TULAROSA

07076 UNIV PK-TORTUGAS

07077 VAUGHN

07078 WAGON MOUND

07079 WHITE ROCK

07080 WHITE SANDS

07081 ZUNI PUEBLO
NEW MEXICO

COUNTY NAME POPULATION LAT LONG

$\begin{array}{lrllll}\text { VALENCIA } & 973 & 34 & 48 & 106 & 46 \\ \text { BERNALILLO } & 1900 & 35 & 08 & 106 & 38 \\ \text { EDDY } & 1192 & 32 & 17 & 104 & 06 \\ \text { LEA } & 8915 & 32 & 58 & 103 & 21 \\ \text { SOCORRO } & 652 & 34 & 06 & 107 & 14 \\ \text { DONA ANA } & 1402 & 00 & 00 & 000 & 00 \\ \text { CURRY } & 636 & 34 & 26 & 103 & 38 \\ \text { VALENCIA } & 2185 & 35 & 11 & 108 & 48 \\ \text { TORRENCE } & 758 & 34 & 59 & 106 & 03 \\ \text { TORRENCE } & 1022 & 34 & 32 & 106 & 16 \\ \text { BERNALILLO } & 10366 & 35 & 05 & 106 & 38 \\ \text { SAN MIGUEL } & 598 & 35 & 34 & 105 & 41 \\ \text { ROOSEVELT } & 10554 & 34 & 12 & 103 & 20 \\ \text { TAOS } & 1095 & 36 & 43 & 105 & 36 \\ \text { COLEAX } & 6962 & 36 & 54 & 104 & 27 \\ \text { CHAVES } & 33908 & 33 & 24 & 104 & 33 \\ \text { LINCOLN } & 2216 & 33 & 20 & 105 & 42 \\ \text { LINCOLN } & 702 & 33 & 20 & 105 & 39 \\ \text { SANDOVAL } & 1187 & 35 & 26 & 106 & 27 \\ \text { BERNALILLO } & 6867 & 35 & 08 & 106 & 19 \\ \text { SANTA FE } & 41167 & 35 & 41 & 105 & 57 \\ \text { GUADALUPE } & 2485 & 34 & 56 & 104 & 42 \\ \text { SANDOVAL } & 1662 & 35 & 35 & 106 & 28 \\ \text { GRANT } & 7751 & 32 & 47 & 108 & 16 \\ \text { SOCORRO } & 4687 & 34 & 04 & 106 & 55 \\ \text { BERNALILLO } & 29389 & 35 & 05 & 106 & 38 \\ \text { COLFAX } & 1574 & 36 & 22 & 104 & 36 \\ \text { TAOS } & 2475 & 36 & 24 & 105 & 35 \\ \text { TAOS } & 1030 & 36 & 26 & 105 & 34 \\ \text { LEA } & 982 & 33 & 16 & 103 & 18 \\ \text { CURRY } & 772 & 34 & 14 & 103 & 05 \\ \text { SIERRA } & 4656 & 33 & 08 & 107 & 16 \\ \text { QUAY } & 7189 & 35 & 11 & 103 & 44 \\ \text { OTERO } & 2851 & 33 & 04 & 106 & 02 \\ \text { DONA ANA } & 4165 & 32 & 18 & 106 & 47 \\ \text { GUADALUPE } & 867 & 34 & 35 & 105 & 14 \\ \text { MORA } & 630 & 36 & 01 & 104 & 44 \\ \text { LOS ALAMOS } & 3861 & 35 & 48 & 106 & 16 \\ \text { DONA ANA } & 4167 & 32 & 47 & 106 & 04 \\ \text { MC KINLEY } & 3958 & 35 & 05 & 108 & 52\end{array}$

TABLE 8. CITY ID, CITY NAME, COUNTY NAME, POPULATION, LATITUDE AND LONGITUDE 


\begin{tabular}{|c|c|c|c|c|c|c|c|}
\hline $\begin{array}{l}\text { CITY } \\
\text { ID }\end{array}$ & CITY NAME & COUNTY NAME & POPULATION & \multicolumn{2}{|c|}{ LAT } & \multicolumn{2}{|c|}{ LONG } \\
\hline 08001 & ALPINE & $U T A B$ & 1047 & 40 & 29 & 111 & 47 \\
\hline 08002 & AMERICAN FORK & $U T A B$ & 7713 & 40 & 24 & 111 & 48 \\
\hline 08003 & $B E A V E R$ & $B E A V E R$ & 1453 & 38 & 18 & 112 & 38 \\
\hline 08004 & BLANDING & SAN JUAN & 2250 & 37 & 37 & 109 & 29 \\
\hline 08005 & BOUNTIFUL & DAVIS & 27853 & 40 & 54 & 111 & 54 \\
\hline 08006 & BRIGHAM CITY & $B O X$ ELDER & 14007 & 41 & 30 & 112 & 02 \\
\hline 08007 & CASTLE DALE & EMERY & 541 & 39 & 12 & 111 & 00 \\
\hline 08008 & CEDAR CITY & IRON & 8946 & 37 & 40 & 113 & 04 \\
\hline 08009 & CENTERVILLE & DAVIS & 3268 & 40 & 56 & 111 & 54 \\
\hline 08010 & CLEARFIELD & DAVIS & 13316 & 41 & 07 & 112 & 03 \\
\hline 08011 & CLINTON & DAVIS & 1768 & 41 & 14 & 112 & 08 \\
\hline 08012 & COALVILLE & SUMMIT & 864 & 40 & 55 & 111 & 25 \\
\hline 08013 & COTTONWOOD HEIGHTS & SALT LAKE & 8431 & 40 & 38 & 111 & 49 \\
\hline 08014 & DELTA & MILLARD & 1610 & 39 & 22 & 112 & 35 \\
\hline 08015 & DRAGERTON & CARBON & 1614 & 39 & 32 & 110 & 25 \\
\hline 08016 & DUCHESNE & DUCHESWE & 1094 & 40 & 10 & 110 & 24 \\
\hline 08017 & DUGWAY & TOOELE & 2357 & 40 & 15 & 112 & 50 \\
\hline 08018 & EAST LAYTON & DAVIS & 763 & 40 & 56 & 111 & 59 \\
\hline 08019 & EAST MTLLCREEK & SALT LAKE & 26579 & 40 & 41 & 111 & 49 \\
\hline 08020 & ENTERPRISE & WASHINGTON & 844 & 37 & 43 & 113 & 43 \\
\hline 08021 & EPHRAIM & SANPETE & 2127 & 39 & 21 & 111 & 35 \\
\hline 08022 & ESCALANTE & GAREIELD & 638 & 37 & 47 & 111 & 35 \\
\hline 08023 & EUREKA & $J U A B$ & 753 & 39 & 57 & 112 & 09 \\
\hline 08024 & FAIRVIEW & SANPETE & 696 & 39 & 38 & 111 & 27 \\
\hline 08025 & FARMINGTON & DAVIS & 2526 & 40 & 50 & 111 & 55 \\
\hline 08026 & FERRON & EMERY & 663 & 39 & 00 & 111 & 04 \\
\hline 08027 & FILLMORE & MILLARD & 1411 & 38 & 58 & 112 & 20 \\
\hline 08028 & ERIUT HEIGHTS & DAVIS & 800 & 00 & 00 & 000 & 00 \\
\hline 08029 & GARLAND & $B O X$ ELDER & 1187 & 41 & 45 & 112 & 10 \\
\hline 08030 & GRANGER-EUNTER & SALT LAKE & 9029 & 40 & 41 & 111 & 58 \\
\hline 08031 & GRANITE PARK & SALT LAKE & 9573 & 40 & 07 & 113 & 16 \\
\hline ง8032 & GRANTSVILLE & TOOELE & 2931 & 40 & 36 & 112 & 29 \\
\hline 08033 & GREEN RIVER & EMERY & 1033 & 38 & 55 & 109 & 55 \\
\hline 08034 & GUNNISON & SANPETE & 1073 & 39 & 09 & 111 & 50 \\
\hline 38035 & HARRISVILLE & WEBER & 603 & 00 & 00 & 000 & 00 \\
\hline 08036 & HEBER CITY & WASATCH & 3245 & 40 & 32 & 111 & 22 \\
\hline 08037 & HELPER & CARBON & 1964 & 39 & 40 & 110 & 51 \\
\hline 08038 & HOLLADAY & SALT ILAKE & 23014 & 40 & 40 & 111 & 50 \\
\hline 08039 & HONEYVILLE & BOX ELDER & 640 & 41 & 32 & 112 & 02 \\
\hline 08040 & BUNTINGTON & EMERY & 857 & 39 & 19 & 110 & 58 \\
\hline 08041 & HUNTSVILLE & WEBER & 553 & 41 & 15 & 111 & 45 \\
\hline 08042 & HURRICANE & WASEINGTON & 1408 & 37 & 10 & 113 & 16 \\
\hline
\end{tabular}

UTAB

\begin{tabular}{|c|c|c|c|c|c|c|c|}
\hline $\begin{array}{l}\text { CITY } \\
\text { ID }\end{array}$ & CITY NAME & COUNTY NAME & POPULATION & $L A$ & & LO & $N G$ \\
\hline 08001 & ALPINE & UTAB & 1047 & 40 & 29 & 111 & 47 \\
\hline 08002 & AMERICAN FORK & $U T A B$ & 7713 & 40 & 24 & 111 & 48 \\
\hline 08003 & $B E A V E R$ & $B E A V E R$ & 1453 & 38 & 18 & 112 & 38 \\
\hline 08004 & BLANDING & SAN JUAN & 2250 & 37 & 37 & 109 & 29 \\
\hline 08005 & BOUNTIFUL & DAVIS & 27853 & 40 & 54 & 111 & 54 \\
\hline 08006 & BRIGHAM CITY & $B O X$ ELDER & 14007 & 41 & 30 & 112 & 02 \\
\hline 08007 & CASTLE DALE & EMERY & 541 & 39 & 12 & 111 & 00 \\
\hline 08008 & CEDAR CITY & IRON & 8946 & 37 & 40 & 113 & 04 \\
\hline 08009 & CENTERVILLE & DAVIS & 3268 & 40 & 56 & 111 & 54 \\
\hline 08010 & CLEAREIELD & DAVIS & 13316 & 41 & 07 & 112 & 03 \\
\hline 08011 & CLINTON & DAVIS & 1768 & 41 & 14 & 112 & 08 \\
\hline 08012 & COALVILLE & SUMMIT & 864 & 40 & 55 & 111 & 25 \\
\hline 08013 & COTTONWOOD HEIGHTS & SALT LAKE & 8431 & 40 & 38 & 111 & 49 \\
\hline 08014 & DELTA & MILLARD & 1610 & 39 & 22 & 112 & 35 \\
\hline 08015 & DRAGERTON & CARBON & 1614 & 39 & 32 & 110 & 25 \\
\hline 08016 & DUCHESNE & DUCHESNE & 1094 & 40 & 10 & 110 & 24 \\
\hline 08017 & DUGWAY & TOOELE & 2357 & 40 & 15 & 112 & 50 \\
\hline 08018 & EAST LAYTON & DAVIS & 763 & 40 & 56 & 111 & 59 \\
\hline 08019 & EAST MILLCREEK & SALT LAKE & 26579 & 40 & 41 & 111 & 49 \\
\hline 08020 & ENTERPRISE & WASHINGTON & 844 & 37 & 43 & 113 & 43 \\
\hline 08021 & EPHRAIM & SANPETE & 2127 & 39 & 21 & 111 & 35 \\
\hline 08022 & ESCALANTE & GAREIELD & 638 & 37 & 47 & 111 & 35 \\
\hline 08023 & EUREKA & $J U A B$ & 753 & 39 & 57 & 112 & .09 \\
\hline 08024 & FAIRVIEW & SANPETE & 696 & 39 & 38 & 111 & 27 \\
\hline 08025 & FARMINGTON & DAVIS & 2526 & 40 & 50 & 111 & 55 \\
\hline 08026 & FERRON & EMERY & 663 & 39 & 00 & 111 & 04 \\
\hline 08027 & FILLMORE & MILLARD & 1411 & 38 & 58 & 112 & 20 \\
\hline 08028 & FRIUT HEIGHTS & DAVIS & 800 & 00 & 00 & 000 & 00 \\
\hline 08029 & GARLAND & BOX ELDER & 1187 & 41 & 45 & 112 & 10 \\
\hline 08030 & GRANGER-EUNTER & SALT LAKE & 9029 & 40 & 41 & 111 & 58 \\
\hline 0.8031 & GRANTTE PARK & SALT LAKE & 9573 & 40 & 07 & 113 & 16 \\
\hline ๑8032 & GRANTSVILLE & TOOELE & 2931 & 40 & 36 & 112 & 29 \\
\hline 08033 & GREEN RIVER & EMERY & 1033 & 38 & 55 & 109 & 55 \\
\hline 08034 & GUNNISON & SANPETE & 1073 & 39 & 09 & 111 & 50 \\
\hline 08035 & HARRISVILLE & WEBER & 603 & 00 & 00 & 000 & 00 \\
\hline 08036 & HEBER CITY & WASATCH & 3245 & 40 & 32 & 111 & 22 \\
\hline 08037 & HELPER & CARBON & 1964 & 39 & 40 & 110 & 51 \\
\hline 08038 & HOLLADAY & $S A L T \quad I A K E$ & 23014 & 40 & 40 & 111 & 50 \\
\hline 08039 & HONEYVILLE & BOX ELDER & 640 & 41 & 32 & 112 & 02 \\
\hline 08040 & EUNTINGTON & EMERY & 857 & 39 & 19 & 110 & 58 \\
\hline 08041 & HUNTSVILLE & WEBER & 553 & 41 & 15 & 111 & 45 \\
\hline 08042 & HURRTCANE & WASEINGTON & 1408 & 37 & 10 & 113 & 16 \\
\hline
\end{tabular}

TABLE 8. CITY ID, CITY NAME, COUNTY NAME, POPULATION, LATITUDE AND LONGITUDE

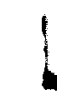




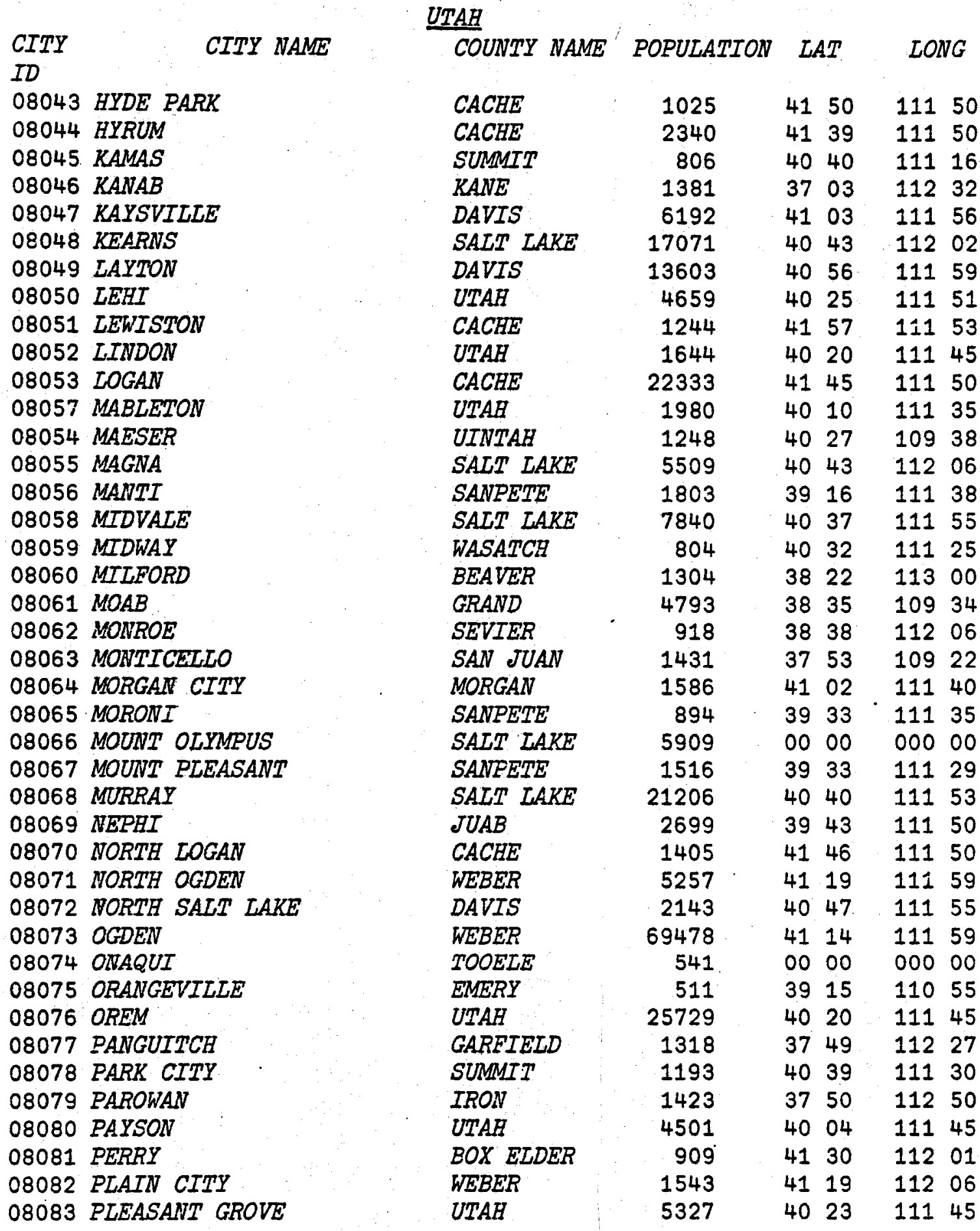

TABLE 8. CITY ID, CITY NAME, COUNTY NAME, POPULATION, LATITUDE AND LONGITUDE 


\begin{tabular}{|c|c|c|c|c|c|c|c|}
\hline $\begin{array}{l}\text { CITY } \\
\text { ID }\end{array}$ & CITY NAME & COUNTY NAME & POPULATION & $L A$ & $A T^{\circ}$ & LON & $N G$ \\
\hline 08084 & PLEASANT VIEW & WEBER & 2028 & 41 & 18 & 112 & 00 \\
\hline 08085 & PRICE & CARBON & 6218 & 39 & 35 & 110 & 49 \\
\hline 08086 & PROVIDENCE & CACHE & 1608 & 41 & 43 & 111 & 48 \\
\hline 08087 & PROVO & $U T A B$ & 53131 & 40 & 15 & 111 & 40 \\
\hline 08088 & RANDOLPH & RICH & 500 & 41 & 41 & 111 & 10 \\
\hline 08089 & RICHFIELD & SEVIER & 4471 & 38 & 45 & 112 & 05 \\
\hline 08090 & RICHMOND & CACHE & 1000 & 41 & 57 & 111 & 49 \\
\hline 08091 & RIVERDALE CITY & WEBER & 3704 & 00 & 00 & 000 & 00 \\
\hline 08092 & RIVER EEIGHTS & CACEE & 1008 & 00 & 00 & 000 & 00 \\
\hline 08093 & RIVERTON & SALT LALEE & 2320 & 40 & 32 & 111 & 56 \\
\hline 08094 & ROOSEVELT & DUCHESNE & 2005 & 40 & 18 & 110 & 00 \\
\hline 08095 & ROY & WEBER & 14356 & 41 & 07 & 112 & 01 \\
\hline 08097 & SALIM & UTAH & 1081 & 40 & 04 & 111 & 40 \\
\hline 08098 & SALINA & SEVIER & 1494 & 38 & 57 & 111 & 52 \\
\hline 08099 & SALT LAKE CITY & SALT LAKE & 175885 & 40 & 45 & 111 & 55 \\
\hline 08100 & SANDY & $S A L T L A K E$ & 6438 & 40 & 37 & 111 & 53 \\
\hline 08101 & SANTAQUIN & $U T A B$ & 1236 & 39 & 57 & 111 & 42 \\
\hline 08102 & SMITHETELD & CACHE & 3342 & 41 & 50 & 111 & 50 \\
\hline 08103 & SOUTE JORDAN & SALT ILAKE & 2942 & 40 & 32 & 111 & 55 \\
\hline 08104 & SOUTH OGDEN & WEBER & 9991 & 41 & 12 & 111 & 59 \\
\hline 08105 & SOUIE SALT LAKE1 & SALT IAKE & 7810 & 40 & 42 & 111 & 55 \\
\hline 08106 & SOUTH WEBER & DAVIS & 1073 & 00 & 00 & 000 & 00 \\
\hline 08107 & SPAEISH FORK CITY & $U T A B$ & 7284 & 40 & 07 & 111 & 39 \\
\hline 08108 & SRRINGVILLE & UTAH & 8790 & 40 & 10 & 111 & 36 \\
\hline 08096 & $S T$ GEORGE & WASHINGTON & 7097 & 37 & 06 & 113 & 35 \\
\hline 08109 & SUNSET & DAVIS & 6268 & 00 & 00 & 000 & 00 \\
\hline 08110 & SYRACUSE & DAVIS & 1843 & 41 & 05 & 112 & 08 \\
\hline 08111 & TOOELE & TOOELE & 12539 & 40 & 32 & 112 & 18 \\
\hline 08112 & TREMONTON & BOX ELDER & 2794 & 41 & 43 & 112 & 10 \\
\hline 08113 & VERNAL & UINTAB & 3908 & 40 & 26 & 109 & 32 \\
\hline 08114 & WASHINGTON & WASHINGTON & 750 & 37 & 08 & 113 & 30 \\
\hline 08115 & WASEINGTON TERRACE & WEBER & 7241 & 41 & 10 & 111 & 58 \\
\hline 08116 & WELLTMGTON & CARBON & 922 & 39 & 33 & 110 & 45 \\
\hline 08117 & WELLSVILLE & CACHE & 1267 & 41 & 39 & 111 & 56 \\
\hline 08118 & WEWDOVER & TOOELE & 781 & 40 & 45 & 114 & 02 \\
\hline 08119 & WEST BOUNTIFUL & DAVIS & 1246 & 40 & 50 & 111 & 55 \\
\hline 08120 & WEST JORDAN & $S A L T$ LAKE & 4221 & 40 & 32 & 111 & 57 \\
\hline 08121 & WEST POINT & DAVIS & 1020 & 41 & 00 & 112 & 03 \\
\hline 08122 & WHITE & SALT LAKE & 6402 & 00 & 00 & 000 & 00 \\
\hline 08123 & WILLARD & $B O X$ ELDER & 1045 & 41 & 25 & 112 & 03 \\
\hline 08124 & WOODS GROSS & $D A V I S$ & 3124 & 40 & 54 & 111 & 55 \\
\hline
\end{tabular}

TABLE 8. CITY ID, CITY NAME, COUNTY NAME, POPULATION, LATITUDE AND LONGITUDE 


\begin{tabular}{|c|c|c|c|c|c|c|c|}
\hline $\begin{array}{l}\text { CITY } \\
I D\end{array}$ & CITY NAME & $\frac{A L I F O R N I A}{\text { COUNTY NAME }}$ & POPULATION & IA & & LOI & \\
\hline 09063 & ADELANTO & SANIA BARBAR & 2115 & 34 & 34 & 117 & 25 \\
\hline 09180 & ALPINE & SAN DIEGO & 1570 & 32 & 46 & 116 & 42 \\
\hline 09010 & $A L T A$ HILL & $N E V A D A$ & 1185 & 0 & 0 & 0 & 0 \\
\hline 09001 & ALTURAS & MODOC & 2799 & 41 & 30 & 120 & 34 \\
\hline 09223 & ANDERSON & SHASTA & 5492 & 40 & 28 & 122 & 18 \\
\hline 09061 & ANGELS CAMP & CALARERAS & 1710 & 38 & 05 & 120 & 33 \\
\hline 09066 & APPLE VALLEY & SANTA BARBAR & 6702 & 0 & 0 & 0 & 0 \\
\hline 09141 & ARBUCKLE & COLUSA & 1037 & 39 & 02 & 122 & 04 \\
\hline 09146 & $A R V I N$ & KERN & 5090 & 35 & 11 & 118 & 50 \\
\hline 09170 & ATWATER & $M E R C E D$ & 11640 & 37 & 20 & 120 & 37 \\
\hline 09047 & AUBURN & PLACER & 6570 & 38 & 53 & 121 & 04 \\
\hline 09218 & AUGUST SCHOOL AREA & SAN JOAQUINE & 6293 & 0 & 0 & 0 & 0 \\
\hline 09148 & EAKERSFIELD & KERN & 69515 & 35 & 20 & 118 & 52 \\
\hline 09043 & BANNING & RIVERSIDE & 12034 & 33 & 56 & 116 & 52 \\
\hline 09069 & EARSTOW & SANTA BARBAR & 17442 & 34 & 55 & 117 & 01 \\
\hline 09287 & $B E A L E$ EAST & YUBA & 7029 & 39 & 02 & 121 & 27 \\
\hline 09288 & $B E A L E$ WEST & YUBA & 2325 & 39 & 02 & 121 & 28 \\
\hline 09044 & BEAUMONT & RIVERSIDE & 5484 & 33 & 56 & 117 & 00 \\
\hline 09070 & $E I G \quad B E A R$ & SANTA BARBAR & 5268 & 34 & 15 & 116 & 53 \\
\hline 09130 & BIGGS & BUTTE & 1115 & 39 & 27 & 121 & 44 \\
\hline 09013 & BISHOP & INYO & 3498 & 37 & 20 & 118 & 24 \\
\hline 09075 & BLOOMINGTON & SANTA BARBAR & 3059 & 0 & 0 & 0 & 0 \\
\hline 09037 & BLYTHE & RIVERSIDE & 7047 & 33 & 38 & 114 & 35 \\
\hline 09038 & BLYTHEE & RIVERSIDE & 1252 & 33 & 38. & 114 & 25 \\
\hline 09226 & BOWWY VIEW & SHASTA & 48982 & 0 & 0 & 0 & 0 \\
\hline 09151 & BORON & $K E R N$ & 1999 & 35 & 05 & 117 & 39 \\
\hline 09048 & BOWMAN AUBURN & PLACER & 2089 & 38 & 55 & 121 & 04 \\
\hline 09099 & BRAWLEY & IMPERIAL & 13746 & 32 & 59 & 115 & 30 \\
\hline 09225 & BURNEY & SHASTA & 2190 & 40 & 55 & 121 & 40 \\
\hline 09149 & BUTTONWILLO & $K E R N$ & 1193 & 35 & 24 & 119 & 29 \\
\hline 09045 & CABAZON & RIVERSIDE & 598 & 33 & 50 & 116 & 47 \\
\hline 09100 & CALEXICO & IMPERIAL & 10625 & 32 & 39 & 115 & 28 \\
\hline 09152 & CALIFORNIA CITY & KERN & 1309 & 37 & 53 & 122 & 27 \\
\hline 09101 & CAIIPATRIA & IMPERIAL & 1824 & 33 & 09 & 115 & 30 \\
\hline 09111 & CALWA & ERESNO & 5191 & 36 & 41 & 119 & 43 \\
\hline 09204 & $C A R D I F F-B Y-T H E-S E A$ & SAN DIEGO & 5724 & 33 & 00 & 117 & 18 \\
\hline 09181 & CARLSBAD & SAN DIEGO & 14944 & 33 & 09 & 117 & 20 \\
\hline 09171 & CASTLE & MERCED & 1903 & 37 & 20 & 120 & 37 \\
\hline 09015 & CATHEDRAL CITY & RIVERSIDE & 3640 & 33 & 45 & 116 & 27 \\
\hline 09229 & CENTRAL VALLEY & SHASTA & 2361 & 40 & 42 & 122 & 24 \\
\hline 09241 & CERES & STANISLAUS & 6029 & 37 & 36 & 120 & 58 \\
\hline 09046 & CHERRY VALLEY & RIVERSIDE & 3165 & 0 & 0 & 0 & 0 \\
\hline 09004 & CHESTER & PLUMAS & 1531 & 40 & 20 & 121 & 14 \\
\hline 09131 & CHICO & BUTTE & 19580 & 39 & 46 & 121 & 50 \\
\hline 09132 & CHICO NORTH & BUTTE & 6656 & 39 & 46 & 121 & 50 \\
\hline 09133 & CHICO WEST & BUTTE & 4787 & 39 & 46 & 121 & 50 \\
\hline 09153 & CHINA LAKE & KERN & 11105 & 35 & 45 & 117 & 36 \\
\hline 09071 & CHINO & SANTA BARBAR & 20411 & 35 & 55 & 117 & 37 \\
\hline 09109 & CHOWCHILLA & MADERA & 4349 & 37 & 07 & 120 & 14 \\
\hline
\end{tabular}

TABLE 8. CITY ID, CITY NAME, COUNTY NAME, POPULATION, LATITUDE AND LONGITUDE 


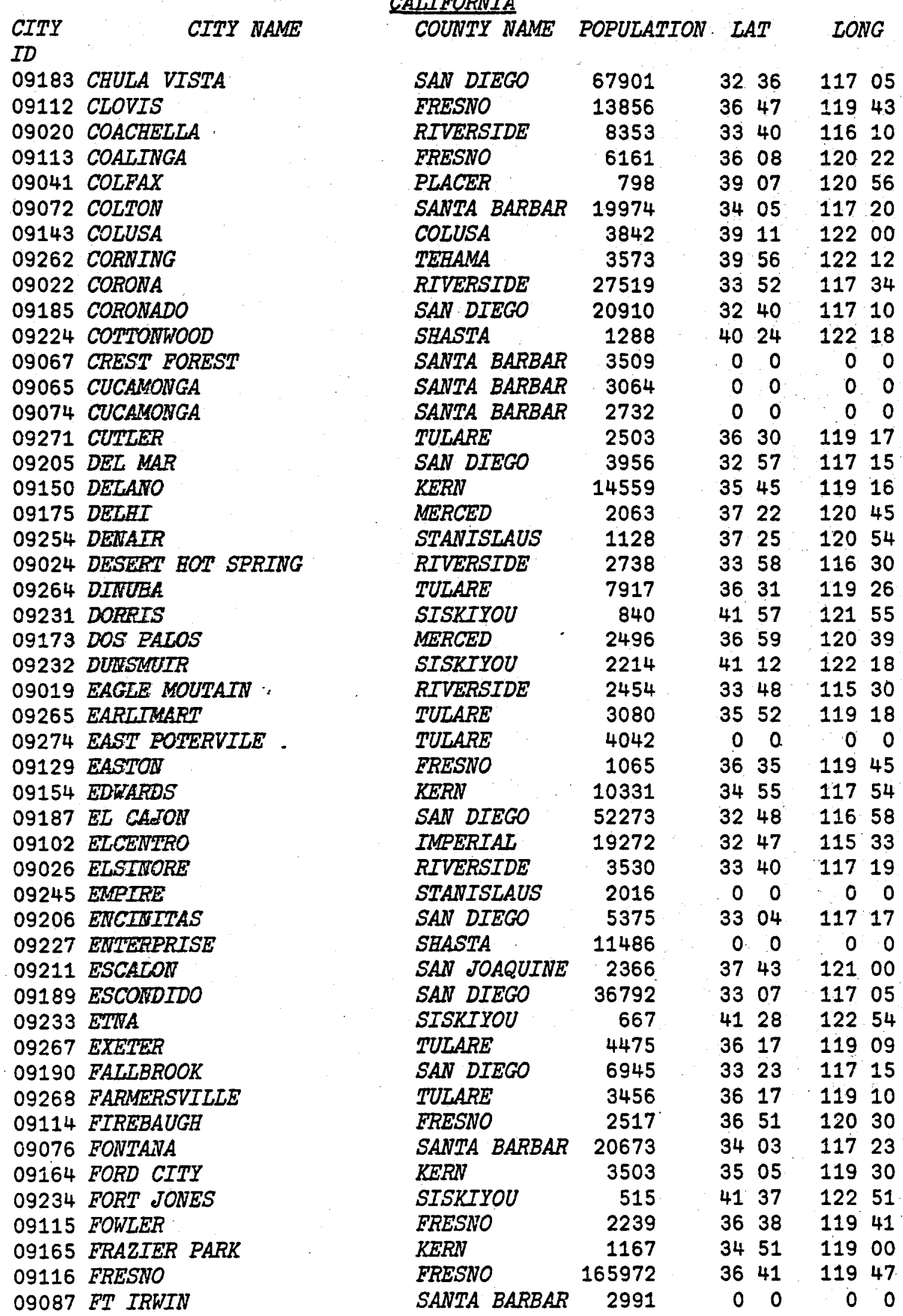

TABLE 8. CITY ID, CITY NAME, COUNTY NAME, POPULATION, LATITUDE AND LONGITUDE 


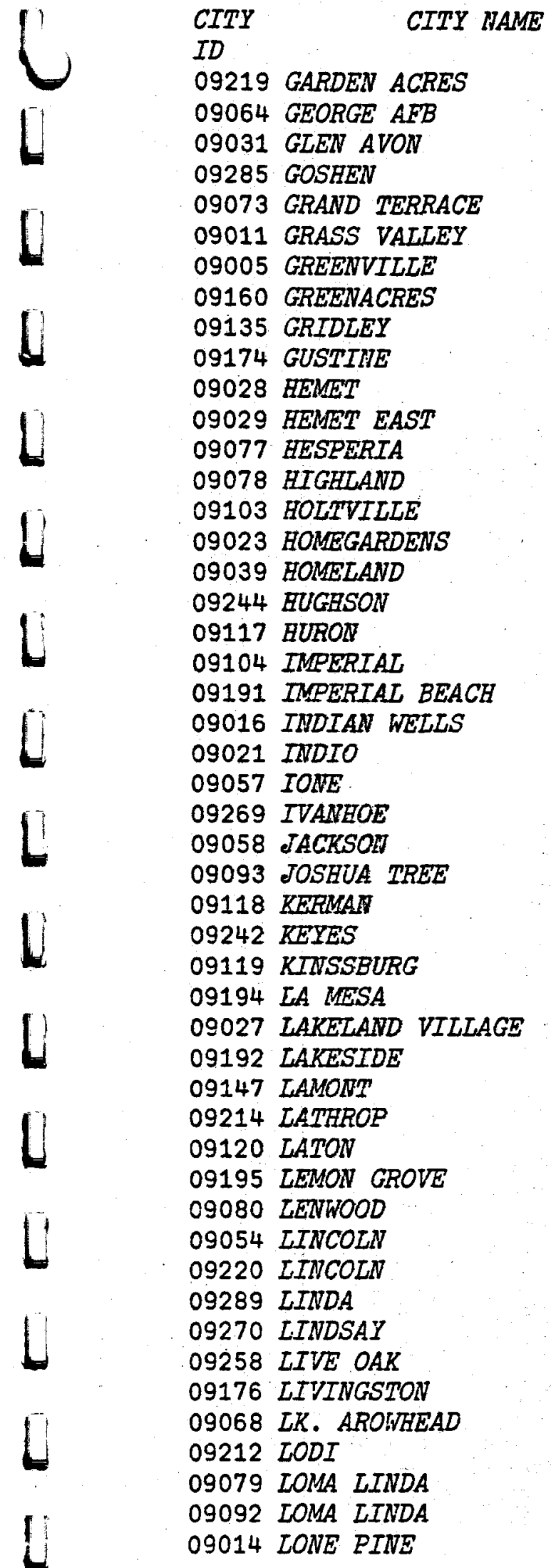

CALIFORNIA COUNTY NAME POPULATION LAT LONG

$\begin{array}{lrrrrr}\text { SAN JOAQUINE } & 7870 & 0 & 0 & 0 & 0 \\ \text { SANTA BARBAR } & 7404 & 34 & 30 & 117 & 18 \\ \text { RIVERSIDE } & 5759 & 0 & 0 & 0 & 0 \\ \text { TULARE } & 1324 & 36 & 20 & 119 & 26 \\ \text { SANTA BARBAR } & 5901 & 0 & 0 & 0 & 0 \\ \text { NEVADA } & 5149 & 39 & 13 & 121 & 04 \\ \text { PLUMAS } & 1073 & 40 & 09 & 120 & 57 \\ \text { KERN } & 2116 & 35 & 26 & 119 & 03 \\ \text { BUTTE } & 3534 & 39 & 24 & 121 & 42 \\ \text { MERCED } & 2793 & 37 & 14 & 121 & 00 \\ \text { RIVERSIDE } & 12252 & 33 & 45 & 116 & 58 \\ \text { RIVERSIDE } & 8598 & 33 & 45 & 116 & 55 \\ \text { SANTA BARBAR } & 4592 & 34 & 25 & 117 & 19 \\ \text { SANTA BARBAR } & 12669 & 34 & 08 & 117 & 11 \\ \text { IMPERIAL } & 3496 & 32 & 47 & 115 & 22 \\ \text { RIVERSIDE } & 5116 & 0 & 0 & 0 & 0 \\ \text { RIVERSIDE } & 1187 & 0 & 0 & 0 & 0 \\ \text { STANISLAUS } & 2144 & 37 & 35 & 120 & 53 \\ \text { FRESNO } & 1525 & 36 & 14 & 120 & 05 \\ \text { IMPERIAL } & 3094 & 32 & 51 & 115 & 33 \\ \text { SAN DIEGO } & 20244 & 32 & 51 & 115 & 33 \\ \text { RIVERSIDE } & 760 & 33 & 45 & 116 & 19 \\ \text { RIVERSIDE } & 14459 & 33 & 44 & 116 & 14 \\ \text { AMADOR } & 2369 & 38 & 20 & 120 & 55 \\ \text { TULARE } & 1595 & 36 & 20 & 119 & 15 \\ \text { AMADOR } & 1924 & 38 & 19 & 120 & 49 \\ \text { SANTA BARBAR } & 1211 & 34 & 09 & 116 & 20 \\ \text { FRESNO } & 2667 & 36 & 42 & 120 & 04 \\ \text { STANISLAUS } & 1875 & 37 & 31 & 120 & 52 \\ \text { FRESNO } & 3843 & 36 & 29 & 119 & 31 \\ \text { SAN DIEGO } & 39178 & 32 & 45 & 117 & 00 \\ \text { RIVERSIDE } & 1724 & 33 & 32 & 117 & 30 \\ \text { SAN DIEGO } & 11991 & 32 & 51 & 116 & 55 \\ \text { KERN } & 7007 & 35 & 15 & 118 & 56 \\ \text { SAN JOAQUINE } & 2137 & 0 & 0 & 0 & 0 \\ \text { FRESNO } & 1071 & 36 & 25 & 119 & 42 \\ \text { SAN DIEGO } & 19690 & 32 & 45 & 116 & 58 \\ \text { SANTA BARBAR } & 3834 & 34 & 52 & 117 & 05 \\ \text { PLACER } & 3176 & 38 & 53 & 121 & 18 \\ \text { SAN JOAQUINE } & 6772 & 38 & 53 & 121 & 18 \\ \text { YUBA } & 7731 & 39 & 05 & 121 & 40 \\ \text { TULARE } & 5206 & 36 & 11 & 119 & 05 \\ \text { SUTTER } & 2645 & 39 & 16 & 121 & 40 \\ \text { MERCED } & 2588 & 37 & 20 & 120 & 45 \\ \text { SANTA BARBAR } & 2682 & 34 & 10 & 117 & 10 \\ \text { SAN JOAQUINE } & 28691 & 38 & 07 & 121 & 18 \\ \text { SANTA BARBAR } & 6804 & 34 & 05 & 117 & 13 \\ \text { SANTA BARBAR } & 2993 & 34 & 05 & 117 & 13 \\ \text { INYO } & 1241 & 36 & 35 & 118 & 04\end{array}$

TABLE 8. CITY ID, CITY NAME, COUNTY NAME, POPULATION, LATITUDE AND LONGITUDE 


\begin{tabular}{|c|c|}
\hline \multirow{2}{*}{\multicolumn{2}{|c|}{$\begin{array}{l}\text { CITY } \\
\text { ID }\end{array}$}} \\
\hline & \\
\hline 09177 & LOS BANOS \\
\hline 09008 & LOYALTON \\
\hline 09166 & MAICOPA \\
\hline 09215 & MANTECA \\
\hline 09034 & $M A R C H A F B$ \\
\hline 09290 & MARYSVILLE \\
\hline 09235 & MCCLOUD \\
\hline 09158 & MCFARLAND \\
\hline 09110 & MEDERA \\
\hline 09121 & MENDOTA \\
\hline 09178 & MERCED \\
\hline 09032 & MIRA IOUA \\
\hline 09246 & MCDESTO \\
\hline 09155 & MOJAVE \\
\hline 09236 & MOWTAGUE \\
\hline 09083 & MONTCLAIR \\
\hline 09221 & MORADA \\
\hline 09237 & MOUNT SHASTA \\
\hline 09134 & MULEERRY \\
\hline 09090 & MUSCOY \\
\hline 09197 & NATIONAL CITY \\
\hline 09081 & NEBO CNTR \\
\hline 09084 & NEEDLES \\
\hline C9012 & IEVVADA CITY \\
\hline 09249 & NEWMAN \\
\hline 09035 & NORCO \\
\hline 09186 & NORTH ISLAND \\
\hline 09250 & OAKDALE \\
\hline 09198 & OCEARSIDE \\
\hline 09159 & OILDALE \\
\hline 09291 & OTTVEHURST \\
\hline 09085 & ONTARIO \\
\hline 09122 & ORANGE COVE \\
\hline 09144 & ORLLAND \\
\hline 09272 & OROSI \\
\hline 09136 & OROVILLE \\
\hline 09184 & OTAY-CASTLE PARK \\
\hline 09139 & PALERMO \\
\hline 09017 & PALM DESERT \\
\hline 09036 & PALM SPRGS \\
\hline 09140 & PARADISE \\
\hline 09123 & PARLIER \\
\hline 09251 & PATTERSON \\
\hline 09199 & PENDLETON NORTH \\
\hline 09200 & PENDLETON SOUTH \\
\hline 09040 & PERRIS \\
\hline 09273 & PIXLEY \\
\hline 09056 & PLACER VILLE \\
\hline
\end{tabular}

CALIFORNIA COUNTY NAME POPULATION LAT LONG

$\begin{array}{lrrrrr}\text { PLACER } & 1108 & 38 & 45 & 121 & 15 \\ \text { MERCED } & 9188 & 37 & 04 & 120 & 51 \\ \text { SIERRA } & 945 & 39 & 41 & 120 & 15 \\ \text { KERN } & 740 & 00 & 00 & 000 & 00 \\ \text { SAN JOAQUINE } & 13845 & 37 & 49 & 121 & 15 \\ \text { RIVERSIDE } & 2002 & 0 & 0 & 0 & 0 \\ \text { YUBA } & 9353 & 39 & 10 & 121 & 34 \\ \text { SISKIYOU } & 1643 & 41 & 16 & 122 & 09 \\ \text { KERN } & 4177 & 35 & 37 & 119 & 15 \\ \text { MADERA } & 16044 & 0 & 0 & 0 & 0 \\ \text { FRESNO } & 2705 & 36 & 44 & 120 & 24 \\ \text { MERCED } & 22670 & 37 & 17 & 120 & 29 \\ \text { RIVERSIDE } & 8482 & 33 & 55 & 117 & 30 \\ \text { STANISLAUS } & 61712 & 37 & 37 & 121 & 00 \\ \text { KERN } & 2573 & 35 & 02 & 118 & 11 \\ \text { SISKIYOU } & 890 & 41 & 45 & 122 & 31 \\ \text { SANTA BARBAR } & 22546 & 33 & 57 & 117 & 45 \\ \text { SAN JOAQUINE } & 2936 & 0 & 0 & 0 & 0 \\ \text { SISKIYOU } & 2163 & 41 & 19 & 122 & 20 \\ \text { BUTTE } & 1795 & 00 & 00 & 000 & 00 \\ \text { SANTA BARBAR } & 7091 & 0 & 0 & 0 & 0 \\ \text { SAN DIEGO } & 43184 & 32 & 39 & 117 & 06 \\ \text { SANTA BARBAR } & 1828 & 0 & 0 & 0 & 0 \\ \text { SANIA BARBAR } & 4051 & 34 & 51 & 114 & 36 \\ \text { NEVADA } & 2314 & 39 & 16 & 121 & 00 \\ \text { STANISLAUS } & 2505 & 37 & 20 & 121 & 04 \\ \text { RIVETSIDE } & 14511 & 33 & 47 & 117 & 32 \\ \text { SAN DIEGO } & 6002 & 00 & 00 & 000 & 00 \\ \text { STANISLAUS } & 6594 & 37 & 45 & 120 & 50 \\ \text { SAN DIEGO } & 40494 & 33 & 12 & 117 & 23 \\ \text { KERN } & 20586 & 35 & 25 & 119 & 00 \\ \text { YUBA } & 8100 & 39 & 03 & 121 & 32 \\ \text { SANTA BARBAR } & 64118 & 34 & 04 & 117 & 38 \\ \text { FRESNO } & 3392 & 36 & 35 & 119 & 17 \\ \text { GLENN } & 2884 & 39 & 45 & 122 & 13 \\ \text { TULARE } & 2757 & 36 & 31 & 119 & 17 \\ \text { BUTTE } & 7536 & 39 & 31 & 121 & 34 \\ \text { SAN DIEGO } & 15445 & 32 & 33 & 117 & 00 \\ \text { BUTTE } & 1960 & 39 & 27 & 121 & 34 \\ \text { RIVERSIDE } & 6171 & 33 & 44 & 116 & 21 \\ \text { RIVERSIDE } & 20936 & 33 & 49 & 116 & 34 \\ \text { BUTTE } & 14539 & 39 & 46 & 121 & 38 \\ \text { FRESNO } & 1993 & 36 & 35 & 119 & 31 \\ \text { STANISLAUS } & 3147 & 37 & 29 & 121 & 10 \\ \text { SAN DIEGO } & 11803 & 33 & 15 & 117 & 23 \\ \text { SAN DIEGO } & 13692 & 33 & 15 & 117 & 23 \\ \text { RIVERSIDE } & 4228 & 33 & 48 & 117 & 12 \\ \text { TULARE } & 1584 & 35 & 58 & 119 & 20 \\ \text { ELDORADO } & 5416 & 38 & 43 & 120 & 50\end{array}$

TABLE 8. CITY ID, CITY NAME, COUNTY NAME, POPULATION, LATITUDE AND LONGITUDE 
CALIEORNIA

ID

09179 PLANADA

O9059 PLYMOUTH

09278 POPLAR P

09275 PORTERVILLE

09276 PORTERVILLE NORTHWEST

09277 PORTERVILLE WEST

09006 PORTOLA

09201 POWAY

09230 PROJECT CITY

09007 QUINCY

09202 RAMONA

09018 RANCHO MIRAG

09263 RED BLUFF

09228 REDDING

09086 REDLANDS

09124 REEDLEY

09089 RIALTO

09266 RICHGROVE

09156 RIDGECREST

09216 RIPON

09042 RIVERSIDE

09125 RIVERDALE

09252 RIVERBANK

09052 ROCKLIN

09157 ROSAMOND

09053 ROSEVILLE

09033 RUBIDOUX

09253 SALIDA

09062 SAN AUDREAS

09091 SAN BERNARDINO

09203 SAN DIEGO

09030 SAN JACINTO

09127 SAN JUAQUIN

09208 SAN MARCOS

09126 SANGER

O9193 SANTEE

09209. SANTEE

09088 SCARLE VALLEY

09128 SELMA

09188 SENTEE

09161 SHAFTER

09207 SOLANA BEACH

09106 SONORA

09055 SOUTH LAKE TABOE

09137 SOUTH OROVILLE

09167 SOUTH TAET

09243 SOUTH MODESTO P

09247 SOUTH MODESTO $P$

$\begin{array}{lrrrrr}\text { MERCED } & 2056 & 37 & 16 & 120 & 18 \\ \text { AMADOR } & 501 & 38 & 29 & 120 & 52 \\ \text { TULARE } & 1205 & 36 & 01 & 119 & 02 \\ \text { TULARE } & 12602 & 36 & 05 & 119 & 02 \\ \text { TULARE } & 2517 & 36 & 05 & 119 & 02 \\ \text { TULARE } & 6200 & 36 & 05 & 119 & 02 \\ \text { PLUMAS } & 1625 & 39 & 45 & 120 & 20 \\ \text { SAN DIEGO } & 9442 & 32 & 57 & 117 & 00 \\ \text { SHASTA } & 1431 & 40 & 42 & 122 & 24 \\ \text { PLUMAS } & 3343 & 39 & 56 & 120 & 56 \\ \text { SAN DIEGO } & 3554 & 33 & 02 & 116 & 52 \\ \text { RIVERSIDE } & 1298 & 0 & 0 & 0 & 0 \\ \text { TEHAMA } & 7676 & 40 & 11 & 122 & 16 \\ \text { SEASTA } & 16659 & 40 & 35 & 122 & 24 \\ \text { SANTA BARBAR } & 36355 & 34 & 03 & 117 & 10 \\ \text { FRESNO } & 8131 & 36 & 35 & 119 & 27 \\ \text { SANTA BARBAR } & 38370 & 34 & 03 & 117 & 21 \\ \text { TULARE } & 1023 & 35 & 46 & 119 & 08 \\ \text { KERN } & 7629 & 35 & 33 & 117 & 39 \\ \text { SAN JOAQUINE } & 2679 & 37 & 44 & 121 & 08 \\ \text { RIVERSIDE } & 140089 & 33 & 59 & 117 & 22 \\ \text { ERESNO } & 1722 & 36 & 26 & 119 & 53 \\ \text { STANISLAUS } & 3949 & 37 & 43 & 120 & 56 \\ \text { PLACER } & 3039 & 38 & 43 & 121 & 17 \\ \text { KERN } & 2281 & 34 & 52 & 118 & 10 \\ \text { PLACER } & 17895 & 38 & 44 & 121 & 19 \\ \text { RIVERSIDE } & 13969 & 0 & 0 & 0 & 0 \\ \text { STANISLAUS } & 1456 & 37 & 40 & 121 & 02 \\ \text { CALARERAS } & 1564 & 38 & 20 & 120 & 40 \\ \text { SANTA BARBAR } & 104251 & 34 & 07 & 117 & 18 \\ \text { SAN DIEGO } & 696769 & 32 & 45 & 117 & 10 \\ \text { RIVERSIDE } & 4385 & 33 & 48 & 116 & 58 \\ \text { FRESNO } & 1506 & 36 & 35 & 120 & 10 \\ \text { SAN DIEGO } & 3896 & 0 & 0 & 0 & 0 \\ \text { FRESNO } & 10088 & 36 & 41 & 119 & 35 \\ \text { SAN DIEGO } & 19321 & 32 & 51 & 117 & 00 \\ \text { SAN DIEGO } & 15858 & 0 & 0 & 0 & 0 \\ \text { SANTA BARBAR } & 3828 & 35 & 30 & 117 & 36 \\ \text { FRESNO } & 7459 & 36 & 34 & 119 & 38 \\ \text { SAN DIEGO } & 1786 & 00 & 00 & 000 & 00 \\ \text { KERN } & 5327 & 35 & 30 & 119 & 16 \\ \text { SAN DIEGO } & 5023 & 32 & 58 & 117 & 17 \\ \text { TUOLUMNE } & 3100 & 38 & 00 & 120 & 21 \\ \text { ELDORADO } & 12921 & 39 & 03 & 120 & 00 \\ \text { BUTTE } & 4111 & 39 & 31 & 121 & 34 \\ \text { KERN } & 2214 & 35 & 08 & 119 & 28 \\ \text { STANISLAUS } & 1337 & 37 & 37 & 121 & 00 \\ \text { STANISLAUS } & 6552 & 37 & 37 & 121 & 00 \\ & & & & & \end{array}$

TABLE 8. CITY ID, CITY NAME, COUNTY NAME, POPULATION, LATITUDE AND LONGITUDE 


\begin{tabular}{|c|c|c|c|c|c|c|c|}
\hline & & IFORNIA & & & & & \\
\hline $\begin{array}{l}\text { CITY } \\
\text { ID }\end{array}$ & CITY NAME & COUNTY NAME & POPULATION & $L A$ & & LOl & \\
\hline 09255 & SOUTH TURLOCK & STANISLAUS & 1762 & 37 & 29 & 120 & 50 \\
\hline 09261 & SOUTH YUBA CITY & SUTTER & 5352 & 39 & 09 & 121 & 36 \\
\hline 09182 & SPRING VALLEY & SAN DIEGO & 29742 & 32 & 41 & 116 & 57 \\
\hline 09196 & SPRING VALLEY & SAN DIEGO & 24493 & 00 & 00 & 000 & 00 \\
\hline 09217 & STOCKTON & SAN JOAQUINE & 107644 & 37 & 59 & 121 & 20 \\
\hline 09279 & STRATHMORE & TULARE & 1221 & 36 & 05 & 119 & 03 \\
\hline 09041 & SUN CITY & RIVERSIDE & 5519 & 0 & 0 & 0 & 0 \\
\hline 09025 & SUNNY MEAD & RIVERSIDE & 6708 & 0 & 0 & 0 & 0 \\
\hline 09002 & SUSANVILLE & LASSEN & 6608 & 40 & 26 & 120 & 40 \\
\hline 09060 & SUTTER CREEK & AMADOR & 1508 & 38 & 24 & 120 & 50 \\
\hline 09259 & SUTTER & SUTTER & 1488 & 38 & 25 & 120 & 54 \\
\hline 09168 & TAFT & KERN & 4285 & 35 & 08 & 119 & 28 \\
\hline 09169 & TAFT HEIGHTS & $K E R N$ & 2108 & 35 & 03 & 119 & 30 \\
\hline 09050 & TABOE & PLACER & 1394 & 39 & 05 & 120 & 00 \\
\hline 09162 & TEAACHAPI & $K E R N$ & 4211 & 35 & 08 & 118 & 27 \\
\hline 09280 & TERRA BELLA & TULARE & 1037 & 35 & 58 & 119 & 03 \\
\hline 09138 & THERMALITO & BUTTE & 4217 & 39 & 31 & 121 & 34 \\
\hline 09222 & TRACY & SAN JOAQUINE & 14724 & 37 & 43 & 121 & 27 \\
\hline 09009 & TRUCKEE & NEVADA & 1392 & 39 & 20 & 120 & 10 \\
\hline 09282 & TULARE & TULARE & 16235 & 36 & 13 & 119 & 22 \\
\hline 09283 & TULARE EAST & TULARE & 2361 & 36 & 13 & 119 & 22 \\
\hline 09284 & TULARE NORTHWEST & TULARE & 1801 & 36 & 13 & 119 & 22 \\
\hline 09238 & TULELAKE & SISKIYOU & 857 & 41 & 54 & 121 & 31 \\
\hline 09107 & TUOLUMNE & TUOLUMNE & 1365 & 37 & 59 & 120 & 15 \\
\hline 09256 & TURLOCK & STANISLAUS & 13992 & 37 & 29 & 120 & 50 \\
\hline 09108 & TWATN BARTE & TUOLUNRE & 1484 & 38 & 00 & 120 & 14 \\
\hline 09096 & UPLAND & SANTA BARBAR & 32551 & 34 & 06 & 117 & 38 \\
\hline 09097 & VICTORVILLE & SANTA BARBAR & 10845 & 34 & 31 & 117 & 17 \\
\hline 09210 & VISTA & SAN DIEGO & 24688 & 33 & 12 & 117 & 15 \\
\hline 09163 & WASCO & $K E R N$ & 8269 & 35 & 35 & 119 & 22 \\
\hline 09257 & WATERFORD & STANISLAUS & 2243 & 37 & 37 & 120 & 46 \\
\hline 09239 & WEED & SISKIYOU & 2983 & 41 & 26 & 122 & 23 \\
\hline 09105 & WEST MORLAND & IMPERIAL & 1175 & 33 & 03 & 115 & 37 \\
\hline 09248 & IEST MODESTO & STANISLAUS & 6135 & 37 & 37 & 121 & 00 \\
\hline 09003 & WESTWOOD & LASSEN & 1862 & 40 & 20 & 121 & 00 \\
\hline 09292 & THEATLAND & $Y U B A$ & 1280 & 39 & 01 & 121 & 24 \\
\hline 09142 & WILLIAMS & COLUSA & 1571 & 39 & 09 & 122 & 09 \\
\hline 09145 & WILLOWS & GLENN & 4085 & 39 & 32 & 122 & 10 \\
\hline 09172 & WINTON & MERCED & 3393 & 00 & 00 & 000 & 00 \\
\hline 09213 & WCODBRIDGE & SAN JOAQUINE & 1397 & 38 & 08 & 121 & 19 \\
\hline 09286 & WOODLAKE & TULARE & 3371 & 36 & 26 & 119 & 07 \\
\hline 09281 & WOODVILLE & TULARE & 1031 & 36 & 05 & 119 & 15 \\
\hline 09082 & YERMO & SANTA BARBAR & 1304 & 34 & 55 & 116 & 50 \\
\hline 09095 & YOLLA VALLEY & SANTA BARBAR & 3893 & 33 & 05 & 116 & 30 \\
\hline 09240 & YREXA & SISKIYOU & 5394 & 41 & 44 & 122 & 39 \\
\hline 09260 & YUBA CITY & SUTTER & 13986 & 39 & 09 & 121 & 36 \\
\hline 09098 & YUCAIPA & SANTA BARBAR & 19284 & 33 & 59 & 117 & 00 \\
\hline 09094 & 29 PALMS & SANTA BARBAR & 5667 & 34 & 09 & 116 & 03 \\
\hline
\end{tabular}

TABLE 8. CITY ID, CITY NAME, COUNTY NAME, POPULATION, LATITUDE AND LONGITUDE 


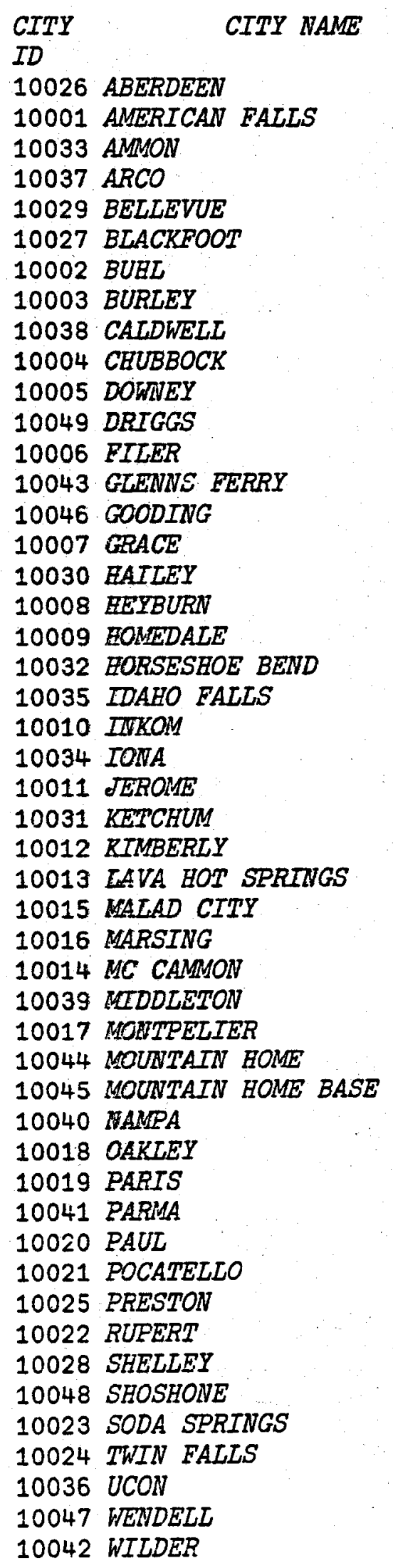

IDABO COUNTY NAME POPULATTON LAT . LONG

$\begin{array}{lrllll}\text { BINGHAM } & 1542 & 42 & 57 & 112 & 50 \\ \text { POWER } & 2769 & 42 & 47 & 112 & 50 \\ \text { BONNEVILLE } & 1338 & 43 & 30 & 111 & 57 \\ \text { BUTTE } & 1244 & 43 & 38 & 113 & 18 \\ \text { BLAINE } & 537 & 43 & 27 & 114 & 16 \\ \text { BINGHAM } & 8716 & 43 & 13 & 112 & 20 \\ \text { TWIN FALIS } & 2975 & 42 & 37 & 114 & 46 \\ \text { CASSIA } & 8279 & 42 & 32 & 113 & 48 \\ \text { CANYON } & 14219 & 43 & 39 & 116 & 40 \\ \text { BANNOCK } & 2924 & 42 & 55 & 112 & 26 \\ \text { BANNOCK } & 7586 & 42 & 26 & 112 & 12 \\ \text { TETON } & 727 & 43 & 45 & 111 & 08 \\ \text { TWIN EALLS } & 1173 & 42 & 36 & 114 & 37 \\ \text { ELMOR } & 1386 & 42 & 57 & 115 & 19 \\ \text { GOODING } & 2599 & 42 & 56 & 114 & 44 \\ \text { CARIBOU } & 826 & 42 & 35 & 111 & 45 \\ \text { BLAINE } & 1425 & 43 & 31 & 114 & 19 \\ \text { MINIDOKA } & 1637 & 42 & 33 & 113 & 46 \\ \text { OWYHEE } & 1411 & 43 & 37 & 116 & 55 \\ \text { BOISE } & 511 & 43 & 55 & 116 & 11 \\ \text { BONNEVILLE } & 35776 & 43 & 30 & 112 & 01 \\ \text { BANNOCK } & 522 & 42 & 48 & 112 & 15 \\ \text { BONNEVILLE } & 890 & 43 & 33 & 111 & 56 \\ \text { JEROME } & 4183 & 42 & 44 & 114 & 31 \\ \text { BLAINE } & 1454 & 43 & 41 & 114 & 23 \\ \text { TWIN FALLS } & 1557 & 42 & 32 & 114 & 23 \\ \text { BANNOCK } & 516 & 42 & 37 & 112 & 00 \\ \text { ONEIDA } & 1848 & 42 & 12 & 112 & 15 \\ \text { OWYHEE } & 610 & 43 & 33 & 116 & 48 \\ \text { BANNOCK } & 673 & 42 & 39 & 112 & 12 \\ \text { CANYON } & 739 & 43 & 43 & 116 & 37 \\ \text { BEAR LAKE } & 2604 & 42 & 20 & 111 & 20 \\ \text { ELMOR } & 6451 & 43 & 09 & 115 & 42 \\ \text { ELMOR } & 6038 & 43 & 09 & 115 & 42 \\ \text { CANYON } & 20758 & 43 & 35 & 116 & 34 \\ \text { CASSIA } & 656 & 42 & 15 & 113 & 53 \\ \text { BEAR LAKE } & 615 & 42 & 15 & 111 & 24 \\ \text { CANYON } & 1228 & 43 & 49 & 116 & 58 \\ \text { MINIDOKA } & 911 & 42 & 37 & 113 & 48 \\ \text { BANNOCK } & 40036 & 42 & 53 & 112 & 26 \\ \text { ERANKLIN } & 3310 & 42 & 06 & 111 & 53 \\ \text { MINIDOKA } & 4563 & 42 & 37 & 113 & 40 \\ \text { BINGHAM } & 2614 & 43 & 25 & 112 & 07 \\ \text { LINCOLN } & 1233 & 42 & 57 & 114 & 25 \\ \text { CARIBOU } & 2977 & 42 & 40 & 111 & 35 \\ \text { TWIN FALLS } & 21914 & 42 & 34 & 114 & 30 \\ \text { BONNEVILLE } & 664 & 43 & 36 & 111 & 58 \\ \text { GOODING } & 1122 & 42 & 47 & 114 & 42 \\ \text { CANYON } & 564 & 43 & 43 & 116 & 40\end{array}$

TAELE 8. CITY ID, CITY NAME, COUNTY NAME, POPULATION, LATITUDE AND EONGITUDE 


$\begin{array}{ll}\text { CITY } & \text { CITY NAME } \\ \text { ID } & \\ 11020 & \text { ATWOOD } \\ 11018 & \text { BIRD CITY } \\ 11023 & \text { CIMARRON } \\ 11017 & \text { COLBY } \\ 11025 & \text { DIGHTON } \\ 11001 & \text { ELKHART } \\ 11026 & \text { FOWLER } \\ 11010 \text { GARDEN CITY } \\ 11016 \text { GOODLAND } \\ 11030 \text { HOXIE } \\ 11002 \text { HUGOTON } \\ 11004 \text { JOHNSON } \\ 11009 \text { LAKIN } \\ 11012 \text { LEOTI } \\ 11003 \text { LIBERAL } \\ 11027 \text { MEADE } \\ 11024 \text { MONTEZUMA } \\ 11029 \text { NESS CITY } \\ 11015 \text { OAKLEY } \\ 11021 \text { OBERLIN } \\ 11022 \text { QUINTER } \\ 11006 \text { SATANTA } \\ 11013 \text { SCOTT CITY } \\ 11014 \text { SHARON SPRINGS } \\ 11019 \text { ST ERANCIS } \\ 11007 \text { SUBLETTE } \\ 11008 \text { SYRACUSE } \\ 11011 \text { TRIBUNE } \\ 11005 \text { ULYSSES } \\ 11028 \text { WEST PLATNS }\end{array}$

KANSAS COUNTY NAME POPULATION LAT LONG

RAWLINS

CHEYENNE

GRAY

THOMAS

IANE

MORTON

MEADE

FINNEY

SEERMAN

SEERIDAN

STEVENS

STANTON

KEARNEY

WICEITA

SEWARD

$M E A D E$

GRAY

NESS

LOGAN

DECATUR

GOVE.

BASKELL

SCOTT

WALTACE

CHEYENNE

HASKELL

BAMILTON

GREELEY

GRALT

MEADE

$\begin{array}{rllll}1658 & 39 & 48 & 101 & 03 \\ 667 & 39 & 45 & 101 & 32 \\ 1373 & 37 & 49 & 100 & 20 \\ 4658 & 39 & 24 & 101 & 04 \\ 1540 & 38 & 28 & 100 & 28 \\ 2089 & 37 & 01 & 101 & 55 \\ 588 & 37 & 23 & 100 & 13 \\ 14708 & 37 & 57 & 100 & 54 \\ 5510 & 39 & 20 & 101 & 43 \\ 1419 & 39 & 21 & 100 & 27 \\ 2739 & 37 & 11 & 101 & 22 \\ 1038 & 37 & 34 & 101 & 47 \\ 1570 & 37 & 57 & 101 & 16 \\ 1916 & 38 & 28 & 101 & 22 \\ 13471 & 37 & 03 & 100 & 56 \\ 1899 & 37 & 17 & 100 & 21 \\ 606 & 37 & 35 & 100 & 27 \\ 1756 & 38 & 27 & 99 & 54 \\ 2327 & 39 & 08 & 100 & 53 \\ 2291 & 39 & 49 & 100 & 33 \\ 930 & 39 & 04 & 100 & 15 \\ 1161 & 37 & 26 & 100 & 59 \\ 4001 & 38 & 28 & 100 & 55 \\ 1012 & 38 & 54 & 101 & 46 \\ 1725 & 39 \cdot 47 & 101 & 47 \\ 1208 & 37 & 28 & 100 & 52 \\ 1720 & 37 & 59 & 101 & 46 \\ 1013 & 38 & 27 & 101 & 46 \\ 3779 & 37 & 36 & 101 & 23 \\ 857 & 37 & 16 & 100 & 40\end{array}$

TABLE 8. CITY ID, CITY NAME, COUNTY NAME, POPULATION, LATITUDE AND LONGITUDE 
ID

12021 ALLIANCE

12024 ANSLEY

12034 ARAPAHOE

12025 ARNOLD

12013 BAYARD

12035 BEAVER CITY

12003 BENKELMAN

12012 BRIDGEPORT

12026 BROKEN BOW

12027 CALLAWAY

12036 CAMBRIDGE

12008 CHAPPELL

12029 COZAD

12001 CULBERTSON

12033 CURTIS

12014 GERING

12041 GORDON

12030 GOTHEN

12042 BAY SPRINGS

12022 HEMINGFORD

12004 HERSHEY

12039 INDIANOLA

12011 KIMBALL

12031 LEXINTON

12015 LYMAN

12040 MCCOOK

12016 MINATARE

12017 MITCHELL

12018 MORILL

12038 MULLEN

12005 NORTH PLATTE

12009 OSHKOSH

12032 OVERTON

12037 OXFORD

12007 PAXTON

12043 RUSHVILLE

12028 SARGENT

12020 SCOTTS BLUFF

12010 SIDNEY

12006 SUTHERLAND

12019 TERRYTOWN

12002 TRENTON

12023 VALENTINE
NEBRASKA COUNTY NAME POPULATION LAT . LONG

$\begin{array}{lrrrrr}\text { BOX BUTTE } & 6862 & 42 & 08 & 102 & 54 \\ \text { CUSTER } & 631 & 41 & 19 & 99 & 22 \\ \text { FURNAS } & 1147 & 40 & 19 & 99 & 52 \\ \text { CUSTER } & 752 & 41 & 16 & 100 & 11 \\ \text { MORRILL } & 1338 & 41 & 46 & 103 & 20 \\ \text { FURNAS } & 802 & 40 & 09 & 99 & 50 \\ \text { DUNDY } & 1349 & 40 & 02 & 101 & 31 \\ \text { MORRILL } & 1490 & 41 & 40 & 103 & 05 \\ \text { CUSTER } & 660 & 41 & 26 & 99 & 38 \\ \text { CUSTER } & 523 & 41 & 18 & 99 & 55 \\ \text { FURNAS } & 1145 & 40 & 18 & 100 & 11 \\ \text { DEUEL } & 1204 & 41 & 06 & 102 & 29 \\ \text { DAWSON } & 4219 & 40 & 51 & 99 & 59 \\ \text { HITCHCOCK } & 801 & 40 & 14 & 100 & 49 \\ \text { FRONTIER } & 1166 & 40 & 00 & 100 & 30 \\ \text { SCOTTS BLUFF } & 5639 & 41 & 50 & 103 & 30 \\ \text { SHERIDAN } & 2106 & 42 & 48 & 103 & 12 \\ \text { DAWSON } & 3154 & 00 & 00 & 00 & 00 \\ \text { SBERIDAN } & 682 & 42 & 41 & 102 & 42 \\ \text { BOX BUTTE } & 734 & 42 & 20 & 103 & 05 \\ \text { LINCOLN } & 526 & 41 & 09 & 100 & 59 \\ \text { RED WILLOW } & 576 & 40 & 16 & 100 & 24 \\ \text { KIMBALL } & 3680 & 41 & 16 & 103 & 40 \\ \text { DAWSON } & 5618 & 40 & 46 & 99 & 48 \\ \text { SCOTTS BLUFF } & 561 & 41 & 57 & 104 & 02 \\ \text { RED WILLOW } & 8285 & 40 & 13 & 100 & 35 \\ \text { SCOTTS BLUFF } & 939 & 41 & 50 & 103 & 30 \\ \text { SCOTTS BLUFF } & 1842 & 41 & 56 & 103 & 48 \\ \text { SCOTTS BLUFF } & 937 & 41 & 58 & 103 & 58 \\ \text { HOOKER } & 667 & 42 & 03 & 101 & 02 \\ \text { LINCOLN } & 19447 & 41 & 09 & 100 & 45 \\ \text { GARDEN } & 1067 & 41 & 26 & 102 & 22 \\ \text { DAWSON } & 506 & 40 & 44 & 99 & 32 \\ \text { EURNAS } & 878 & 40 & 16 & 99 & 40 \\ \text { KIETH } & 503 & 41 & 08 & 101 & 22 \\ \text { SHERIDAN } & 1137 & 42 & 45 & 102 & 27 \\ \text { CUSTER } & 789 & 41 & 39 & 99 & 22 \\ \text { SCOTTS BLUFF } & 14507 & 41 & 52 & 103 & 40 \\ \text { CHEYENNE } & 6403 & 41 & 09 & 103 & 00 \\ \text { LINCOLN } & 840 & 41 & 10 & 101 & 08 \\ \text { SCOTTS BLUFF } & 747 & 41 & 49 & 103 & 40 \\ \text { HITCHCOCK } & 770 & 40 & 11 & 101 & 01 \\ \text { CHERRY } & 2662 & 42 & 53 & 100 & 31 \\ & & & & & \end{array}$

TABLE 8. CITY ID, CITY NAME, COUNTY NAME, POPULATION, LATITUDE AND LONGITUDE 
CITY

ID

13001 BOISE CITY

13003 GUYMON

13004 HOOKER

13002 KEYES

13005 TEXHOMA

13006 TYRONE
CITY NAME

:

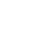

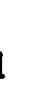

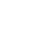

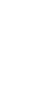

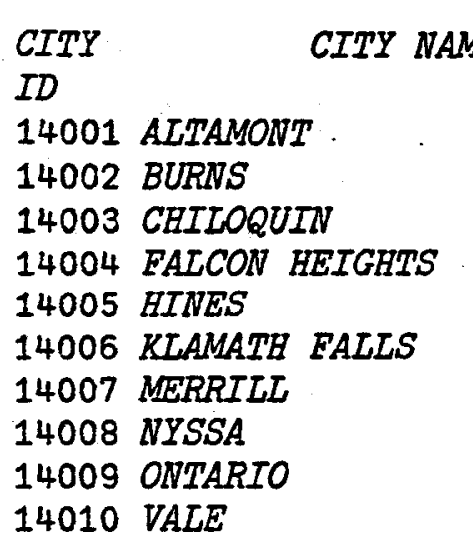

\section{OKLABOMA}

COUNTY NAME POPULATION LAT LONG

$\begin{array}{lrrrrr}\text { CIMARRON } & 1993 & 36 & 44 & 102 & 31 \\ \text { TEXAS } & 7674 & 36 & 42 & 101 & 30 \\ \text { TEXAS } & 1615 & 36 & 51 & 101 & 13 \\ \text { CIMARRON } & 569 & 36 & 48 & 102 & 13 \\ \text { TEXAS } & 921 & 36 & 30 & 101 & 47 \\ \text { TEXAS } & 588 & 36 & 57 & 101 & 02\end{array}$

OREGON

\section{COUNTY NAME POPULATION LAT LONG}

$\begin{array}{lrllll}\text { KLAMATH } & 15746 & 42 & 12 & 121 & 47 \\ \text { BARNEY } & 3293 & 43 & 36 & 119 & 03 \\ \text { KLAMATH } & 826 & 42 & 35 & 121 & 53 \\ \text { KLAMATH } & 1389 & 00 & 00 & 000 & 00 \\ \text { BARNEY } & 1407 & 43 & 34 & 119 & 04 \\ \text { KLAMATH } & 15775 & 42 & 14 & 121 & 47 \\ \text { KLAMATH } & 722 & 42 & 02 & 121 & 37 \\ \text { MALEEUR } & 2620 & 43 & 54 & 117 & 00 \\ \text { MALHEUR } & 6523 & 44 & 02 & 116 & 58 \\ \text { MALHEUR } & 1448 & 43 & 59 & 117 & 15\end{array}$

TABLE 8. CITY ID, CITY NAME, COUNTY NAME, POPULATION, LATITUDE AND LONGITUDE 


CITY
ID
15056 ABERNATHY NAME
15071 ABERNATHY
15085 AMARILLO
15035 AMHERST
15018 ANDREWS
15004 ANTHONY
15025 ANTON
15008 BALMORHEA
15010 BARSTOW
15087 BIG LAKE
15062 BIG SPRING
15002 BIGGS
15064 BORGER
15038 BOVINA
15023 BROWNFIELD
15065 BUNAVISTA
15080 CACTUS
15005 CANUTILLO
15086 CANYON
15041 CLAUDE
15063 COABOMA
15016 CRANE
15049 CROSBYTON
15030 DALHART
15021 DEMVER CITY
15029 DIMMIT
15081 DUMAS
15032 EARTH
15001 EL PASO
15006 EABENS
15039 FARWELL
15053 ELOYDADA
15083 FORT STOCKTON
15040 FRIONA
15066 ERITCH
15003 ET BLISS
15011 GRANDFALLS
15045 GROOM
15060 GRUVER
15057 HALE CENTER
15089 BAPPY
15031 HEREFORD
15069 IDALOU
15084 IRAAN
15014 KERMIT
15090 KRESS
15052 LAMESA

TEXAS

COUNTY NAME POPULATION LAT LONG

$\begin{array}{lrllll}\text { HALE } & 1921 & 33 & 50 & 101 & 52 \\ \text { LUBBOCK } & 704 & 33 & 50 & 101 & 52 \\ \text { POTTER } & 86477 & 35 & 14 & 101 & 50 \\ \text { LAMB } & 825 & 34 & 02 & 102 & 26 \\ \text { ANDREWS } & 8625 & 32 & 19 & 102 & 34 \\ \text { EL PASO } & 2154 & 32 & 00 & 106 & 36 \\ \text { HOCKLEY } & 1034 & 33 & 51 & 102 & 12 \\ \text { REEVES } & 655 & 31 & 00 & 103 & 46 \\ \text { WARD } & 614 & 31 & 27 & 103 & 24 \\ \text { REGAN } & 2489 & 31 & 12 & 101 & 29 \\ \text { HOWARD } & 28735 & 32 & 15 & 101 & 30 \\ \text { EL PASO } & 4226 & 31 & 50 & 106 & 23 \\ \text { EUTCHINSON } & 14195 & 35 & 39 & 101 & 24 \\ \text { PARMER } & 1428 & 34 & 31 & 102 & 54 \\ \text { TERRY } & 9647 & 33 & 11 & 102 & 16 \\ \text { BUTCHINSON } & 1402 & 00 & 00 & 000 & 00 \\ \text { MOORE } & 644 & 36 & 03 & 102 & 10 \\ \text { EL PASO } & 1588 & 31 & 05 & 106 & 37 \\ \text { RANDAL } & 8333 & 34 & 58 & 101 & 56 \\ \text { ARMSTRONG } & 992 & 35 & 06 & 101 & 22 \\ \text { HOWARD } & 1158 & 32 & 18 & 101 & 17 \\ \text { CRANE } & 3427 & 31 & 23 & 102 & 22 \\ \text { CROSBY } & 2251 & 33 & 40 & 101 & 12 \\ \text { DALLOM } & 4340 & 36 & 05 & 102 & 32 \\ \text { YOAKUM } & 4133 & 32 & 58 & 102 & 50 \\ \text { CASTRO } & 4327 & 34 & 33 & 102 & 20 \\ \text { MOORE } & 9771 & 35 & 51 & 101 & 57 \\ \text { LAMB } & 1152 & 34 & 14 & 102 & 25 \\ \text { EL PASO } & 322261 & 31 & 45 & 105 & 30 \\ \text { EL PASO } & 3241 & 31 & 29 & 106 & 21 \\ \text { PARMER } & 1185 & 31 & 23 & 103 & 03 \\ \text { FLOYD } & 4109 & 33 & 58 & 101 & 20 \\ \text { PECOS } & 8283 & 30 & 54 & 102 & 54 \\ \text { PARMER } & 3111 & 34 & 38 & 102 & 44 \\ \text { HUTCHINSON } & 1778 & 35 & 39 & 101 & 36 \\ \text { EL PASO } & 13288 & 31 & 45 & 106 & 30 \\ \text { WARD } & 622 & 31 & 09 & 102 & 55 \\ \text { CARSON } & 808 & 35 & 12 & 101 & 03 \\ \text { HANSFORD } & 1265 & 36 & 14 & 101 & 25 \\ \text { HALE } & 1964 & 34 & 04 & 101 & 52 \\ \text { SWISHER } & 627 & 34 & 44 & 101 & 52 \\ \text { DEAF SMITH } & 13414 & 34 & 49 & 102 & 25 \\ \text { LUBBOCK } & 1729 & 33 & 40 & 101 & 40 \\ \text { PECOS } & 996 & 30 & 42 & 101 & 56 \\ \text { WINKLER } & 7884 & 31 & 49 & 103 & 07 \\ \text { SWISHER } & 578 & 34 & 22 & 101 & 46 \\ \text { DAWSON } & 11559 & 32 & 43 & 101 & 57\end{array}$

TABLE 8. CITY ID, CITY NAME, COUNTY NAME, POPULATION, LATITUDE AND LONGITUDE 


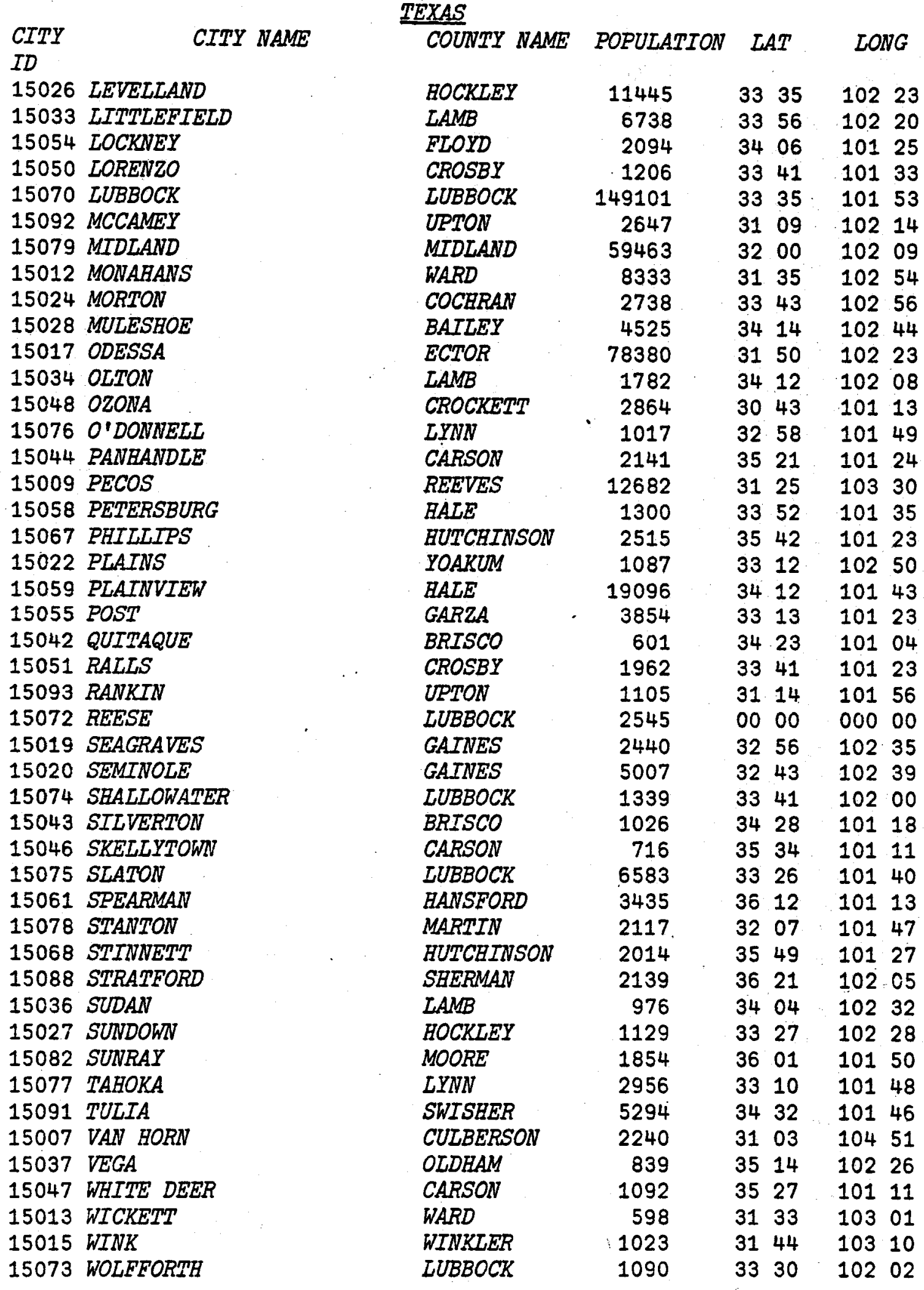

TABLE 8. CITY ID, CITY NAME, COUNTY NAME, POPULATION, LATITUDE AND LONGITUDE 


$\begin{array}{ll}\text { CITY } & \text { CITY NAME } \\ \text { ID } & \\ 16001 & \text { AFTON } \\ 16002 & \text { BASIN } \\ 16003 & \text { BIG PINEY } \\ 16004 & \text { BUFEALO } \\ 16005 & \text { CASPER } \\ 16006 & \text { CHEYENNE } \\ 16007 & \text { CODY } \\ 16008 & \text { DOUGLAS } \\ 16009 & \text { DUBOIS } \\ 16010 & \text { EVANSTON } \\ 16011 & \text { EVANSVILLE } \\ 16012 & \text { FOX FARM } \\ 16013 & \text { GILETTE } \\ 16014 & \text { GLENROCK } \\ 16015 & \text { GREEN RIVER } \\ 16016 & \text { GREYBULL } \\ 16017 & \text { GUERNSEY } \\ 16018 & \text { JACKSON } \\ 16019 & \text { KEMMERER } \\ 16020 & \text { LANDER } \\ 16021 & \text { LARAMIE } \\ 16022 & \text { LOVELL } \\ 16023 & \text { LUSK } \\ 16024 & \text { LYMAN } \\ 16025 & \text { MILLS } \\ 16026 & \text { MOORCROFT } \\ 16027 & \text { MOUNTAIN VIEW } \\ 16028 & \text { NEWCASTLE } \\ 16029 & \text { ORCHARD VALLEY } \\ 16030 & \text { PARADISE VALLEY } \\ 16031 & \text { PINE BLUFES } \\ 16032 & \text { PINEDALE } \\ 16033 & \text { POWELL } \\ 16034 & \text { RAWLINS } \\ 16035 & \text { RIVERTON } \\ 16036 & \text { ROCK SPRINGS } \\ 16037 & \text { SARATOGA } \\ 16038 & \text { SHERIDAN } \\ 16039 & \text { SHOSHONI } \\ 16040 & \text { SUNDANCE } \\ 16041 & \text { THERMOPOLIS } \\ 16042 & \text { TORRINGTON } \\ 16043 & \text { UPTON } \\ 16044 & \text { WARREN } \\ 16045 & \text { WHEATLAND } \\ 16046 & \text { WORLAND } \\ \end{array}$

WYOMING COUNTY NAME POPULATION LAT LONG

$\begin{array}{lrllll}\text { LINCOLN } & 1290 & 42 & 44 & 110 & 55 \\ \text { BIG HORN } & 1145 & 44 & 24 & 108 & 02 \\ \text { SUBLETTE } & 570 & 42 & 32 & 110 & 06 \\ \text { JOHNSON } & 3394 & 44 & 21 & 106 & 40 \\ \text { NATRONA } & 39361 & 42 & 50 & 106 & 20 \\ \text { LARAMIE } & 40914 & 41 & 08 & 104 & 50 \\ \text { PARK } & 5161 & 44 & 32 & 109 & 04 \\ \text { CONVERSE } & 2677 & 42 & 48 & 105 & 23 \\ \text { FREMONT } & 898 & 43 & 32 & 109 & 36 \\ \text { UINTA } & 4462 & 41 & 16 & 110 & 58 \\ \text { NATRONA } & 832 & 42 & 51 & 106 & 16 \\ \text { LARAMIE } & 1329 & 00 & 00 & 000 & 00 \\ \text { CAMBELL } & 7194 & 44 & 18 & 105 & 30 \\ \text { CONVERSE } & 1515 & 42 & 52 & 105 & 52 \\ \text { SWEETWATER } & 4196 & 41 & 33 & 109 & 27 \\ \text { BIG HORN } & 1953 & 44 & 30 & 108 & 02 \\ \text { PLATTE } & 793 & 42 & 17 & 104 & 45 \\ \text { TETON } & 2101 & 43 & 28 & 110 & 45 \\ \text { LINCOLN } & 2292 & 41 & 47 & 110 & 33 \\ \text { FREMONT } & 7125 & 42 & 49 & 108 & 44 \\ \text { ALBANY } & 23143 & 41 & 20 & 105 & 38 \\ \text { BIG HORN } & 2371 & 44 & 50 & 108 & 15 \\ \text { NIOBRARA } & 1495 & 42 & 47 & 104 & 26 \\ \text { UNITA } & 643 & 41 & 20 & 110 & 16 \\ \text { NATRONA } & 1724 & 42 & 50 & 106 & 24 \\ \text { CROOK } & 981 & 44 & 15 & 104 & 58 \\ \text { NATRONA } & 1641 & 41 & 16 & 110 & 20 \\ \text { WESTON } & 3432 & 43 & 52 & 104 & 14 \\ \text { LARAMIE } & 1015 & 41 & 04 & 104 & 50 \\ \text { NATRONA } & 1764 & 42 & 49 & 106 & 24 \\ \text { LARAMIE } & 937 & 41 & 10 & 104 & 06 \\ \text { SUBLETTE } & 948 & 42 & 51 & 109 & 50 \\ \text { EARK } & 4807 & 44 & 45 & 108 & 46 \\ \text { CARBON } & 7855 & 41 & 46 & 107 & 16 \\ \text { EREMONT } & 7995 & 43 & 02 & 108 & 22 \\ \text { SWEETWATER } & 11657 & 41 & 35 & 109 & 13 \\ \text { CARBON } & 1181 & 41 & 28 & 106 & 48 \\ \text { SHERIDAN } & 10856 & 44 & 48 & 106 & 57 \\ \text { FREMONT } & 562 & 43 & 15 & 108 & 04 \\ \text { CROOK } & 1056 & 44 & 23 & 104 & 22 \\ \text { HOT SPRINGS } & 3063 & 43 & 39 & 108 & 12 \\ \text { GOSHEN } & 4237 & 42 & 05 & 104 & 11 \\ \text { WESTON } & 987 & 44 & 05 & 104 & 36 \\ \text { LARAMIE } & 4527 & 00 & 00 & 000 & 00 \\ \text { PLATTE } & 2498 & 42 & 03 & 104 & 57 \\ \text { WASHAKIE } & 5055 & 44 & 01 & 107 & 58\end{array}$

TABLE 8. CITY ID, CITY NAME, COUNTY NAME, POPULATION, LATITUDE AND LONGITUDE 


\begin{tabular}{|c|c|c|c|c|c|}
\hline \multicolumn{6}{|c|}{ ARIZONA } \\
\hline $\begin{array}{l}\text { COUNTY } \\
\text { ID }\end{array}$ & COUNTY NAME & $\left\{\begin{array}{l}\text { COUNTY } \\
\text { ID }\end{array}\right.$ & COUNTY NAME & $\begin{array}{l}\text { COUNTY } \\
\text { ID }\end{array}$ & COUNTY NAME \\
\hline 401 & APACHE & 406 & GREELEE & 411 & PINAL \\
\hline 402 & COCHTSE & 407 & MARICOPA & 412 & SANTA CRUZ \\
\hline 403 & COCONINO & 408 & MOHAVE & 413 & YAVAPAI \\
\hline 404 & GILA & 409 & NAVAJO & 414 & YUMA \\
\hline 405 & GRABAM & 410 & PIMA & & \\
\hline
\end{tabular}

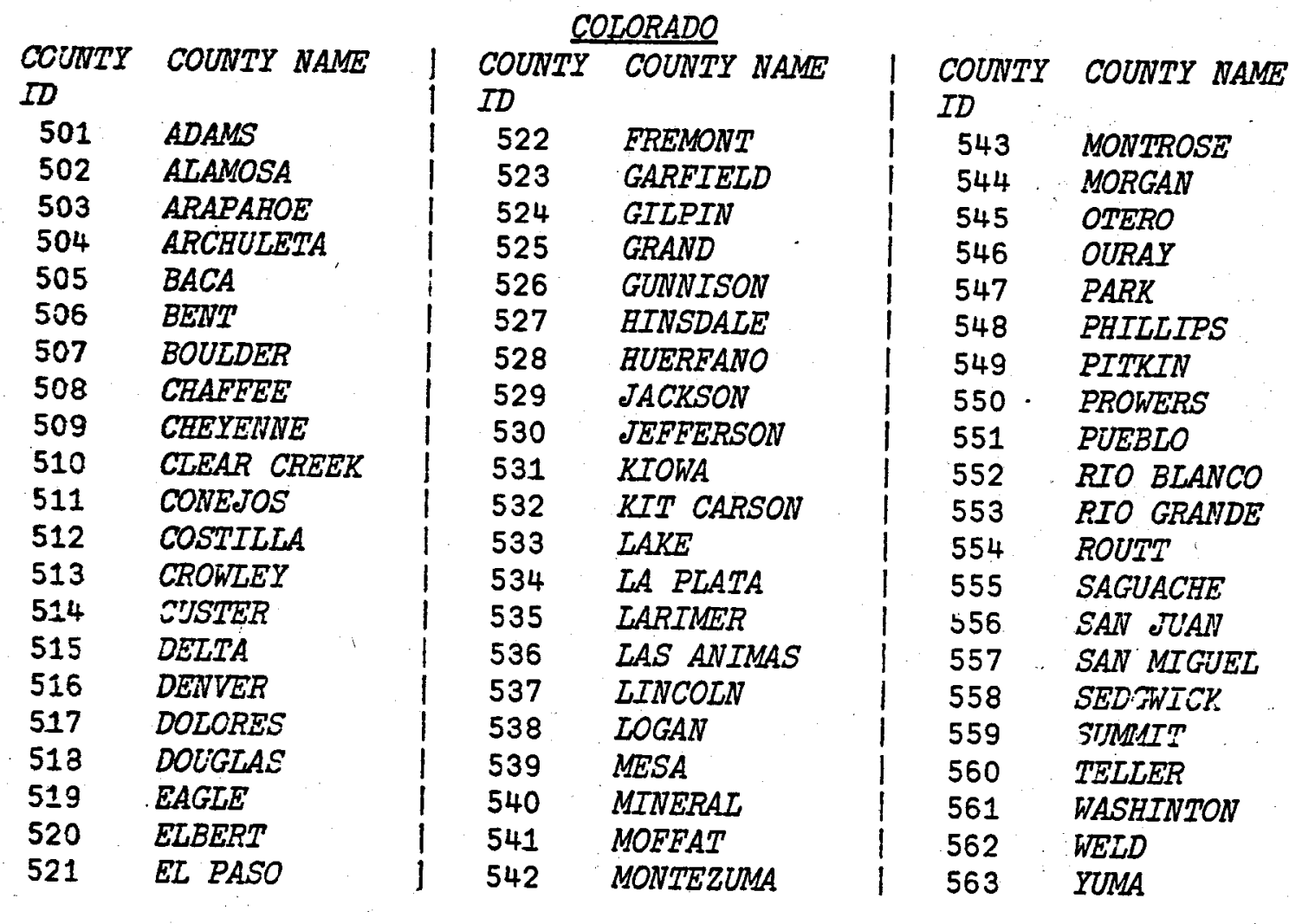

TABLE 9. COUNTY ID AND COUNTY NAME 
NEVADA

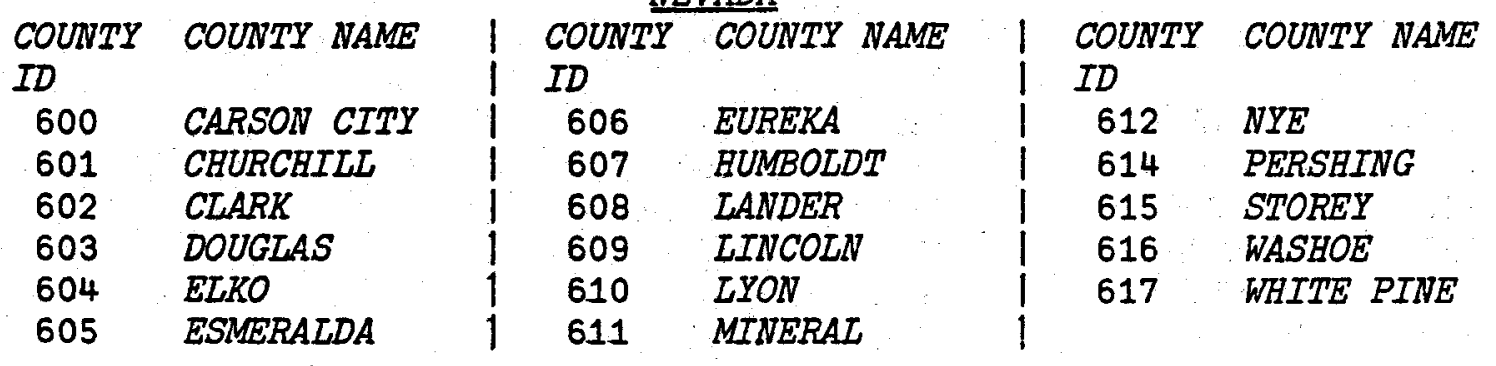

NEW MEXICO

\begin{tabular}{|c|c|c|c|c|c|}
\hline $\begin{array}{l}\text { COUNTY } \\
\text { ID }\end{array}$ & COUNTY NAME & $\begin{array}{l}\text { COUNTY } \\
\text { ID }\end{array}$ & COUNTY NAME & $\begin{array}{l}\text { COUNTY } \\
\text { ID }\end{array}$ & COUNTY NAME \\
\hline 701 & BERNALILLO & 712 & HIDALCO & 723 & SANDOVAL \\
\hline 702 & CATRON & 713 & LEA & 724 & SAN JUAN \\
\hline 703 & CHAVES & 714 & LINCOLN & 725 & SAN MIGUEL \\
\hline 704 & COLFAX & 715 & LOS ALAMOS & 726 & SANTA FE \\
\hline 705 & CURRY & 716 & LUNA & 727 & SIERRA \\
\hline 706 & $D E B A C A$ & 717 & MCXINLEY & 728 & SOCORRO \\
\hline 707 & DONA ANA & 718 & MORA & 729 & TAOS \\
\hline 708 & EDDY & 719 & OTERO & 730 & TORRANCE \\
\hline 709 & CRANT & .720 & QUAY & 731 & UNION \\
\hline 710 & GUADALUPE & 721 & RIO ARRIBA & 732 & VALENCIA \\
\hline 711 & $E A R D I N G$ & 722 & ROOSEVELT & & \\
\hline
\end{tabular}

UTAH

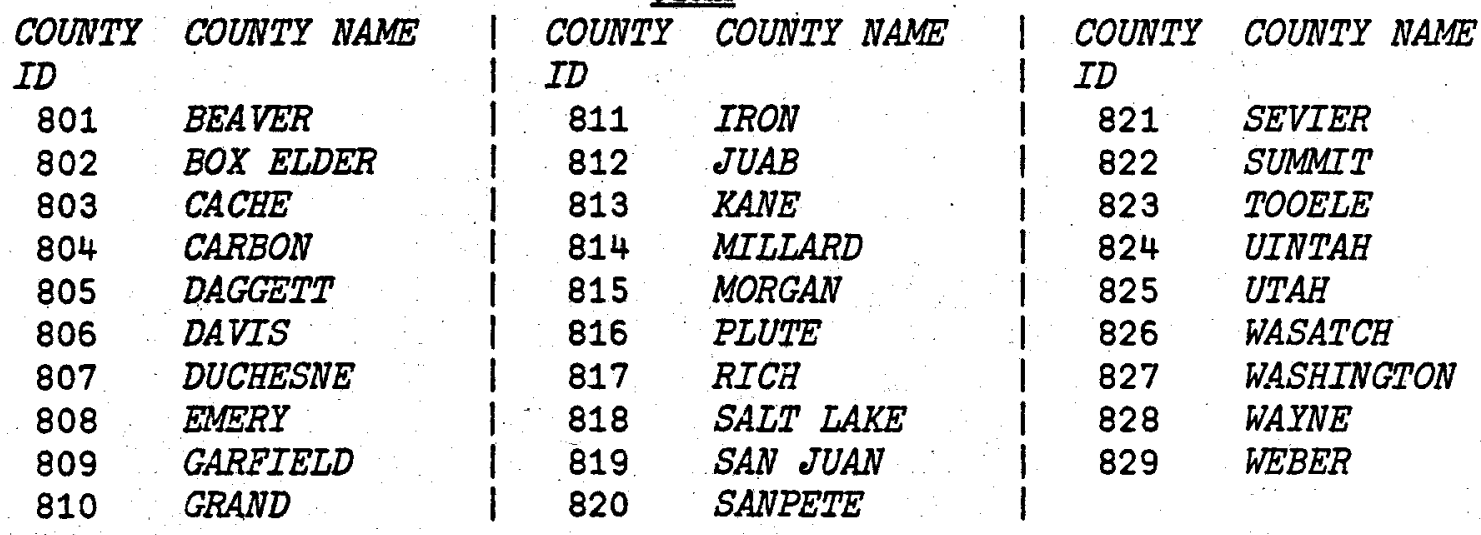

TABLE 9. COUNTY ID AND COUNTY NAME 


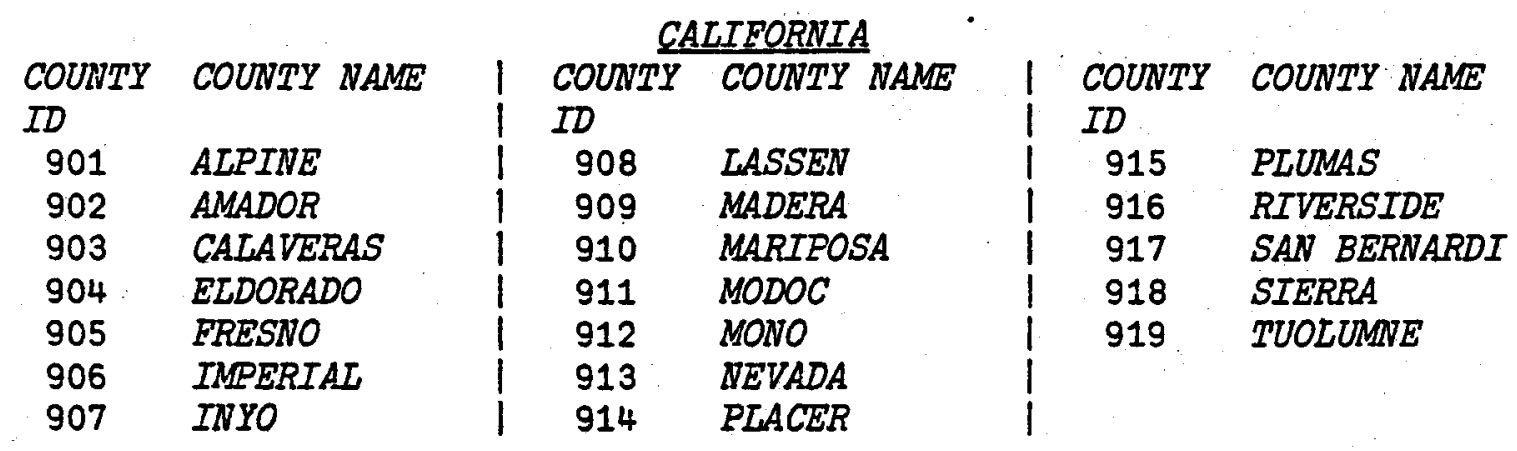

IDAHO

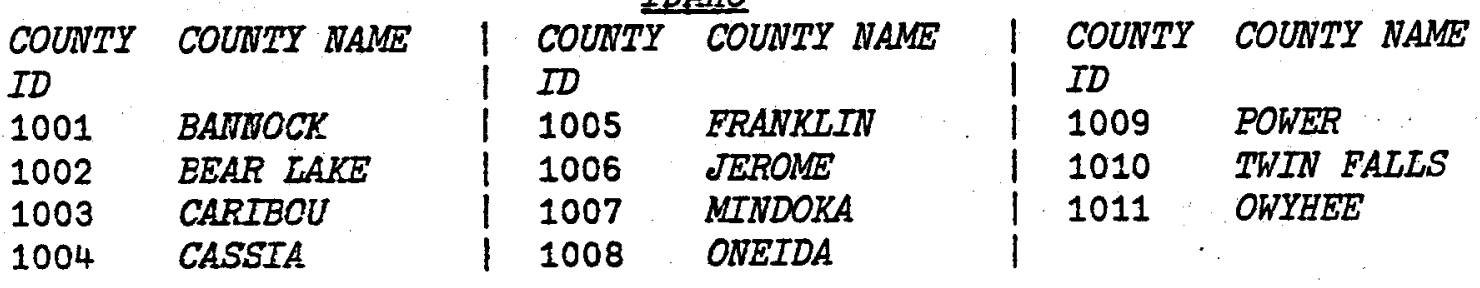

KANSAS

\begin{tabular}{|c|c|c|c|c|c|}
\hline COUNTY & COUWTT IRAME & COUNTY & COUNTY NAME & COUNTY & COUNTY NAME \\
\hline$I D$ & & $I D$ & & $I D$ & \\
\hline 1101 & CHEYEWVE & 1107 & KEARNY & 1113 & SEWARD \\
\hline 1102 & FTNDEY & 1108 & LOGAN & 1114 & STANTON \\
\hline 1103 & GRANT & 1109 & MORTON & 1115 & STEVENS \\
\hline 1104 & GREEEEY & 1110 & RAWLINS & 1116 & THOMAS \\
\hline 1105 & HAMILTON & 1111 & SCOTT & 1117 & WALLACE \\
\hline 1106 & RASKELL & 1112 & SHERMAN & 1118 & WICHITA \\
\hline
\end{tabular}

NEBRASKA

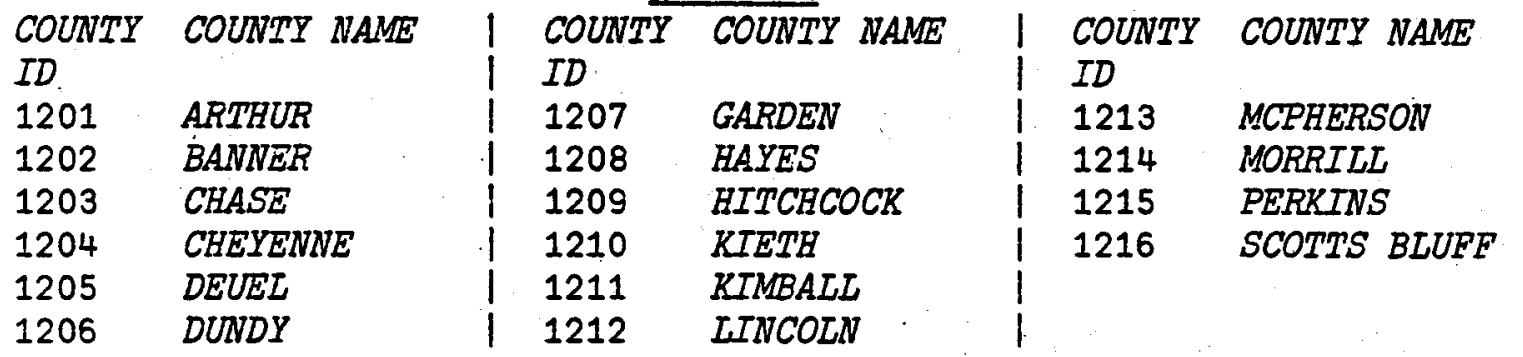

TABLE 9. COUNTY ID AND COUNTY NAME 
COUNTY COUNTY OKLABOMA

ID 1301 CIMARRON

ID

130
COUNTY COUNTY NAME I COUNTY COUNTY NAME 302 TEXAS

$$
\text { ID }
$$

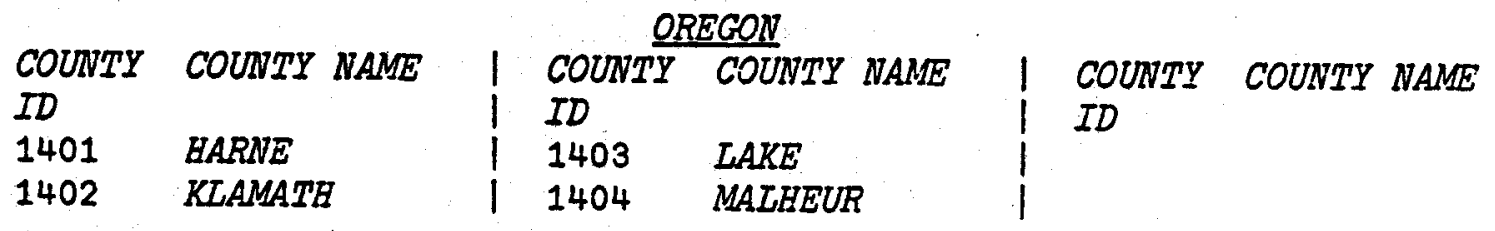

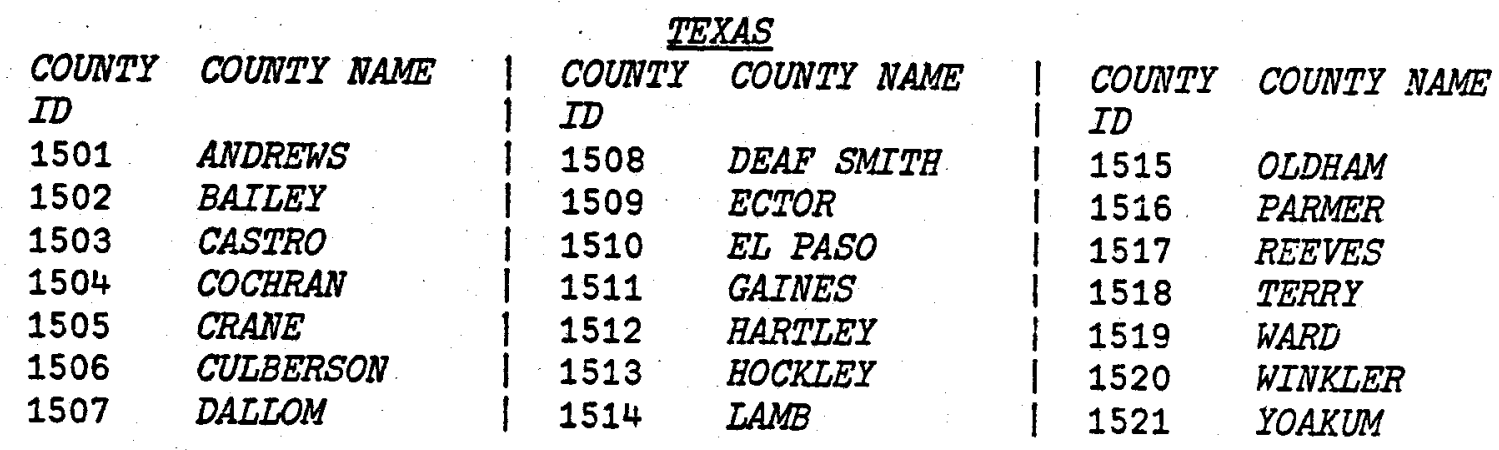

WYOMTNG

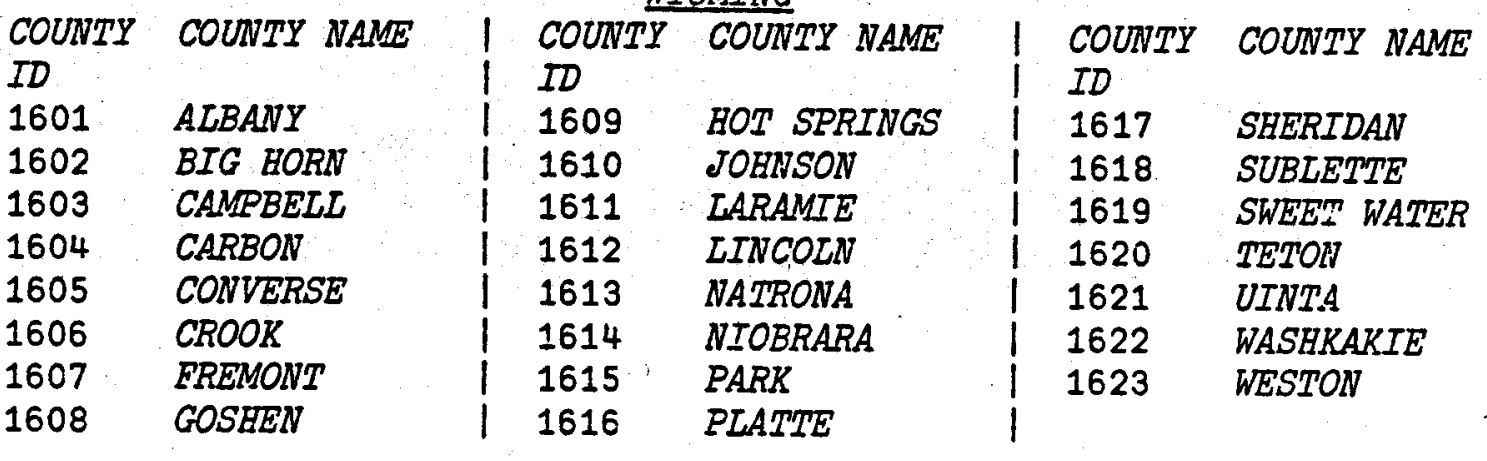

TABLE 9. COUNTY ID AND COUNTY NAME 
APPENDIX 4

\author{
SUMMARY OF FEDERAL, STATE, AND PRIVATE ACTIONS \\ RECOMMENDED TO ACCEIERATE GEOTHERMAL ENERGY \\ DEVELOPMENT IN THE SOUTHWEST REGION
}

\author{
Prepared by \\ Richard T. Meyer, Ph.D. \\ Western Energy Planners, Ltd. \\ for the
}

Regional Operations Research Program for Development of Geothermal Energy

in the Southwest United States

DOE Contract No. EG-77-5043992

June 10, 1978

New Mexico State University New Mexico Energy Institute Las Cruces, New Mexico 



\section{SUMMARY OF FEDERAI, STATE, AND PRIVATE ACTIONS RECOMMENDED TO ACCELERATE GEOTHERMAL ENERGY DEVELOPMENT IN THE SOUTHWEST REGION}

The New Mexico Energy Institute at New Mexico State University, in participation with the States of Arizona, Colorado, Nevada, New Mexico and Utah, is conducting a Regional operations Research Program for Development of Geothermal Energy in the Southwest United States. The project is funded by the U.S. Department of Energy, Four Corners Regional Commission, and State of New Mexico Energy Resources Board.

The objectives of the program are:

- To develop realistic but aggressive scenarios with certainty factors for the development of each identified geothermal resource area in Arizona, Colorado, Nevada, New Mexico, and Utah.

- To delineate the public actions, together with their schedules required, for the scenarios to materialize.

- To develop a computer-base data storage and retrieval system of a regional program progress monitor of the level of a preliminary working model which is capable of displaying program approach, but not loaded with all available data.

This document addresses the second of the above program objectives, but includes private actions as well as public actions necessary to accelerate geothermal energy development in the southwest. This report is only one component of the work products directed toward the second objective, The NMEI Core Team and the five state Teams also describe Federal, State and private actions in their quarterly progress reports and in the first year final report. The context of this report is based largely upon a questionnaire prepared by the consultant and distributed to the State Teams and to the Regional Advisory Committee for the Southwest OR Project. It is also based upon direct communications which the consultant has had with the Core Team, the State Teams, geothermal industry representatives, and other state and Federal officials throughout the first year of the project.

This report summarizes recommended actions which are necessary to develop and utilize the geothermal energy resources which exist in the five States of the Southwest Region. The magnitude of the potential geothermal resource is considerable. Both electric and non-electric, direct thermal : 
applications exist and are being explored. As of this time, however, no commmercial-scale geothermal project is in operation. The Federal and state governments and the private geothermal industry, including utilities, have strong interests in developing the geothermal potential. The actions recommended in this report, if implemented, would speed geothermal development on its way toward a significant contribution to the energy produced, consumed, and exported by the Southwest Region.

The report is divided into three major sections. Section 2.0 delineates actions required of the Federal, State and private sectors for the entire Southwest Region. The first seven "recommended regional actions" are in decreasing order of the priority generated by the questionnaire. The next six action items are not prioritized, except for being of lesser importance than the first seven, Section 3.0 lists actions required more specifically on a stateby-state basis, but include Federal and private actions as well as state actions. Section 4.0 tabulates the various recommended actions by the principal party responsible for implementation-Federal, state and private. 
2.1. Tax Incentives

The number one priority recommendation of the state Teams, the federal agency representatives, and the geothermal developers is to provide state and federal tax incentives to the geothermal industry by the 1980's. Tax incentives similar to those currently received by the oil and gas industry are typically specified, but other special incentives are advised also.

\subsubsection{Depletion Allowance}

Allowance of the 22 percent depletion allowance and the expensing of intangible drilling costs are the prime tax incentives that axe recommended. Some question exists as to whether the geothermal resource is a depletable resource, and, therefore, does it technically qualify for a depletion allowance. However, the mere fact that the question is a real question testifies to the uncertainty of knowledge regarding the several forms of geothermal energy and to the risks to industry in expending funds for geothermal resource development.

It is certainly possible that a resource area may provide geothermal energy for an infinite period of time, but it is also possible that the rate of energy withdrawal may be sufficiently great to cause a short or long texm depletion of the energy at the quality and quantity necessary for economic utilization. From the point of view of practical economics, geothermal developers and utility companies must generally scale their construction costs and production schedules on a thirty-year period of amortization and operation. Only actual experience over the next twenty-five to fifty years will prove whether geothermal resources are depletable and whether the thirty years production schedule is realistic. In order to obtain that experience, however, a geothermal resource depletion allowance will have to be provided or the development of geothermal energy will not readily occur.

\subsubsection{Intangible Drilling Costs}

The case for the expensing of intangible drilling costs for state and federal income tax purposes is identical to that offered by and provided to the oil and gas industry. The risks of obtaining dry holes in geothermal drilling are great. In addition, even if a hot or wet hole is obtained, considerable time elapses between drilling and energy production; these time 
periods often see major changes in economic or political conditions which may jeopardize the advancement of the drilled well to an actual energy production well.

\subsubsection{Property Taxes}

The deferral of property taxes on the geothexmal land and physical installation until energy production for commercial purposes occurs is a recommended special tax incentive for the geothermal industry. This recomendation originates not just within the framework of creative tax incentives but primarily because of the aforementioned time intervals between drilling for geothermal field development and energy production from a constructed power facility for commercial transmission and consumption. The time required can easily range from three to six years, so that significant tax savings and increased investment capital can be realized by the geothermal industry.

\subsubsection{Exemptions for Non-Productive Leases}

A related tax incentive calls for the elimination and or return of property taxes on land leases which have been proven to be non-productive for commercial energy purposes. While special provisions might be necessary to disallow speculative holdings of geothermal leases, the objective of this incentive is to encourage exploration for producing leases without a tax disincentive for non-producing leases.

\subsubsection{Investment Tax Credit}

An investment tax credit (10\%) is advocated for the geothermal development industry. The tax cxedit would apply to physical equipment and facilities necessary for the production, conversion and transmission of energy of geothermal origin. As with other investment tax credits, the purposes of a geothermal investment tax credit axe to stimulate investment of capital funds in geothermal energy equipment and to promote the increased development of geothermal energy as an alternative energy source.

\subsubsection{Retrofit Incentive}

A tax incentive for the outfitting or the retrofitting of existing business and industry buildings, equipment or processes to utilize direct thermal geothermal energy is recommended. For the energy-using sector of business and 
industry, this incentive would complement those tax incentives recommended above for the energy-producing industry. The technology does exist for many low temperature, direct thermal applications of geothermal energy and the geothermal resources exist also. Nevertheless, a stimulus is believed necessary to allow business and industry to adapt their present facilities to a new energy form and to speed the development. of specialized low temperature applications.

\subsubsection{Early Adoption of Tax Incentives}

The final recommendation on tax incentives is that they be instituted by the early 1980's at the latest, for three major reasons: First, the incentives are needed now to stimulate growth and competition within the geothermal industry. Second, the industry is small enough at the present time such that the total geothermal-related taxes going to state and federal treasuries are not all that significant; therefore, it is better to institute the tax credits and exemptions now before their impacts on the state and federal treasuries would require major adjustments in the flow of tax dollars. Third, tax incentives are viewed as absolutely essential. for geothermal energy to make a significant contribution to the nation's energy needs.

\section{$2.2 \quad$ Development Drilling}

Tax incentives are viewed by the geothermal industry as the primary mechanism for instituting an expanded national and regional effort in geothermal resource assessment and exploration and geothermal field development; i.e. tax incentives would free up the capital necessary for industry itself to support a substantial increase in development drilling. However, geologists, developers, researchers, and state government officials all agree that development drilling must be expanded and supported financially for geothermal development to reach its potential in the southwestern states. The objectives of an accelerated development drilling program should be (1) to define geophysically the resource areas and (2) to reduce the development risks to the geothermal industry. Preferred mechanisms for accelerating development drilling are as follows:

- Provide tax incentives to the geothermal industry

- Eliminate stringent environmental restrictions on exploration drilling 
- Continue the DOE Case Study Program on bottom-hole drilling information

2.3 Land Leasing and Time Delays

Considerable concern exists by all parties in the Southwest over problems with the leasing of federal and state lands and with time periods associated with regulatory or institutional actions. More specifically, four problems and solutions are identified:

\subsubsection{Lease Acreage Limitations}

Present Federal law restricts individual or corporate leaseholders of Federal geothermal leases to 2,560 acres per tract and 20,480 acres per state. These limitations were conceived primarily to promote competition among investors and developers and to prevent speculative holdings, but in actual fact are found to be highly restrictive to geothermal development. The time durations for leases and the lease fees are associated problems."

The limitation of 2,560 acres per tract is particularly restrictive because of the still undefined geophysical characteristics of most geothermal resources and the absence of proven knowledge of resource requirements for the economic application of geothermal energy. The 2,560 acre limitation creates severe development engineering and financing problems for a geothermal developer because a given geothermal resource often spans several tracts belonging to different lease holders.

The 20,480 acre per state limitation and the associated time limit of ten years of exploration leases poses another kind of problem. The time period from lease application to commerical energy production is six to twelve years, with a majority of those years required for the various regulatory and institutional processes (permits, EISs, etc.). This acreage limitation often forces a developer to release lands from lease before exploration and development can be completed. A developer is forced to make "speculative" judgements on which lands have energy producing potential in order to keep an active, integrated leasing, exploration, and development program underway in a state.

\subsubsection{U.S. Forest Service Land Leases}

A majority complaint (from the states of Arizona, Colorado, and New Mexico of the five Southwestern states) is with the inability of the U.S. Forest Service to process geothermal lease applications. The Forest service has had 
lease applications pending since 1974 and/or 1975 in Arizona, Colorado, and New Mexico. It is reported that the lease applications are a low priority item for the Forest service, because of their lack of personnel and funds to process them. It is recommended that the U.S. Forest service act more expeditiously on lease applications on a regular basis and act irmediately to clear the outstanding applications.

\subsubsection{Time Delays on Required Institutional/Regulatory Actions}

Reference has already been made to the time intervals required to process lease applications, drilling permits, EISs, etc. At the present time, these actions constitute the majority of the time involved from lease application to energy production. The state Teams and the Core Team in the Southwest Project are currently analyzing the state and Federal procedures that must be followed and are compiling flow charts of sequential steps required. The evaluation has already revealed that, in almost all instances, no time limits are specified by the applicable legislation or the regulative procedures within which the administrative agencies must operate and render definitive actions. It is contended that a considerable reduction in processing time and a significant savings in costs to the developer would occur if specific time limits were prescribed. The geothermal industry would prefer to have a decision, whether positive or negative, than no decision at all.

\subsubsection{Restrictive Feature of KGRA's}

Federal law prescribes that federal lands will be designated as known Geothermal Resource Areas (KGRA's), if two or more lease applications are filed for the same or adjoining land areas. The severe consequence of the KGRA designation if that the existing lease applications are voided and the KGRA is opened for competitive bidding. Once again, the KGRA was conceived to promote competitive bidding and to prevent speculative holdings. The actual consequence, however, has been to decelerate substantially geothermal exploration. Developers are highly reluctant to expose themselves to competitive bidding on lands for which they have only limited geochemical/geophysical/ geological information bearing upon the geothermal potential. In most all areas of the southwest, considerable exploration is still required to determine the geothermal potential. The costs associated with competitive bidding on unproven resources are actually a front-end cost deterrent to geothexmal exploration and development. 
As with most alternative energy sources and systems le.g. solar, wind, oil shale, coal gasification, etc.), favorable economic conditions and realistic fuel pricing must prevail for geothermal energy to be competitive economically within state and regional markets. In order to place geothermal energy in a realistic position, two actions are recommended. The first is that oil and natural gas be priced at the world market value or at energy replacement values. The second is that more quantitative supply and demand analyses of geothermal energy be conducted to define the economic conditions required to support geothermal energy development.

\subsection{Influence of Environmental Advocates}

Among the private, state and federal participants in the Southwest Geothermal Project, there is a very strong posture that environmental advocacy groups have an unduely large influence on and have significantly hindered geothermal development. The negative effect of their actions is regarded as not representative of the majority of citizens and of state and local governments. It is recommended that less attention be given by legislative, regulatory and administrative agencies at both the state and Federal levels to the actions of the environmental advocacy groups and that a more balanced appraisal of energy development and environmental protection be provided.

\subsection{Standardization of State Regulatory Provisions}

Current restrictions on geothermal development in the Southwest have included that certain states have not generated legislative and regulatory pro-. visions specifically for geothermal energy and that legal definitions of the geothermal resource have not existed. Some states are in the process of approving new regulations; defining leasing terms; etc. Unfortunately, the fluid and. unsettled nature of regulations at the state level have caused significant delays of exploration and development action by the geothermal industry.

The Southwest States in general appear to support the development of geothermal energy and are participating cooperatively in the Southwest OR Project. The OR Project does encompass an examination of institutional and regulatory procedures. Yet no concerted, collaborative action has been initiated by the state governments at either the legislative or executive levels to examine the beneficial features of standardized regulatory provisions. It is 
recommended that such a detailed examination be a major component of the continuing or project.

\subsection{Environmental Restrictions on Exploration}

The existence of environmental factors as a limitation on geothermal development in the southwest appears twice in the above 1istings. It appears again here within the specific context of severe limitations on the exploration phase. The geothermal industry regards exploration as that phase of overall development which is essentially 100\% financial risk to industry but is their investment for the nation in seeking new energy resources.

The physical aspects of exploration do require moving equipment over relatively unexplored or untouched lands and do cause minimal disturbances to the natural environment. Each new hole drilling is based upon information gained from the preceeding holes drilled and the exploration decisions are made largely in the field; in other words, the drilling pattern and locations can not often be prescribed precisely in advance. Therefore, the exploration phase does not lend itself to the highly specific requirements of EISs and similar regulatory proceedings. In particular, the industry finds that the archaeological impediments to exploration permits give rise to frequent time delays and to additional costs of exploration. In general, the industry finds that there are more environmental barriers to exploration than there are incentives and aids to a positive exploration ethic.

\subsection{Low Temperature Technologies}

In inventorying the geothermal resources and applications, the state Teams have identified extensive opportunities for low temperature utilization of geothermal energy throughout the southwest. Many of these applications are for business and industry operations and processes which haye not previously been engineered for direct thermal geothermal energy. Technology development is required both for the capturing of the energy from the low temperature reservoirs and for specific business, industrial, and agricultural applications. The Arizona state Team has compiled an extensive list of direct thermal applications and is evaluating their potential for Arizona business and industry.

2.9 Demonstration Projects for Low Temperature Applications

The more advanced of the low temperature, direct thermal applications 
of geothermal energy are greenhouse heating and municipal district heating. Several communities throughout the southwest have feasibility studies underway, have demonstration project proposals pending with the DOE, or are strongly interested in district heating applications. These communities are in need of planning and design assistance from their state governments or consulting engineers; more specifically, the communities need the funds to support these activities. In addition, with an increasing awareness of the potential for district heating (largely generated by the activities of the State Teams during the past year), communities are calling for a continuation and expansion of the DOE program for direct thermal geothermal demonstration projects.

\subsection{Water Resources and water Rights}

Concern exists throughout the entire Western region over the effect that the withdrawal of geothermal waters will have on existing water tables used for agricultural, municipal and other purposes. Examples of temporary draw-down of local water tables from geothermal operations have been reported in Utah, for example. The geothermal industry maintains that their deep wells for electrical power production are far below the depths of.municipal and agricultural wells and into entirely different aquifers. The question of water rights immediately impinges on geothermal development whenever surface waters or aquifers which supply surface waters are touched by the development: The specific recommendation on this subject is that more attention and more funding be provided to an analysis of water resources and water rights as geothermal development proceeds. In addition, the geothermal industry prefers a legislative remedy, rather than judicial judgement, to the definition of geothermal waters; the industry appears to prefer the DOE proposal to remove "geothermal water" from the Federal "water resource."

\subsection{DOE Case Study and Loan Guarantee Programs}

The DOE Case Study (bottom hole information) and Loan Guarantee Programs are highly regarded by geologists, geothermal developers, and state government representatives in the Southwest Region. These programs are supportive of the geothermal industry. Whereas both programs initially received cool attention from the geothermal industry, the Case study. Program is drawing more and more participation and the Loan Guarantee Program has several applications approved 
or in process. It is being recommended that the Case study Program be extended beyond its current cut-off date of

The geothermal industry regards the Ioan Guarantee Program as a more effective program for stimulating development and commercialization than cost-sharing demonstration projects. Indeed, the Loan Guarantee Program applies at the point of commercialization and revenue generation, which is where the industry prefers to operate. However, the program is not fully useable by the larger geothermal companies, (a) because of the limitation of guarantees of $\$ 25$ million per project and $\$ 50$ million per borrower, and (b) because no large company will risk default on such small loans anyway.

Three specific recommendations are advanced to enhance the Ioan Guarantee Program: (1) The Congressional limit of $\$ 200$ million for the entire outstanding amount of guaranteed loans needs to be increased to provide for the surge of geothermal projects that are potentially possible in the 1980's; (2) the requirement for the geothermal "borrowex" to put up 25\% of the project financing should be modified to allow credits for the actual prior investments by industry to bring the project to the commercializaiton/loan guarantee stage; i.e. the value to the project at the time of loan guarantee application should apply to the $25 \%$ financing requirement; and (3) the allowable interest rate by the lender should be reduced to the prime rate rather than $25 \%$ over the prime rate (the industry investment of $25 \%$ of project financing should be sufficient to guarantee low risk financing to the lender).

\subsection{Public Education}

Geothermal energy development has not received the financial support nor the public attention that other alternative energy sources have, particularly solar. For the general public, geothermal energy is still largely a mystery and is viewed with scepticism and misunderstanding. The contrast in public perception between solar energy and geothermal is most striking: solar derives from the brilliant radiance of the sun and geothermal derives from the mysterious, dark bowels of the earth! similarly, solar is promoted as free of environmental impact and geothermal is challenged on land, air, and water factors.

The state Teams have witnessed this dramatic disparity in public perceptions as they have discussed the prospects of geothermal energy use with businesses and communities. Some residents of rural communities will not even listen to proposals for geothermal use. This lack of knowledge and broad misunderstanding of geothermal energy extends throughout the general populace. 4-11 
The situation allows environmental advocacy groups to dominant decisionmaking, not only at the local level, but also at the Federal level when energy program funds are allocated.

It is recommended that the DOE and state governments sponsor a major public education program which puts forward the potentials and advantages for geothermal energy.

\subsection{Handbooks of Institutional/Regulatory Procedures}

As previously mentioned, the State Teams and the Core Team for the OR Project are compiling and analyzing information on the institutional and regulatory procedures for the entire geothermal process, The institutional/ regulatory process is different in each state, with different principals, agencies and practices involved. In addition, the process is often complex, providing for different points of entry, time elements, and options for the government decision-maker.

While these procedures are often known to the large geothermal developers and to the utilities, they are generally not known, understood, or accessible to the individual lease applicant, community official, small business/ industry energy user, out-of-state investor, etc. Therefore, it is recommended that handbooks of flow charts and instructions be prepared which cover the institutional and regulatory procedures from lease application to specific end uses of the geothermal energy.

\subsection{RECOMMENDED STATE-BY-STATE ACTIONS}

Many of the recommended actions in Section 2.0 apply to all of the states in the southwest. In addition to those actions, the following specific actions are needed within the individual states to accelerate geothemal development.

\section{$3.1 \quad$ Arizona}

3.1.1 Approval and application of the proposed new State geothermal rules and regulations in order to activate again the leasing of geothermal lands.

3.1.2 Expanded exploratory drilling to assess the geothermal resource potential throughout the state. 
3.1.3 Technological studies and technology transfer information on new, primarily direct thermal, uses of geothermal energy by business, industry, and agriculture:

3.1.4 Technology development of absorption cooling and heat pumps for space cooling applicaitons to reduce the demand for electrical energy.

\section{$3.2 \quad$ Colorado}

3.2.1 Issuance of leases by the U.S. Forest Service on applications pending since 1974 .

3.2.2 Development of geothermal space heating applications to relieve the demand for natural gas.

3.2.3 Financing and planning assistance for community and small business geothermal projects.

\subsection{Nevada}

3.3.1 Participation of the geothermal industry in the formulation and legislation of state laws and regulations regarding geothermal energy resources in order to provide an institutional/regulatory process conducive to geothermal development.

3.3.2 Integration of state and Federal leasing and regulatory actions to accomodate the fact that 868 of Nevada is Federal land.

3.3.3 Expanded Federal lease acreage allowance per tract and pex state to allow access to and utilization of adjoining state and Federal lands.

\section{$3.4 \quad$ New Mexico}

3.4.1 Extension of the State lease duration from five years to ten years to conform to Federal standards and to activate leasing of state lands again by the state Land Department. 
3.4.2 Eliminate Federal drilling restrictions on depth in order to promote deeper well drilling for space heating applications.

3.4.3 Rejection of unreasonable demands by environmentalists that would halt geothermal development.

\section{$3.5 \quad \underline{\operatorname{tah}}$}

3.5.1 Industry needs to acquire more drilling rigs to match the requirements indicated by the Utah development scenarios for production well drilling over the next 20 years.

3.5.2 U,S. Congress needs to authorize higher dollar limits for Loan Guarantee Program and make Program applicable to the larger geothermal companies.

3.5.3 State government needs to specify the tax rates on geothermal developm ments in order to allow the industry to calculate that element of its developm ment costs.

\subsection{SUMMARY}

In this final section, an attempt is made to summarize the recommended actions by the principal parties which must implement the actions--Federal, state, or private; naturally some multiple responsibility exists.

\subsection{Federal Actions}

- Provide tax incentives

- Support development drilling

- Accelerate and expand leasing of lands

- Reduce time delays of institutional/regulatory procedures

- Generate favorable economic conditions

- Reduce influence of environmental advocates

- Reduce environmental restrictions on exploration

- Develop technologies and provide demonstration programs for low temperature applications 
- Analyze water resources and rater rights

- Continue DOE Case Study Program

- Expand Loan Guarantee Program

- Education of the public

\subsection{State Actions}

- Accelerate leasing of lands

- Reduce time delays of institutional/regulatory procedures

- Standardize regulatory procedures and legal definition of the geothermal resource

- Reduce environmental restrictions on exploration

- Provide planning assistance to communities for low temperature applications

- Clarify water rights related to geothermal resources

- Education of the public

- Provide handbooks of institutional/regulatory procedures

\subsection{Private Sector Actions}

- Development Drilling

- Participation in DOE Case Study Program

- Utilization of Federal Loan Guarantee Program

- Education of the public

- Expand drilling rig capacity

- Assist in formulation of state laws and regulations

- Develop low temperature technologies 